\title{
IntechOpen
}

\section{Geopolymers and Other Geosynthetics}

Edited by Mazen Alshaaer and Han-Yong Jeon
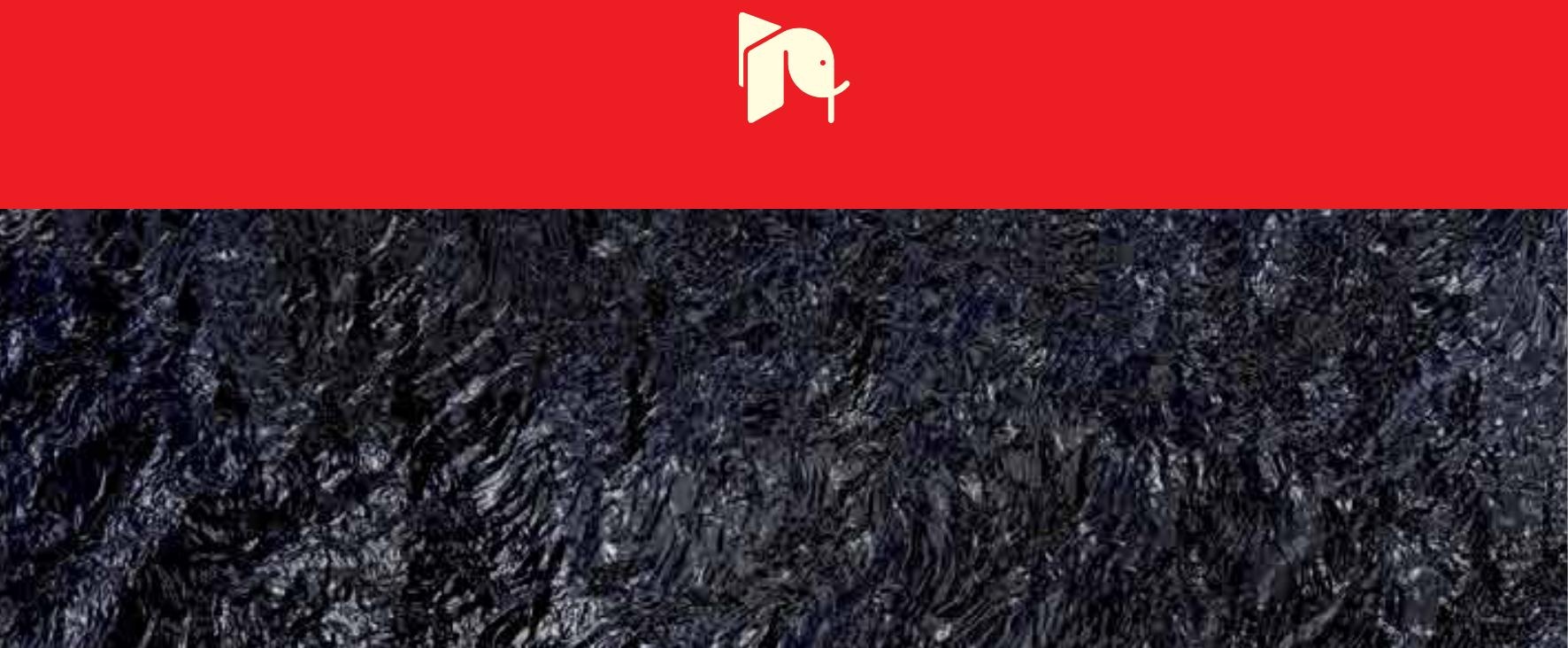



\title{
Geopolymers and Other Geosynthetics
}

\author{
Edited by Mazen Alshaaer \\ and Han-Yong Jeon
}



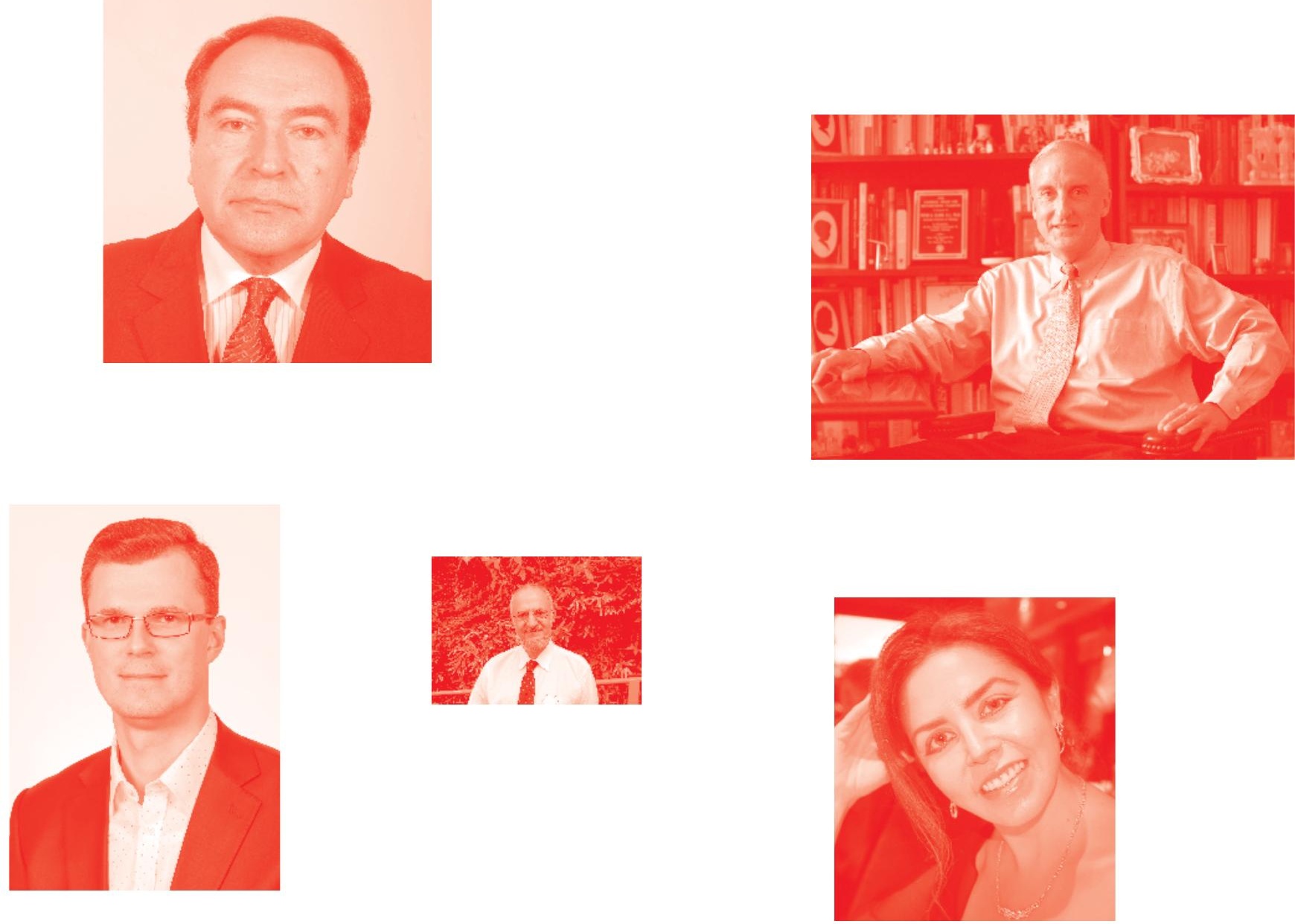

Supporting open minds since 2005
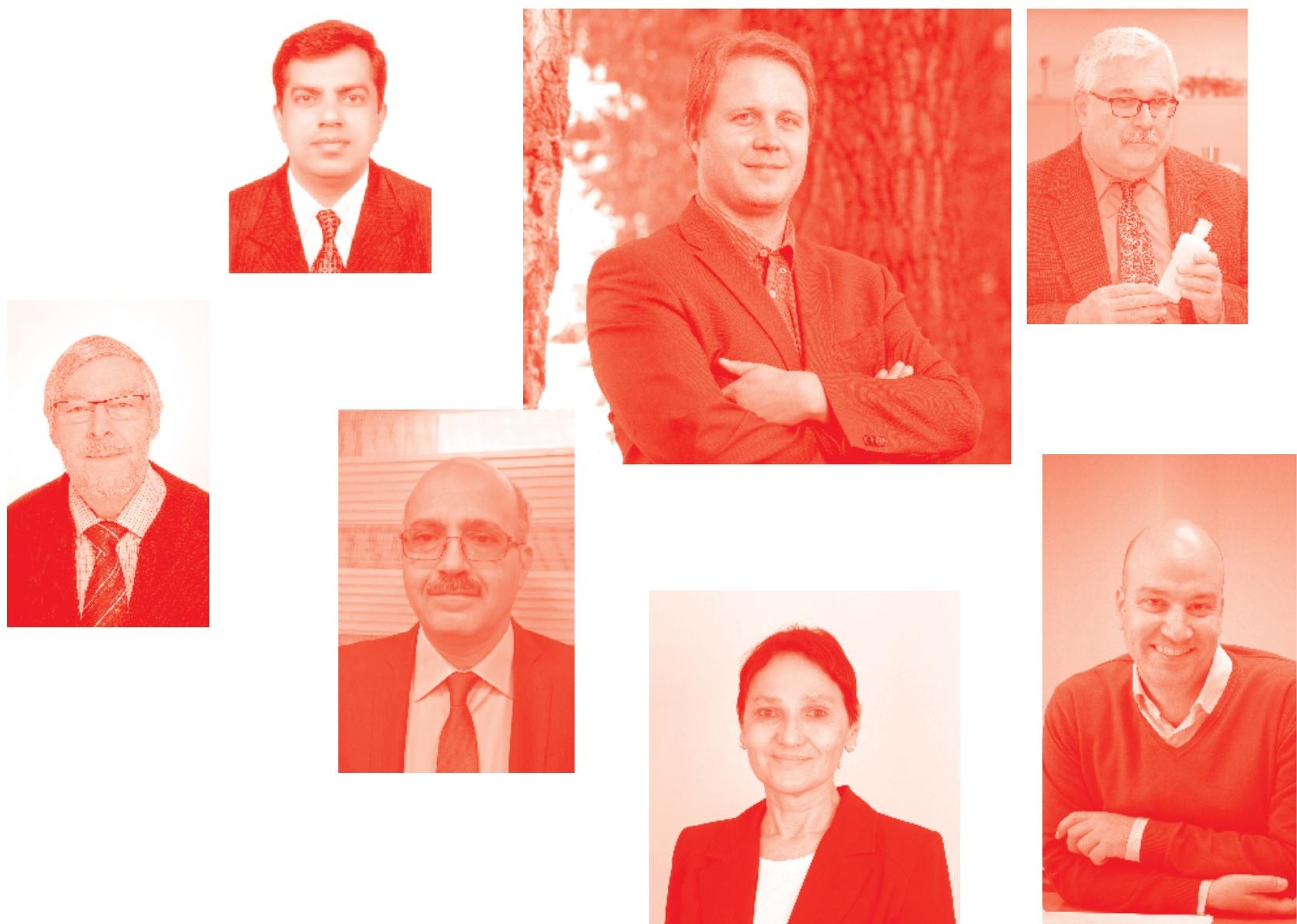
Geopolymers and Other Geosynthetics

http: //dx. doi. org/10.5772/intechopen. 79204

Edited by Mazen Alshaaer and Han-Yong Jeon

Contributors

Anantha Padmanaban D, Mazen Alshaaer, Jingkun Yuan, S.S Amritphale, Rainy Gupta, Pooja Bhardwaj, Raghunandan Kumar, Beulah M, Pranab Das, Arjun Hr, Georgie Ignatius, Sekou Traore, Doussou L. Traoré, Nabil Hossiney, Mothi Krishna Mohan, Anirban Roy, Arun Kumar N, Han-Yong Jeon, Juan Carlos Ruge, Julian Gomez, Carlos Moreno, Dr. Meshari Almutairi

(-) The Editor(s) and the Author(s) 2020

The rights of the editor(s) and the author(s) have been asserted in accordance with the Copyright, Designs and Patents Act 1988. All rights to the book as a whole are reserved by INTECHOPEN LIMITED . The book as a whole (compilation) cannot be reproduced, distributed or used for commercial or non-commercial purposes without INTECHOPEN LIMITED's written permission. Enquiries concerning the use of the book should be directed to INTECHOPEN LIMITED rights and permissions department (permissions@intechopen.com).

Violations are liable to prosecution under the governing Copyright Law .

\section{(cc) BY}

Individual chapters of this publication are distributed under the terms of the Creative Commons Attribution 3.0 Unported License which permits commercial use, distribution and reproduction of the individual chapters, provided the original author(s) and source publication are appropriately acknowledged. If so indicated, certain images may not be included under the Creative Commons license. In such cases users will need to obtain permission from the license holder to reproduce the material. More details and guidelines concerning content reuse and adaptation can be found at http : //www . intechopen . com/copyright-policy. html.

\section{Notice}

Statements and opinions expressed in the chapters are these of the individual contributors and not necessarily those of the editors or publisher. No responsibility is accepted for the accuracy of information contained in the published chapters. The publisher assumes no responsibility for any damage or injury to persons or property arising out of the use of any materials, instructions, methods or ideas contained in the book.

First published in London, United Kingdom, 2020 by IntechOpen

IntechOpen is the global imprint of INTECHOPEN LIMITED, registered in England and Wales,

registration number: 11086078, 7th floor, 10 Lower Thames Street, London,

EC3R 6AF, United Kingdom

Printed in Croatia

British Library Cataloguing-in-Publication Data

A catalogue record for this book is available from the British Library

Additional hard and PDF copies can be obtained from orders@intechopen.com

Geopolymers and Other Geosynthetics

Edited by Mazen Alshaaer and Han-Yong Jeon

p. cm.

Print ISBN 978-1-78985-176-2

Online ISBN 978-1-78985-539-5

eBook (PDF) ISBN 978-1-78985-540-1 


\section{We are IntechOpen, \\ the world's leading publisher of Open Access books}

\section{Built by scientists, for scientists}

\section{$4,600+$}

Open access books available

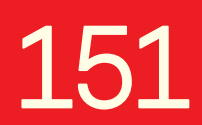

Countries delivered to

\section{$120,000+$}

International authors and editors

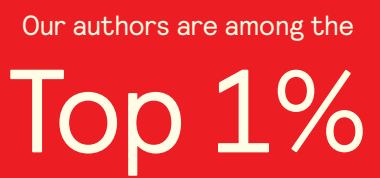

most cited scientists

Contributors from top 500 universities
$135 \mathrm{M}+$

Downloads
$12.2 \%$

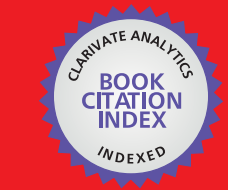

WEB OF SCIENCE ${ }^{\text {M }}$

Selection of our books indexed in the Book Citation Index in Web of Science ${ }^{\mathrm{TM}}$ Core Collection (BKCI)

\section{Interested in publishing with us? \\ Contact book.department@intechopen.com}

Numbers displayed above are based on latest data collected.

For more information visit www.intechopen.com 



\section{Meet the editors}

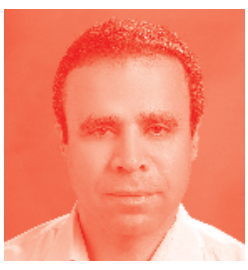

Mazen Alshaaer is an Associate Professor of Materials Science at the Prince Sattam bin Abdulaziz University. He received his doctorate degree in Materials Science, with specialization in synthesis of inorganic materials, from Vrije Universiteit Brussel (Belgium) in 2006. He worked at the University of Jordan from 2006 until 2012. He has been a visiting scholar at the University of Aveiro (Portugal) Technical University of Crete (Greece). He has published over 50 peer-reviewed papers in reputed international journals and conferences, as well as one patent and has been the principal investigator or coordinator on 10 research projects. His current research interests include green construction materials, synthesis of bioceramics, cement, and scaffolds for bone tissue engineering, functional geopolymeric materials, and low cost construction.

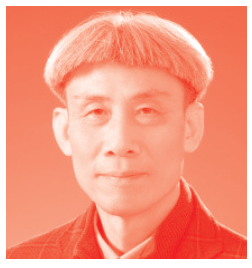

Dr. Han-Yong Jeon is a professor at Inha University, Incheon, Korea (South), and a geosynthetics/technical organic materials researcher. He was the 32nd President of the Korean Fiber Society (2014-2015) and the sixth President of the Korean Geosynthetics Society (2011-2013). He has published more than 943 proceedings and abstracts in domestic and international conferences. His research is focused on the manufacturing, application, and evaluation of technical organic materials and the manufacturing, evaluation, standardization, and regulation of geosynthetics/environmental and structural polymeric composites, etc. He has written 24 texts, including Geosynthetics, and has published 158 papers in domestic and international journals. He was given the Marquis Who'sWho-Science and Engineering award in 2003-2019 and also received the 33rd Academy Award of the Korean Fiber Society in 2006 as well as the "Excellent Paper Award of 2012" by the Korean Federation of Science and Technology Societies. 



\section{Contents}

Preface

Chapter 1

Introductory Chapter: Case Studies of Functional Geopolymers

by Mazen Alshaaer

Chapter 2

Advanced Geopolymerization Technology

by Sudhir Sitaram Amritphale, Pooja Bhardwaj and Rainy Gupta

Chapter 3

Summary of Some Selected Characterization Methods of Geopolymers by Dattaguru Ananthapadmanaban

Chapter 4

Geopolymer Bricks Using Iron Ore Tailings, Slag Sand, Ground Granular Blast Furnace Slag and Fly Ash by Raghunandan Kumar, Pranab Das, M. Beulah and H.R. Arjun

Chapter 5

Utilization of Iron Ore Mines Waste as Civil Construction Material through Geopolymer Reactions

by Pranab Das, Beulah Matcha, Nabil Hossiney, Mothi Krishna Mohan, Anirban Roy and Arun Kumar

Chapter 6

Survey of Bauxite Resources, Alumina Industry and the Prospects of the Production of Geopolymer Composites from the Resulting by-product by Sékou Traoré, A. Diarra, O. Kourouma and D.L. Traoré

Chapter 7

Thermal Evolution of Geopolymer in the Process of High-Temperature

Treatment

by Jingkun Yuan, Peigang He and Dechang Jia

Chapter 8

Review of Sustainable Geosynthetic Development Trend with

Environmental Adaptive and Eco-Environmental Performances

Point of View

by Han-Yong Jeon 
Chapter 9

Analysis of the Creep and the Influence on the Modulus Improvement

Factor (MIF) in Polyolefin Geocells Using the Stepped Isothermal

Method

by Juan Carlos Ruge, Julian Gonzalo Gomez and Carlos Andres Moreno

Chapter 10

The Assessment Strategy for Selecting and Evaluating Geoenvironmental Remediation

by Meshari Almutairi 


\section{Preface}

Twenty years ago I decided to conduct postgraduate research in the field of geopolymers (or inorganic polymers). Surprisingly, I did not find enough references or articles on the subject for the literature survey. But during the past twenty years this topic has become a subject of global concern, and there are tens of thousands of publications covering it in various countries of the world. So I thought it was worth editing this book, which focuses on certain aspects of geopolymers and its applications. This book, Geopolymers and Other Geosynthetics, deals with the basics of geopolymers as an extension of the rest of the geosynthetics structures. This book contains ten chapters. Chapter 1 , the introductory chapter, provides a general introduction to geopolymers and the challenges facing their use on a large scale, as well as studying geopolymers as functional materials that have more than one use. Chapter 2 discusses geopolymers, their synthesis methods, as well as their advanced applications. Chapter 3 summarizes some selected advanced characterization methods of geopolymers, mainly the microstructure, such as SEM, TEM, NMR, and Synchrotrons. Chapters 4 and 5 describe the synthesis of geopolymer bricks using low cost and available precursors such as iron ore tailings, slag sand, slag, and fly ash. Chapter 6 discusses the synthesis of geopolymers using different precursors particularly bauxite, red mud, and wastes. Chapter 7 presents the phase composition, microstructure evolution, and thermal expansion behaviors of the ceramics derived from the geopolymers. Chapters 8, 9, and 10 discuss the geotechnical properties and the geosynthetic structures indirectly related to geopolymers. This book represents the background of the science of geopolymers.

Mazen Alshaaer

Prince Sattam Bin Abdulaziz University, Saudi Arabia

Han-Yong Jeon Inha University, South Korea 



\title{
Introductory Chapter: Case Studies of Functional Geopolymers
}

\author{
Mazen Alshaaer
}

\section{Introduction}

Geopolymers are a relatively new material [1-5]. Basically, this term is applied to material class that is chemically transformed from low-crystallinity aluminosilicates to three-dimensional inorganic polymers (tectosilicates). The resulting material has properties similar to natural minerals, so it is called artificial rock [3, 6]. Actually these materials exhibit chemical composition and mineralogical structure similar to feldspar, feldspathoid, and zeolites consisting of a polymeric Si-O-Al framework, with a microcrystalline or an amorphous structure. Geopolymers were termed for this group of materials by Prof. Davidovits [1].

The major aim of developing the geopolymers is to find alternatives to portland cement and thus to reduce carbon dioxide emissions during cement processing [7]. But in recent years, there has been an observable development in geopolymers and their applications, which have been used in various fields such as construction, waste management, art, and decoration $[6,8]$. The precursors of geopolymers are characterized by the availability, whether earth materials such as kaolinitic soil or waste such as fly ash. Many geopolymeric materials are still under development, but some products are already commercialized and used in different fields.

Although geopolymers have attractive engineering and environmental characteristics, there are some challenges in commercializing these materials $[9,10]$. In this chapter, these challenges will be addressed along with introducing the functional geopolymers as one of the effective approaches to commercialize these materials and make them economically feasible. Functional geopolymers are defined as geopolymers with more than one use at a time, such as use in construction and water purification or use in construction and passive cooling of houses [11].

\section{Functional geopolymers and their applications}

In the following sections, some of the most important functional geopolymers and their applications are discussed.

\subsection{Geopolymers for construction and water treatment}

This research approach is related to the use of geopolymers not only for construction purposes but also for water purification. The major interest is based on 


\begin{tabular}{lccc}
\hline Kaolinite & & \multicolumn{2}{c}{ Zeolitic tuff (ZK) } \\
\hline Compound & Composition\% & Compound & Composition $\%$ \\
\hline $\mathrm{MnO}$ & 0.01 & $\mathrm{MnO}$ & 0.04 \\
\hline $\mathrm{Na} \mathrm{O}_{2}$ & 0 & $\mathrm{Na}_{2} \mathrm{O}$ & 0.77 \\
\hline $\mathrm{CaO}$ & 0.06 & $\mathrm{CaO}$ & 14.66 \\
\hline $\mathrm{K}_{2} \mathrm{O}$ & 1.05 & $\mathrm{~K}_{2} \mathrm{O}$ & 3.42 \\
\hline $\mathrm{MgO}$ & 0.93 & $\mathrm{MgO}$ & 2.76 \\
\hline $\mathrm{P}_{2} \mathrm{O}_{5}$ & 0.4 & $\mathrm{P}_{2} \mathrm{O}_{5}$ & 0.05 \\
\hline $\mathrm{Fe}_{2} \mathrm{O}_{3}$ & $\mathrm{Fe}_{2} \mathrm{O}_{3}$ & 1.36 \\
\hline $\mathrm{Al}_{2} \mathrm{O}_{3}$ & 0.29 & $\mathrm{Al}_{2} \mathrm{O}_{3}$ & 11.04 \\
\hline $\mathrm{SiO}_{2}$ & 33.57 & $\mathrm{SiO}_{2}$ & 58.35 \\
\hline $\mathrm{TiO}_{2}$ & 41.14 & $\mathrm{LOI}$ & 7.55 \\
\hline $\mathrm{LOI}$ & 0.36 & & \\
\hline
\end{tabular}

Table 1.

The chemical analysis of kaolinite and zeolitic tuff (ZK) [8].

\begin{tabular}{lc}
\hline Series & Zeolitic tuff/metakaolinite weight ratio \\
\hline G1 & 0 \\
\hline G2 & 0.25 \\
\hline G3 & 0.50 \\
\hline G4 & 0.75 \\
\hline
\end{tabular}

Table 2.

Composition of geopolymers [8].

the physical properties of materials as well as porosity. Therefore, in addition to the geopolymer porous matrix, natural zeolite is used as a filler or partial reactant.

Geopolymers were prepared using metakaolin, zeolitic tuff (ZK), and alkaline activators. The natural zeolitic tuff, mordenite, was collected from Kimolos Island, Greece. This mineral is associated with calcite and dolomite [8]. Metakaolin was prepared by calcination of kaolinite (Fluka, Germany) at $750^{\circ} \mathrm{C}$ for 3 to $4 \mathrm{~h}$. The chemical composition of both the zeolitic tuff and kaolinite is reported in Table 1. Alkaline activators are prepared using sodium silicate solution and sodium hydroxide. The $\mathrm{SiO} 2$-to-Na2O molar ratio is 1 , and the $\mathrm{Na2O}$-to-Al2O3 ratio (from metakaolin) is 1 . Finally the molar ratio of $\mathrm{H} 2 \mathrm{O} / \mathrm{Na} 2 \mathrm{O}$ is 7 . The zeolitic tuff is added in different ratios as reported in Table 2.

Geopolymers exhibit a nanoporous matrix gel as reported in Figure 1 [8, 12-14]. This porous matrix assists in increasing the surface area and the physicochemical adsorption of micropollutants. The adsorption capacity of geopolymers with different zeolites/metakaolins was studied in terms of adsorption of $\mathrm{Cu} 2+$ ions at a $\mathrm{pH}$ of 3 .

All the geopolymeric specimens exhibit high adsorption capacity of $8 \mathrm{mg} \mathrm{Cu} / \mathrm{g}$ for samples G3 and G4 after 1 day (Figure 2). It is observed that the adsorption capacity of bulk disks of geopolymers is comparable with powdered zeolites in other findings [15]. Figure 2 illustrates that increasing the zeolitic tuff percentages to $50 \%$ causes an increment in the adsorption capacity by several times. Therefore, this type of geopolymer can be used effectively in water treatment. 


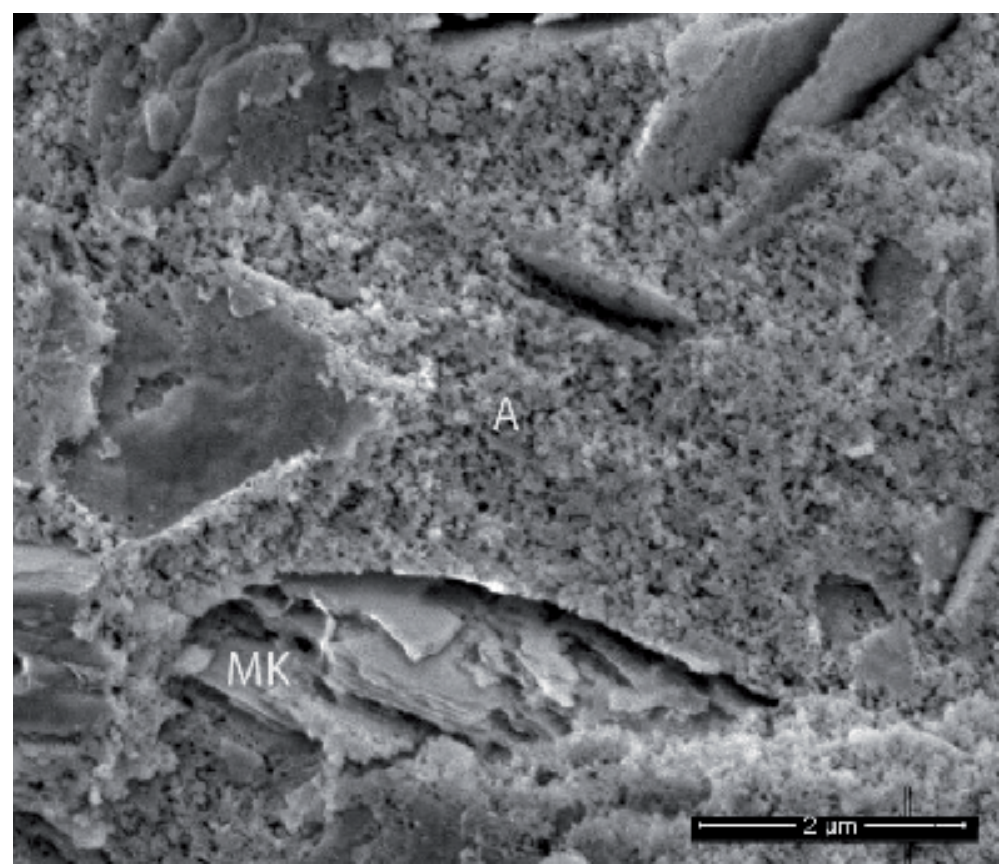

Figure 1.

SEM image of geopolymers. MK: Partially transformed metakaolinite. A: Geopolymer gel [8].

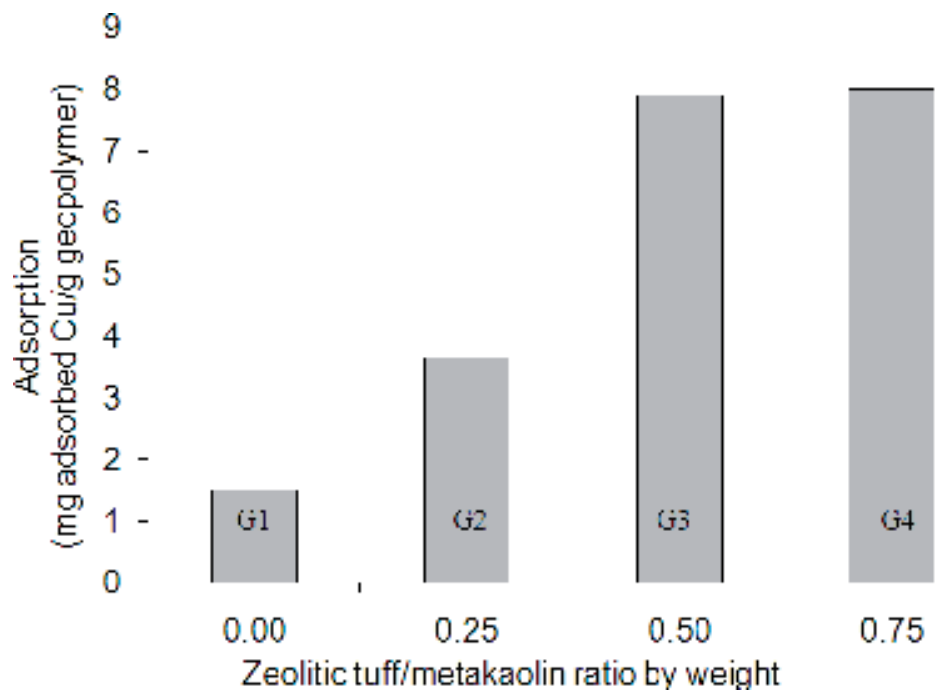

Figure 2.

Adsorption of $\mathrm{Cu}$ (II) onto geopolymeric disks, $\mathrm{pH}=3$ [8].

\subsection{Natural fiber-reinforced geopolymers for construction and passive cooling systems}

In a recent research, vascular natural fiber is used to improve the properties of end products to be used for more than one purpose. The use of natural fibers such as Luffa cylindrica fibers (LCF) as reinforcements for geopolymers has several objectives. In addition to improving mechanical properties, these vascular fibers improve the microstructural properties of the resulting material. In this research, 


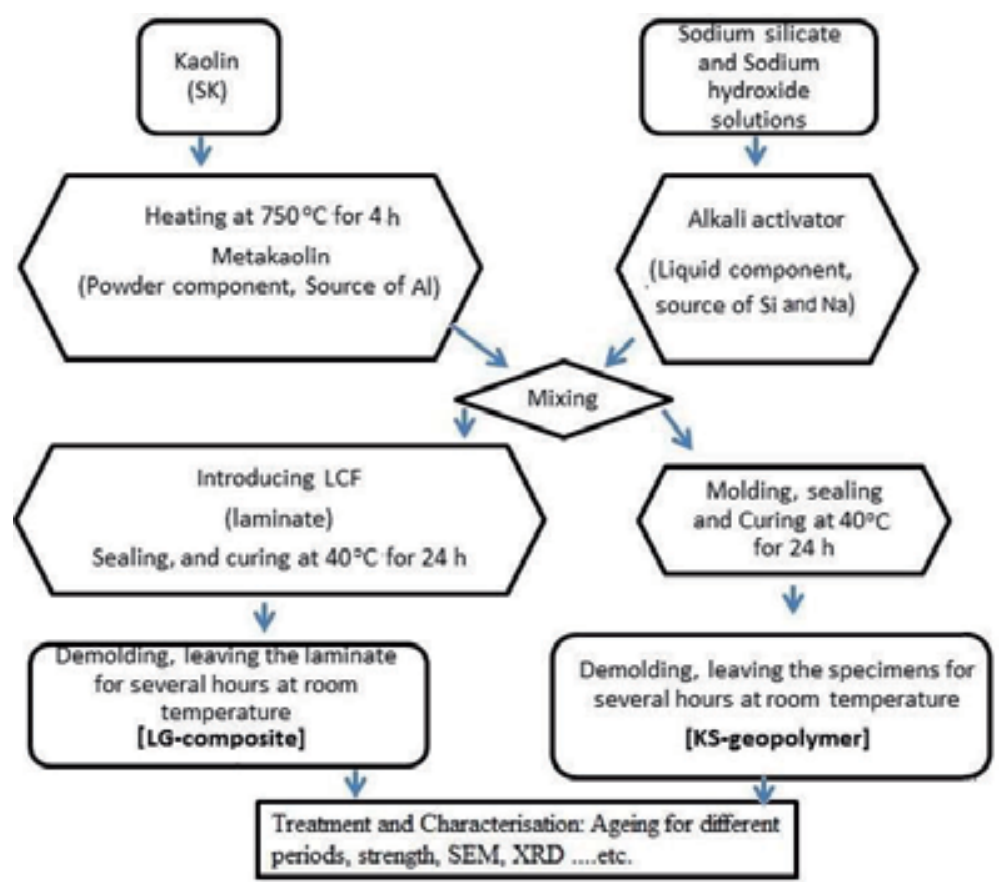

Figure 3.

The schematic diagram of the research methodology [11].

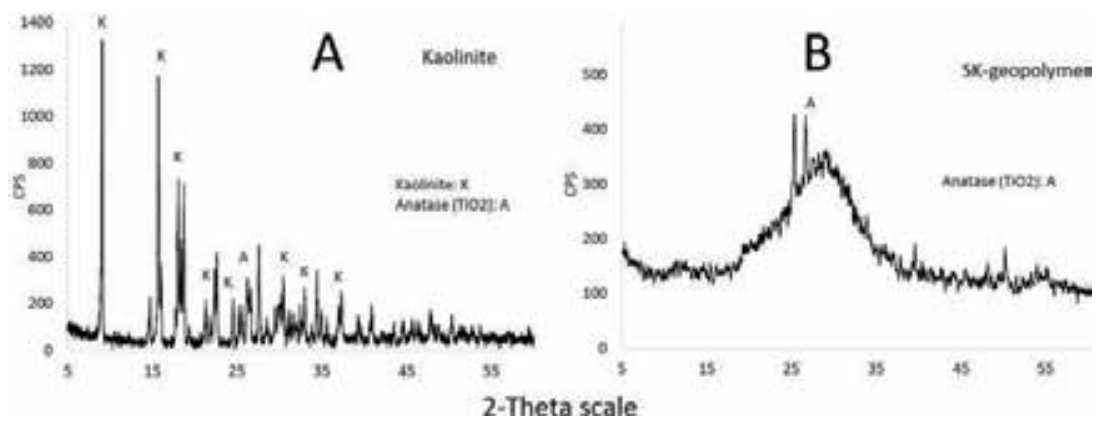

Figure 4.

XRD patterns corresponding to kaolin and the resultant geopolymer [11].

geopolymers (Sk-geopolymer) and LCF-reinforced geopolymers (LG composite) were made for reference and polymer composites using fiber as a reinforcing material with volume percentage of $10 \%$ as shown in Figure 3. The composition of the Sk-geopolymer was reported in our previous work [11].

As can be seen from X-ray tests, Figure 4, kaolinitic soil is transformed to an amorphous geopolymer gel as a result of the calcination at $750^{\circ} \mathrm{C}$ and the subsequent geopolymerization reactions $[11,16,17]$. These XRD results are in agreement with the SEM images as reported in Figure 5. The kaolin layers in Figure 5A break down by the geopolymerization process to obtain geopolymers with a semi-uniform nano-pore network as shown in Figure 5B. We also note the presence of bundles of tubes forming LC fiber. Both phases, whether the porous geopolymeric matrix or vascular LCF, help to increase the surface moisture of the material, which helps in the applications of passive cooling systems, especially in hot and dry regions.

On the other hand, we note that introducing LCF contributed significantly in improving the mechanical properties of geopolymeric products, where the 
Introductory Chapter: Case Studies of Functional Geopolymers DOI: http://dx.doi.org/10.5772/intechopen.90363
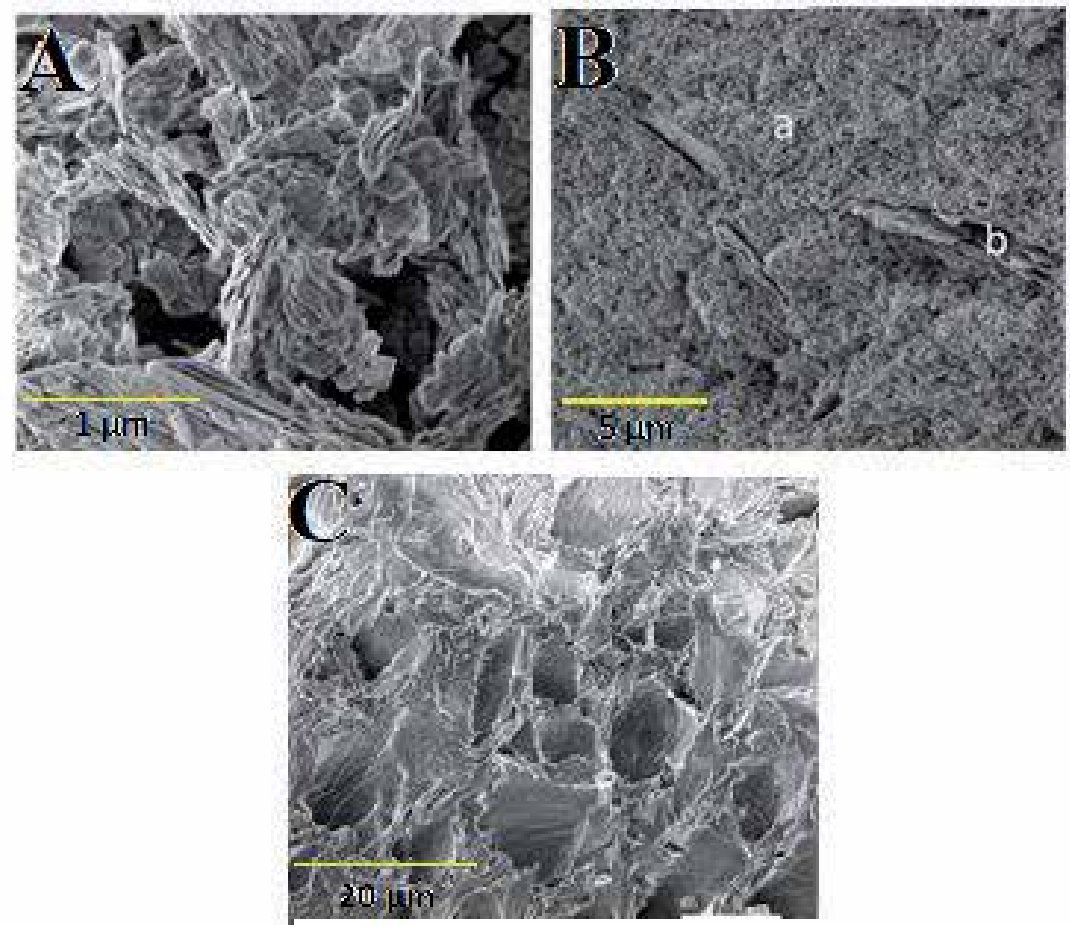

Figure 5.

SEM images of the precursor (A), geopolymer matrix (B), and the LCF cross section $(C)[8,11]$.
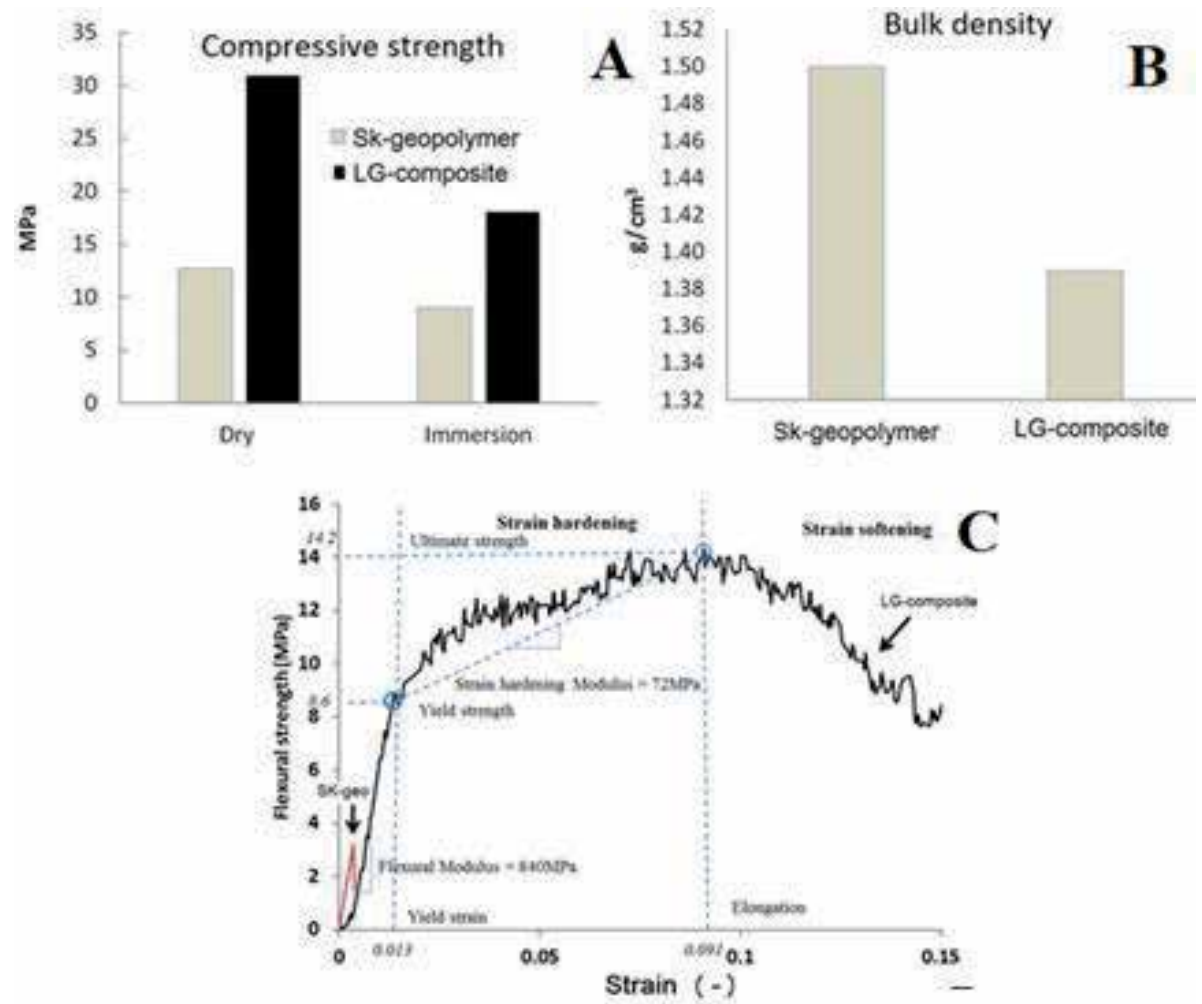

Figure 6.

Mechanical and physical properties of geopolymers (Sk-geopolymer) and geopolymer composite (LG-composite): Compressive strength $(A)$, Bulk density $(B)$, and Stress-strain curve $(C)$ [11]. 


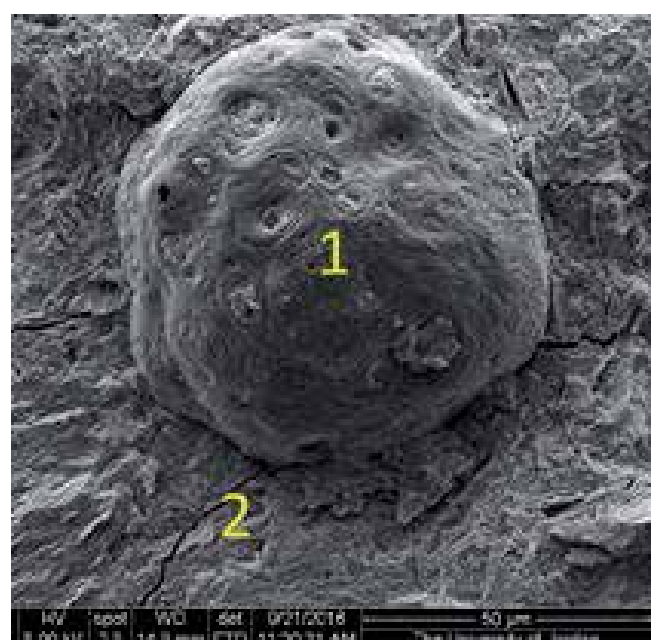

Figure 7.

HFO granules (point 1) in the geopolymeric matrix (point 2).

\begin{tabular}{lccc}
\hline Element & Toxicity (IUPAC) [19] & HFO (ppm) & HFO geopolymer matrix (ppm) \\
\hline $\mathrm{Na}$ & $\mathrm{X}$ & 21.6 & 179.2 \\
\hline $\mathrm{Ca}$ & $\mathrm{X}$ & 0.6 & 1.6 \\
\hline $\mathrm{Zn}$ & $\mathrm{X}$ & 164.0 & 0.0 \\
\hline $\mathrm{Mg}$ & $\mathrm{X}$ & 0.1 & 0.6 \\
\hline $\mathrm{Fe}$ & $\mathrm{X}$ & 3.3 & 0.1 \\
\hline $\mathrm{Mn}$ & $\mathrm{X}$ & 1.0 & 0.0 \\
\hline $\mathrm{Al}$ & $\mathrm{X}$ & 189.0 & 39.2 \\
\hline $\mathrm{Ni}$ & Toxic & 32.0 & 0.0 \\
\hline $\mathrm{Co}$ & Toxic & 0.1 & 0.0 \\
\hline $\mathrm{Pb}$ & Toxic & 1.6 & 0.0 \\
\hline $\mathrm{Cu}$ & Toxic & 1.2 & 0.0 \\
\hline $\mathrm{Cr}$ & Toxic & 4.1 & 0.0 \\
\hline
\end{tabular}

Table 3.

Concentration (ppm) of leached metals from crude HFO and HFP geopolymer matrix after immersion in $p H=7$ for 1 day.

compressive strength was doubled as shown in Figure 6A. It was observed also that the density of products was reduced by up to $10 \%$, Figure $6 \mathrm{~B}$, thanks to the addition of vascular LC fiber as reinforcement. This reduction in density is due to the fact that these fibers exhibit low bulk density compared to the geopolymer matrix. The most important influence for LC fibers on the mechanical properties of geopolymers is to significantly increase the tensile strength as shown in Figure 6C. Brittle geopolymer matrix also acquires the ductile failure thanks to LC fibers.

It is observed in this research that the LCF geopolymer composites have attracted mechanical and physical properties. In addition, the presence of multiple structures of porous networks, whether the geopolymeric matrix or the vascular LC fibers, plays an active role in the manufacture of passive cooling materials. Thus, these materials can be used as construction materials and in reducing the energy consumed in the indoor conditioning. 


\title{
2.3 Immobilization and stabilization of toxic wastes in geopolymers
}

Geopolymers have been used in recent years as a matrix for immobilization and stabilization of toxic wastes. The finished products can be used for specific construction purposes as well. Therefore, this geopolymerization process achieves several goals at once. In this study [18], heavy oil fly ash (HFO) containing toxic elements such as $\mathrm{Ni}, \mathrm{Cr}, \mathrm{Pb}$, etc. was added to the geopolymeric matrix as a filler. As can be seen in Figure 7, the granules of the HFO are fixed in the geopolymers. The resultant HFO geopolymer exhibits mechanical properties comparable with pure geopolymer [18]. As for the examination of the immobilization of toxic elements, it is observed in Table 3 that these elements were fixed in the geopolymeric matrix and they were not leached in water after a full day of immersion in water. Accordingly, this research achieves several objectives: the use of geopolymers in the recycling of $\mathrm{HFO}$ as a waste and the stabilization of toxic elements, in addition to its use as construction materials in specific applications.

\section{Conclusions}

There are several challenges and drawbacks facing the commercialization of geopolymers as an alternative to conventional cement and other conventional materials in construction. One important strategy to overcome these challenges is the manufacture of functional geopolymers with multiple uses. Three different applications of polymers in the fields of water purification, passive cooling systems, and waste recycling were presented in this introductory chapter. It is noticeable that the results are of great importance in many applications and confirm that this strategy will play a key role in the commercialization of geopolymers as products with multiple uses in engineering and environmental applications.

\section{Author details}

\author{
Mazen Alshaaer \\ Department of Physics, College of Science and Humanities in Al-Kharj, \\ Prince Sattam Bin Abdulaziz University, Al-Kharj, Saudi Arabia
}

*Address all correspondence to: mazen72@yahoo.com

\section{IntechOpen}

(C) 2020 The Author(s). Licensee IntechOpen. This chapter is distributed under the terms of the Creative Commons Attribution License (http://creativecommons.org/licenses/ by/3.0), which permits unrestricted use, distribution, and reproduction in any medium, provided the original work is properly cited. (cc) BY 


\section{References}

[1] Davidovits J. Geopolymers: Inorganic polymeric new material. Journal of Thermal Analysis. 1991;37:1633-1656

[2] Ferone C, Liguori B, Capasso I, Colangelo F, Cioffi R, Cappelletto E, et al. Thermally treated clay sediments as geopolymer source material. Applied Clay Science. 2015;107:195-204

[3] Alshaaer M. Two-phase geopolymerization of kaolinite-based geopolymers. Applied Clay Science. 2013;86:162-168

[4] Kuenzel C, Grover LM, Vandeperre L, Boccaccini AR, Cheeseman CR. Production of nepheline/quartz ceramics from geopolymer mortars. Journal of the European Ceramic Society. 2013;33:251-258

[5] Geraldes CFM, Lima AM, Delgado-Rodrigues JJ, Mimoso M, Pereira SRM. Geopolymers as potential repair material in tiles conservation. Applied Physics A: Materials Science and Processing. 2016;122:197

[6] Alshaaer M, Cuypers H, Wastiels J. Stabilisation of kaolinitic soil for construction purposes by using mineral polymerisation technique. In: Resheidat $M$, editor. Proceedings of the 6th International Conference Technology for Developing Countries. Vol. 3. pp. 1085-1092. Jordan; 2002

[7] Davidovits J. Global warming impact on the cement and aggregates industries. World Resource Review. 1994;6(2):263-278

[8] Alshaaer M, Zaharaki D, Komnitsas K. Microstructural characteristics and adsorption potential of a zeolitic tuff-metakaolin geopolymer. Desalination and Water Treatment. 2014;56:338-345. DOI: 10.10 80/19443994.2014.938306.2014
[9] Van Deventer J, Provis J, Duxson P. Technical and commercial progress in the adoption of geopolymer cement. Minerals Engineering. 2012;29:89-104

[10] McLellan BC, Williams RP, Lay J, van Riessen A, Corder GD. Costs and carbon emissions for geopolymer pastes in comparison to ordinary Portland cement. Journal of Cleaner Production. 2011;19(9-10):1080-1090

[11] Alshaaer M, Abu Mallouh S, Al-Kafawein J, Al-Faiyz Y, Fahmy T, Kallel A, et al. Fabrication, microstructural and mechanical characterization of Luffa cylindrical fibre-reinforced geopolymer composite. Applied Clay Science. 2017;143:125-133

[12] Azimi EA, Abdullah MMAB, Ming LY, Yong HC, Hussin K, Aziz IH. Review of dolomite as precursor of Geopolymer materials. In: MATEC Web of Conferences. Vol. 78. 2016. p. 01090. DOI: $10.1051 /$ matecconf/20167801090

[13] Komnitsas K, Zaharaki D. Geopolymerisation: A review and prospects for the minerals industry. Minerals Engineering. 2007;20:1261-1277

[14] Komnitsas K, Zaharaki D, Perdikatsis V. Effect of synthesis parameters on the compressive strength of low-calcium ferronickel slag inorganic polymers. Journal of Hazardous Materials. 2007;161:760-768

[15] El-Eswed B, Yousef RI, Alshaaer M, Khalili F, Khoury H. Alkali solid-state conversion of kaolin and zeolite to effective adsorbents for removal of lead from aqueous solution. Desalination and Water Treatment. 2009;8:124-130

[16] Alzeer M, MacKenzie KJD. Synthesis and mechanical properties of novel composites of inorganic polymers (geopolymers) with unidirectional 
Introductory Chapter: Case Studies of Functional Geopolymers

DOI: http://dx.doi.org/10.5772/intechopen.90363

natural flax fibres. Applied Clay

Science. 2013;75-6:148-152

[17] Hajjaji W, Andrejkovičová S, Zanelli C, Alshaaer M, Dondi M, Labrincha JA, et al. Composition and technological properties of geopolymers based on metakaolin and red mud.

Materials and Design. 2013;52:648-654

[18] Alshaaer M, Shqair M,

Abdelwahed HG, Abuhasel K, Zamorano M. International Journal of Applied Engineering Research. 2017;12(4):488-497

[19] The International Union of Pure and Applied Chemistry (IUPAC). United States: Research Triangle Park, NC 27709-3757 . Available from: https:// iupac.org/ 



\title{
Advanced Geopolymerization Technology
}

\author{
Sudhir Sitaram Amritphale, Pooja Bhardwaj and Rainy Gupta
}

\begin{abstract}
Advanced geopolymerization is a novel approach for the manufacture of geopolymers via innovative solid-state chemistry mechanism in which tailored geopolymeric precursors in solid powder form are the one part requirement, and only water is needed for its conversion to advanced geopolymeric material, in contrast to conventional process, where first solution of alkali is prepared and then mixed with silicoaluminous source materials. This novel process comprises of tailored geopolymeric precursors in solid powder form which is obtained via mechanochemical dry grinding of raw materials for prolonged hours. The basic raw materials include vitreous silica- and alumina-containing waste material/by-products, e.g. fly ash, activated by sodium hydroxide with or without sodium silicate. The solid powder needs only addition of water to form geopolymeric material. The advanced process includes solid-state reactions during dry grinding process and enables sequencing of reactions for preparation of geopolymeric material.
\end{abstract}

Keywords: advanced geopolymers, mechanochemical grinding, fly ash, mechanism, solid-state

\section{Introduction}

Nowadays, safe disposal of different waste materials and industrial by-products is a key concern for global communities. In this context, the possibility to reuse industrial waste like fly ash to produce economical value-added important products, viz. geopolymers, by mitigating environmental hazards related to waste disposal is being explored on a large scale worldwide. The construction industries benefited using the concept of utilization of waste materials as resource material for the development of value-added materials certainly due to increasing cost and shortage of virgin raw materials. Reuse of industrial by-products to generate valueadded products is one of the promising ways to attain green and sustainable development. Geopolymers are one of the commercially important products suitable for construction sector manufactured using waste products like fly ash, slag, etc.

In this work a brief status of barriers in adopting conventional geopolymerization and the challenges that must be overcome to commercialize geopolymers is considered as research objective and successfully achieved by introducing advanced geopolymerization process for the manufacture of solid-state advanced geopolymeric materials. The authors of this research focused their aim to establish a new chemical mechanism behind advanced geopolymerization contrasting reaction mechanism of conventional geopolymerization with an objective to broaden application spectrum of geopolymer which will be an important part of sustainable development. 


\section{Geopolymers}

Geopolymers can be defined as covalently bonded noncrystalline $\mathrm{Si}-\mathrm{O}-\mathrm{Al}$ networks in which $\mathrm{SiO}_{4}$ and $\mathrm{AlO}_{4}$ tetrahedral frameworks are linked by shared oxygen to form a dense amorphous to semicrystalline three-dimensional framework. These are termed as geological polymers for the reason that their starting raw materials is of geological origin, and formation of geopolymer proceeds via inorganic polymerization and condensation reactions [1].

Prof. J. Davidovits in 1978 introduced the term geopolymer and described it as cement-free green cementitious material. These are the inorganic polymers obtained from alkali activation of aluminosilicate materials like fly ash. These are structurally and chemically comparable to natural rocks and are synthesized by the condensation mechanism similar to thermosetting organic polymers therefore termed as geopolymers. Earlier these were considered as a special case of 'soil cement/silicates' or alkali-activated aluminosilicate cement and termed as 'geocements' as it consists of three-dimensional framework of cross-linked polysialate chains [2, 3].

Geopolymers have the potential to replace ordinary Portland cement (OPC) and to overcome the limitations associated with OPC. The production of OPC requires high temperature for calcinations which is not a requisite for the production of geopolymers. Unlike OPC, the production mechanism of geopolymers does not produce greenhouse gas $\mathrm{CO}_{2}$ and possess extraordinary chemical properties and mechanical strength. Thus, geopolymers are environment-friendly substitutes for $\mathrm{OPC}$ and are frequently referred to as 'green cement'.

Geopolymers can be produced from sources of geological origin (e.g. kaolinite, clay) or industrial by-products such as fly ash, granulated blast furnace slag, red mud, waste paper sludge, rice husk ash, wheat straw ash, etc. $[4,5]$. The choice of source material in geopolymerization technology depends upon the competitive cost, availability, and specific application. Fly ash [Class F fly ash]-based geopolymerization is getting intense research interest in past few years. It is a coal combustion residue generated from thermal power plants extensively rich in silica and alumina content [6]. Alkali activation of reactive silica- and alumina-rich raw materials produces an intense $3 \mathrm{D}-\mathrm{Si}-\mathrm{O}-\mathrm{Al}-\mathrm{O}-$ polymerization network [7]. The compact 3D framework thus formed after hardening is known as geopolymer, and the complete process is termed as geopolymerization (Figure 1).

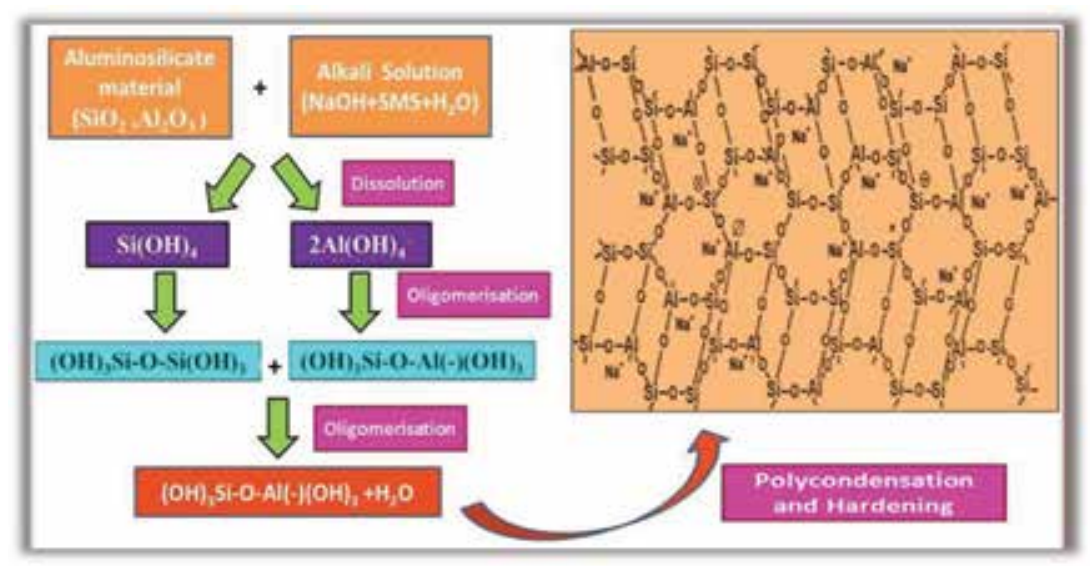

Figure 1.

Schematic representation of conventional geopolymerization. 


\section{Geopolymerization}

Geopolymerization is the process of transforming aluminosilicate raw material into covalently bonded 3D network consisting $[-\mathrm{Si}-\mathrm{O}-\mathrm{Al}-\mathrm{O}-]_{\mathrm{n}}$ bonds. In other words, geopolymerization process refers to geosynthesis, i.e. synthesis of chemically integrated minerals. The geopolymerization reaction results in the formation of viscous cementitious slurry which upon hardening forms strong, durable, and compact geopolymeric material $[6,8,9]$. Moreover much has been known about geopolymers and their chemistry in the last two decades, and efforts are still going on to uncover and discover some new scientific aspects of these wonder materials including some innovative applications besides construction sector $[10,11]$. Considering this numerous scientists and researchers are engaged all over the world to extract out more potentiality in geopolymeric materials. The knowledge regarding geopolymer science during the last two decades indicated that the inorganic geopolymers are prepared by using starting raw materials which should essentially contain reactive silica and alumina in their structure, e.g. fly ash, and the alkaline activator solution containing mixture of sodium hydroxide and sodium silicate [12-14]. Conveniently we termed this process of developing geopolymer as conventional geopolymerization technology. It is to note that geopolymers can be prepared by utilization of different aluminosilicate sources such as red mud, blast furnace slag, kaolinite, rice husk ash, etc., and the starting material plays important role in deciding physicochemical and mechanical properties of geopolymeric material $[15,16]$. The basic understanding of geopolymer formation and chemical reactions involved during conventional geopolymerization can be summarized as follows:

- Chemically, the conventional process includes solution chemistry mechanism in which amorphous aluminosilicate, e.g. fly ash, reacts with the solution of sodium hydroxide with sodium silicate and forms geopolymeric gel. Therefore geopolymer formation follows the bimolecular nucleophilic substitution $\left(\mathrm{SN}_{2}\right)$ mechanism [17]. Though geopolymerization reactions via solution chemistry mechanism cannot be fully understood, the complete mechanism can be understood under following heads including association, dissociation, oligomerization, and autopolycondensation.

- Step I is association, that is, association of water molecules to siloxane bond (-Si-O-Si-) present in aluminosilicate raw material. This association leads to the formation of an intermediate silicon species. The structure of intermediate silicon species is pentavalent making it highly reactive. The intermediate pentavalent silicon possesses distorted trigonal bipyramid structure and due to highly reactive nature undergoes dissociation rapidly to from silanols [12, 18-20].

- Step II is dissociation; in this step of SN2 mechanism, intermediate pentavalent silicon undergoes dissociation in a concerted manner and forms silanol $(>\mathrm{Si}-\mathrm{OH})$ and aluminol $(>\mathrm{Al}-\mathrm{OH})$ groups $[12,18-22]$.

- The silanols further reacts and forms silanediol $\mathrm{SiO}(\mathrm{OH})_{2}$, silanetriol $\mathrm{SiO}(\mathrm{OH})_{3}$ and silanetetraol $\mathrm{Si}(\mathrm{OH})_{4}$ species. It is to be noted that the hydrated silica behaves as an acidic oxide in the presence of alkaline solution and possesses tendency to go into solution. Further, $\mathrm{OH}^{-}$ions break siloxane bridges and result into the formation of alkaline silicates [23-26]. 


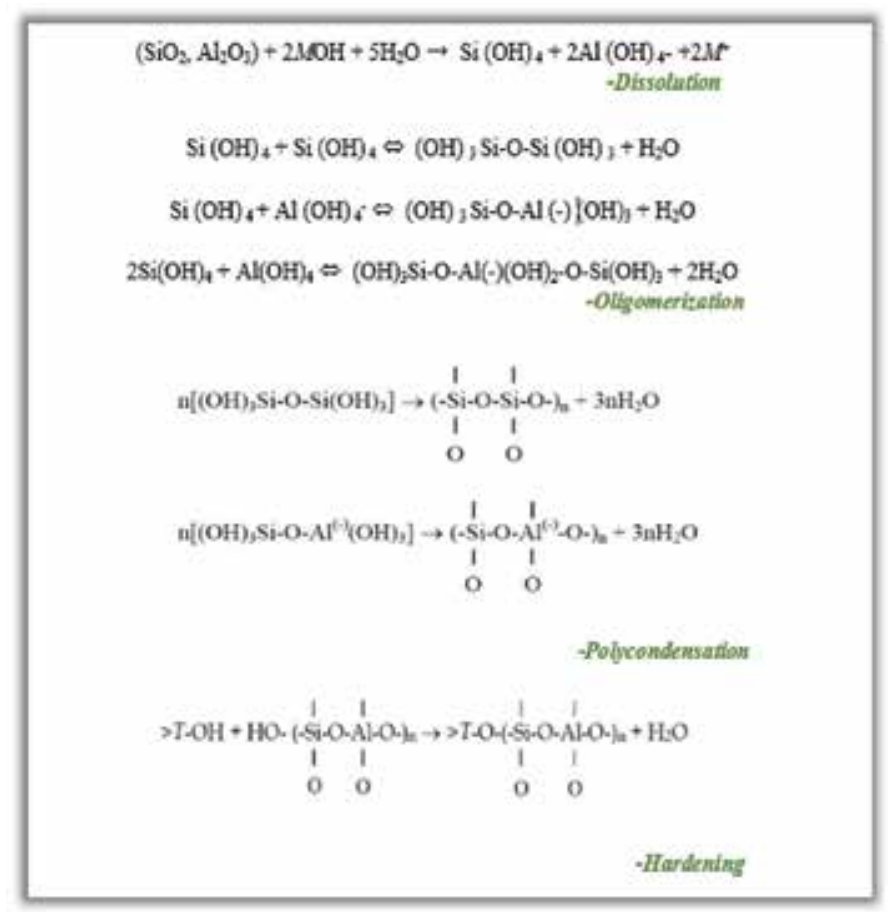

Figure 2.

Geopolymerization reactions proposed by [1-3].

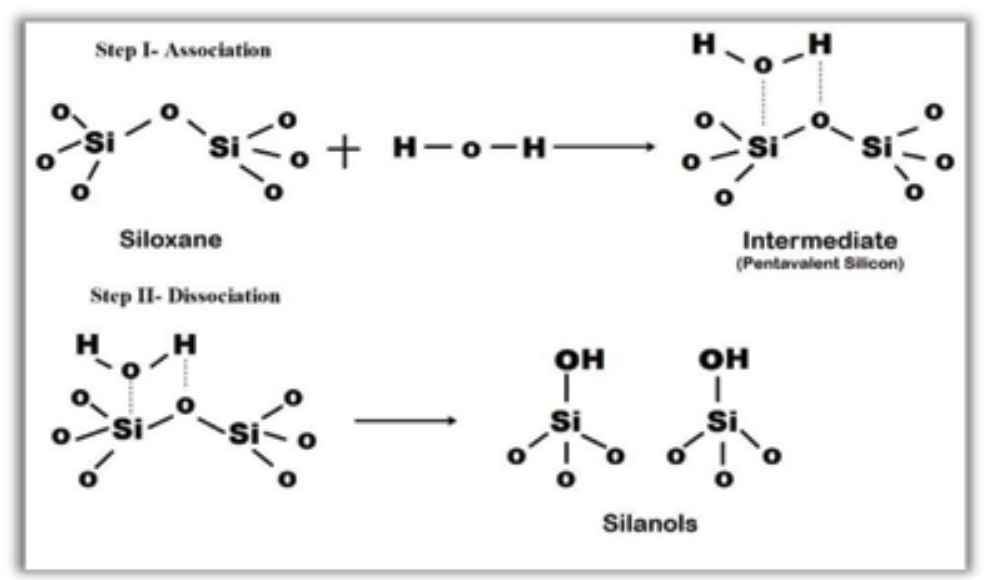

Figure 3.

Illustration of silanol and aluminol linkages in geopolymerization via $\mathrm{SN}_{2}$-solution chemistry mechanism.

- Similarly in aluminosilicate materials, oxides of $\mathrm{Al}$ get hydrated and form aluminol $(>\mathrm{Al}-\mathrm{OH})$ containing one negative charge and represented as $\mathrm{Al}$ $(\mathrm{OH})^{4-} . \mathrm{Al}^{3+}$ developed in fourfold coordination structure as it contributed only three electrons to bonding framework in place of four silicon atoms and because of this carry one negative charge [13].

- Autopolycondensation of silanols and aluminols takes place, and oligomers are transformed into polymer with the release of water molecules, further hardened to compact, strong $3 \mathrm{D}$ structure of $[-\mathrm{Si}-\mathrm{O}-\mathrm{Al}-\mathrm{O}-]_{\mathrm{n}}$ framework. 
In the geopolymeric chemistry, the negative charge on $\mathrm{Al}$ is balanced by cationic species like $\mathrm{Na}^{+}$to maintain the electrical neutrality. These are stereo-specific reactions which proceed with inversion of configuration. The rate of concerted mechanism depends on the concentration of both nucleophiles $\mathrm{OH}^{-}$and the molecule undergoing attack. The complete reaction sequence for $\mathrm{SN}_{2}$ mechanism is presented in Figure 2. On the other hand, Figure 3 is the complete illustration of silanol and aluminol linkages in geopolymerization via $\mathrm{SN}_{2}$-solution chemistry mechanism.

\section{Drawbacks of conventional geopolymerization process}

In order to make large-scale commercialization of geopolymeric materials, it is essential to replace this conventional synthesis method because it is not a userfriendly process. The dissolution of $\mathrm{NaOH}$ in water is an exothermic reaction which leads to the formation of highly hazardous alkaline solution. The handling of alkaline solution is risky and prone to on-site hazardous accidents. Besides, the conventional method produced geopolymers with the properties suited for the confined commercial applications. With the conventional method, tailoring of properties of geopolymeric product is not possible. It is noteworthy that, for multifunctional applications of any product, tailoring of properties is highly desired for large-scale production. With this context, the conventional process seems to be ineffective regarding tailoring of properties for broad-range applications. Therefore to overcome these limitations, we introduce the concept of advanced geopolymerization and its basic reaction mechanism further in this chapter.

\section{Advanced geopolymers}

Advanced geopolymerization is a novel approach for the manufacture of geopolymers via innovative solid-state chemistry mechanism invented and patented by [27]. The advanced process is one part system, i.e. the tailored geopolymeric precursors in solid powder form are the one part requirement and only water is needed for its conversion to advanced geopolymeric material, in contrast to conventional process, where the first solution of alkali is prepared and then mixed with source materials. In the novel process, tailored geopolymeric precursors in solid powder form are obtained via mechanochemical dry grinding of raw materials for 8 hours. The basic raw materials include vitreous silica- and alumina-containing waste material, i.e. fly ash and $\mathrm{NaOH}$ with or without sodium silicate. This solid powder needs only the addition of water to form geopolymeric material. The advanced process comprises solid-state reactions during dry grinding process and enables tailoring of raw materials and sequencing of reactions among them for the preparation of geopolymeric materials. These geopolymeric materials can be used on site easily just like ordinary Portland cement.

\section{Mechanochemistry/solid-state method}

Grinding is an important operation that is used industrially for particle size reduction and production of large surface areas or liberating valuable things from any mineral. It comprises of different steps including material transport to grinding zone, grinding action, initiation and propagation of cracks, breakage of particle, or initiation of solid-state reactions within. Size reduction and intergranular breakage are significantly achieved by subjecting particles to mechanical pressure for a prolonged period. Generally, the breakage and fracturing process during grinding involves 
rupturing of chemical bonds in order to create several reactive sites. The reactive sites when created are highly prone to undergo change and form some new chemical bonds with some other additive if present in the same reaction mixture [28]. This concept forms the basis of mechanochemical grinding reactions in dry state.

Mechanochemistry involves transformations supported by mechanical force in the form of milling or grinding [29-31]. The reactions proceed with grinding or milling are cleaner and efficient in terms of solvent, chemicals, materials, etc. [29]. It is known that the mechanical activation of aluminosilicate material, e.g. fly ash, results in enhanced reactivity. This is due to the combined effects of particle size reduction and physiochemical changes induced during high-energy milling of fly ash particles [32]. The mechanochemical activation on the other hand involves breakage of existing bonds and formation of new chemical bonds during high-energy milling process in the presence of any chemical agent in dry environment along with particle size reduction and increased amorphization. Solid-state chemical transformation occurs during mechanochemical grinding process of raw materials used for the advanced geopolymerization process.

The basic study for advanced geopolymerization was conducted by [27] in which grinding of fly ash along with $\mathrm{NaOH}$ in a ball mill exposed to mechanochemical forces that trench the internal bonding of fly ash and $\mathrm{NaOH}$ due to friction and impact with tumbling balls for prolonged durations. The amorphous reactive $\mathrm{Si} /$ Al phase disperses uniformly throughout the grinding process and reacts with $\mathrm{Na}^{+}$ ions to form three intermediate phases which are termed as precursor phases for advanced geopolymerization reaction. The solid powder obtained after mechanochemical grinding of fly ash and $\mathrm{NaOH}$ is therefore termed as advanced geopolymeric precursors $[8,9,33,34]$.

Figure 4 is the pictorial presentation of the advanced geopolymerization technology which clearly shows that by just addition of only water to the advanced geopolymeric precursor phases, gelation occurred, and this gel essentially contain $\mathrm{N}-\mathrm{A}-\mathrm{S}-\mathrm{H}$ phase [sodium aluminium silicate hydrate-geopolymeric phase].

(a) Mechanochemical grinding

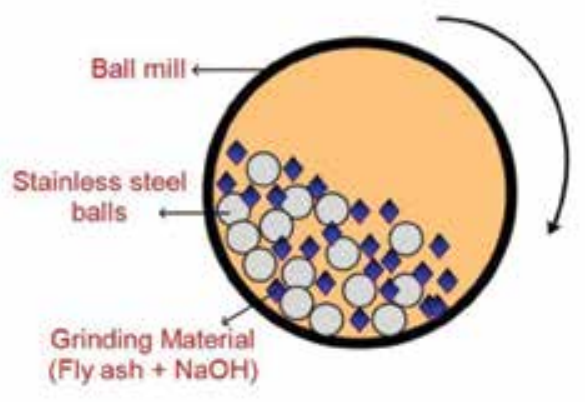

(b) Solid state trasformations

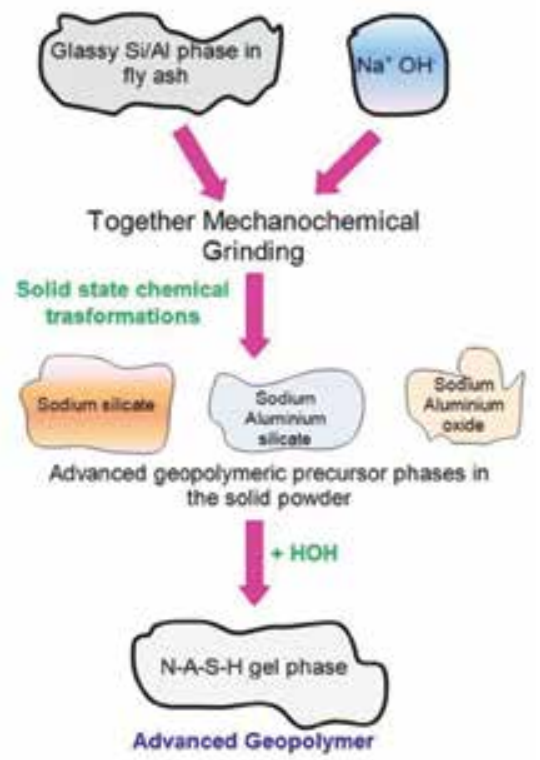

Figure 4.

Mechanochemical grinding of raw materials and development of advanced geopolymeric precursor phases due to solid-state chemical transformations. 
Later on, established by a number of experimental analyses, it can be said that advanced geopolymer possesses improved properties in terms of strength of the material and excellent corrosion protection [8, 9, 33-35].

\section{Plausible solid-state mechanism for advanced geopolymerization}

The solid-state mechanism involved in advanced geopolymerization reaction is different from that of conventional geopolymerization in the initial steps [33]. So the plausible chemical reaction mechanism for advanced geopolymerization can be understood under the following points:

- The 8 hours of mechanochemical activation of glassy silica/alumina in fly ash led to the dissociation of bonds present in glassy Si/Al phase; hence unlike conventional geopolymerization, the first step in the solid-state mechanism is dissociation. This step led to the formation of unstable silanone species $-\mathrm{Si}=\mathrm{O}$ from siloxane $-\mathrm{Si}-\mathrm{O}-\mathrm{Si}-$.

- This unstable $\mathrm{Si}=\mathrm{O}$ is active in nature and rapidly transform into silanol even in the presence of minimum amount of water. So the next step is the association of intermediate with the water molecules to form silanol.

- First dissociation, followed by association reaction for the formation of advanced geopolymer, confirms its unimolecular nucleophilic substitution $\left(\mathrm{SN}_{1}\right)$ mechanism as also presented in Figure 5.

- In the presence of water, silanols form - $\mathrm{Si}-\mathrm{O}-\mathrm{Al}$ - linkages, and geopolymeric gel is then formed which on drying produces advanced geopolymeric material with considerable enhanced properties.

\section{Step I- Dissociation}

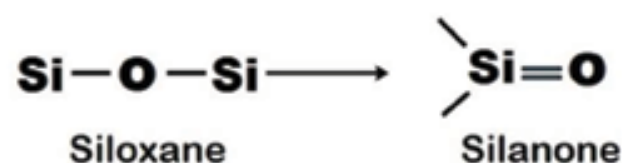

Step II- Association

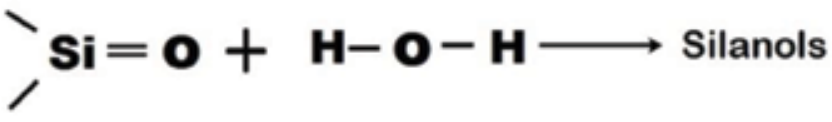

Figure 5.

Illustration of formation of silanone and silanols for advanced geopolymerization via $\mathrm{SN}_{1}$ solid-state chemistry mechanism [33].

\section{Advantages of advanced process over conventional process}

There are numerous advantages of advanced geopolymerization over conventional process. As we know, alkaline solution [pH around 10-14] is hazardous in nature which can cause skin hazards when accidently comes in contact with people 
dealing with it. The most important advantage of advanced geopolymerization is that it obviates the use of handling of highly alkaline solution as the advanced process involves reactions in dry state and only water is added to the geopolymeric precursor mixture which makes it a non-hazardous process. Unlike conventional geopolymerization, the geopolymeric precursor prepared by advanced process can be considered as ready-to-use premixture just like OPC which only requires addition of known amount of water to form cementitious material, thus facilitating its use for on-site application.

Moreover, advance geopolymerization is advantageous in terms of its application spectrum. The advanced geopolymeric precursor material is suited not only for application as cementitious material but also best suited for prefabricated or pre-engineered geopolymeric end products which enhance its commercialization. Tailoring of properties can be performed at the precursor stage by altering basic formulations before the stage of mechanochemical grinding. In other words, to get the desired properties from geopolymeric end product, advanced geopolymerization technology allows the user to tailor properties of the geopolymeric end product which is not possible in the case of conventional geopolymerization. Also advanced geopolymers are capable to address the concerns related to high cost, transportation, and long-term storage that are important challenges for building and construction materials.

\section{Advanced applications}

Having all the properties required for traditional applications of geopolymers, the advanced geopolymers also offer additional commercial applications due to their eco-friendlier and user-friendlier approach. The advanced geopolymerization process via solid-state route enables the tailoring of the properties of end products as per requirement. Some of the important applications of advanced geopolymers are given below:

1. Advanced ready-to-use geopolymeric cement just like OPC for cementitious functions by adding water alone instead of hazardous alkaline solution

2. Advanced household cement-free green cements for manufacture of geopolymeric construction products like tiles, panels, and paver blocks addressing rural development

3. Advanced corrosion protection material to provide corrosion protection to mild steel.

4. Advanced geopolymeric instant repairing material to reconstruct or repair damaged structures 


\section{Author details}

Sudhir Sitaram Amritphale*, Pooja Bhardwaj and Rainy Gupta Materials for Radiation Shielding and Cement Free Concrete Division, Council of Scientific and Industrial Research (CSIR)-Advanced Materials and Processes Research Institute (AMPRI), Bhopal, Madhya Pradesh, India

*Address all correspondence to: ssamritphale@hotmail.com

\section{IntechOpen}

(C) 2019 The Author(s). Licensee IntechOpen. This chapter is distributed under the terms of the Creative Commons Attribution License (http://creativecommons.org/licenses/ by/3.0), which permits unrestricted use, distribution, and reproduction in any medium, provided the original work is properly cited. (cc) BY 


\section{References}

[1] Davidovits J. Geopolymers: Inorganic polymeric new materials. Journal of Materials Education. 1994;16:91-139

[2] Davidovits J. Geopolymer Chemistry and Applications. Saint-Quentin, France: Institute Geopolymere; 2008

[3] Davidovits J. Geopolymers: Inorganic polymeric new materials. Journal of Thermal Analysis. 1991;37:1633-1656

[4] Hua X, Jannie S, van Deventer JSJ. Geopolymerization of multiple minerals. Minerals Engineering. 2002;15:1131-1139

[5] Lee WKW, Van Deventer JSJ. The effect of ionic contaminants on the early-age properties of alkali-activated fly ash-based cements. Cement and Concrete Research. 2002;32:577-584

[6] Phair JW, van Deventer JSJ. Effect of silicate activator $\mathrm{pH}$ on the leaching and material characteristics of wastebased inorganic polymers. Minerals Engineering. 2001;14(3)

[7] Palomo A, Grutzeck MW, Blanco MT. Alkali-activated fly ashes: A cement for the future. Cement and Concrete Research. 1999;29:1323-1329

[8] Gupta R, Bhardwaj P, Mishra D, Mudgal M, Chouhan RK, Prasad M, et al. Evolution of advanced geopolymeric cementitious material via a novel process. Advances in Cement Research. 2017;29(3):125-134

[9] Gupta R, Bhardwaj P, Mishra D, Prasad M. Amritphale SS formulation of mechanochemically evolved fly ash based hybrid inorganic-organic geopolymers with multilevel characterization. Journal of Inorganic and Organometallic Polymers and Materials. 2017;27(2):385-398

[10] Sumajouw DMJ, Hardjito D, Wallah SE, Rangan BV. Behavior and strength of geopolymer concrete column. In: Green Processing. The Australian Institute of Mining and Metallurgy; 2004. 237 pp

[11] Swanepoel C, Strydom CA. Utilization of fly ash in a geopolymeric material. Applied Geochemistry. 2002;17:1143-1148

[12] Du J. Molecular dynamics simulations of the structure and properties of low silica yttrium aluminosilicate glasses. American Ceramic Society. 2009;92(1):87-95

[13] Giannopoulou I, Panias D. Structure, design and applications of geopolymeric materials. In: III. International Conference on Deformation Processing and Structure of Materials. 2007. pp. 5-15

[14] Xu H, Van Deventer JSJ. Ab initio calculations on the five-membered alumino-silicate framework rings model: Implications for dissolution in alkaline solutions. Computers and Chemistry. 2000;24(3-4):391-404

[15] Provis JL, Duxson P, Lukey GC, Van Deventer JSJ. A statistical thermodynamic model for $\mathrm{Si} /$ $\mathrm{Al}$ ordering in amorphous aluminisicates. Chemistry of Materials. 2005;17(11):2976-2986

[16] Provis JL, Duxson P, Van Deventer JSJ, Lukey GC. The role of mathematical modelling and gel chemistry in advancing geopolymer technology. Chemical Engineering Research and Design. 2005;83(7):853-860

[17] Michalske T, Freiman S. A molecular interpretation of stress corrosion in silica. Nature. 1982;295:511-512

[18] Demontis P, Stara G, Suffritti GB. Behavior of water in the hydrophobic zeolite- silicate at different temperatures. A molecular dynamics 
study. Journal of Physical Chemistry B. 2003;107(18):4426-4436

[19] Lasaga AC. Atomic treatment of mineral-water surface reactions. Reviews in Minerology and Geochemistry. 1990;23(1)

[20] Puibasset J, Pellenq RJM. A comparison of water adsorption on ordered and disordered silica substrates. Physical Chemistry Chemical Physics. 2004;6(8):1933-1937

[21] Geisinger KL, Gibbs GV, Navrotsky A. A molecular orbital study of bond length and angle variations in framework structures. Physics and Chemistry of Minerals. 1985;11(6):266-283

[22] Lasaga AC. Fundamental approaches in describing mineral dissolution and precipitation rates. In: White $\mathrm{AF}$, Brantley SL, editors. Proceedings of Chemical Weathering Rates of Silicate Minerals, vol. 31(1). Mineralogical Society of America; 1995. pp. 23-86

[23] Feuston BP, Garofalini SH. Waterinduced relaxation of the vitreous silica surface. Journal of Applied Physics. 1990;68(9):4830-4845

[24] Garofalini SH. Molecular dynamics computer simulations of silica surface structure and adsorption of water molecules. Journal of Non-Crystalline Solids. 1990;120(1-3):1-12

[25] Knight CTG, Balec RJ, Kinrade SD. The structure of silicate anions in aqueous alkaline solutions. Angewandte Chemie International Edition. 2007;46:8148-8152

[26] Mahadevan TS, Garofalini SH. Dissociative chemisorption of water onto silica surfaces and formation of hydronium ions. Journal of Physical Chemistry C. 2008;112(5):1507-1515

[27] Amritphale SS, Mudgal M, Chouhan RK, Mishra D, Chandra N. Novel process for the preparation of geopolymeric functional materials in a solid form. In: US Patent 20150203405. 2015

[28] El-Shall H, Somasundaran P. Physico-chemical aspects of grinding: A review of use of additives. Powder Technology. 1984;38:275-293

[29] Halasz I, Kimber SAJ, Beldon PJ, Belenguer AM, Adams F, Honkimaki V, et al. In situ and real-time monitoring of mechanochemical milling reactions using synchrotron X-ray diffraction. Nature Protocols. 2013;8(9):1718-1729

[30] James SL, Adams CJ, Bolm C, et al. Mechanochemistry: Opportunities for new and cleaner synthesis. Chemical Society Reviews. 2012;41(1):413-447

[31] Takacs L. The historical development of mechanochemistry. Chemical Society Reviews. 2013;42(18):7649-7659

[32] Kumar R, Kumar S, Mehrotra SP. Towards sustainable solutions for fly ash through mechanical activation. Resources, Conservation and Recycling. 2007;52(2):157-179

[33] Bhardwaj P, Gupta R, Mishra D, Mudgal M, Amritphale SS. Synthesis of advanced phosphatic geopolymers utilizing fly ash via greener route. Emerging Materials Research. 2017;6(1):168-177

[34] Gupta R, Bhardwaj P, Deshmukh K, Mishra D, Prasad M, Amritphale SS. Development and characterization of inorganic-organic ( $\mathrm{Si}-\mathrm{O}-\mathrm{Al}$ ) hybrid geopolymeric precursors via solid state method. Silicon. 2018:1-12

[35] Bhardwaj P, Gupta R, Mishra D, Mudgal M, Amritphale SS. ${ }^{27} \mathrm{Al}$ NMR MAS spectral studies inferring the initiation of geopolymerization reaction on together mechanochemical grinding of raw materials. Journal of the Chinese Chemical Society. 2018;65:485-489 



\title{
Summary of Some Selected Characterization Methods of Geopolymers
}

\author{
Dattaguru Ananthapadmanaban
}

\begin{abstract}
All modern day materials have to be characterized in order to understand their properties. Simple techniques can be used for macrostructural and microstructural characterization. Many a time, however, advanced techniques may be required in order to understand structure property relationships in a better way. Advanced characterization techniques include scanning electron microscope (SEM), transmission electron microscope TEM, nuclear magnetic resonance (NMR), synchrotron, X-ray fluorescence microscopy and a few others. Geopolymers have advanced to the level of nanogeopolymers, and in order to understand the fundamental properties of nanogeopolymers, it becomes imperative to gain a fundamental understanding of characterization methods. SEM, TEM, NMR and synchrotrons have been briefly described, and advances in these characterization techniques have been emphasized. Microstructures of common geopolymers have been discussed with special emphasis on nanogeopolymers.
\end{abstract}

Keywords: SEM, TEM, X-rays, NMR, synchrotron

\section{Introduction}

Characterization studies are essential to gain practical knowledge about materials. They can also be used to correlate structure with properties. There is a host of characterization techniques used to identify materials. They include scanning electron microscopy, transmission electron microscopy, X-ray diffraction, TEM, $\mathrm{XRD}, \mathrm{X}$-ray fluorescence, NMR (nuclear magnetic resonance) and synchrotron techniques. However, no single technique can give a full analysis of the material being characterized. In practical research work, conclusions have to be drawn by using 2 or 3 characterization techniques. This chapter examines the use of various characterization techniques for researching geopolymers.

Aluminosilicate binder gel has an amorphous structure. Some years back, a study of amorphous structures was not possible since characterization techniques had not advanced to that extent. But, now it is possible to study amorphous structures, and hence characterization of geopolymers, which can occur in the amorphous state, is possible. Most of the literature in geopolymers concentrates on cements and substitutions/additions to cement. An additional advantage is the high compressive strength of geopolymers. Many geopolymers are manufactured using binders, and most of these binders exist in an amorphous state. These binders are 
obtained by the reaction between an alkali source and a solid aluminosilicate powder. The aluminosilicate can be one among metakaolin, fly ash and/or blast-furnace slag. These geopolymers are increasingly being used as construction materials to replace Portland cement [1-3]. Geopolymers based on natural zeolite have also been studied and found to have good adhesion to concrete. These geopolymers have been characterized using XRD and SEM [4]. Fly ash has also been activated by alkali to form a geopolymer, but there are concerns regarding mechanical properties of this material [5]. Geopolymers based on phosphoric acid and illito-kaolinitic clay have been synthesized with reasonably good compression strength [6]. Hence, among all the geopolymers studied, kaolinite-based geopolymers seem to hold promise for the future, and this geopolymer has been used mainly for description of characterization.

Characterization methods have been classified into (a) microscopy (b) X-raybased tomography and fluorescence (c) and other modern methods of characterization which include imaging, nuclear magnetic resonance, FTIR spectra and synchrotron. Each division of characterization has been described briefly before taking up case studies. Selective characterization techniques have been described with metakaolin as an example. Other geopolymers have also been characterized as and when required. During the description of selective characterization techniques, the use of characterization in metakaolin has been dealt with first, and then some more examples of characterization of other geopolymers have been studied as and when required.

\section{Microscopy}

Microscopy is commonly used in research and lab studies to throw light upon the detailed features of a material. Optical micrographs are generally used to study the metallurgical microstructures. But, in the case of geopolymers, we are concerned with the pore formation, distribution and other more intricate features. So either scanning electron microscope (SEM) or transmission electron microscope (TEM) is used in recent research. Figure 1 summarizes the types of rays that are produced when an electron hits a sample target.

Electron beams strike the surface of the sample in all cases of electron microscopy. It would be worthwhile to have a short discussion of what happens when the electron beam strikes the surface. The Figure 1 shown above gives a gist of the type of rays emitted after striking a sample. The backscattered electrons are used in SEM backscattered image. Unscattered electrons are used in TEM. Auger electrons are used in Auger spectroscopy, and emitted X-rays are used in EDS (electron dispersive spectra) and EPMA (electron probe microanalysis).

\subsection{SEM imaging}

Scanning electron microscopy has been widely used to study fractured surfaces. The images give an idea of whether the fracture is ductile or brittle. Sometimes, it is possible to have a mixed mode failure too (Figure 2).

\subsection{TEM imaging}

Figure 3 shown above gives in brief the differences between SEM and TEM. Here, the specimens have to be prepared to thin slices of less than $100 \mathrm{~nm}$ thickness. Again, similar to SEM, specimen preparation is of utmost importance. Vacuum has to be maintained in the TEM, and any flaw in the maintenance of 


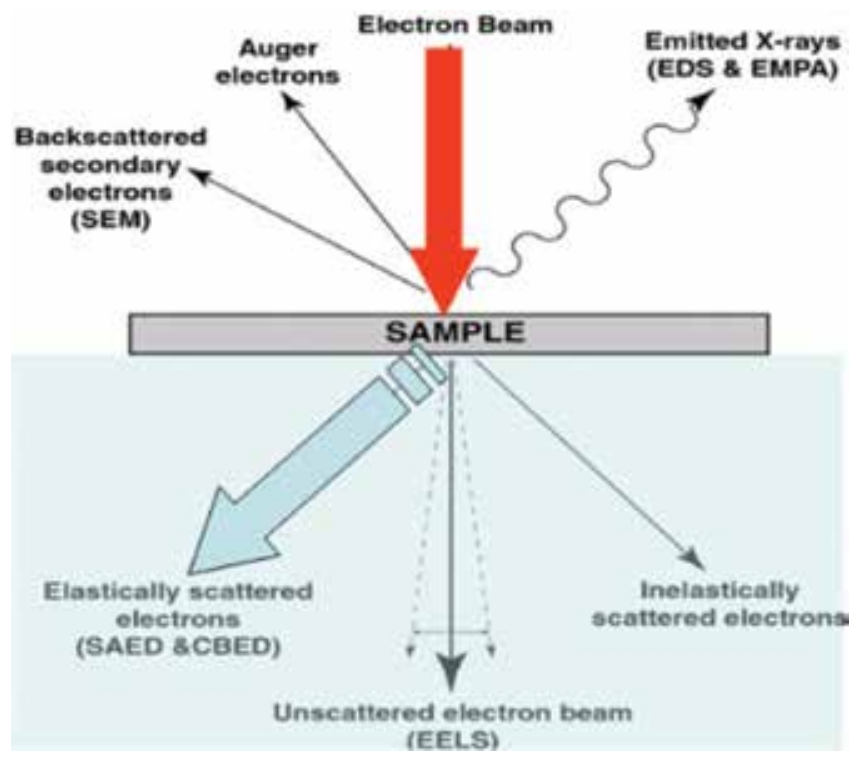

Figure 1.

Different types of reflected and transmitted rays.

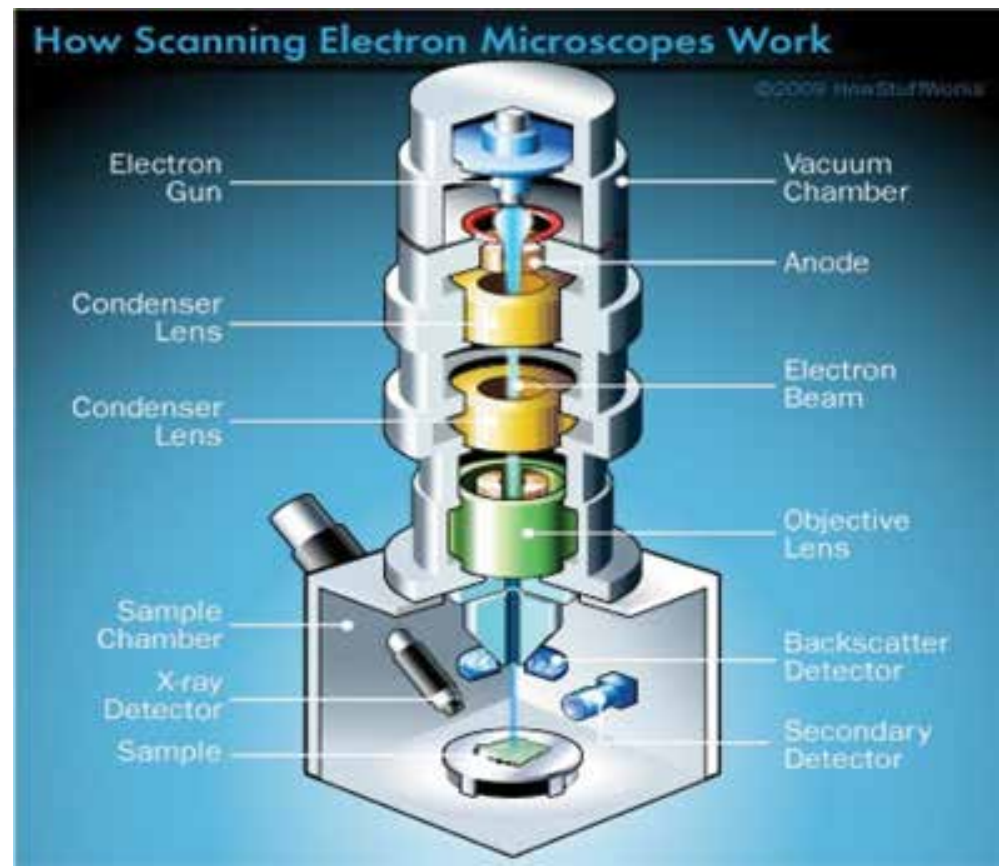

Figure 2.

Working principle of SEM-source [7].

vacuum will reflect in the performance of the TEM. Usually, dislocation density and second phase precipitation can be clearly seen in TEM images.

The electron gun is a source of electrons. The electrons are focused with the help of condenser lens and objective lens. There is a chamber to hold the workpiece. Care should be taken to prepare the workpiece very carefully and specialists are required for SEM sample preparation. The chamber consists of a backscatter detector and a secondary detector. So the SEM can be operated under two modes. 

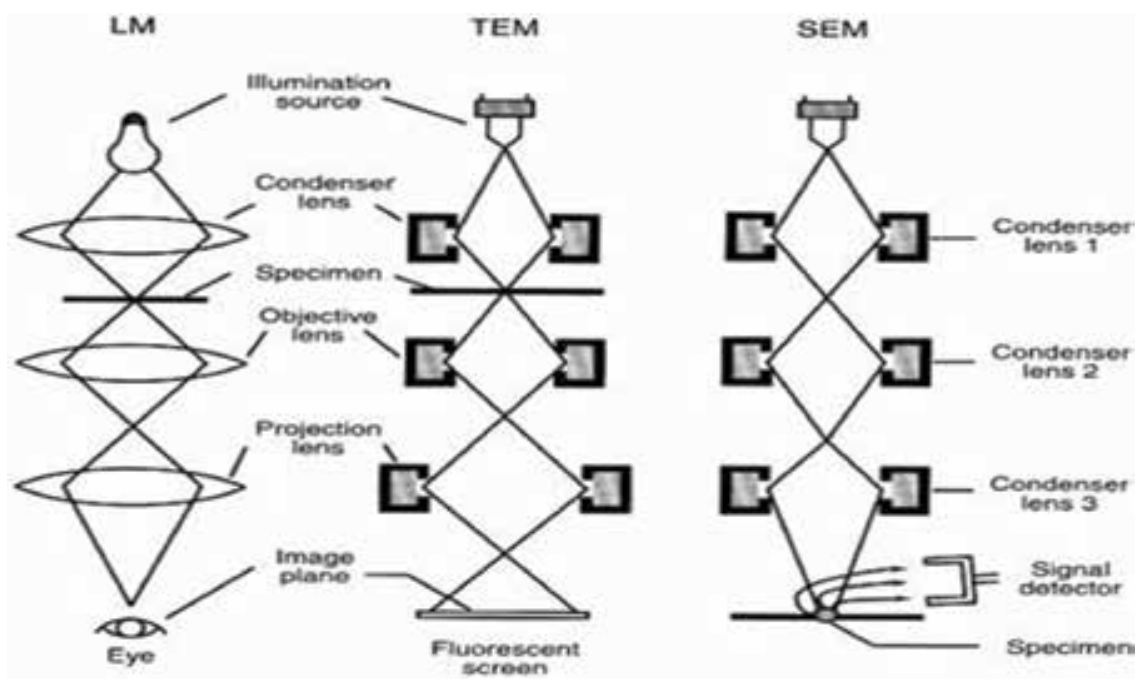

Figure 3.

Difference between light microscope, SEM and TEM.

Figure 4 depicts uniform distribution of metakaolin and possibly a ductile fracture. The SEM image above shows a wide variety of shapes of fly ash, tending towards a spherical shape. There seems to be agglomeration and there also seem to be some cracks. Cracks often lead to brittleness. This SEM micrograph of a fly ash geopolymer seems to indicate mixed mode of failure (Figures 5 and 6 ).

Again, this SEM shows an even wider distribution of particles and a very large particle size distribution too. It appears, from the cracks seen and the fragments in the SEM that in this case, there has been a brittle fracture. This possibility is supported by the fact that most concrete fails in a brittle fashion. Addition of geopolymer/substitution of various geopolymeric elements like fly ash could change the morphology and influence fracture to some extent.

Research in these areas is still in the nascent stage. However, it is worth mentioning here that considering the danger that Mother Earth is facing under the deluge of huge amounts of metallic and ceramic waste, it would be a very worthwhile task to look for alternatives to concrete or make some substitutions to concrete to make it more environmentally friendly. It is here that geopolymeric materials could help (Figure 7).

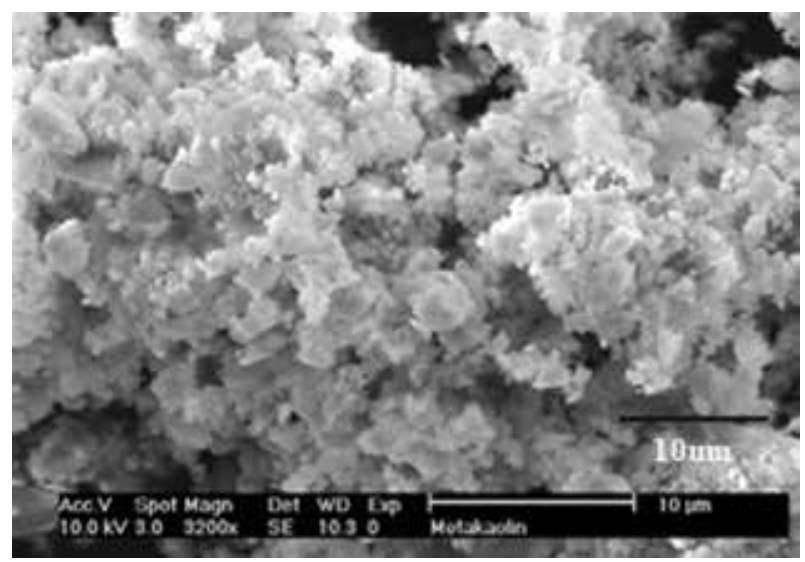

Figure 4.

SEM image of metakaolin; source-Wiki Image [8]. 


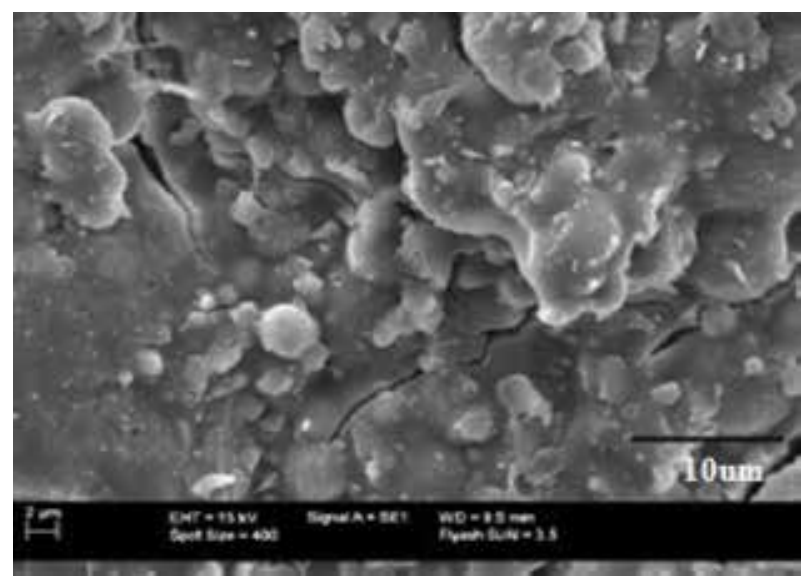

Figure 5.

SEM image of geopolymer fly ash after heating at 820 Celsius_courtesy of Temujin et al. [9].

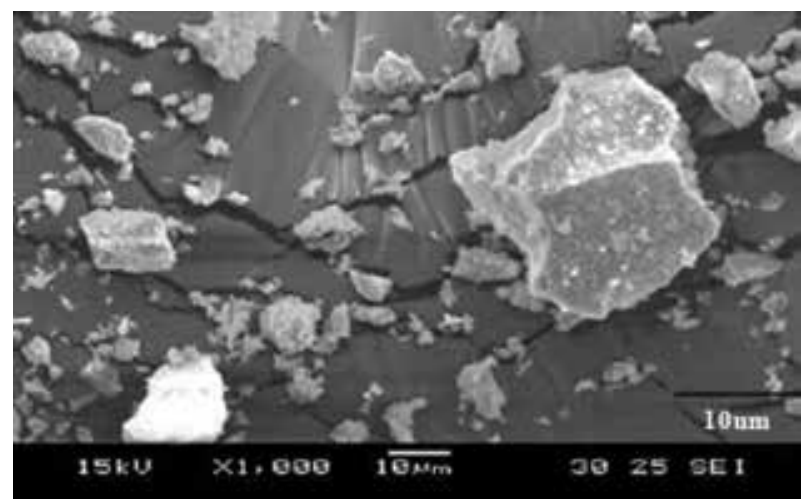

Figure 6.

SEM micrograph of fly ash geopolymer [10].

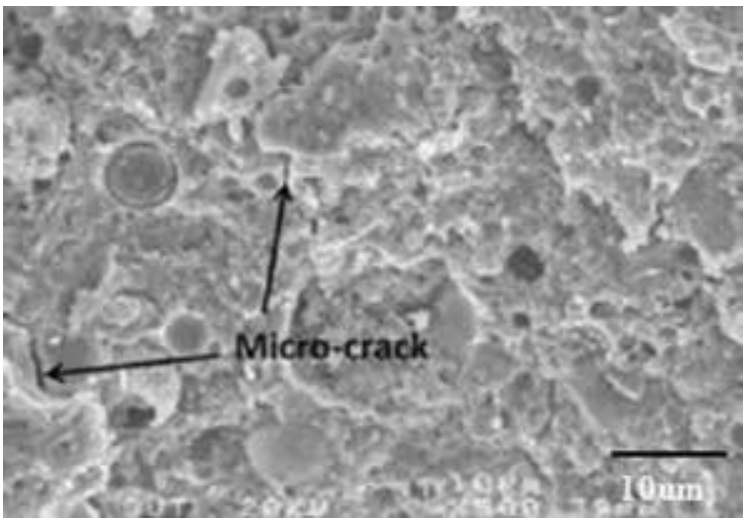

Figure 7.

SEM micrograph clay-based geopolymer brick cured at 85 Celsius for 24 hours [11].

Here, since the geopolymer is clay-based, the SEM shows a ductile type of fracture. Curing may be necessary to improve strength and bonding. Usage without curing may lead to lower tensile strength. Microcrack formations are seen in the SEM, but these are too small to be of any importance or create any immediate 
danger of failing to the geopolymer. Another study of ground-granulated blast-furnace slag (GGBS)-amended fly ash was conducted by Sharma AK et al. This can be used as soil conservative. The SEM shown below shows a fairly ductile fracture. The interface condition is good and porosity is not seen. This indicates that there is good contact between soil particles and cementitious mix. C-S-H and calcium oxide formations have also been confirmed in this study. SEM evidence has shown that fly ash mixed with GGBS has the potential to improve the properties of expansive soil with a minimum requirement of chemical additives such as lime (Figure 8).

In Figure 9, clustering can be seen. The bright-field transmission electron micrograph of a slag-based geopolymer is shown in Figure 9. The figure shows the clustering of slag. This may have a deleterious effect on properties.

In Figure 10(a) Medri et al. [8] tested two metakaolins manufactured industrially by the company Imerys with two different kiln technologies. One called M1000 is calcined in a rotary kiln and characterized by rounded massive aggregates of lamellar particles. The second, called M1200S, calcined in a flash kiln, is made up of fine lamellar particles with lower agglomeration. Figure 10(b) reports that the geopolymer structure is characterized by gel (amorphous) phase, and also some crystalline phases are present as in most geopolymers.

TEM image shows agglomeration of slag, which can be seen with SEM also, but SEM can be used only for surface studies, whereas TEM can be used to find details of subsurface.
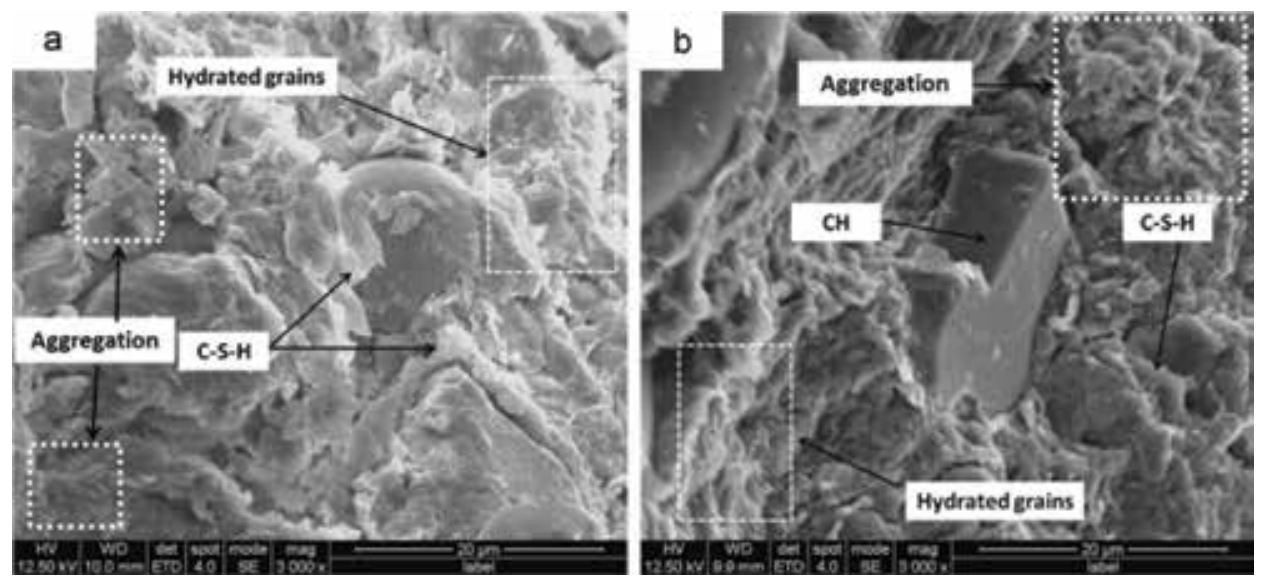

Figure 8.

C-S-H bonds and aggregation [10].

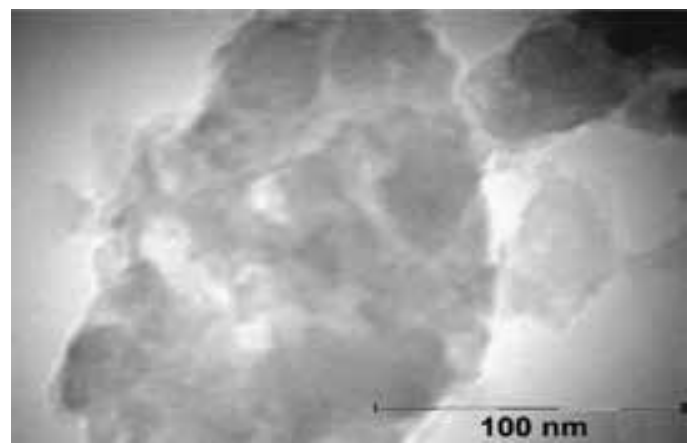

Figure 9.

Bright-field image of slag-based geopolymer. 

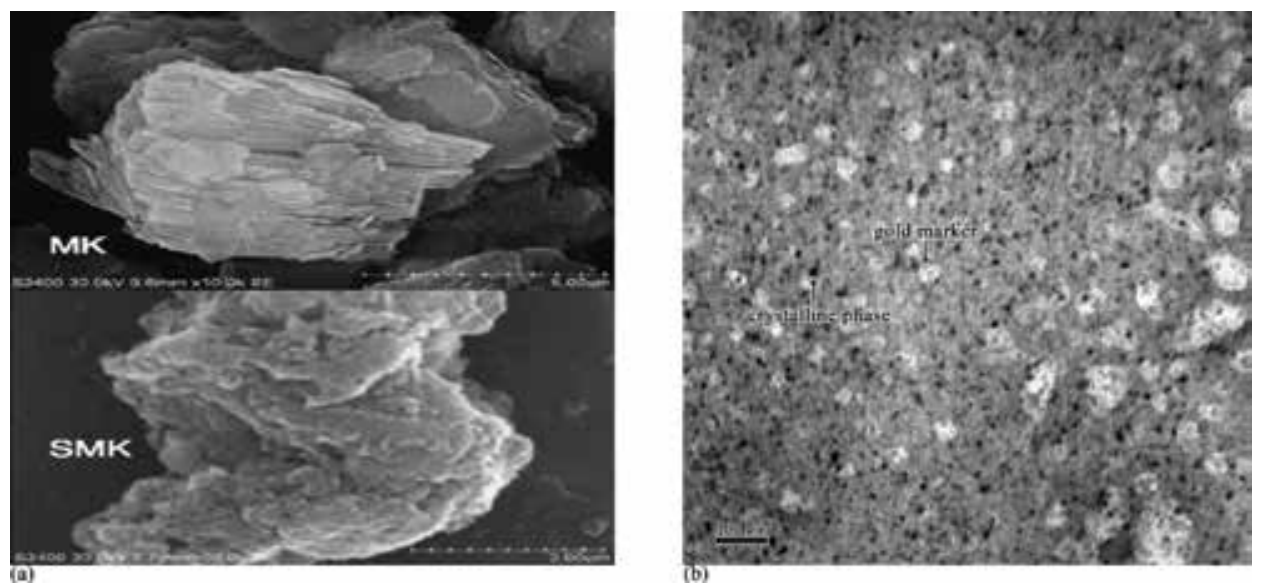

Figure 10.

(a) SEM images of natural and synthetic metakaolins (Cui et al.) [12] and (b) pore structure in coal ashbased geopolymer [13].

\section{X-ray tomography and fluorescence microscopy}

Many different cross-sectional views are created suing X-rays. These are then assembled to create a 3D image of the object. The size of the pixels which are created in this manner so created are in micrometers and hence the word, microtomography. It should be noted that the 3D model is a virtual model and is not in real time. These pixel sizes have also resulted in the terms high-resolution X-ray tomography, micro-computed tomography (micro-CT or $\mu \mathrm{CT}$ ) and similar terms. In today's terminology, tomography automatically implies computer tomography.

Figure 11 illustrates the features of a slag-based geopolymer using the X-ray microtomograph. Furthermore, histogram, Figure 11, also depicts particle size distribution. In general, fly ash-based polymers have been studied by Das et al. and characterized by X-ray tomography [14].

The X-ray tomography shows the distribution of phases. Slag particles can be clearly seen as a white product. There also seem to be some cracks, which, if allowed to propagate, could lead to premature failure of the component in use (Figure 12).

According to The Royal Chemical Society, X-Ray Fluorescence is an imaging technique where a beam of X-rays is directed at the specimen-Rays are emitted
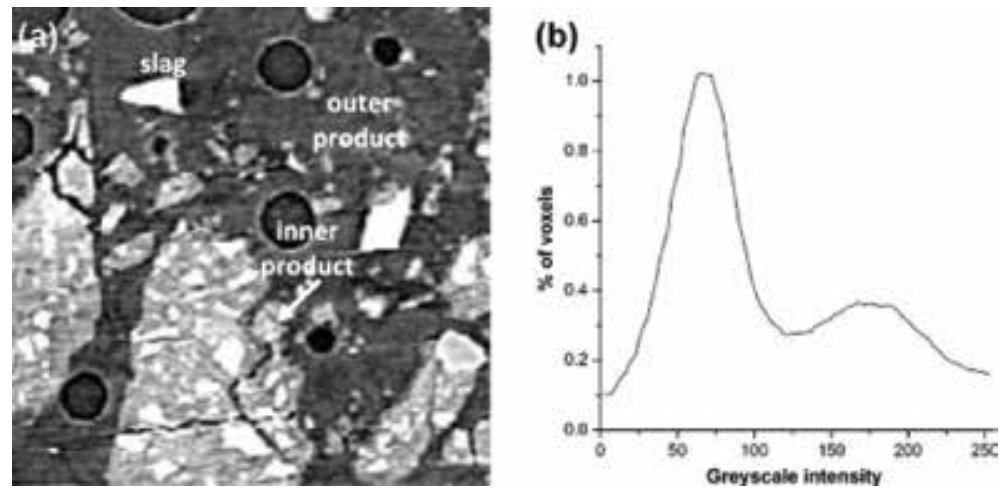

Figure 11.

$X$-ray microtomography scan of a sodium silicate-activated binder ( $80 \%$ slag/20\% metakaolin, activat) (b) a histogram depicting volume of pixels of the volume of interest. 

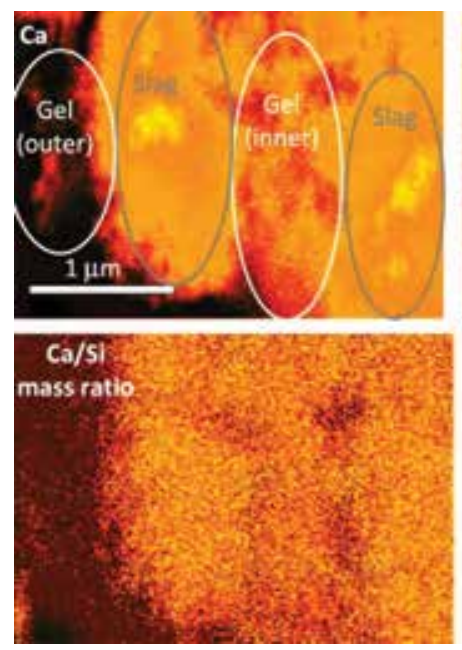
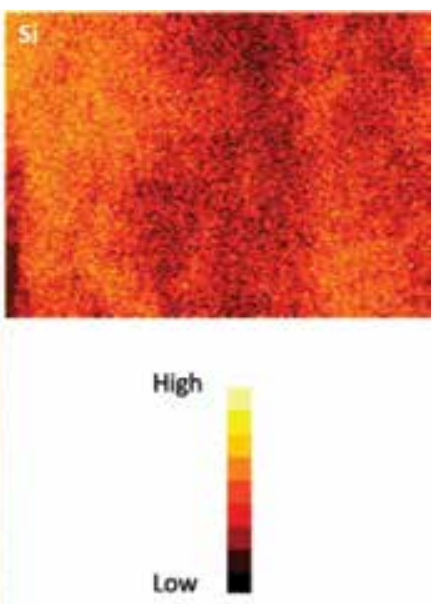

Figure 12.

$X$-ray fluorescence micrographs of a sodium metasilicate-activated binder (75\% slag/25\% metakaolin) [13].

due to transitions and the intensities of the X-rays emitted due to are detected as a function of wavelength and position. As these energies are element-specific, X-ray fluorescence microscopy can be used to determine spatially resolved elemental composition.

The X-Ray fluorescence image shown above shows different emitted colors for inner gel and for outer gel. As can be seen, the differences in $\mathrm{Ca} / \mathrm{Si}$ ratio also can be mapped based upon the color.

\section{Nuclear magnetic resonance (NMR) spectra}

Nuclear magnetic resonance (NMR) is a physical phenomenon in which nuclei in a strong static magnetic field are perturbed by a weak oscillating magnetic field. This field is very close to the surface. It does not involve electromagnetic interactions or waves and respond by producing an electromagnetic signal with a frequency characteristic of the magnetic field at the nucleus. This process occurs near resonance. As we are aware, during resonance, two frequencies have to match, and the resultant frequency is far ahead in intensity compared to the two participating frequencies. When the oscillation frequency matches the intrinsic frequency of the nuclei, which depends on the strength of the static magnetic field, the chemical environment and the magnetic properties of the isotope involved; in practical applications with static magnetic fields up to ca. 20 tesla, the frequency is similar to VHF and UHF television broadcasts (60-1000 MHz). NMR results from specific magnetic properties of certain atomic nuclei. Nuclear magnetic resonance spectroscopy is widely used to determine the structure of organic molecules in solution and study molecular physics, crystals as well as noncrystalline materials. NMR is also routinely used in advanced medical imaging techniques, such as in magnetic resonance imaging (MRI).

Nuclear magnetic resonance spectra can be used to identify elemental groups. Each group has a characteristic shift in wavelength. The shifts for different geopolymers are shown in Figure 14.

Figure 13 depicts wavelength shift [15].

Figure 14 depicts the difference between amorphous and semi-crystalline geopolymers. Mathematical analysis has been done on these peaks, and Gaussian peak deconvolution has been used to characterize short range order in T-O-T bonds, 


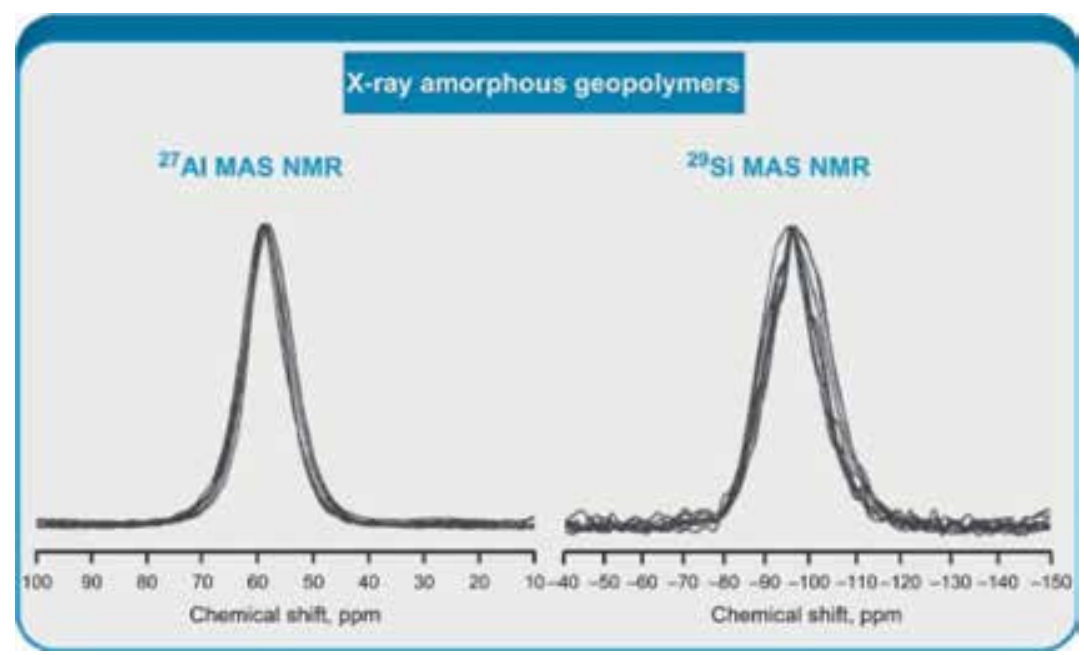

Figure 13.

The shift in wavelengths in the case of aluminum and silicon in aluminosilicate geopolymers. The first peak is for aluminum-based and the second peak is for silicon-based amorphous polymers [15].

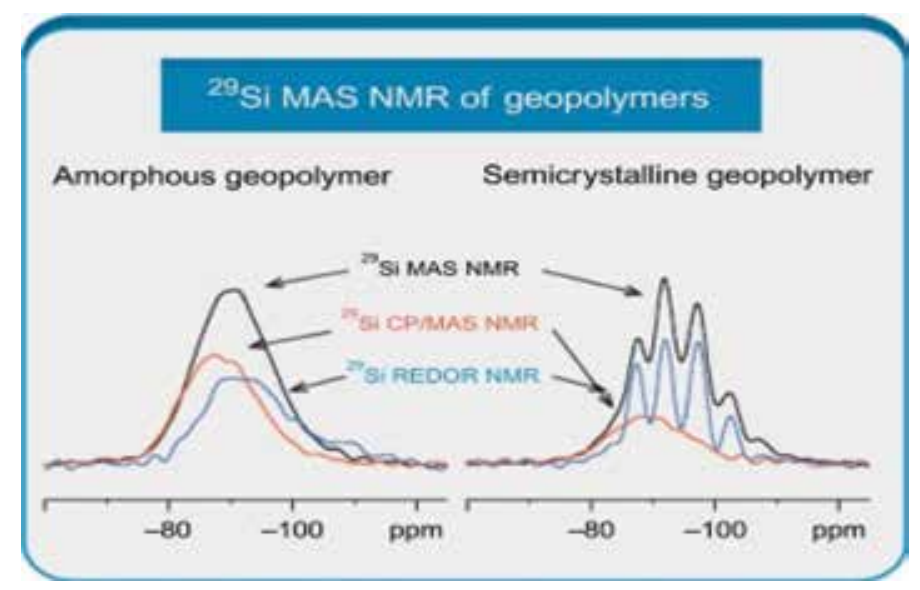

Figure 14 .

Shift in amorphous geopolymer as compared to semi-crystalline geopolymers [15].

where $\mathrm{T}$ can be either $\mathrm{Al}$ or $\mathrm{Si}$ [15]. Fly ash and consolidated materials have been studied using NMR. The signals obtained are wide in nature, indicating a heterogeneous distribution of $\mathrm{Si}$ atoms in these matrices [16].

According to the 29Si RMN MAS spectra of fly ash-based geopolymer, the main shift equal to $-94,66 \mathrm{ppm}$ indicates the presence of Q4 (2 Al) and Q4 (3Al) units in the geopolymer matrix [17]. The shift equal to $-107 \mathrm{ppm}$ corresponding to the Q4 (0Al) coordination was less represented, which points to the $\mathrm{Al}$ penetration into the [SiO4] 4- skeleton. This interpretation of the NMR spectra is also shared by other workers $[18,19]$.

\section{FTIR spectra}

A schematic diagram of FTIR spectroscopy is reported in Figure 15. There is a broadband infrared source, which gives radiation. This radiation is split in the beam splitter. The split beam gets deflected onto the sample through a parabolic mirror. 


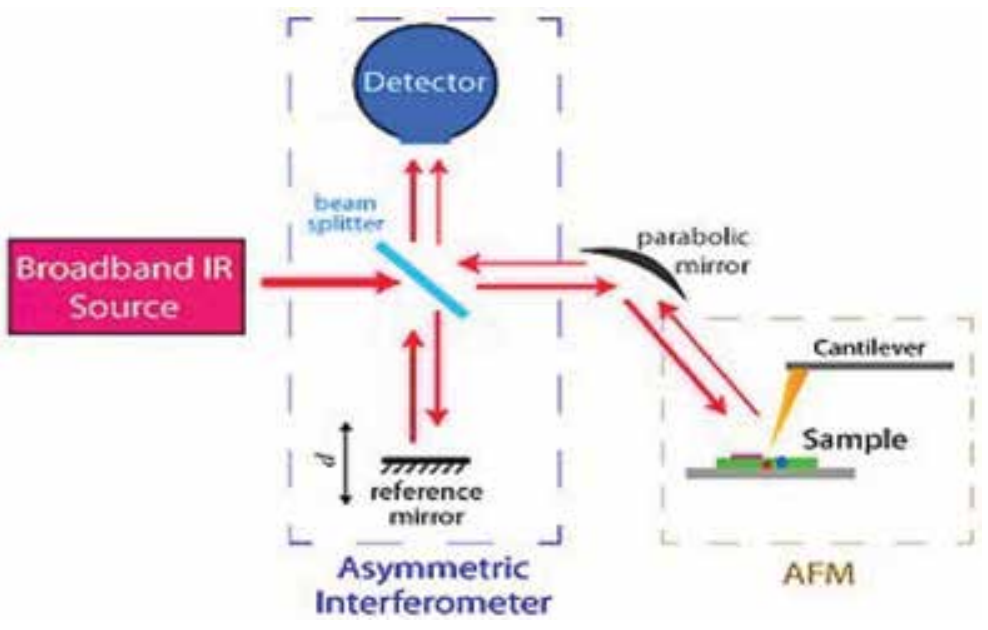

Figure 15.

Schematic of FTIR spectroscope.

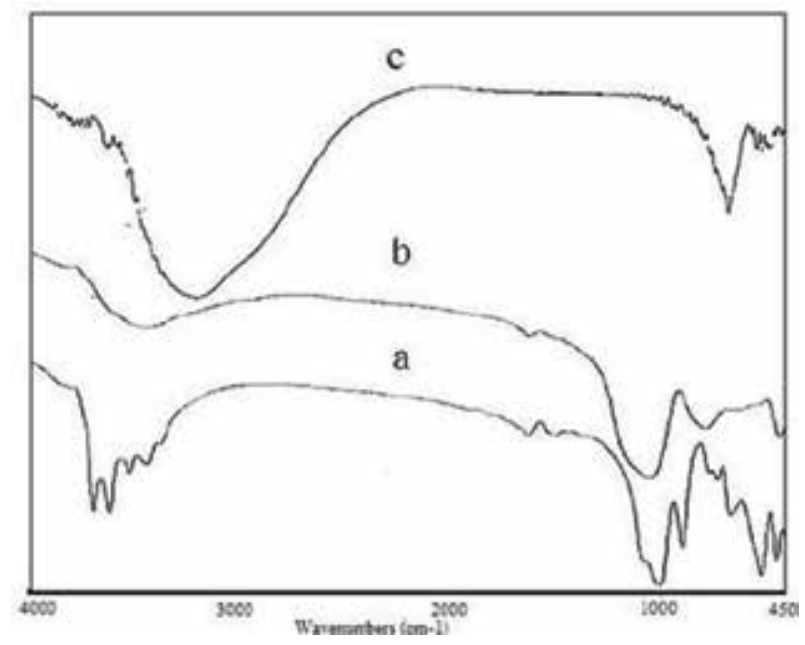

Figure 16.

Spectra for (a) soft kaolin and (b) metakaolin [15].
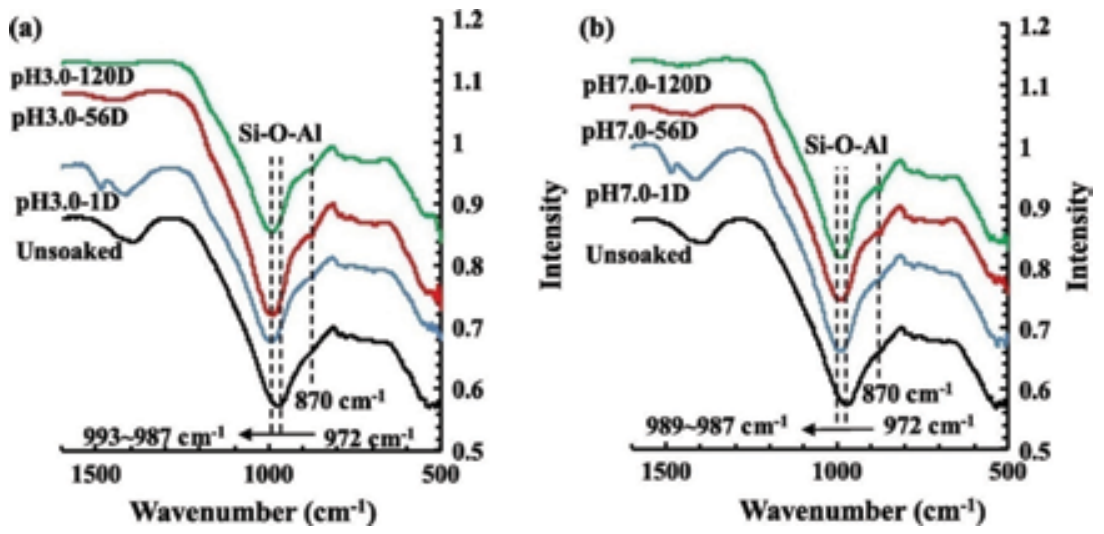

Figure 17.

FTIR spectra of unsoaked RFFG sample and RFFG samples soaked in $(a)$ sulfuric acid $(p H=3.0)$ and $(b)$ deionized water $(\mathrm{pH}=7.0)$ for 1,56 and 120 days [20]. 

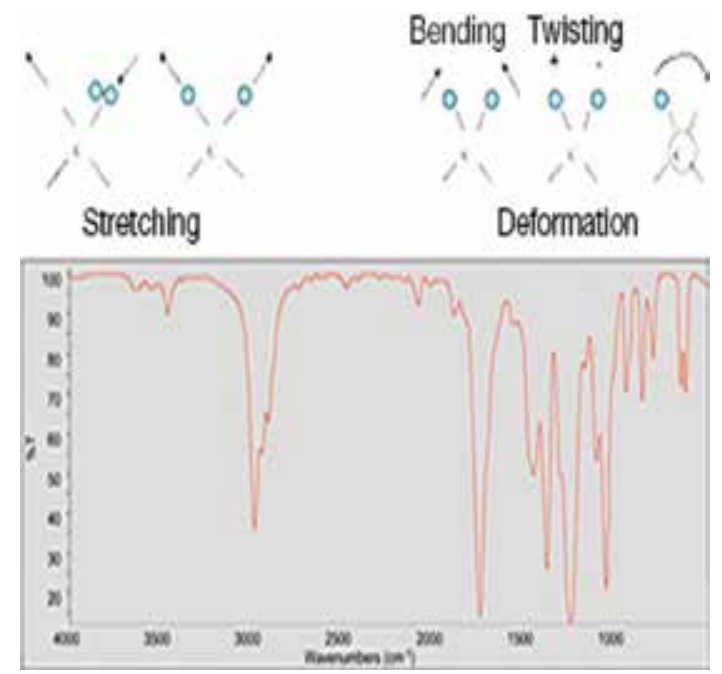

Figure 18.

Stretching, bending and twisting as seen in FTIR spectra.

The sample is kept in an atomic force microscope. The radiation from the reflection from the sample is detected using a detector.

Figure 16 gives the difference between the spectra for soft kaolin and metakaolin. There is a distinct change in the spectral lines. Comparison of spectra for red mud fly ash-based geopolymers is given in Figure 15.

The vertical dotted lines in Figure 17 both indicate the position of the asymmetric stretching vibration band of Si-O-T for geopolymer gels. The dip or movement of the Si-O-T bond has to be carefully noticed while interpreting results.

Generally, as shown in Figure 18, stretching, bending and twisting are clearly seen as dips in the FTIR.

\section{Synchrotron}

A synchrotron is a high energy device in which particles are accelerated to a very high voltage. Figure 19 is a schematic diagram of a synchrotron.

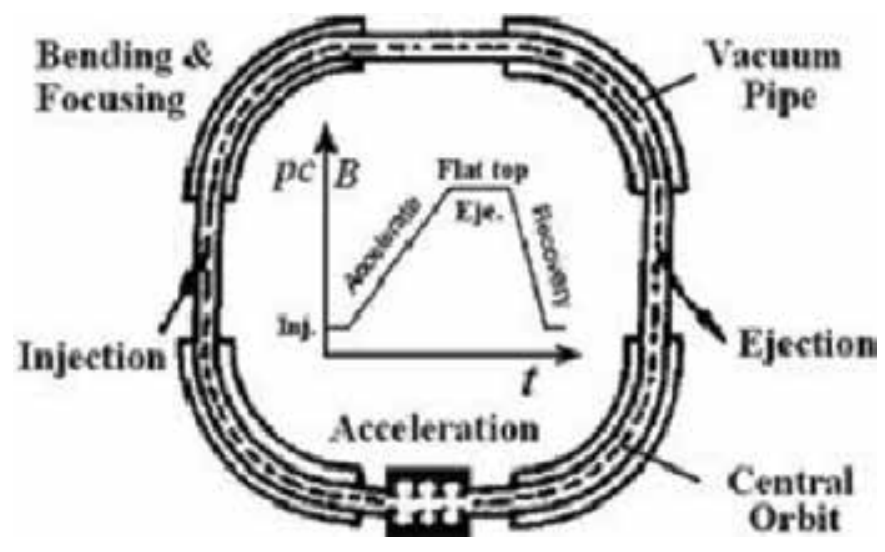

Figure 19.

A schematic of a synchrotron. 

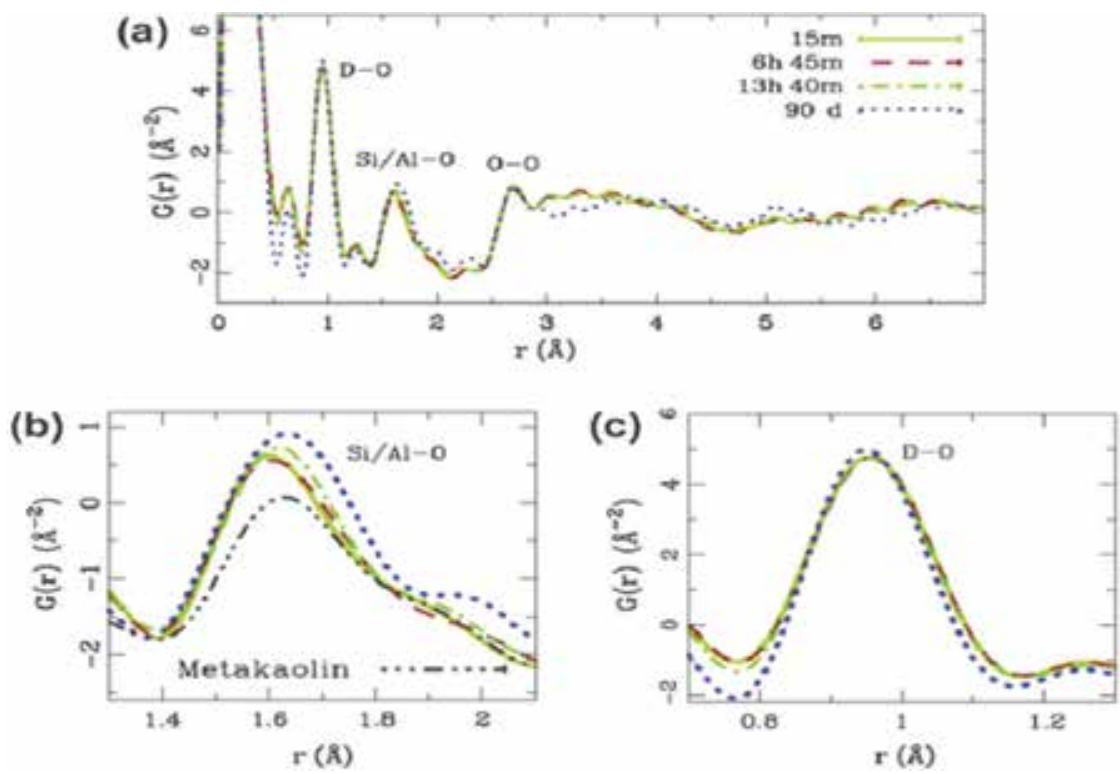

Figure 20.

Synchrotron infrared microscopy of metakaolin-based geopolymer [21].

(a)

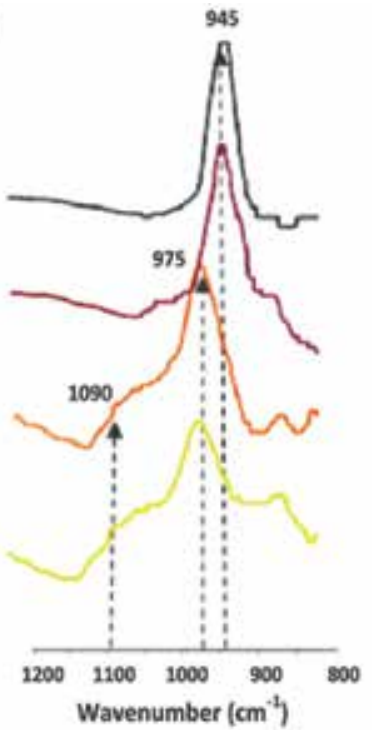

(c)

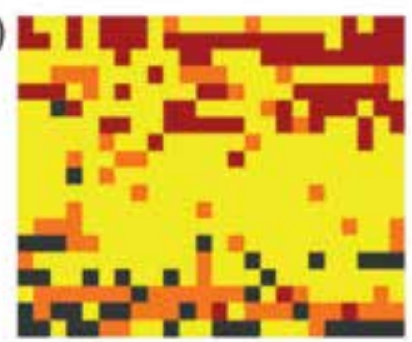

(b)

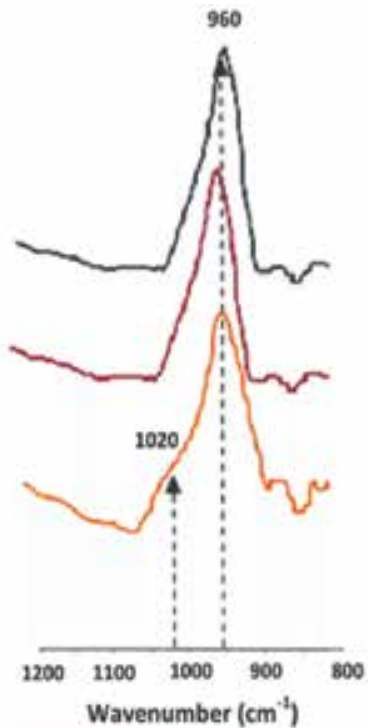

(d)

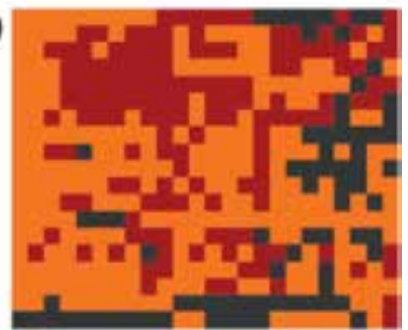

Figure 21.

Synchrotron peaks (a) without and (b) with seeding [21] already given as [21]. 
A synchrotron is a special type of cyclic particle accelerator. It is a modified form of cyclotron, in which the accelerating particle beam travels around a fixed closed-loop path. The magnetic field bends the particle beam into a closed path. This magnetic field increases with time during the accelerating process. The increased magnetic field is synchronized to the increasing kinetic energy of the particles. The concept of synchrotron facilitated and enabled the building of large scale research facilities to study particles in greater detail. Bending, beam focusing and acceleration can be separated into different components. The most powerful modern particle accelerators use versions of the basic synchrotron design. The largest synchrotrontype accelerator, also the largest particle accelerator in the world, is the 27-kilometer-circumference (17 mi) Large Hadron Collider (LHC) near Geneva, Switzerland, built in 2008 by the European Organization for Nuclear Research (CERN). It can accelerate beams of protons to an energy of 6.5 teraelectronvolts $(\mathrm{TeV})$.

The block diagram shown in Figure 19 shows the particles subjected to acceleration, injection, bending and focusing and final ejection.

Figure 20 reports a typical synchrotron infrared spectrum of a metakaolinbased geopolymer. Information on the Si/Al-O bonds can be deduced from this spectrum. Homogeneity of distribution can be determined using this data. This is an important result with consequences in geopolymer mix design for optimal gel structure and stability.

Synchrotron infrared microscopy data for geothermal silica-sodium aluminate geopolymer binders have been generated by John L. Provis et al. Figure 21 shown above gives the synchrotron peaks without (a) and with $0.5 \mathrm{wt} . \%$ nano- $\mathrm{Al}_{2} \mathrm{O}_{3}$ seeding (b).

\section{Conclusions}

A summary of selected characterization techniques that have been used to study geopolymers has been given in this chapter. Some concrete examples of research work on geopolymers have been reviewed, and characterization techniques that have been practically applied in research have been explained.

\section{Acknowledgements}

I thank Intech Publishers for motivating me to write this chapter. I thank the management, SSN College of Engineering, for the academic freedom given. I thank all members of my family for their encouragement and help offered at various times. 


\section{Author details}

Dattaguru Ananthapadmanaban

Department of Mechanical Engineering, SSN College of Engineering, Chennai, India

*Address all correspondence to: ananthapadmanaban.dattaguru@gmail.com

\section{IntechOpen}

(C) 2018 The Author(s). Licensee IntechOpen. This chapter is distributed under the terms of the Creative Commons Attribution License (http://creativecommons.org/licenses/ by/3.0), which permits unrestricted use, distribution, and reproduction in any medium, provided the original work is properly cited. (cc) BY 


\section{References}

[1] van Deventer JSJ, Provis JL, Duxson P. Technical and commercial progress in the adoption of geopolymer cement. Minerals Engineering. 2012;29:89-104

[2] Shi C, Krivenko PV, Roy DM. AlkaliActivated Cements and Concretes. Abingdon (UK): Taylor \& Francis; 2006

[3] van Deventer JSJ, Provis JL, Duxson P, Brice DG. Chemical research and climate change as drivers in the commercial adoption of alkali activated materials. Waste and Biomass Valorization. 2010;1:145-155

[4] Nikolov A, Rostovsky I, Nugteren H. Geopolymer materials based on natural zeolite. Case Studies in Construction Materials. 2017;6:198-205

[5] Zhuang XY, Chen L, Komarneni S, Zhou CH, Tong DS, Yang HM, et al. Fly ash-based geopolymer: Clean production, properties and applications. Journal of Cleaner Production.

2016;125:253-267

[6] Louati S, Baklouti S, Samet B. Geopolymers based on phosphoric acid and illito-kaolinitic clay. Advances in Materials Science and Engineering. 2016;2016:2359759

[7] Eberle AL, Mikula S, Schalek R. High-resolution, high-throughput imaging with a multibeam scanning electron microscope. Journal of Microscopy. 2015;259(2):114-120

[8] Medri V, Fabbri S, Dedecek J, Sobalik Z, Tvaruzkova Z, Vaccari A. Role of the morphology and the dehydroxylation of metakaolins on geopolymerization. Applied Clay Science. 2010;50:538-545

[9] Temujin J, Jadambaa T, Burmaa G, Erdenechimeg S, Amarsanaa J, MacKenzie KJD. Ceramics International. 2004;30:251-255

[10] Sharma AK, Sivapullaiah PV. Ground granulated blast furnace slag amended fly ash as an expansive soil stabilizer. Soils and Foundations. 2016;56(2):205-212

[11] Muhammad Faheem MT, Mustafa Al Bakri AM, Kamarudin H, Binhussain M, Ruzaidi CM, Izzat AM. Application of clay-based geopolymer in brick production: A review. Advanced Materials Research. 2013;626:878-882

[12] Cui X-M, Zheng G-J, Han Y-C, Feng S, Ji Z. A study on electrical conductivity of chemosynthetic $\mathrm{Al}_{2} \mathrm{O}_{3}$ $2 \mathrm{SiO}_{2}$ geopolymer materials. Journal of Power Sources. 2008;184:652-656

[13] Lee S, Jou H-T, van Riessen A, Rickard WDA, Chon C-M, Kang $\mathrm{N}-\mathrm{H}$. Three-dimensional quantification of pore structure in coal ash-based geopolymer using conventional electron tomography. Construction and Building Materials. 2014;52:221-226

[14] Das S, Yang P, Singh SS, Mertens JCE, Xiao X, Chawla N, et al. Effective properties of a fly ash geopolymer: Synergistic application of X-ray synchrotron tomography, nanoindentation, and homogenization models. Cement and Concrete Research. 2015;78(Part B):252-262

[15] Duxson P, Provis JL, Lukey GC, Separovic F, van Deventer JSJ. ${ }^{29} \mathrm{Si}$ NMR study of structural ordering in aluminosilicate geopolymer gels. Langmuir. 2005;21(7):3028-3036

[16] Alehyen S, EL Achouri M, Taibi $\mathrm{M}$. Characterization, microstructure and properties of fly ash-based geopolymer. Journal of Materials and Environmental Science. 2017;8(5):1783-1796

[17] Bansal NP, Singh JP, Kriven WM, Schneider H. Ceramic Transactions. 2003;153:175 
[18] Singh PS, Bastow T, Trigg M. Journal of Materials Science. 2005;40:3951

[19] Hoa JP, Mccormick PG, Byrne LT. Journal of Materials Science. 2002;37:2311

[20] Zhang M, Zhao M, Zhang G, Mann D, Lumsden K, Tao M. Durability of red mud-fly ash based geopolymer and leaching behavior of heavy metals in sulfuric acid solutions and deionized water. Construction and Building Materials. 2016;124:373-382

[21] Provis JL, Hajimohammadi A, White CE, Bernal SA, Myers RJ, Winarski RP, et al. Nanostructural characterization of geopolymers by advanced beamline techniques. Cement and Concrete Composites. 2013;36:56-64 


\title{
Geopolymer Bricks Using Iron Ore Tailings, Slag Sand, Ground Granular Blast Furnace Slag and Fly Ash
}

\author{
Raghunandan Kumar, Pranab Das, M. Beulah \\ and H.R. Arjun
}

\begin{abstract}
World is pound with million tonnes of industrial wastes such as ground granulated blast furnace slag (GGBS), flyash and mine tailings as a various industrial waste. The best way to make use of these wastes is to incorporate these materials as structural elements, which in turn minimizes the carbon foot print. In this contest, this study focuses on using iron ore tailings and slag sand as a replacement for clay or natural sand for the production of stabilized geopolymer blocks. Also, in this study geopolymer is used as a stabilizer instead of cement. Development of geopolymer binder based bricks using flyash and ground granulated blast furnace slag has been carried out in this research. The study includes mechanical properties of the geopolymer bricks. Sodium silicate $\left(\mathrm{Na}_{2} \mathrm{SiO}_{3}\right)$ and sodium hydroxide $(\mathrm{NaOH})$ solution have been used as alkaline activators. The ratio of alkaline liquid to aluminosilicate solid ratio and percentage of binder had major influence on the strength of brick. The bricks were casted and cured at ambient temperature. The compressive strength was carried out at 7, 14 and 28 days.
\end{abstract}

Keywords: iron ore tailings, slag sand, fly ash, GGBS, geopolymer, sodium silicate, sodium hydroxide

\section{Introduction}

World over there is a huge demand on the natural resources to cater to the housing, commercial spaces and the infrastructure for the ever growing population. Once, it has been decided to build a new building or an infrastructure, a very significant commitment to consume natural resources is made. Designers and contractors may be able to help limit that consumption, but they cannot change the overall commitment $[1,2]$.

Geopolymer, which is a synthesized inorganic material, is now used as an alternate binder in a wide range of construction applications and products. Davidovits [3] proposed that an alkaline liquid could be used to react with the silicon ( $\mathrm{Si}$ ) and the aluminum $(\mathrm{Al})$ in a source material of geological origin or in a by-product material such as fly ash to produce binders. As the chemical reaction that takes place in 
this case is a polymerization process, he coined the term 'Geopolymer' to represent these binders.

There are two main constituents of geopolymers, namely the source materials and the alkaline liquids. The source materials for geopolymers should be rich in silicon ( $\mathrm{Si}$ ) and aluminum (Al). These could be natural minerals such as kaolinite and natural clays. By-product materials such as fly ash, ground granulated blast furnace slag (GGBS), silica fume, slag, rice-husk ash, and red mud can also be used as source materials. The alkaline liquids are from soluble alkali metals that are usually sodium or potassium based. The alkaline liquid used in geopolymerization is a combination of sodium hydroxide $(\mathrm{NaOH})$ or potassium hydroxide $(\mathrm{KOH})$ and sodium silicate or potassium silicate.

Geopolymers are used to manufacture construction products like, geopolymer bricks [4], tiles and concrete. In geopolymer bricks and in geopolymer concretes, geopolymers do not form C-S-H gel (calcium-silicate-hydrates) unlike the Ordinary Portland Cements (OPC), for matrix formation and strength in a geopolymer concrete, but it utilizes the polycondensation of silica and alumina and high alkali content.

Earth is the oldest building material used by man for millennia. All over the world there are thousands of earth buildings which are over 500 years old. All these structures are still in sound condition and are well occupied. Even if earth is an ancient building material [1], the earth building tradition has been kept blooming in many countries and the technology is constantly being adapted to the requirements of modern civilization. In terms of sustainability, un-stabilized earth outdoes any other building material, including timber, owing to its low carbon footprint, its durability and its unlimited recyclability. The advantages of earth buildings are as follows [1]:

a. $100 \%$ natural local resource

b. Very low carbon footprint

c. Good for indoor climate

d.Low life cycle cost

e. Detoxifying effect

f. Moisture control

g. Fire resistance

h.Noise control

i. Affordable

j. Zero waste

The earth as a construction material has the following disadvantages:

a. Low resistance to water penetration resulting in structural failure due to crumbling.

b. High shrinkage and swelling resulting in structural cracks when exposed to changing weather conditions.

c. Low resistance to abrasion requiring frequent repairs and maintenance. 
Sand is one such material which is highly used in the construction industry. Sand has by now become the most widely consumed natural resource on the planet after fresh water. Depletion of sand in the stream bed and along coastal areas leads to the deepening of rivers and estuaries, and enlargement of river mouths and coastal inlets. Therefore, the goal of sustainable construction is to use locally available resources without affecting the environment and its people.

Iron ore tailings (IOT) [6], are waste material obtained from the process of smelting of iron. The rapid growth in the surface mines led the production of Iron Ore tailings which remains as overburden. The safe disposal or utilization of such vast mineral wealth in the form of ultra- fine slime remains a major unsolved and challenging task. Use of iron ore tailing will help in finding a new construction material and also help in finding a proper solution for disposal of tailings. In order to reduce the adverse impact of indiscriminate mining of natural sand, iron ore tailings which is the waste products of mining industries is used as an alternative to the river sand in the manufacturing of concrete and bricks.

Geopolymer is a type of inorganic polymer that can be formed at room temperature by using industrial waste or by-products as source materials to form a solid binder that looks like and performs a similar function to Ordinary Portland Cement (OPC). Geopolymer binder can be used in applications to fully or partially replace OPC with environmental and technical benefits, including an $80-90 \%$ reduction in $\mathrm{CO}_{2}$ emissions and improved resistance to fire and aggressive chemicals.

Mud bricks are made by mixing earth with water [7], placing the mixture into molds and drying the bricks in the open air. Straw or other fibers that are strong in tension are often added to the bricks to help reduce cracking. Mud bricks are joined with a mud mortar and can be used to build walls, vaults and domes.

To summarize, geopolymer, an inorganic polymer, made using sodium hydroxide and sodium silicate with the prescribed molarity, can be used as binder with industrial waste/reject materials rich in silicon ( $\mathrm{Si}$ ) and aluminum ( $\mathrm{Al}$ ), such as fly ash, ground granulated blast furnace slag (GGBS), silica fume, slag and rice-husk ash, to make geopolymers bricks and tiles which conform to the standards of commercially available burnt bricks, and are environmental friendly and can also be called as green bricks since they do not use fuel for firing and also do not contribute to the greenhouse gases.

\section{Materials and methods}

\subsection{Materials}

A good brick earth, which is available as a natural resource, usually consist of $50-60 \%$ of silica, $20-30 \%$ of alumina, $5 \%$ of lime and $5-6 \%$ of oxide of iron [7].

However, for non-fired green bricks which can be made by using industrial wastes, materials to be used includes iron ore tailings (IOT), slag sand, fly ash and ground granulated blast furnace slag (GGBS), which can replace good brick earth of similar constituents [4]. Geopolymer is synthesized by using fly ash, GGBS, sodium hydroxide $(\mathrm{NaOH})$, sodium silicate $\left(\mathrm{Na}_{2} \mathrm{SiO}_{3}\right)$ and water. These bricks can be manufactured without firing, but using geopolymer as binder.

\subsubsection{Iron ore tailings}

Iron ore tailings (IOT) $[6,8]$ are the waste materials obtained during the process of separating the valuable fraction of iron from the iron ore. The different steps involved in this process are crushing, screening, grinding, washing, jigging, 
cyclizing etc. The Iron ore tailing usually contains about $20-30 \%$ of iron. Further extraction of iron is too expensive. The composition of the ore and the process of mineral extraction adopted have a direct influence over the composition of the tailings. The iron ore tailings are obtained from Bellary, Karnataka, India, where steel companies are located (Please refer to Table 1 for the chemical composition and Table 2 for the physical properties of the iron ore tailings used).

Similar iron ore tailings are available in other parts of India and world too which have different percentage of iron in the tailings.

\subsubsection{Slag sand}

Slag sand, is an eco-friendly building material obtained as a by-product of the industrial process which can replace conventional river sand in the construction of buildings. It caters to the increasing demand and quality requirements of the fine aggregates. Slag sand as an alternative to river sand will protect river banks and save the environment (Please refer to Table 3 for chemical composition and Table 4 for the physical properties of slag sand).

Therefore, replacing river sand with slag sand leads to a better environment and becomes an economically viable solution for the shortage of fine aggregates.

\subsubsection{Fly ash}

Fly ash is extracted from flue gases by means of electrostatic precipitator in dry form. It is a fine material and possesses good pozzolanic property. Fly ash is a by-product of thermal power stations of India and it is of good quality as it contains low sulfur and very low un-burnt carbon. The pozzolanic property of fly ash makes

\begin{tabular}{lc}
\hline Constituents & Percentage (\%) \\
\hline $\mathrm{SiO}_{2}$ & 16.05 \\
\hline $\mathrm{Fe}$ & 44.82 \\
\hline $\mathrm{Al}_{2} \mathrm{O}_{3}$ & 6.34 \\
\hline $\mathrm{CaO}$ & 1.52 \\
\hline $\mathrm{MgO}$ & 0.28 \\
\hline $\mathrm{MnO}$ & 1.20 \\
\hline $\mathrm{TiO}_{2}$ & 0.38 \\
\hline L.O.I & 10.09 \\
\hline
\end{tabular}

Table 1.

Chemical composition of iron ore tailings.

\begin{tabular}{lc}
\hline Properties & Results \\
\hline Specific gravity & 3.4 \\
\hline Fineness modulus & 2.81 \\
\hline Optimum moisture content & $13 \%$ \\
\hline Bulk density & 2.54 \\
\hline Maximum dry density & 2.25 \\
\hline
\end{tabular}

Table 2.

Physical properties of iron ore tailings. 
Geopolymer Bricks Using Iron Ore Tailings, Slag Sand, Ground Granular Blast Furnace Slag... DOI: http://dx.doi.org/10.5772/intechopen.81748

\begin{tabular}{lc}
\hline Constituents & Percentage (\%) \\
\hline $\mathrm{SiO}_{2}$ & 30.73 \\
\hline $\mathrm{Fe}_{2} \mathrm{O}_{3}$ & 0.56 \\
\hline $\mathrm{Al}_{2} \mathrm{O}_{3}$ & 16.32 \\
\hline $\mathrm{CaO}$ & 38.47 \\
\hline $\mathrm{MgO}$ & 6.41 \\
\hline
\end{tabular}

Table 3.

Chemical composition of slag sand.

\begin{tabular}{lc}
\hline Properties & Results \\
\hline Specific gravity & 2.65 \\
\hline Water absorption & $1 \%$ \\
\hline Fineness modulus & 3.363 \\
\hline
\end{tabular}

Table 4 .

Physical properties of slag sand.

it a reserve for making cement and other ash based products. The specific gravity of fly ash used is 2.17 in the present work. (Please refer to Table 5 for chemical composition of Fly ash used).

\subsubsection{Ground granulated blast furnace slag (GGBS)}

Granulated blast furnace slag (GGBS), is obtained by rapidly chilling (quenching) the molten ash from the furnace with the help of water. During this process, the slag gets fragmented and transformed into amorphous granules (glass). This granulated slag is then ground to the desired fineness for producing GGBS. It is one of the greenest construction materials. GGBS replaces something that is produced by a highly energy-intensive process. The specific gravity of GGBS used in this work is 2.61. (Please refer to Table 6 for the chemical composition of GGBS).

\subsubsection{Sodium hydroxide}

Sodium hydroxide is obtained from sodium carbonate which is formerly known as caustic soda. At room temperature, sodium hydroxide exists as a white crystalline odorless solid which absorbs moisture from the air. When dissolved in water or neutralized with acid it liberates substantial heat, which may be sufficient to ignite combustible materials. It is very corrosive. It is generally used as a solid or as $50 \%$ solution. Sodium hydroxide is one of the widely used chemical substances in laboratory and in industries. It is also used in the manufacture of other products like paper pulp and various chemical products like plastics, synthetic textiles, geopolymers etc. (Please refer to Table 7 for the specification of sodium hydroxide, $\mathrm{NaOH}$ ).

\subsubsection{Sodium silicate}

Sodium silicate is usually known as water glass or liquid glass. It is well-known due to its wide commercial and industrial application. It is composed of oxygensilicon polymer backbone lodging water in molecular matrix pores. Sodium silicate products are manufactured as solids or thick liquids, depending on proposed 


\begin{tabular}{lc}
\hline Constituents & Percentage (\%) \\
\hline $\mathrm{SiO}_{2}$ & 66.87 \\
\hline $\mathrm{Fe}_{2} \mathrm{O}_{3}$ & 4.41 \\
\hline $\mathrm{Al}_{2} \mathrm{O}_{3}$ & 23.34 \\
\hline $\mathrm{CaO}$ & 1.17 \\
\hline $\mathrm{MgO}$ & 0.31 \\
\hline
\end{tabular}

Table 5.

Chemical composition of fly ash.

\begin{tabular}{lc}
\hline Constituents & Percentage (\%) \\
\hline $\mathrm{SiO}_{2}$ & 31.79 \\
\hline $\mathrm{Fe}_{2} \mathrm{O}_{3}$ & 0.49 \\
\hline $\mathrm{Al}_{2} \mathrm{O}_{3}$ & 17.07 \\
\hline $\mathrm{CaO}$ & 38.78 \\
\hline $\mathrm{MgO}$ & 6.23 \\
\hline
\end{tabular}

Table 6.

Chemical composition of GGBS.

\begin{tabular}{lc}
\hline Specifications of $\mathrm{NaOH}$ & \\
\hline $\mathrm{M}$ & $40.0 \mathrm{~g} / \mathrm{mol}$ \\
\hline Assay $(\mathrm{NaOH})$ & $\geq 97 \%$ \\
\hline Carbonate $\left(\mathrm{Na}_{2} \mathrm{CO}_{3}\right)$ & $\leq 2 \%$ \\
\hline Heavy metals $(\mathrm{as} \mathrm{Pb})$ & $\leq 0.002 \%$ \\
\hline
\end{tabular}

Table 7 .

Specifications of sodium hydroxide $(\mathrm{NaOH})$.

function. Sodium silicate is a versatile, inorganic chemical manufactured by combining different ratios of sand and soda ash at high temperature.

This process gives a variety of products with unique chemistry that are used in many industrial chemistry that are used in many industrial and consumer applications.

\subsubsection{Water}

Potable water is used for the manufacturing of geopolymer bricks.

\subsection{Mix proportion}

Six different mix proportions shall be considered viz.; GB-1, GB-2, GB-3, GB-4, GB-5 and GB-6. The slag sand shall be mixed with portions of IOT as a partial replacement with the following percentages; 20,30 and $40 \%$ of the total dry mix. Fly ash (15\%) and ground granulated blast furnace slag (15\%), which are kept constant, all together contribute $30 \%$ of the total dry mix. The molarity of the sodium hydroxide solution adopted shall be 8 and $10 \mathrm{M}$. The alkaline solution shall contribute $10 \%$ of the total mix. The optimum moisture content adopted shall be $8 \%$. The $\mathrm{Na}_{2} \mathrm{SiO}_{3}$ to $\mathrm{NaOH}$ ratio adopted shall be 2.5. Alkaline solution to binder 
Geopolymer Bricks Using Iron Ore Tailings, Slag Sand, Ground Granular Blast Furnace Slag... DOI: http://dx.doi.org/10.5772/intechopen.81748

\begin{tabular}{lccccc}
\hline & \multicolumn{3}{c}{ Quantity of ingredients/stabilizer } \\
\cline { 2 - 5 } Brick ID & IOT\% & Sand\% & Fly ash\% & GGBS\% & Allkaline solution\% \\
\hline GB-1 & 20 & 40 & 15 & 15 & \multirow{2}{*}{10 (8 M NaOH Soln.) } \\
\cline { 1 - 5 } GB-2 & 30 & 30 & 15 & 15 & \\
\hline GB-3 & 40 & 20 & 15 & 15 & \multirow{2}{*}{10 (10 M NaOH Soln.) } \\
\hline GB-4 & 20 & 40 & 15 & 15 & \\
\hline GB-5 & 30 & 30 & 15 & 15 & \\
\hline GB-6 & 40 & 20 & 15 & 15 & \\
\hline
\end{tabular}

Table 8.

Mix proportions of geopolymer bricks.

material ratio adopted shall be 0.35 . (Please refer to Table 8 for the mix proportion including the molarity).

\subsection{Process of block making}

'MARDINI' is the advanced version of the mud block press machine developed at the Department of Civil Engineering/ASTRA, Indian Institute of Science, Bengaluru, India. The size of stabilized mud block manufactured in the machine shall be $230 \times 110 \times 100 \mathrm{~mm}$. The process of block making involves a series of sequential steps as below:

a. Soil preparation

b.Alkaline solution preparation

c. Mixing of soil and stabilizer

d.Addition of extra water

e. Weighing of soil in scoop

f. Block pressing

g. Block ejection and stacking

h.Curing of the block (7, 14 and 28 days)

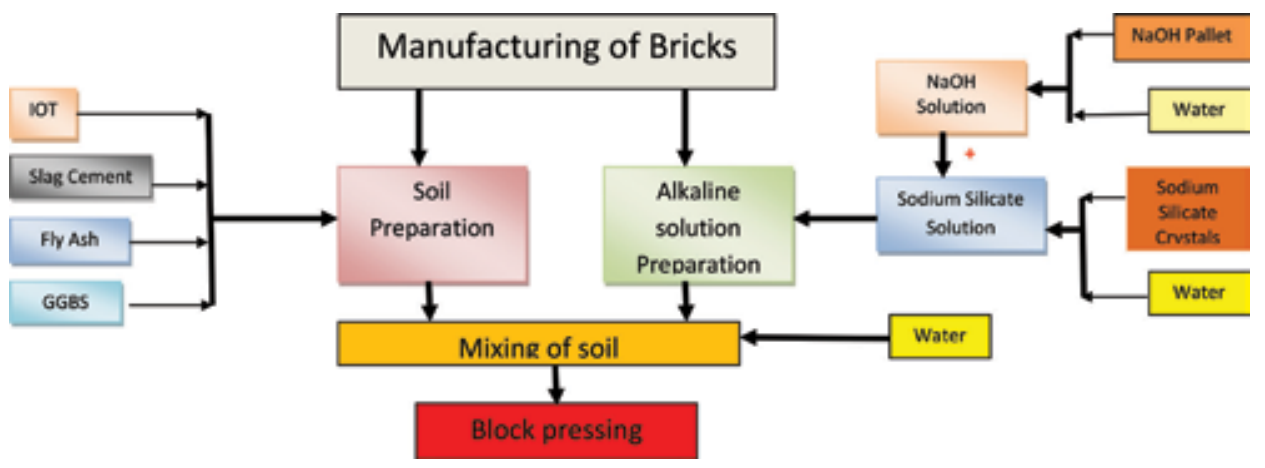




\subsection{Tests on bricks}

\subsubsection{Compressive strength}

The compressive test of a brick is considered as an index of its durability and ability in a masonry wall to resist crushing loads [5, 7]. Even though most of the bricks are specified in terms of strength, it is important not to sacrifice on the properties of durability and bond for higher compressive strengths. Most of the bricks will a have strength generally ranging from $3.5 \mathrm{MPa}$ to over $10 \mathrm{MPa}$. The dry compression test shall be carried out according to IS: 3495-Part [1] -1992 specification (or alternate as per the local relevant codes Figure 1). Five bricks per mix shall be taken for testing and their average value turns will be the "Dry Compressive Strength" of the brick. (Please refer to Table 9 for the results of the compressive strength of the samples tested).

$$
\text { Compressive Strength }=\text { Failure Load } / \text { Area of Bed Face. }
$$

\subsubsection{Brick density}

Brick density is one of the primary tests on bricks. This test shall be done for both dry and wet bricks [5]. The formula used for finding brick density is as below:

$$
\text { brick density }=\frac{\text { dry weight }}{\text { volume of brick }}=\frac{\mathrm{kg}}{\mathrm{m}^{3}}
$$

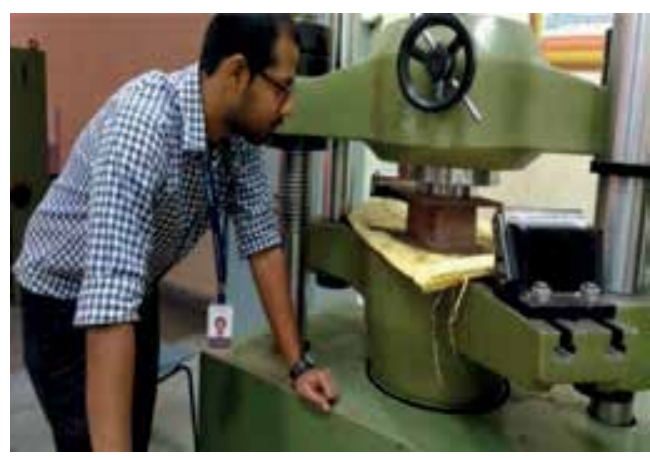

Figure 1.

Compression test of geopolymer bricks.

\begin{tabular}{ccccc}
\hline \multirow{2}{*}{$\begin{array}{l}\text { BDick } \\
\text { ID }\end{array}$} & \multicolumn{2}{c}{ Dry compressive strength $\left(\mathbf{N} / \mathbf{m m}^{\mathbf{2}}\right)$} & & Wet compressive strength $\left(\mathbf{N} / \mathbf{m m}^{\mathbf{2}}\right)$ \\
\cline { 2 - 4 } & 7th day & 14th day & 28th day & \\
\hline GB-1 & 15.41 & 17.79 & 21.86 & 13.79 \\
\hline GB-2 & 13.04 & 14.82 & 18.46 & 11.70 \\
\hline GB-3 & 11.86 & 13.44 & 16.68 & 10.67 \\
\hline GB-4 & 17.59 & 20.16 & 25.3 & 20.95 \\
\hline GB-5 & 15.22 & 17.39 & 21.58 & 17.39 \\
\hline GB-6 & 13.24 & 15.02 & 18.38 & 15.18 \\
\hline
\end{tabular}

Table 9.

Compressive strength of geopolymer bricks. 
Geopolymer Bricks Using Iron Ore Tailings, Slag Sand, Ground Granular Blast Furnace Slag... DOI: http://dx.doi.org/10.5772/intechopen.81748

\begin{tabular}{lcc}
\hline Brick ID & Dry density $\left(\mathbf{k g} / \mathbf{m}^{\mathbf{3}}\right)$ & Wet density $\left(\mathbf{k g} / \mathbf{m}^{3}\right)$ \\
\hline GB-1 & 1978 & 2110 \\
\hline GB-2 & 2001 & 2086 \\
\hline GB-3 & 2055 & 2152 \\
\hline GB-4 & 2006 & 2127 \\
\hline GB-5 & 2061 & 2136 \\
\hline GB-6 & 2120 & 2180 \\
\hline
\end{tabular}

Table 10.

Density of geopolymer bricks.

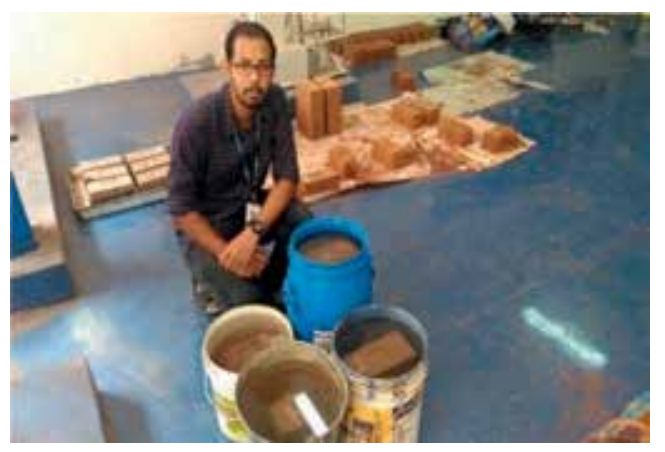

Figure 2.

Water absorption test of geopolymer bricks.

\begin{tabular}{lcc}
\hline Brick ID & Initial rate of absorption $\left(\mathbf{k g} / \mathbf{m}^{2} / \mathbf{m i n}\right)$ or $(\mathbf{g})$ & Water absorption $(\%)$ \\
\hline GB-1 & $1.06(27)$ & 6.67 \\
\hline GB-2 & $0.94(24)$ & 4.22 \\
\hline GB-3 & $1.03(26)$ & 4.71 \\
\hline GB-4 & $1.28(32)$ & 6.04 \\
\hline GB-5 & $1.06(27)$ & 3.71 \\
\hline GB-6 & $0.90(23)$ & 2.83 \\
\hline
\end{tabular}

Table 11.

Water absorption test results of geopolymer bricks.

(Please refer to Table 10 for the density obtained for the samples tested).

\subsubsection{Water absorption}

The water absorption for dry bricks should not exceed $20 \%$ of the weight of the brick [5]. The acceptable values for initial rate of absorption (IRA) range from 10 to 30 grams. Dry brick with an IRA above 30 should be wetted before using for construction (Please refer to Figure 2 and to Table 11, for the results of water absorption obtained for the samples tested).

\subsubsection{Dimensionality test}

Dimensionality test shall be carried out according to IS: 2185-Part [1] specification (Refer, Figure 3). In this test, 20 or more bricks shall be selected at random and shall be arranged in rows and the dimensions shall be measured to the nearest 


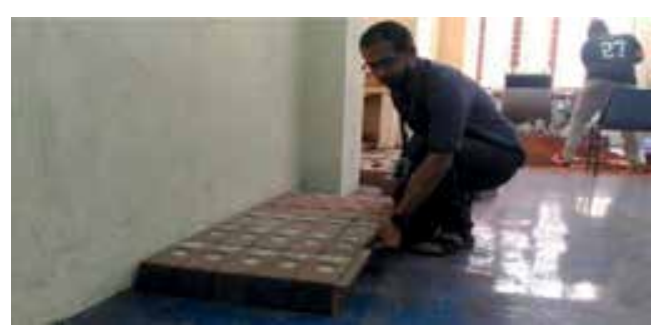

Figure 3.

Dimensionality test of geopolymer bricks.

\begin{tabular}{lcccc}
\hline Dimensions & $\begin{array}{c}\text { No. of } \\
\text { units }\end{array}$ & $\begin{array}{c}\text { Dimension } \\
(\mathbf{m m})\end{array}$ & $\begin{array}{c}\text { Average dimension } \\
(\mathbf{m m})\end{array}$ & $\begin{array}{c}\text { Code recommendations } \\
(\mathbf{m m})\end{array}$ \\
\hline $\mathrm{L}$ & 30 & 230 & 230 & $230 \pm 5$ \\
\cline { 1 - 4 } $\mathrm{B}$ & & 110 & 110 & $110 \pm 3$ \\
\cline { 3 - 5 } $\mathrm{H}$ & & 100 & 100 & $100 \pm 3$ \\
\hline
\end{tabular}

Table 12.

Dimensionality test results of geopolymer bricks.

millimeter. The overall lengths of the arranged bricks shall be measured with the help of a steel tape. Similarly the width and depth of the arranged bricks are measured along straight line. (Please refer to Table 12 for the results obtained for the dimensionality test of the geopolymer bricks).

\subsubsection{Falling test}

In this test, the dried bricks after curing shall be allowed to fall from a height of $1 \mathrm{~m}$ from the ground. The ground shall be firm and leveled. Then the observations shall be noted down specifying whether cracks appeared, failure happened etc. All the samples tested show moderate edge failure which is acceptable. (Please refer to Figure 4 for the results of the falling test).

\subsubsection{Efflorescence test}

The efflorescence is caused due to the presence of alkalis in bricks. When the bricks get exposed to moisture, water is absorbed by them. Due to evaporation this water absorbed dries out from the exposed faces. As a result of this, the soluble

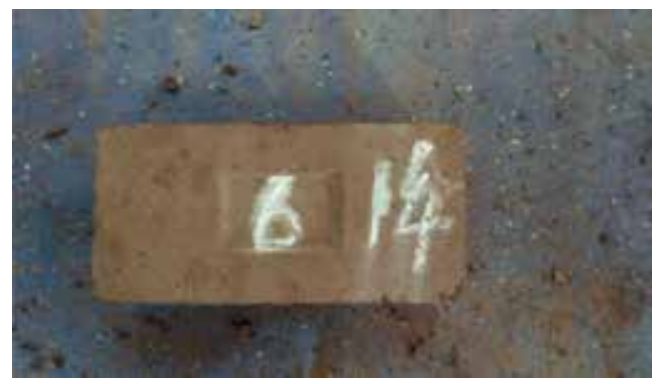

Figure 4.

Falling test of geopolymer bricks. 


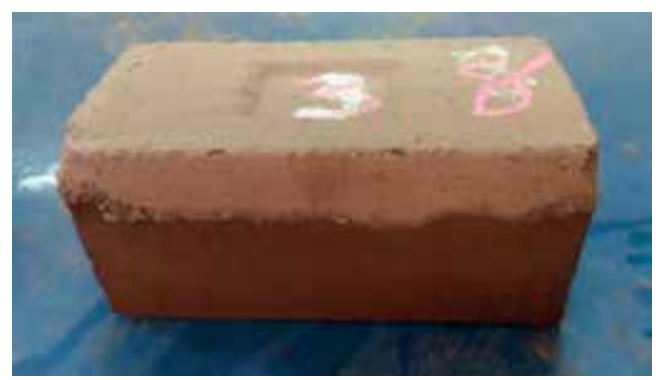

Figure 5.

Efflorescence test of geopolymer bricks.

salts contained within them crystallize out on to the surface. This process continues for several years depending on the amount of salts present in the bricks and their solubility. All the samples tested showed very slight effloresce which is acceptable. (Please refer to Figure 5).

\subsubsection{Soundness test}

The soundness test is conducted by striking two bricks against each other or by a light hammer [5]. If the bricks generate a clear metallic ringing sound and do not break, then those are good quality bricks. All the samples tested for soundness showed that they are heavy and good causing a metallic ringing sound when struck against each other.

\subsubsection{Hardness test}

Hardness of the bricks can be found out with the aid of the scratch of the finger nail [5]. If no impression is left over the surface, the brick is treated to be sufficiently hard. All the samples tested showed very slight indentation, which is acceptable. (Please refer to Figure 6 for the result of the hardness test).

\subsubsection{Structure test}

In structure test, a brick is broken and its structure is inspected. It is observed that the bricks are compact, homogeneous and free from any imperfections such as lumps, holes, etc. (Please refer to Figure 7 for the result of the structure test).

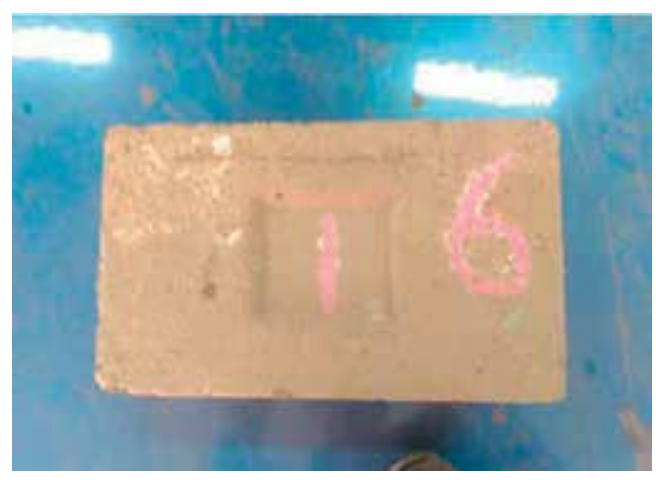

Figure 6.

Hardness test of geopolymer bricks. 


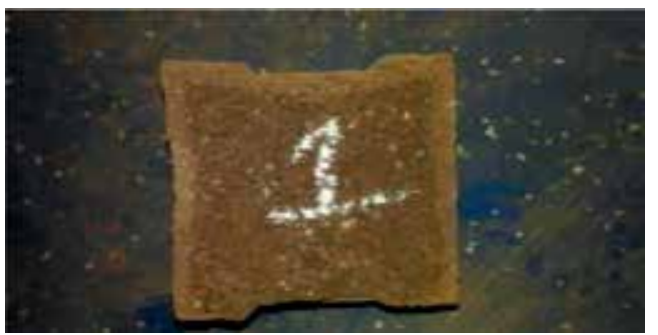

Figure 7.

Structure.

\subsubsection{Scanning electron microscopy}

From the images of the scanning electron microscope (SCM) as seen in Figures 8 and 9 , it is observed that the bricks are homogeneous, compact and free from defects such as holes and lumps.

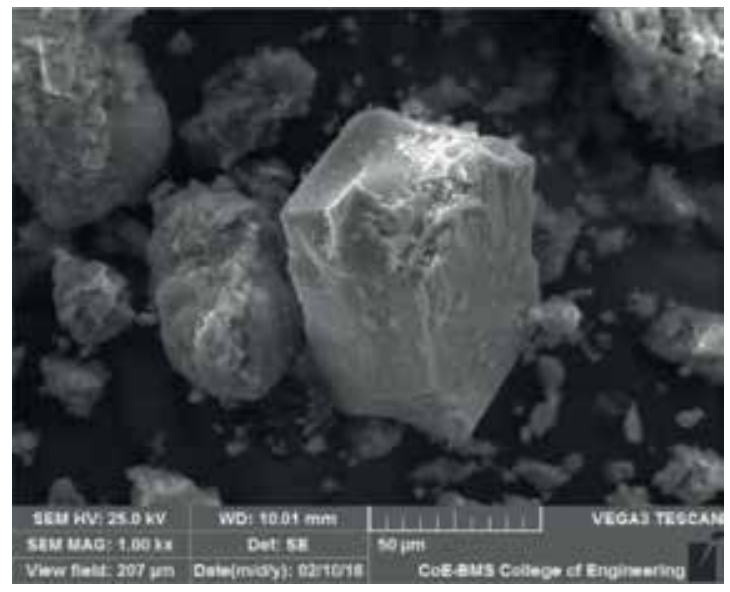

Figure 8.

SEM image of GB-1.

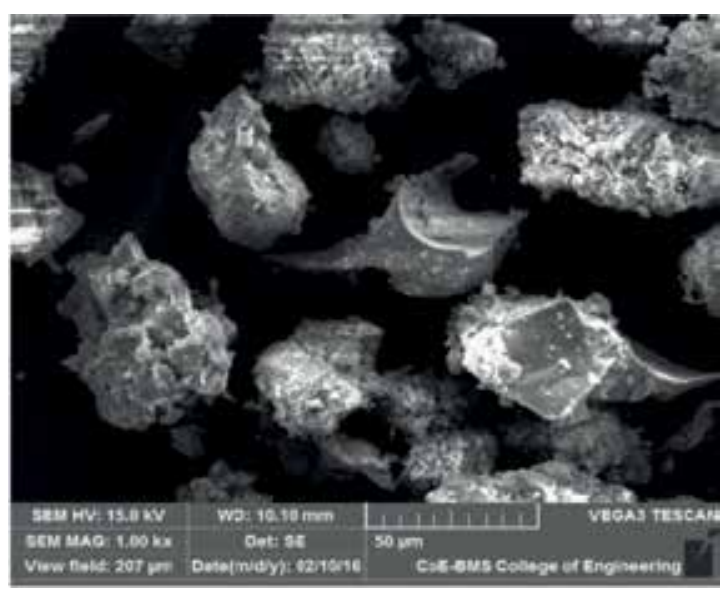

Figure 9.

SEM image of $G B-4$. 
Geopolymer Bricks Using Iron Ore Tailings, Slag Sand, Ground Granular Blast Furnace Slag... DOI: http://dx.doi.org/10.5772/intechopen.81748

\section{Discussions}

In this work a series of tests were carried out to study the strength and durability properties of the geopolymer bricks. Also field tests were conducted to check the quality of bricks.

The following are the key points of the discussions:

The compressive strength of the geopolymer bricks is more for the mix which has higher concentration of the alkaline solution, i.e. $10 \mathrm{M}$ as compared to $8 \mathrm{M}$ and which has the highest percentage of Slag sand.

The compressive strength is minimum for the geopolymer bricks, which were having the least percentage of slag sand and with the highest percentage of iron ore tailings. The highest water absorption percentage obtained also showed the same pattern.

The dimensionality test results were within the Indian Standard code recommendations. In falling test, failure of the geopolymer bricks was not severe and maximum pattern failures were restricted to mild edge failure, moderate edge failure and no failure.

The efflorescence test conducted proved that the bricks were prone to efflorescence slightly. Thus, it satisfied the statement "Efflorescence shall not be more than Slight for Higher class bricks" as all the bricks belong to class AA category, the highest category.

The geopolymer bricks produced clear ringing sound when struck with another brick and proved to be sound and good. The bricks when subjected to hardness test by scratching with a nail did not leave any impressions on the surface and proved to be sufficiently hard.

The structure test and the scanning electronic microscope (SCM) conducted on geopolymer bricks helped to understand the microstructure level of the bricks. The bricks are homogeneous, compact and free from defects such as holes, lumps etc.

\section{Conclusion}

The use of geopolymers proves to be an excellent replacement for cement and can be used as a stabilizer for bricks. Fly ash and ground granulated blast furnace slab acts as excellent solid binders for the synthesis of geopolymers.

The compressive strength of geopolymer bricks with iron ore tailings, slag sand, fly ash, and GGBS increases with the increase in the molarity of the alkaline solution and increases with the increase in the percentage of slag sand. The minimum required compressive strength for geopolymer brick shall be achieved by all the different mixes indicated.

Iron ore tailings (IOT) and slag sand can be used for manufacturing stabilized geopolymer blocks of good quality and strength.

The field tests conducted on geopolymer bricks shows excellent results for being adopting them for sustainable construction. Geopolymer bricks prove to be an excellent replacement for fired bricks based on the studies conducted. 


\section{Author details}

Raghunandan Kumar*, Pranab Das, M. Beulah and H.R. Arjun

Georgie Ignatius Christ (Deemed to be University), Bengaluru, India

*Address all correspondence to: raghunandan.kumar@christuniversity.in

\section{IntechOpen}

(C) 2020 The Author(s). Licensee IntechOpen. This chapter is distributed under the terms of the Creative Commons Attribution License (http://creativecommons.org/licenses/ by/3.0), which permits unrestricted use, distribution, and reproduction in any medium, provided the original work is properly cited. (cc) BY 


\section{References}

[1] Olukoya Obafemi AP, Kurt S.

Environmental impacts of adobe as a building material: The North Cyprus traditional building case. Journal of Case Studies in Construction Materials. 2016;4:32-41

[2] Shakir AA, Mohammed AA.

Manufacturing of bricks in the past, in the present and in the future: A state of the art review. International Journal of Advances in Applied Sciences (IJAAS). 2013;2(3):145-156

[3] Davidovits J. Geopolymer Chemistry and Properties. Proceedings of the 1st International Conference on Geopolymer '88. Compiegne. 1-3 June 1988;1:25-48

[4] Mathew BJ, Sudhakar M, Natarajan C. Development of coal-ash-GGBS based geopolymer bricks. European International Journal of Science and Technology. 2013;2(5):133-139

[5] Indian Standard 3495-1, 2, 3, and 4. Methods of Tests of Burnt Clay Building Bricks [CED 30: Clay and Stabilized Soil Products for Construction]; 1992

[6] Shanmuka KN. Stabilised iron ore tailing blocks-An environment friendly construction material. International Journal of IT, Engineering and Applied Sciences Research. 2014;3(4):4-7

[7] Jagadish KS. Structural Masonry. New Delhi: I.K. International Publishing House Pvt. Ltd; 2015

[8] Ullas SN, Venkatarama Reddy BV. Characteristics of masonry units from iron ore tailings. In: International Conference on Sustainable Built Environment (ICSBE-2010) Kandy. 13-14 December 2010; 2010 



\title{
Utilization of Iron Ore Mines Waste as Civil Construction Material through Geopolymer Reactions
}

\author{
Pranab Das, Beulah Matcha, Nabil Hossiney, \\ Mothi Krishna Mohan, Anirban Roy and Arun Kumar
}

\begin{abstract}
In India, due to fast pace development there is a drastic growth in the iron and steel industry. As of 2017, India is one of the largest producers of crude steel in the world. This has led to drastic increase in mining activity. Mining activity is responsible for generation of wastes, which can pose threat to the environment and its habitants. However, there is also a great potential for mines wastes to be utilized in construction industry, which can become an important ingredient for sustainable and eco-friendly development. In iron and steel industry, Iron ore tailings (IOT) and slimes utilization is still an area of challenge, because of the low content of iron oxide present in them, which is unsuitable for metal extraction. Usually particle size of slimes below $1 \mathrm{~mm}$ is not amenable for further metal extraction through conventional pelletization techniques. In the present study waste from two different iron ore mines have been tried for their utilization as a construction material through geopolymerisation technology. As a primary consideration, shapes made in the form of common bricks were tested for their densification behavior, compressive strength and water absorption. To reduce the cost, industrial wastes like fly ash, ground granulated blast furnace slag, and lime were tried in different batch compositions in addition to sodium silicate and sodium hydroxide. Relationship between compressive strength values with individual ratio of silica to alumina ( $\mathrm{Si} / \mathrm{Al})$, silica to alumina with iron combined $(\mathrm{Si} / \mathrm{Al}+\mathrm{Fe})$, and calcium to silica $(\mathrm{Ca} / \mathrm{Si})$ were developed. Based on the elemental ratios, critical threshold values were established that showed significant effect on the compressive strength of the final composite.
\end{abstract}

Keywords: IOT, geopolymer, GGBS, calcium, fly ash

\section{Introduction}

Numerous scientific studies indicated superiority of the ancient concrete as being much more durable than their modern counterparts made with ordinary portland cement. It has been observed that calcium silicate hydrate formed as a result of the hydration of modern portland cement deteriorates, while the ancient cement remains intact under identical conditions. French scientist, Davidovits [1] proposed 
that the durability of ancient concrete was the result of the presence of alkaline aluminosilicates in the structure. Davidovits named this new class of cementitious material as geopolymers. This is a new generation material with diverse applications in the building industry. Geopolymers are produced from the alkali activation of an aluminosilicate source, for e.g. fly ash, metakaolin etc. These binders have similar chemical composition as the natural zeolitic materials but without the extensive crystalline zeolitic structure $[1,2]$. It is formed by the polymerization of individual aluminate and silicate species, which are dissolved from their original sources at high $\mathrm{pH}$ in the presence of alkali sources and the products exhibit high mechanical strengths having the following general chemical formula.

$$
\mathrm{Mn}\left[-\left(\mathrm{Si}-\mathrm{O}_{2}\right) \mathrm{z}-\mathrm{Al}-\mathrm{O}\right] \text { n.w } \mathrm{H}_{2} \mathrm{O}
$$

where $\mathrm{M}$ is the alkaline element, which indicates the presence of a bond, $\mathrm{z}$ is 1 , 2 or 3 and $n$ is degree of polymerization. Theoretically, any alkali and alkali earth cation $(\mathrm{Ca}, \mathrm{Mg}$ ) can be used as a replacement of the alkaline element $(\mathrm{M})$ in the reaction, However the majority of research has focused on the effect of sodium $(\mathrm{Na}+)$ and potassium $\left(\mathrm{K}_{+}\right)$ions [3], disregarding effect of alkaline earth cations $(\mathrm{Ca}, \mathrm{Mg})$. There have been many studies investigating the role of the $\mathrm{Si} / \mathrm{Al}$ ratio, and how it relates to the mechanical properties of geopolymer. Theoretically, there should be a direct correlation with mechanical strength and silica content because increasing the amount of silica increases the amount of $\mathrm{Si}-\mathrm{O}-\mathrm{Si}$ bonds, which are stronger than $\mathrm{Si}-\mathrm{O}-\mathrm{Al}$ and $\mathrm{Al}-\mathrm{O}-\mathrm{Al}$ bonds [2]. However, it was found for metakaolin geopolymers with a $\mathrm{Si} / \mathrm{Al}$ ratio lower than 1.40 , the composites had a very porous matrix, which led to lower compressive strength. But when the Si/Al ratio was increased over 1.65 the composites showed an increase in strength. This increase was attributed to a homogenous microstructure in the geopolymer. Also in metakaolin based geopolymers it was found that the optimum strength was at an intermediate $\mathrm{Si} / \mathrm{Al}$ ratio [4]. The reduction in strength for high Si/Al ratio mixes was the result of unreacted material, which was soft and acted as a defect in the binder phase [5].

Past research has also shown that the addition of calcium into metakaolin geopolymers has beneficial results for mechanical properties. But the role that calcium plays during the geopolymer reaction period has yet to be elucidated. It has been observed that both geopolymer gel and calcium silicate hydrate form during the reaction process $[6,7]$. For metakaolin geopolymers, it appears that the alkali hydroxide concentration plays a vital role in determining if $\mathrm{C}-\mathrm{S}-\mathrm{H}$ forms in the geopolymer. At low alkali hydroxide concentration, the reaction product favors the formation of $\mathrm{C}-\mathrm{S}-\mathrm{H}$, while at higher concentration (above $10 \mathrm{M}$ ) the reaction favors the formation of the geopolymer gel. This difference is due to the fact that the high hydroxyl concentration hinders the $\mathrm{Ca}^{2+}$ dissolution forcing the dissolved silicates and aluminum species to form geopolymer gel. On the other hand, when the $\mathrm{OH}^{-}$concentration is low, the amount of $\mathrm{Ca}^{2+}$ dissolving increases and causes more $\mathrm{C}-\mathrm{S}-\mathrm{H}$ to form. Addition of calcium has been observed to accelerate the hardening process and increase the strength for fly ash based geopolymers. It was also observed that addition of calcium increases strength for geopolymers cured at ambient conditions, while it reduces mechanical properties of geopolymer cured at elevated temperatures, because the presence of calcium hinders the development of the three-dimensional network structure in the geopolymer gel. However, other research indicates that the presence of both $\mathrm{C}-\mathrm{S}-\mathrm{H}$ and geopolymer gel in a geopolymer could have beneficial effects on strength because the $\mathrm{C}-\mathrm{S}-\mathrm{H}$ phase act like micro-aggregates for the geopolymer gel and 
forms a denser and more uniform binder. More research needs to be conducted to understand the effects of composition and nanostructure on mechanical properties of both the geopolymer gel and the $\mathrm{C}-\mathrm{S}-\mathrm{H}$ phases in the geopolymer. There is a lack of documented research involving geopolymeric reaction mechanisms occurring in natural systems like ore minerals consisting of calcium and alkaline minerals and in such systems it is probable that both $\mathrm{C}-\mathrm{S}-\mathrm{H}$ gel and geopolymeric reactions could be forming simultaneously. As a result, an investigation into the role of calcium in dictating the chemical mechanism will provide answers to the fundamental question as to whether two separate phases will be formed, or a new material will be produced.

In past, industrial wastes have been utilized in manufacturing of bricks. For instance, manufacturing of bricks using waste foundry sand at industrial scale has shown promising results [8]. Similarly, IOT can be a very favorable material for manufacturing of bricks at industrial scale. The suitability of IOT as a partial replacement of sand in mortar for masonry was studied. It was found that up to $20 \%$ IOT can be replaced for sand with desired compressive strength [9]. Masonry units made of IOT in compressed earth block as a replacement for natural sand at 25, 50 and $100 \%$ rates were evaluated [10]. Optimum mix proportion of soil, sand and cement was utilized for manufacturing of stabilized mud blocks. It was found that the water absorption increased with the increase in IOT content, but was within permissible limits. It is also reported that when $7 \%$ of cement is used, the wet compressive strength is $7 \mathrm{MPa}$. The experimental results showed that the significant amount of sand can be replaced by IOT without compromising the strength parameters [10]. Lamani S R et al. [11] investigated the utility of iron ore waste (IOW) in preparing non-fired bricks by using cement and fly ash. Bricks were prepared with different proportions of cement, fly ash, and IOW. The manufactured bricks were cured for 7, 14, 21, and 28d. Compressive strength and water absorption of bricks were evaluated. The results of the study reveals that mixture with $70 \%$ IOW, $15 \%$ cement and $15 \%$ fly ash shows the minimum required compressive strength and water absorption properties of bricks for a minimum curing period of $7 \mathrm{~d}$. The potential of IOT in sandcrete block was evaluated [12]. Maximum IOT used was 30\%, which was replaced for sand in the production of sandcrete blocks. Accordingly the study reported increase in compressive strength with increased IOT replacements from 0 to $30 \%$, and curing period from 7 to $28 \mathrm{~d}$. In another study the sustainability of IOT as a replacement to fine aggregate in mortar for masonry work was studied. It was found that the strength attained was approximately $37 \mathrm{MPa}$ for the optimum combination of IOT and river sand. In selfcompacting concrete the replacement of fine aggregate with IOT up to $40 \%$ and red mud by cement up to $4 \%$ was evaluated [13]. Accordingly the maximum compressive strength was achieved for 30\% IOT mixtures [13]. Nagaraj and Shreyasvi [14], made an explorative study to prepare compressed stabilized earth blocks utilizing various proportions of mine spoil waste (MSW), quarry dust as aggregates, cement, and lime as stabilizers. In their study the researchers used 30-50\% waste along with cement and lime. Cement varied in proportions of 6 and $8 \%$ with $2 \%$ lime. Blocks of $230 \times 110 \times 75 \mathrm{~mm}$ were prepared using Mardini press. The wet compressive strength and water absorption was evaluated for various curing periods of $7,15,30$, 60 and $1800 \mathrm{~d}$. They concluded that wet compressive strength, water absorption and flexure strength of the blocks are meeting the requirements of Indian standards; accordingly they suggested that these blocks can be effectively used as eco-friendly blocks in construction activity [14].

In the present work, research is conducted with the addition of GGBS and lime (commercial grade) in IOT system with fixed amount of sodium silicate. 
It is envisaged, that this will lead to a number of reaction products and the type and number of these products will be dependent on the experimental conditions and, more importantly, depending on the form of calcium present. It is anticipated that likely products to be formed will be calcium silicate hydrate and aluminum silicate geopolymers. Also the isomorphs nature of iron in combination with aluminum will most probably produce alkali $(\mathrm{Al}+\mathrm{Fe})$ geopolymers. It will be interesting to find the application of this waste as regards to its mechanical strength as construction material through calculation of $\mathrm{Si} / \mathrm{Al}, \mathrm{Si} /(\mathrm{Al}+\mathrm{Fe})$, $\mathrm{Ca} / \mathrm{Si}$ ratios. As regards to industrial application the present research explores the possibility of utilizing IOT for the production of eco-friendly bricks. These bricks are produced in Mardini block making machine. The formed bricks are kept in room temperature for extended time periods after which different properties are determined.

\section{Part A: case study with BMM Ispat iron ore mines}

\subsection{Experimental}

\subsubsection{Materials}

The materials used in this study include IOT, sodium silicate solution $\left(\mathrm{Na}_{2} \mathrm{SiO}_{3}\right)$, lime, GGBS and potable water. The mine tailings were received in a sizes ranging $(<150 \mu \mathrm{m})$ from the Bellary mining area (BMM Ispat). The physical properties of the mine tailings are determined as per the standard (IS: 2720 (part 3 \& 7). Ground granulated blast furnace slag (GGBS) is a by-product of steel industry. GGBS can be used as a replacement for, or be blended with portland cement. When blended with Portland cement it is called Portland slag cement. Addition of GGBS has shown improvement in properties of the cement like resistance to chemical attack which results in improved durability of concrete mixtures. The chemical composition of IOT and GGBS is presented in Table 1 . Table 2 presents the physical properties of IOT. Figure 1 shows SEM images of IOT and GGBS, respectively. As seen the IOT surface shows random distribution of irregular particles, while GGBS surface exhibited aggregates which might have happened due to surface kinetics. Figures 2 and 3 show the XRD patterns of IOT and GGBS. XRD pattern of IOT shows the presence

\begin{tabular}{lcc}
\hline Chemical composition & IOT & GGBS \\
\hline $\mathrm{SiO}_{2}$ & 9.02 & 34.16 \\
\hline $\mathrm{Fe}_{2} \mathrm{O}_{3}$ & 66.56 & 1.99 \\
\hline $\mathrm{Al}_{2} \mathrm{O}_{3}$ & 9.56 & 17.54 \\
\hline $\mathrm{CaO}$ & 1.96 & 37.10 \\
\hline $\mathrm{MgO}$ & 2.12 & - \\
\hline $\mathrm{MnO}_{2}$ & 1.15 & - \\
\hline $\mathrm{TiO}_{2}$ & 0.66 & 1.00 \\
\hline $\mathrm{K}_{2} \mathrm{O}$ & - & 0.31 \\
\hline $\mathrm{Na}_{2} \mathrm{O}$ & - & 0.57 \\
\hline
\end{tabular}

Table 1.

Chemical composition of IOT \& GGBS. 
Utilization of Iron Ore Mines Waste as Civil Construction Material through Geopolymer Reactions DOI: http://dx.doi.org/10.5772/intechopen.81709

\begin{tabular}{ll}
\hline Fineness modulus & 1.8 \\
\hline Specific gravity & 2.34 \\
\hline OMC $(\%)$ & 9.8 \\
\hline MDD $\left(\mathrm{g} / \mathrm{cm}^{3}\right)$ & 2.14 \\
\hline Plastic limit $(\%)$ & 16.56 \\
\hline Liquid limit $(\%)$ & 26.1 \\
\hline Plasticity index $(\%)$ & 9.54 \\
\hline
\end{tabular}

Table 2.

Physical properties of IOT and GGBS.

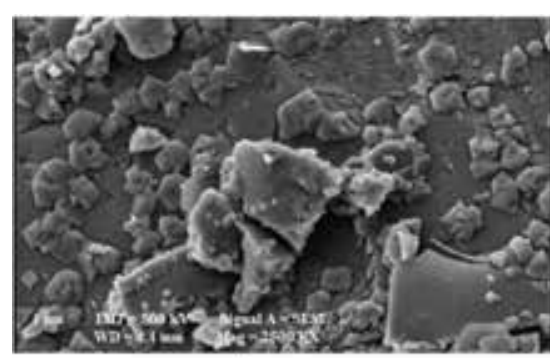

a.

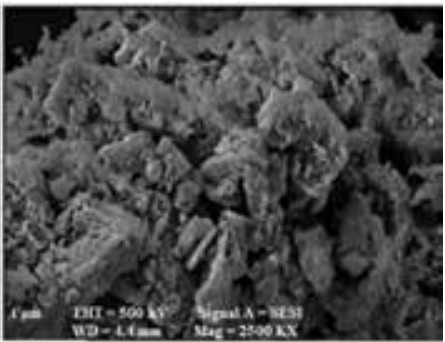

b.

Figure 1.

SEM micrograph (a) IOT, (b) GGBS.

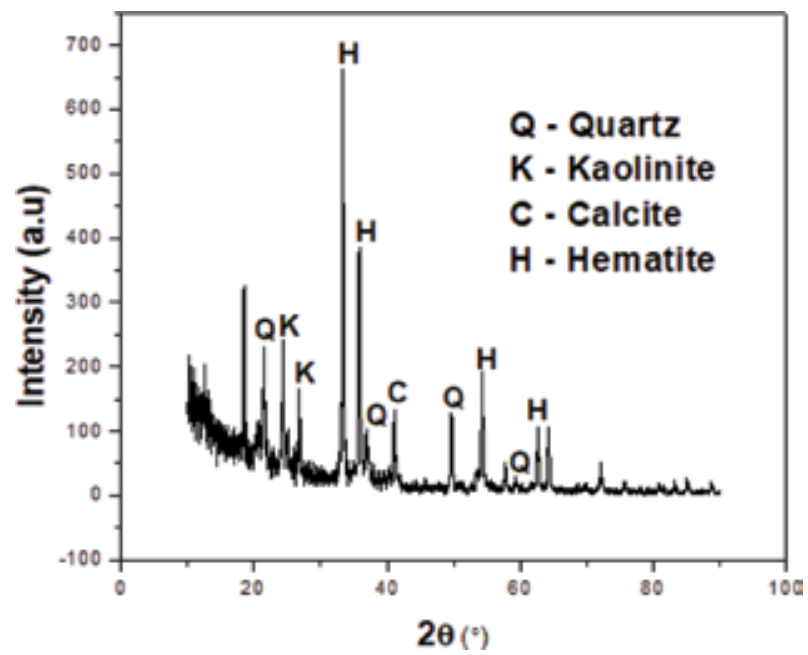

Figure 2.

$X R D$ pattern of Iron ore tailing (IOT).

of kaolinite and calcite in addition to the crystalline phase of hematite. XRD pattern of GGBS shows highly amorphous nature, which is effective to control the geopolymeric reaction. The lime used in this study was commercial grade and slaked in nature, and the purity was more than $96 \%$. Sodium silicate used in this study was procured from a local sodium silicate manufacturer in liquid form in concentration range of $3\left(\mathrm{SiO}_{2}\right): 1\left(\mathrm{Na}_{2} \mathrm{O}\right)$. 


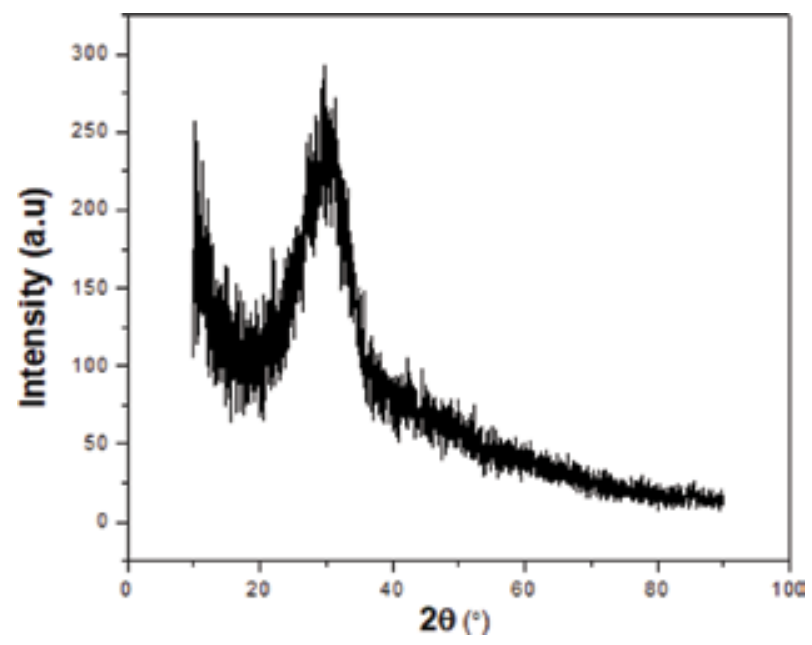

Figure 3.

XRD pattern of GGBS.

\subsubsection{Preparation of brick samples}

In present study standard sized brick $(230 \times 115 \times 75 \mathrm{~mm})$ were made by hand pressing in Mardini press as shown in Figure 4. The brick were cured at room temperature conditions for a period of 7,14 , and $28 \mathrm{~d}$. The variation of IOT was between 30 and $50 \%$ in increments of 5\%. While the amount of lime was kept fixed at $5 \%$ and sodium silicate concentration was fixed at $20 \%$. The addition of GGBS was proportionately decreased from 45 to $25 \%$ such that the total of IOT and GGBS for each composition was $75 \%$. Table 3 presents the details of mix specification. The schematic representation of brick making is shown in Figure 5.

\subsection{Results and discussion}

All the tests on the bricks were performed as per the IS:3495 standard. The maximum stress in the brick specimens were calculated by determining the maximum load at failure to the area of the bed surface of the bricks. Load was
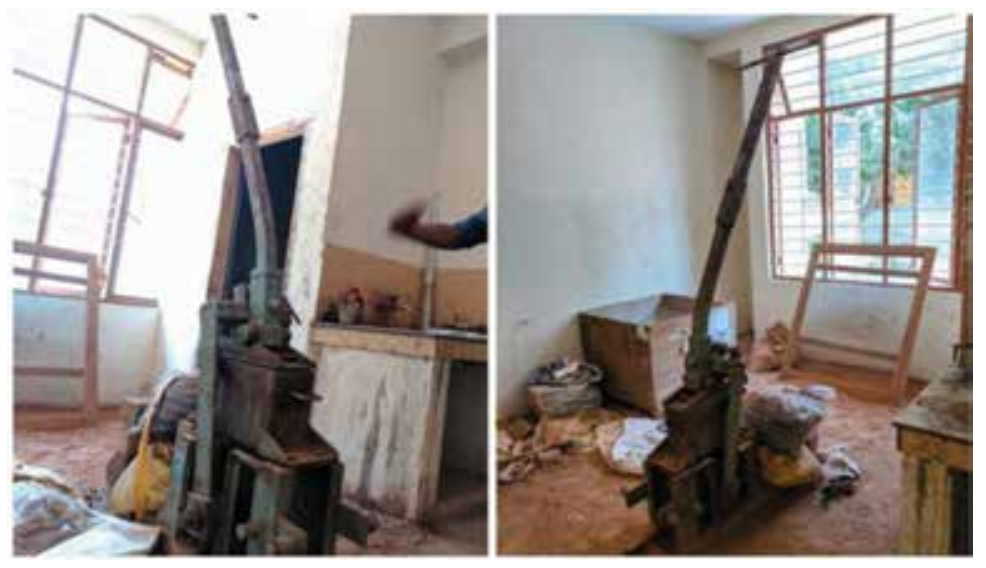

Figure 4.

Mardini block making machine. 
Utilization of Iron Ore Mines Waste as Civil Construction Material through Geopolymer Reactions DOI: http://dx.doi.org/10.5772/intechopen.81709

\begin{tabular}{lcccc}
\hline Mix designation & \multicolumn{4}{c}{ Quantity (\%) } \\
\cline { 2 - 5 } & IOT & GGBS & $\mathrm{Na}_{2} \mathrm{SiO}_{3}$ & Lime \\
\hline B1 & 30 & 45 & 20 & 5 \\
\hline B2 & 35 & 40 & 20 & 5 \\
\hline B3 & 40 & 35 & 20 & 5 \\
\hline B4 & 45 & 30 & 20 & 5 \\
\hline B5 & 50 & 25 & 20 & 5 \\
\hline
\end{tabular}

Table 3.

Details of mix specifications.

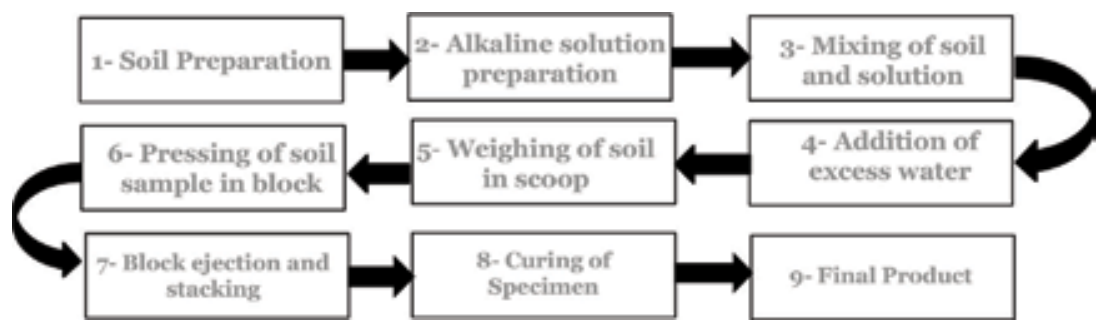

Figure 5.

Schematic representation of brick making.

applied axially at a uniform rate of $14 \mathrm{~N} / \mathrm{mm}^{2}$ per minute till failure. Figure 6 shows the setup for compressive strength test. The results of the strength test are shown in Figure 7. Water absorption data is obtained by immersion of brick specimen in water for $24 \mathrm{~h}$ at room temperature, followed by drying of bricks in oven at $110^{\circ} \mathrm{C}$. The water absorption is determined by obtaining the difference in weights of bricks before and after drying, to its dry weight in percentage. As per the IS: 3495 good quality bricks should not absorb more than $20 \%$ water by its weight. From the results of strength, density, and water absorption, it is seen that there is an increase in strength and density with increase in IOT (as observed in Figures 7 and 8). Similar trends in increase of water absorption and compressive strength for IOT bricks with increased IOT content were reported in past studies. Increase in water absorption as observed in Table $\mathbf{4}$ can be attributed to the higher absorbing capacity of the tailing waste. The water absorption for IOT bricks

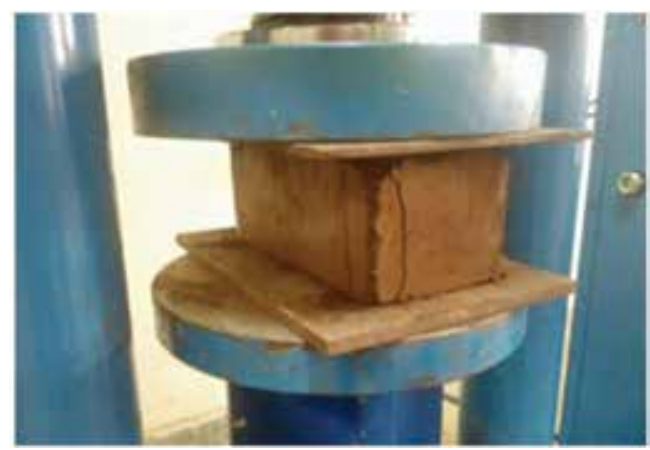

Figure 6.

Compressive strength test setup. 


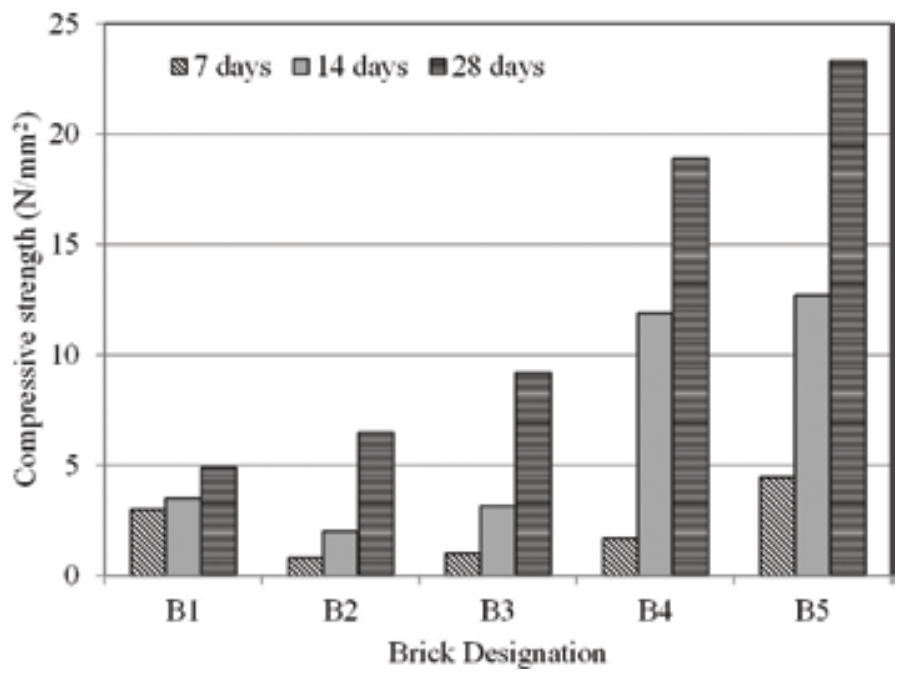

Figure 7.

Compressive strength of bricks at different curing period.

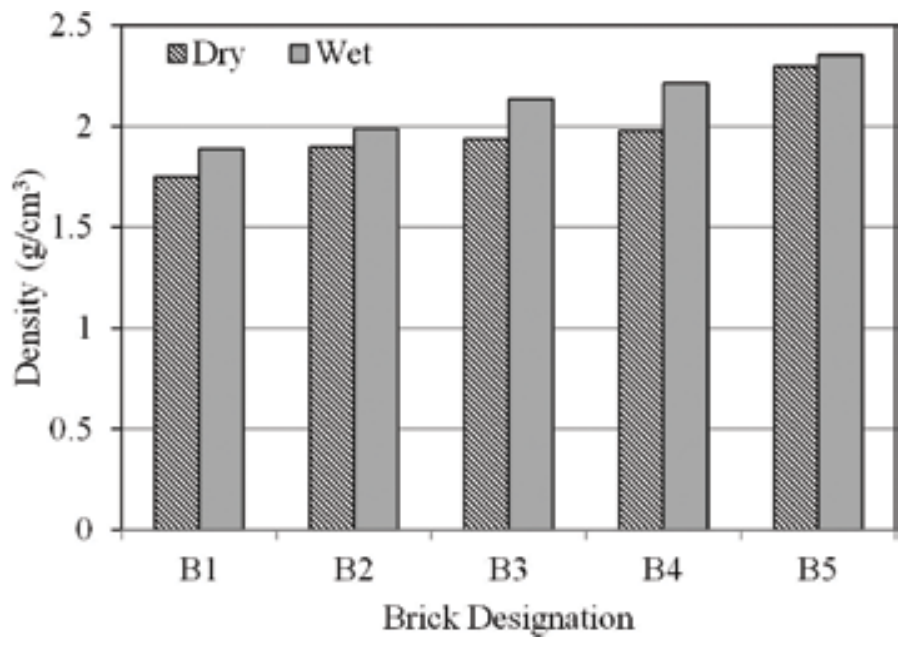

Figure 8.

Density of bricks.

\begin{tabular}{lccccc}
\hline Brick designation & B1 & B2 & B3 & B4 & B5 \\
\hline Water absorption & 5.9 & 7.5 & 10.2 & 12.7 & 13.5 \\
\hline
\end{tabular}

Table 4.

Water absorption of bricks.

are well below the limits of IS standard specifications. The relationship between $\mathrm{Si} / \mathrm{Al}, \mathrm{Ca} / \mathrm{Si}$, and $\mathrm{Si} /(\mathrm{Al}+\mathrm{Fe})$ to compressive strength at different curing periods is shown in Figures 9-11, respectively. It is observed that there is a drastic fall in the compressive strength with increase in the $\mathrm{Si} / \mathrm{Al}, \mathrm{Ca} / \mathrm{Si}$, and $\mathrm{Si} /(\mathrm{Al}+\mathrm{Fe})$ concentrations. At early curing periods (7d) the critical threshold values for $\mathrm{Si} / \mathrm{Al}$. Ca/Si, and 

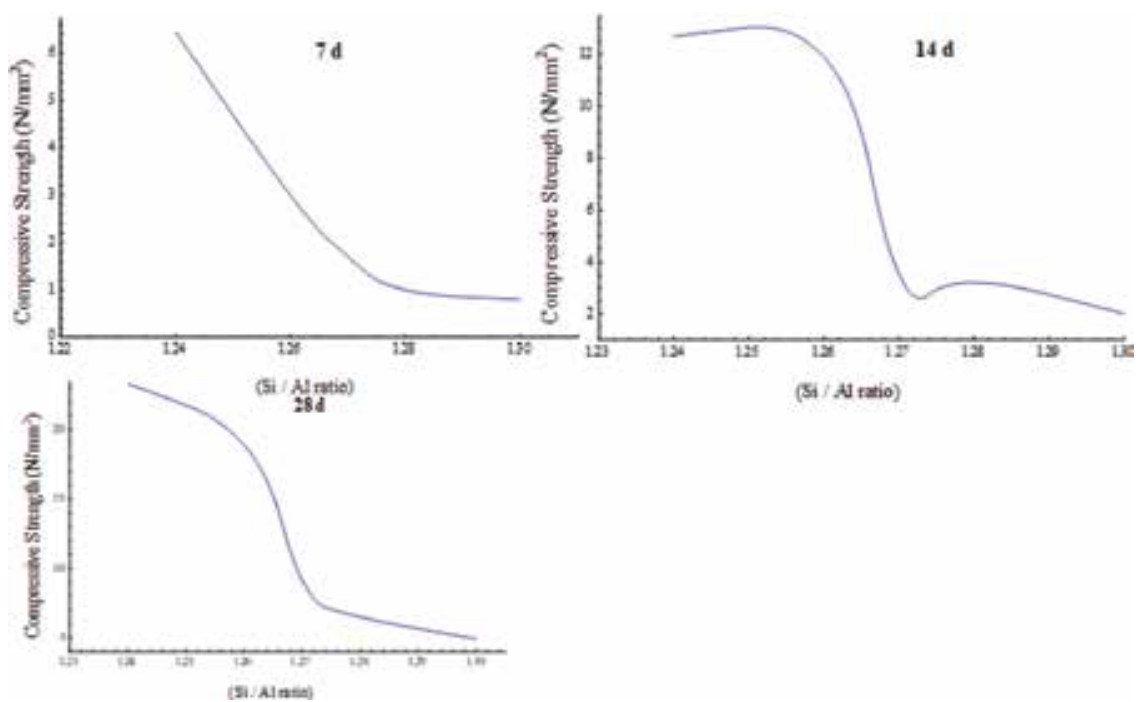

(\$i / As ratio)

Figure 9.

Relationship between Si/Al ratio and compressive strength at different curing periods.

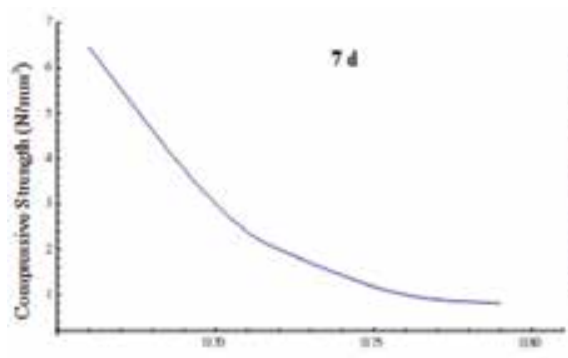

(Ca/ sintio)

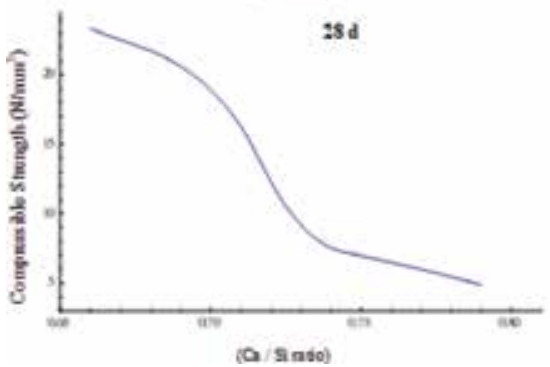

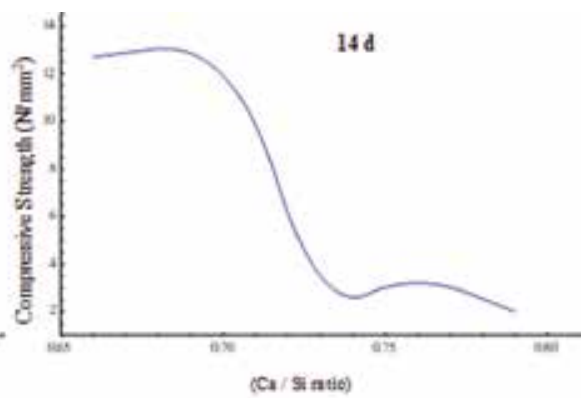

(a)/ Ii atie)

Figure 10.

Relationship between Ca/Si ratio and compressive strength at different curing periods.

$\mathrm{Si} /(\mathrm{Al}+\mathrm{Fe})$ ratios were observed to be $1.25,0.70$, and 0.30 , respectively, beyond the threshold values there was drastic reduction in the compressive strength of the bricks. Similarly, at later curing periods (14 and 28d) the critical threshold values for $\mathrm{Si} / \mathrm{Al}, \mathrm{Ca} / \mathrm{Si}$, and $\mathrm{Si} /(\mathrm{Al}+\mathrm{Fe})$ ratios were observed to be 1.27, 0.73, and 0.34. Figure 12 shows the SEM micrograph of brick specimen with 50\% IOT. Sample cured at room temperature for $7 \mathrm{~d}$ show amorphous phase with gel nature, but the increase in curing period changed the structure to crystalline with less degree of aggregation. 


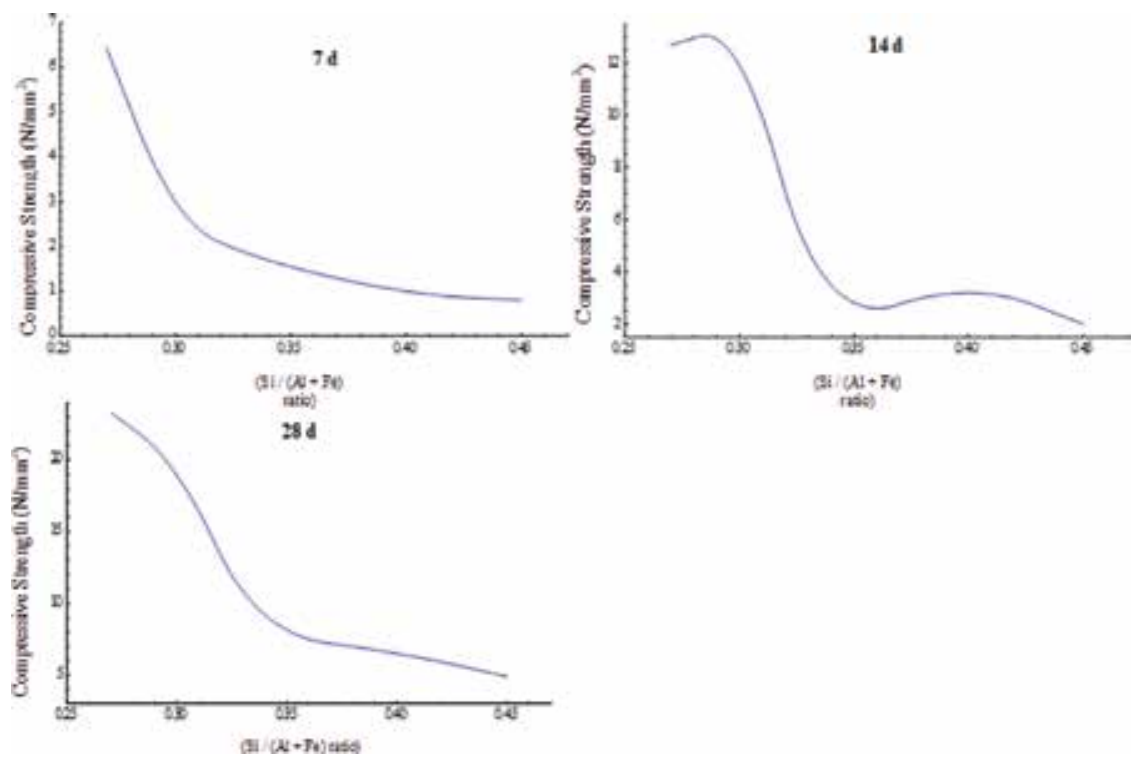

Figure 11.

Relationship between $\mathrm{Si} /(\mathrm{Al}+\mathrm{Fe})$ ratio and compressive strength at different curing periods.

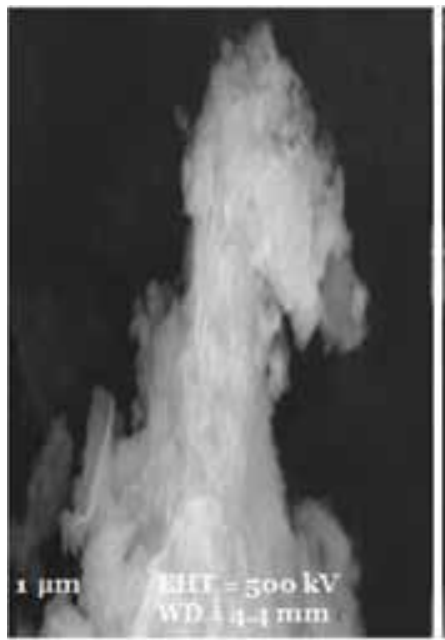

a

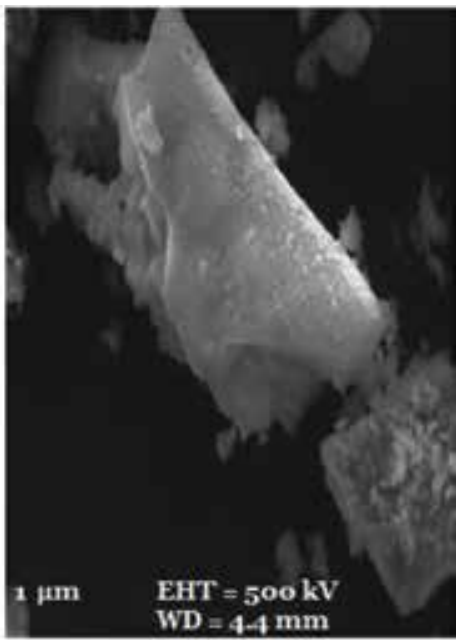

b

Figure 12.

SEM micrograph of brick specimen with $50 \%$ IOT (a) 7 d curing, (b) $28 d$ curing.

\section{Part B: case study with JSW Steel mines Ltd}

\subsection{Experimental}

\subsubsection{Materials}

Raw materials are important in geopolymer formation and materials rich in $\mathrm{Si}$ and $\mathrm{Al}$ are the primary requirement. These two materials react with alkaline solution (comprising of sodium silicate and sodium hydroxide) for dissolution of $\mathrm{Si}$ and $\mathrm{Al}$ to form reactive precursor necessary for mechanical strength. Combination 
of these two materials has traditionally been used for geopolymer formation. The role of calcium either in formation of $\mathrm{C}-\mathrm{S}-\mathrm{H}$ gel giving cementitious bond or as a substitute in $\mathrm{Al}$ and $\mathrm{Si}$ as partial replacement towards geopolymerisation reaction is yet a controversy. In the current study as a calcium source; GGBS, fly ash and slag sand were used in the various batch compositions.

Fly ash is a waste by-product from coal burning power plants for generation of electricity. It has pozzolanic properties and is widely used in cement making industries as an admixture in portland cement. GGBS is a byproduct from iron making industries namely blast furnace. GGBS can be used as a replacement for, or be blended with portland cement. When blended with portland cement it is called portland slag cement. Addition of GGBS has shown improvement in properties of cement, like resistance to chemical attack. However, the quality of slag depends on certain conditions. For instance, slow cooling of the slag results in more crystallized product, while rapid cooling results in desired non-crystallized product which exhibits enhanced reactivity. Slag sand is an admixture of blast furnace slag and other calcia based alumina-silicate compounds produced by Jindal Steel Ltd., Karnataka, India. The materials are generally used in civil engineering construction for early development of strength in concrete. IOT is a low grade iron ore generated in iron ore mines after sorting out of good quality ore ( $>65 \%$ hematite).

Water glass, also known as sodium silicate, contains compounds of sodium oxide $\left(\mathrm{Na}_{2} \mathrm{O}\right)$ and silica $\left(\mathrm{SiO}_{2}\right)$ and forms a glassy material that is soluble in water. Water glass can be produced as both an aqueous solution and as solid material. It is produced when burning sodium carbonate and silica sand in a furnace at temperatures between 1000 and $1400^{\circ} \mathrm{C}$. The viscosity of the solution depends on the ratio of $\mathrm{SiO}_{2}$ and $\mathrm{Na}_{2} \mathrm{O}$; the higher the concentration of both, the more viscous is the solution. Water glass dissolves in water and produces an alkaline solution which is glassy in nature and colorless. Due to the alkali properties, water glass will react under acidic conditions and form a hard glassy gel, which is a very useful as bonding agent. Sodium hydroxide $(\mathrm{NaOH})$, also known as caustic soda is a white material commonly found in the form of pellets, granules or flakes. $\mathrm{NaOH}$ is highly soluble in water and because of its high alkaline activator levels; it is normally used in geopolymer reactions. The $\mathrm{NaOH}$ concentration has a significant effect on the compressive strength of geopolymers.

In the present study 8 and $10 \mathrm{M} \mathrm{NaOH}$ solution were used. The $\mathrm{NaOH}$ was delivered by Merck (Germany). Table 5 presents the chemical composition of all the raw materials used. Figure 13 shows the XRD patterns of different raw materials. XRD analysis was performed to understand the nature of the material. Sharp and intense peaks of samples A and D, is attributed to its crystalline nature. Broad diffraction peaks of samples B and C, exhibited its amorphous nature. The full width at half maximum (FWHM) of a peak is inversely proportional to crystallite size. Lower crystallite size of samples B and C, compared to samples A and D is obvious from the diffraction patterns.

\begin{tabular}{lccccccc}
\hline & $\mathrm{SiO}_{2}$ & $\mathrm{Al}_{2} \mathrm{O}_{3}$ & $\mathrm{CaO}$ & $\mathrm{MgO}$ & $\mathrm{MnO}_{2}$ & $\mathrm{TiO}_{2}$ & $\mathrm{Fe}_{2} \mathrm{O}_{3}$ \\
\hline Fly ash & 66.87 & 23.34 & 1.17 & 0.31 & - & - & 4.41 \\
\hline GGBS & 31.79 & 17.07 & 38.78 & 6.23 & - & - & 0.49 \\
\hline Slag sand & 30.73 & 16.32 & 38.47 & 6.41 & - & - & 0.56 \\
\hline IOT & 16.05 & 6.34 & 1.52 & 0.28 & 1.20 & 0.38 & 44.82 \\
\hline
\end{tabular}

Table 5.

Chemical composition of raw materials. 

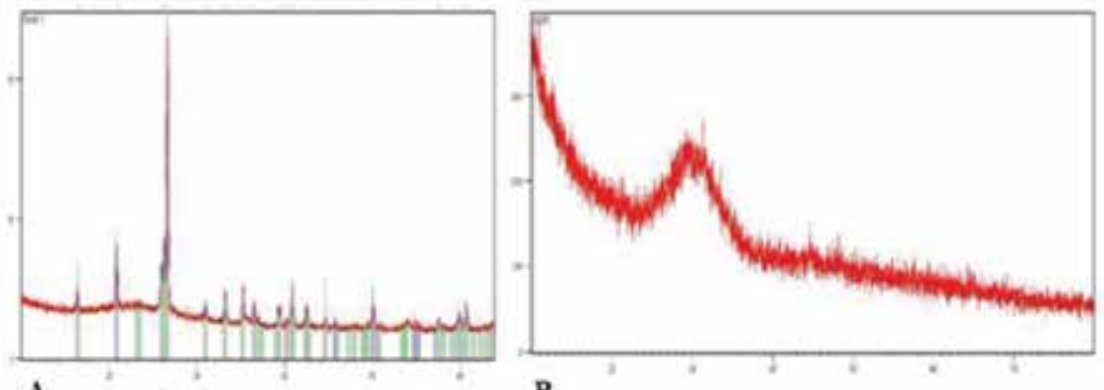

A.

B.
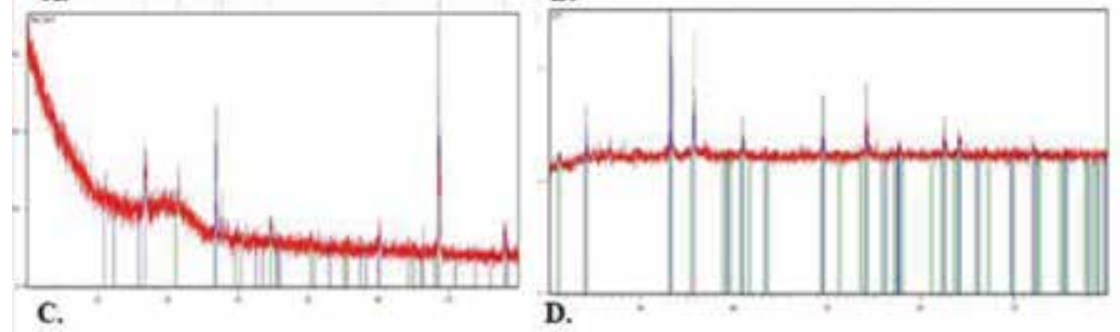

D.

Figure 13.

XRD patterns of (A) fly ash, (B) GGBS, (C) slag sand, and (D) IOT.

\subsubsection{IOT geopolymer with fly ash, GGBS and slag sand composition}

Table 6 presents the details of proportions made with IOT, fly ash, GGBS, and slag sand. The amount of fly ash and GGBS was kept constant as 15\% in all the compositions. As seen in Table 6, IOT increased from 20\% (GB1) to 40\% (GB3). The $\mathrm{Ca} / \mathrm{Si}$ ratio was increased and varied between 0.504 (GB-1) and 0.368 (GB-3). All these compositions were made with $8 \mathrm{M}$ alkaline solutions. Similarly, another set of composition with $10 \mathrm{M}$ alkaline solution was made. IOT varied from $20 \%$ (GB4)

\begin{tabular}{lcccccc}
\hline Sample designation & GB1 & GB2 & GB3 & GB4 & GB5 & GB6 \\
\hline IOT (\%) & 20 & 30 & 40 & 20 & 30 & 40 \\
\hline Slag sand (\%) & 40 & 30 & 20 & 40 & 30 & 20 \\
\hline Fly ash (\%) & 15 & 15 & 15 & 15 & 15 & 15 \\
\hline GGBS (\%) & 15 & 15 & 15 & 15 & 15 & 15 \\
\hline $\begin{array}{l}\text { Alkaline sol. } \\
\text { (concentration) }\end{array}$ & 10 & 10 & 10 & 10 & 10 & 10 \\
\hline $\mathrm{NaOH}$ sol. (\%) & $(8 \mathrm{M})$ & $(8 \mathrm{M})$ & $(8 \mathrm{M})$ & $(10 \mathrm{M})$ & $(10 \mathrm{M})$ & $(10 \mathrm{M})$ \\
\hline $\mathrm{Na}$ 2SiO 3 sol. (\%) & 2.04 & 2.04 & 2.04 & 1.8 & 1.8 & 1.8 \\
\hline $\mathrm{Extra}$ water (\%) & 1.37 & 1.37 & 1.37 & 1.71 & 1.71 & 1.71 \\
\hline $\mathrm{Si}$ (mol) & 3.8 & 3.8 & 3.8 & 3.69 & 3.69 & 3.69 \\
\hline $\mathrm{Al}$ (mol) & 0.767 & 0.730 & 0.693 & 0.770 & 0.733 & 0.696 \\
\hline $\mathrm{Si} / \mathrm{Al}$ (molar ratio) & 0.068 & 0.063 & 0.058 & 0.068 & 0.063 & 0.058 \\
\hline $\mathrm{Ca}$ (mol) & 11.279 & 11.587 & 11.948 & 11.324 & 11.635 & 12.000 \\
\hline $\mathrm{Ca} / \mathrm{Si}$ (molar ratio) & 0.387 & 0.321 & 0.255 & 0.387 & 0.321 & 0.255 \\
\hline & 0.504 & 0.439 & 0.368 & 0.502 & 0.438 & 0.366 \\
\hline
\end{tabular}

Table 6.

Details of mix proportion with fly ash, GGBS, and slag sand. 
Utilization of Iron Ore Mines Waste as Civil Construction Material through Geopolymer Reactions DOI: http://dx.doi.org/10.5772/intechopen.81709

to $40 \%$ (GB6) with $10 \mathrm{M}$ alkaline solution. The ratio of Si/Al varied between 11.32 (GB-4) and 12.00 (GB-6). The Ca/Si ratio varied between 0.502 (GB-4) and 0.366 (GB-6).

\subsection{Results and discussion}

The compressive strength versus $\mathrm{Ca} / \mathrm{Si}$ ratio at different curing periods for the different compositions is shown in Figure 14. The general trend of increase
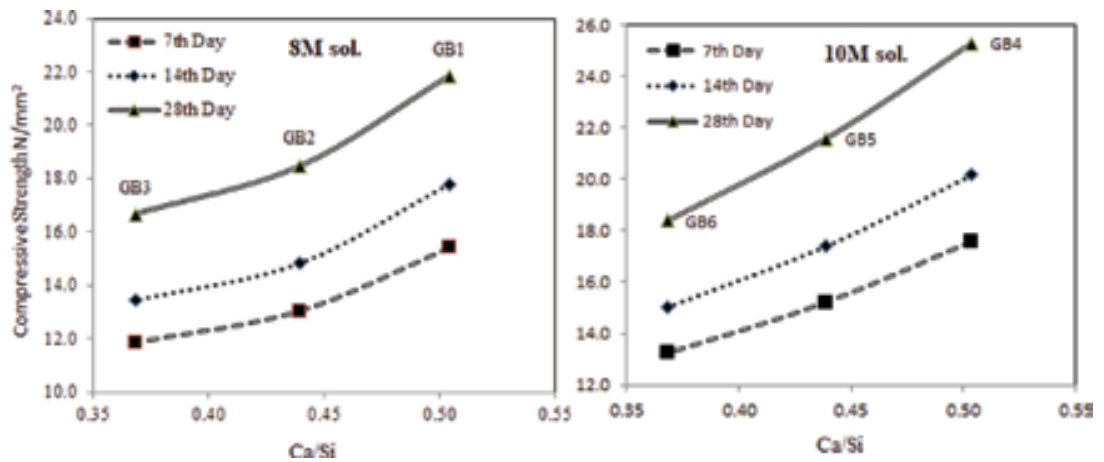

Figure 14 .

Compressive strength vs. $\mathrm{Ca} / \mathrm{Si}$.
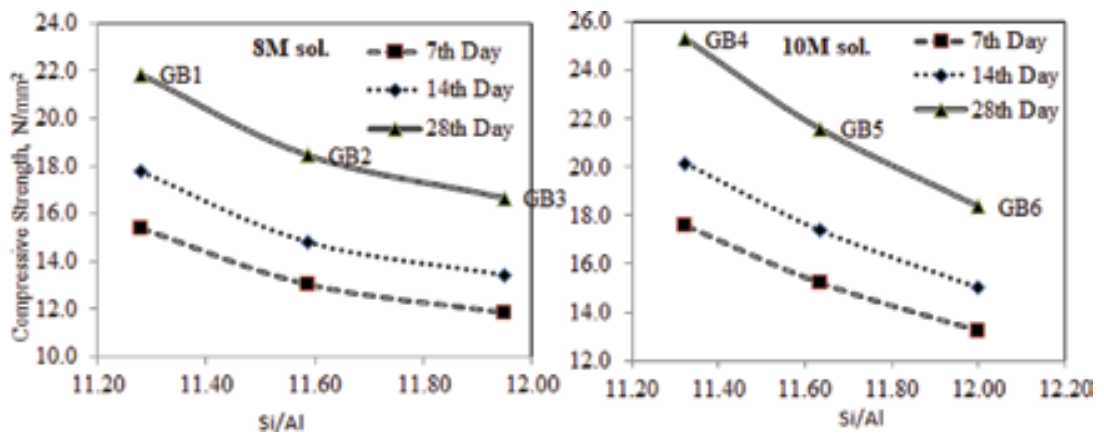

Figure 15.

Compressive strength vs. Si/Al.

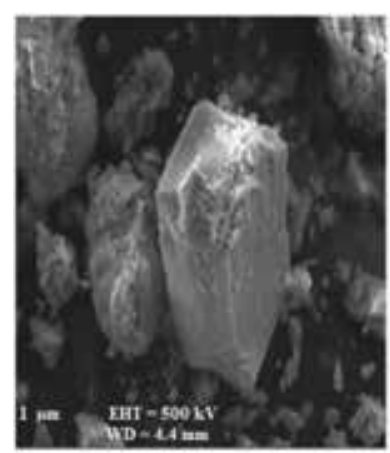

A.

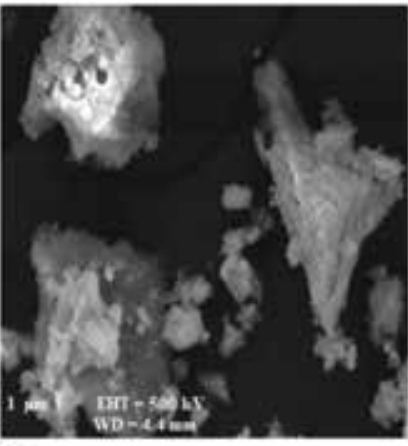

B.

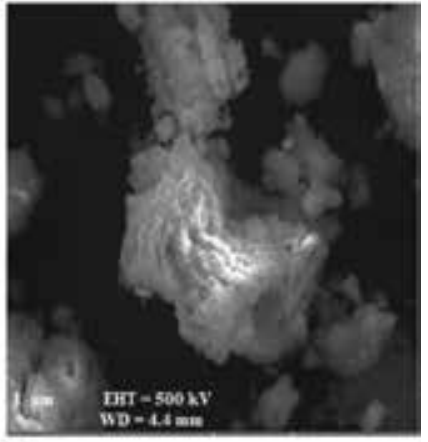

C.

Figure 16.

SEM micrographs of composites with (A) GB1, (B) GB3, and (C) GB6. 
in compressive strength with increase in time period (7, 14, and $28 \mathrm{~d})$ is observed. However, with increase in the amount of IOT (from 20to 40\%) there is a fall in compressive strength. It is observed that in all the different samples the $\mathrm{Ca} / \mathrm{Si}$ decreases with increase in IOT content. This was further attributed to decrease in compressive strength of the brick specimens. Almost identical trends were observed for the specimens with $10 \mathrm{M}$ solution. Figure 15 shows the compressive strength behavior of the bricks and its relationship with $\mathrm{Si} / \mathrm{Al}$ ratio. It will be observed that with increase in $\mathrm{Si} / \mathrm{Al}$ ratio there is decrease in compressive strength.

Figure 16 shows the SEM micrographs of different composites. The SEM micrograph of GB1 reveals the crystalline nature of the material with irregular distribution of shapeless particles. Crystalline nature of the material may positively influence the compressive strength. GB3 sample also exhibited shapeless structures with irregular distribution. The aggregation due to surface kinetics is more compared to GB1. Due to high concentration of NaOH, GB6 is highly aggregated with less number of independent particles. The compressive strength of GB3 was found to be less due to low calcium content, less concentration of sodium hydroxide and irregular distribution of particles with some degree of aggregation.

\section{Conclusion}

In the current study, IOT from two different sources were used to make brick samples in laboratory. The characterization on IOT from different sources revealed the variation in the chemical composition of the raw hematite tailings. In the first sample the combined $\left(\mathrm{SiO}_{2}+\mathrm{Al}_{2} \mathrm{O}_{3}\right)$ was found to be $18.6 \%$, and that of hematite was $66.56 \%$, similarly second sample showed $\left(\mathrm{SiO}_{2}+\mathrm{Al}_{2} \mathrm{O}_{3}\right)$ to be $22.4 \%$ and hematite was $44.8 \%$. With first IOT sample, bricks were manufactured with GGBS, sodium silicate, and lime. In the brick specimens with IOT, GGBS, sodium silicate, and lime there was an increase in compressive strength with increased IOT content. The trend in increased strength was similar for different curing periods. A maximum of $23 \mathrm{~N} / \mathrm{mm}^{2}$ was observed for bricks made with $50 \%$ IOT, $25 \%$ GGBS, $20 \% \mathrm{Na}_{2} \mathrm{SiO}_{3}$, and $5 \%$ lime. The relationship between $\mathrm{Si} / \mathrm{Al}, \mathrm{Ca} / \mathrm{Si}$, and $\mathrm{Si} /(\mathrm{Al}+\mathrm{Fe})$ to compressive strength at different curing periods were developed. From the developed ratios it was observed that at early curing periods (7d) the critical threshold values for $\mathrm{Si} / \mathrm{Al}$. $\mathrm{Ca} / \mathrm{Si}$, and $\mathrm{Si} /(\mathrm{Al}+\mathrm{Fe})$ ratios were $1.25,0.70$, and 0.30 , respectively, beyond the threshold values there was drastic reduction in the compressive strength of the bricks. With second IOT sample, bricks were manufactured with GGBS, fly ash, slag sand, $\mathrm{Na}_{2} \mathrm{SiO}_{3}$, and $\mathrm{NaOH}$ (8 and $10 \mathrm{M}$ ). With increase in IOT content there was decrease in compressive strength of the brick specimens. The maximum compressive strength of $25.7 \mathrm{~N} / \mathrm{mm}^{2}$ was observed for bricks containing $20 \%$ IOT, $40 \%$ slag sand, $15 \%$ fly ash, $15 \%$ GGBS, $\mathrm{Na}_{2} \mathrm{SiO}_{3}$, and $\mathrm{NaOH}(10 \mathrm{M})$. The limited results of the current study shows the effective utilization of waste materials like IOT, GGBS, fly ash along with geopolymerisation results in more eco-friendly and environmental sustainable building material.

\section{Acknowledgements}

The authors wish to thank Ministry of Mines for granting the project (under reference no 14/15/2013-METIV). The authors wish to thank the management of Christ (Deemed to be University) for the help rendered during different stages of the experimental work. 


\section{Author details}

Pranab Das*, Beulah Matcha, Nabil Hossiney, Mothi Krishna Mohan, Anirban Roy and Arun Kumar

Faculty of Engineering, Christ (Deemed to be University), Bangalore, India

*Address all correspondence to: pranab.das@christuniversity.in

\section{IntechOpen}

(C) 2018 The Author(s). Licensee IntechOpen. This chapter is distributed under the terms of the Creative Commons Attribution License (http://creativecommons.org/licenses/ by/3.0), which permits unrestricted use, distribution, and reproduction in any medium, provided the original work is properly cited. (cc) BY 


\section{References}

[1] Davidovits J, Davidovics M.

Geopolymer: Room-temperature ceramic matrix for composites. In: Proceedings of 12th Annual Conference on Composites and Advanced Ceramic Materials; 17-22 January 1988; Florida. pp. 835-842

[2] Davidovits J. Geopolymers: Inorganic polymeric new materials. Journal of Thermal Analysis and Calorimetry. 2005;37:1633-1656. DOI: 10.1007/ BF01912193

[3] Van Jaarsveld JGS, Van Deventer JSJ, Schwartzman A. The potential use of geopolymeric materials to immobilise toxic metals: Part II. Material and leaching characteristics. Minerals Engineering. 1999;12:75-91. DOI: 10.1016/S0892-6875(98)00121-6

[4] Komarneni S, Rustum R, Della MR, Colin AF, Gordon JK, Aksel $\mathrm{AB}$, et al. ${ }^{27} \mathrm{Al}$ and ${ }^{29} \mathrm{Si}$ magic angle spinning nuclear magnetic resonance spectroscopy of Al-substituted tobermorites. Journal of Materials Science. 1985;20:4209-4214. DOI: 10.1007/BF00552416

[5] Tsuji M, Komarneni S, Malla P. Substituted tobermorites: ${ }^{27} \mathrm{Al}$ and ${ }^{29}$ Si MASNMR, cation exchange, and water sorption studies. Journal of the American Ceramic Society. 1991;74:274279. DOI: 10.1111/j.1151-2916.1991. tb06874.x

[6] Barbosa VFF, Mac Kenzie KJD, Thaumaturgo C. Synthesis and characterisation of materials based on inorganic polymers of alumina and silica: Sodium polysialate polymers. International Journal of Inorganic Materials. 2000;2(4):309-317. DOI: 10.1016/S1466-6049(00)00041-6

[7] Granizo ML, Alonso S, Blanco-Varela MT, Palomo A. Alkaline activation of metakaolin: Effect of calcium hydroxide in the products of reaction. Journal of the American Ceramic Society. 2002;85:225-231. DOI: $10.1111 /$ j.11512916.2002.tb00070.x

[8] Hossiney N, Das P, Mothi KM, George J. In-plant production of bricks containing waste foundry sand-A study with Belgaum foundry industry. Case Studies in Construction Materials. 2018;9. DOI: 10.1016/j.cscm.2018. e00170

[9] Ugama TI, Ejeh SP. Iron ore tailing as fine aggregate in mortar used for masonry. International Journal of Advances in Engineering \& Technology. 2014;7(4):1170-1178. DOI: 10.1.1.669.8652

[10] Ullas S, Reddy BV, Rao KN. Characteristics of masonry units from iron ore tailings. In: International Conference on Sustainable Built Environment (ICSBE-2010); Kandy. 2010. pp. $108-114$

[11] Lamani SR, Aruna M, Vardhan $\mathrm{H}$, Shanth A. Development of value added product using iron ore waste for its effective utilization. International Journal of Advanced and Applied Sciences. 2015;2:30-35. DOI: http:// www.science-gate.com/IJAAS/ Articles/2015-2-12-2/06\%202015-2-12pp30-35.pdf

[12] Abdulrahman HS. Potential use of iron ore tailings in sandcrete block making. International Journal of Research in Engineering and Technology. 2015;4:409-414. DOI: https://ijret.org/volumes/2015v04/i04/ IJRET20150404073.pdf

[13] Kuranchie FA. Characterisation and applications of iron ore tailings in building and construction projects 
Utilization of Iron Ore Mines Waste as Civil Construction Material through Geopolymer Reactions DOI: http://dx.doi.org/10.5772/intechopen.81709

[Theses]. Edith Cowan University; 2015.

http://ro.ecu.edu.au/theses/1623

[14] Nagaraj H, Shreyasvi C. Compressed stabilized earth blocks using iron mine spoil waste-an explorative study. Procedia Engineering. 2017;180:1203-

1212. DOI: 10.1016/j.proeng.2017.04.281 



\title{
Survey of Bauxite Resources, Alumina Industry and the Prospects of the Production of Geopolymer Composites from the Resulting by-product
}

\author{
Sékou Traoré, A. Diarra, O. Kourouma and D.L. Traoré
}

\begin{abstract}
Guinea is endowed with huge mineral resources. Several geological surveys have identified bauxite, iron, gold, diamond, and several metal ores. Because of the diversity and the magnitude of its resources, the country is referred to as a geological scandal. Nowadays the aluminum industry is still at the quarrying stage of bauxite, the main raw material that is converted into alumina and further to aluminum. Approximately $35-40 \%$ of the processed bauxite ore goes into the waste as alkaline red mud RM slurry which consists of $15-40 \%$ solids. RM and other industrial wastes material such as fly ash FA, rice husk ash RHA, that poses environmental hazards can be mixed to make them apt for usage in engineering applications. Geopolymers GP represent a new class of materials consisting of $\mathrm{Al}_{2} \mathrm{O}_{3}-\mathrm{SiO}_{2}$-based material suitable for several engineering application. The present chapter presents the bauxitic potential of Guinea, the subsequent developing alumina industry. It reviews the application of RM for the production of geopolymer materials in the perspective of the valorization of the huge bauxite potential of Guinea.
\end{abstract}

Keywords: bauxite, red mud, silicate, activation, geopolymer, compressive strength

\section{Introduction}

Bauxite deposits in Guinea are characteristically gigantic and of higher grade than commercial deposits in other parts of the world. Out of Africa's five producer countries, only Guinea has significantly contributed to worldwide production. The only African alumina refinery is located in Fria, Guinea, and has produced about $1 \%$ of world output since the start of production in 1960. In the Bayer process for alumina production, huge quantities of the insoluble by-product called red mud RM are generated. Per ton of produced alumina, about 1-1.5 tons of bauxite RM is generated. Management of RM is a first-priority issue for all alumina plants. The high alkalinity is considered to be one of the principal reasons for the limited success until today in finding applications for RM. An application in building materials, as a component in Ordinary Portland Cement (OPC) or geopolymers, seems to 
be a straightforward approach in terms of high quantity reuse. Generally, the use of geopolymer as an alternative binder drew the attention because of its excellent properties, such as high compressive strength, resistance to acidic solutions, and thermal stability, in combination with their lower $\mathrm{CO}_{2}$ footprint [1].

The primary function of a geopolymer is to act as a binder and replace OPC in concrete manufacture or provide complementary products [2]. Some of the advantages that geopolymers have over OPC are their high compressive and flexural strength, their very high temperature resistance, a high resistance to acid, and the ability to utilize multiple waste or byproduct streams [2] Geopolymers binders have the potential to incorporate cations, anions, and organic species within their threedimensional structure. A significant ecological and marketing benefit reported for geopolymer binder over OPC is the reduction in $\mathrm{CO}_{2}$; OPC releases 0.55 ton of $\mathrm{CO}_{2}$ emissions. One ton of $\mathrm{CO}_{2}$ from the calcination of limestone and the combustion of carbon-based fuel for heat and power generation produces an average additional $0.40 \mathrm{t}$ of $\mathrm{CO}_{2}$. Comparatively, geopolymer production creates only between 0.2 and 0.5 ton of $\mathrm{CO}_{2}$ per ton of product, depending on inclusion of life cycle and transport factors [2].

\section{Bauxite potential and outlook}

Aluminum ( $\mathrm{Al})$ is the most plentiful metal in earth's crust, representing more than $7 \%$ by weight, and is the third most abundant element after silicon and oxygen. Because aluminum is highly reactive, it is mostly found in oxidized form, of which approximately 250 different minerals exist [3]. Bauxite is the main source of the world's aluminum, supplying $99 \%$ of metallic aluminum [1]. Bauxite is a member of the family of lateritic rocks. It is characterized by a particular enrichment of aluminum-hydroxide minerals, such as gibbsite, boehmite and/or diaspore. Bauxite is formed as a weathering product of low iron and silica bedrock. About $90 \%$ of bauxite resources in the world can be found in tropical areas while the rest in other latitudes have been exposed to prolonged weathering in their geological past [4]. Bauxite is the principle ore for the production of alumina and aluminum metal. Via a two-stage process that involves the refining of bauxite to alumina by the Bayer process, wet chemical caustic leach process and the electrolytic reduction of alumina to aluminum metal.

\subsection{Nature and occurrence}

Bauxite is a naturally occurring heterogeneous material and composes of one or more aluminum hydroxide minerals, principally gibbsite $\left[\mathrm{Al}(\mathrm{OH})_{3}\right]$, boehmite $[\gamma-\mathrm{AlO}(\mathrm{OH})]$ and diaspore $[\alpha-\mathrm{AlO}(\mathrm{OH})]_{4}$. In addition, other compounds are also found in bauxite such as hematite $\left[\mathrm{Fe}_{2} \mathrm{O}_{3}\right]$, goethite $[\mathrm{FeO}(\mathrm{OH})]$, quartz $\left[\mathrm{SiO}_{2}\right]$, rutile/anatase $\left[\mathrm{TiO}_{2}\right]$, kaolinite $\left[\mathrm{Al}_{2} \mathrm{Si}_{2} \mathrm{O}_{5}(\mathrm{OH})_{4}\right]$ with impurities in traces, as shows Table 1. Most commercial bauxite has a minimum $\mathrm{Al}_{2} \mathrm{O}_{3}$ content of $50-55 \%$ [5]. Based on mode of occurrence and parent rock, bauxite deposits can be subdivided into two major groups.

- Alumina-rich or lateritic bauxite, resulting from the weathering of rocks containing alumina.

- Terra rossa, occurring as a weathered residue on, or closely associated, with limestone and dolomite. The relatively mobile ions, including alkalis, alkali earths and silica, are leached out leaving a residue of aluminum and iron hydroxides, titania and other insoluble materials 


\subsection{Bauxite mining and alumina industry in Guinea}

Several concepts are used to define the content of a geological deposit: resource, reserve, potential, etc. No matter definitions used, taking into account its identified bauxite deposits both in tonnage and grade, it appears from all studies that Guinea is the country the most endowed with bauxite in the world [6]. The country account for more than one-third of the world's known reserves.

As shows Table 2 its potential is about 40 billion tons. Its production of bauxite, sourced from three mines located at Sangarédi, Kindia and Fria, is among the largest in the world. At present, crude bauxite and alumina constitute about $60 \%$ of Guinea's exports and generate a quarter of its tax revenues [8].

However, Guinea has not realized the full potential of its mineral resources. Annual production of bauxite is very low considering the proven reserves. A comparison of the country's bauxite reserves and production pattern with other major world producers shows that whereas Guinea has the largest known bauxite reserves in the world it has the lowest alumina to bauxite production ratio of all the major bauxite and alumina producing countries. The country has only one alumina refinery plant which has a production capacity of about 0.6 million tons, hence, more than $95 \%$ of the bauxite is exported raw. Among others a reason for the poor performance of the sector is insufficient emphasis on local transformation. Power supply constraints and a generally weak investment climate are other possible reasons for low growth in the sector [8]. Power supply, which is vital to production of alumina and aluminum, is a major constraint in Guinea. Poor transport infrastructure and lack of human capital and organizational capacity are also serious concerns. Figure 1 shows a train transporting bauxite from Débélé (Kindia) on a distance of $130 \mathrm{~km}$ to the Port of Conakry.

\begin{tabular}{ll}
\hline Name & Composition \\
\hline Gibbsite & $\gamma$-AI(OH $\mathrm{OH}_{3} \alpha-\mathrm{Al}_{2} \mathrm{O}_{3} \cdot 3 \mathrm{H}_{2} \mathrm{O}$ \\
\hline (Hydrargillite) & $\gamma$-AIOOH, $\alpha-\mathrm{AhO}] . \mathrm{H}$ \\
\hline Boehmite & $\gamma$-AIOOH, $\alpha-\mathrm{Al}_{2} \mathrm{O}_{3} \cdot 3 \mathrm{H}_{2} \mathrm{O}$ \\
\hline Diaspore & $\alpha-\mathrm{AIOOH}_{2} \beta-\mathrm{Al}_{2} \mathrm{O}_{3} \cdot 3 \mathrm{H}_{2} \mathrm{O}$ \\
\hline Hematite & $\alpha-\mathrm{Fe}_{2} \mathrm{O}_{3}$ \\
\hline Goethite & $\alpha-\mathrm{FeOOH}$ \\
\hline Magnetite & $\alpha-\mathrm{Fe}_{3} \mathrm{O}_{4}$ \\
\hline Siderite & $\mathrm{FeCO}_{3}$ \\
\hline Ilmenite & $\mathrm{FeOTiO}_{3}$ \\
\hline Anatase & $\mathrm{TiO}_{2}$ \\
\hline Rutile & $\mathrm{TiO}_{2}$ \\
\hline Brookite & $\mathrm{TiO}_{2}$ \\
\hline Halloysite & $\mathrm{Al}_{2} \mathrm{O}_{3} \cdot 2 \mathrm{SiO}_{2} 3 \mathrm{H}_{2} \mathrm{O}$ \\
\hline Kaolinite & $\mathrm{Al}_{2} \mathrm{O}_{3} \cdot 2 \mathrm{SiO}_{2} 2 \mathrm{H}_{2} \mathrm{O}$ \\
\hline Quartz & $\mathrm{SiO}_{2}$ \\
\hline
\end{tabular}

Table 1.

Main minerals of bauxite deposits [5]. 


\begin{tabular}{|c|c|c|c|c|c|c|c|}
\hline Location & $\begin{array}{l}\text { Nr of } \\
\text { bowe }\end{array}$ & $\begin{array}{c}\text { Proven and } \\
\text { probable } \\
\text { reserves }\end{array}$ & $\begin{array}{l}\text { Measured } \\
\text { resources }\end{array}$ & $\begin{array}{l}\text { Indicated } \\
\quad \text { and } \\
\text { supposed } \\
\text { resources }\end{array}$ & $\begin{array}{c}\text { Total } \\
\text { identified } \\
\text { resources and } \\
\text { reserves }\end{array}$ & $\begin{array}{c}\text { Extra } \\
\text { forecasted } \\
\text { resources }\end{array}$ & $\begin{array}{c}\text { Bauxite } \\
\text { potential }\end{array}$ \\
\hline Boké & 94 & 913 & 1945 & 3053 & 5911 & 322 & 8233 \\
\hline $\begin{array}{l}\text { Kogon- } \\
\text { Tominé }\end{array}$ & 144 & & 2893 & 7238 & 10,129 & 1593 & 11,722 \\
\hline Fatala & 115 & 62 & 201 & 1450 & 1713 & 4615 & 6328 \\
\hline $\begin{array}{l}\text { Débélé- } \\
\text { Kindia }\end{array}$ & 49 & 157 & 23 & 69 & 249 & 126 & 375 \\
\hline Mali & 67 & & 277 & 225 & 502 & 622 & 1124 \\
\hline Labé & 85 & & 320 & 2225 & 2545 & 239 & 2784 \\
\hline $\begin{array}{l}\text { Dalaba- } \\
\text { Mamou }\end{array}$ & 57 & & & 455 & 465 & 859 & 1324 \\
\hline $\begin{array}{l}\text { Donghol- } \\
\text { Sigon }\end{array}$ & 49 & & 703 & 982 & 1685 & 272 & 1957 \\
\hline Balin-Ko & 28 & & & 927 & 927 & & 927 \\
\hline Tougué & 111 & 1428 & 925 & 1219 & 3572 & 791 & 4363 \\
\hline Dabola & 64 & 617 & 95 & 740 & 1458 & 855 & 690 \\
\hline $\begin{array}{l}\text { Bafing- } \\
\text { Tinkisso }\end{array}$ & 39 & & & 89 & 89 & 601 & \\
\hline $\begin{array}{l}\text { Littoral- } \\
\text { Islands* }\end{array}$ & 4 & 9 & & 39 & & & \\
\hline Total & 894 & 3178 & 7, 398 & 18,686 & 29,245 & 10,895 & 40,139 \\
\hline
\end{tabular}

Table 2.

Bauxite potential of Guinea (billions of tones) [6, 7].

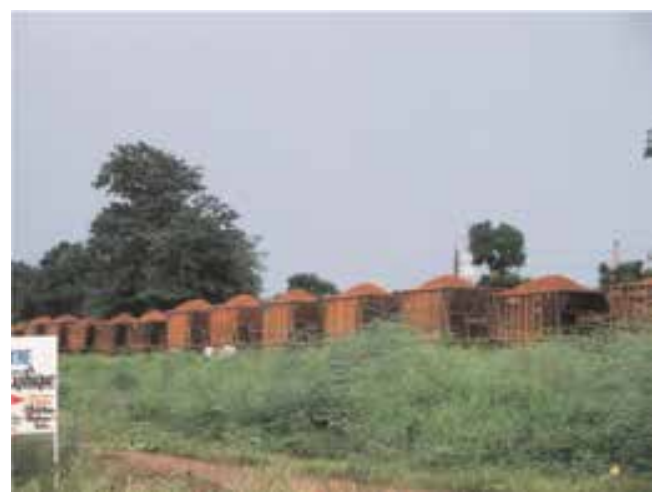

Figure 1.

Bauxite train of the $C B K$.

The bauxite and alumina industry is dominated by three producers: Alumina Compagnie de Guinée (ACG), Compagnie des Bauxites de Guinée (CBG), and Compagnie des Bauxites de Kindia (CBK). CBK and ACG are controlled by the Russian aluminum giant RUSAL. CBG is a joint venture between the American aluminum firm Alcoa Inc., the Canadian aluminum firm Alcan Inc., and the government of Guinea. Its main export markets are North America and Europe. These 
two corporation networks the Russian possessions (Fria and Débélé) and the USAmerican and Australian (CBG in Sangaredi and Kamsar) form two business decision spaces that overlay with the official political structure in Guinea.

The alumina refinery plant ACG in Fria converts bauxite into alumina by the Bayer process summarized in as follows.

\subsubsection{The Bayer process}

The Bayer process is the name for the hydrometallurgical extraction and refinement of alumina from bauxite. Bauxite ore is ground and then digested in highly caustic solutions at elevated temperatures.

$$
\begin{aligned}
& 2 \mathrm{NaOH}+\mathrm{SiO}_{2} \longrightarrow \mathrm{Na}_{2} \mathrm{SiO}_{3}+\mathrm{H}_{2} \mathrm{O} \\
& \mathrm{Na}_{2} \mathrm{SiO}_{2}+\mathrm{Al}_{2} \mathrm{O}_{3} \longrightarrow \mathrm{Na}_{2} \mathrm{O} \cdot \mathrm{Al}_{3} \mathrm{SiO}_{2}
\end{aligned}
$$

The basic digestion reaction is the following:

$$
\mathrm{Al}_{2} \mathrm{O}_{3} \cdot \mathrm{XH}_{2} \mathrm{O}+2 \mathrm{NaOH} \stackrel{135-145^{\circ} \mathrm{C}}{\longrightarrow} 2 \mathrm{NaAlO}+(\mathrm{x}+1) \mathrm{H}_{2} \mathrm{O}
$$

Depending on the specific raw mineral:

$$
\begin{aligned}
& 135-145^{\circ} \mathrm{C} \\
& \text { Gibbsite } \mathrm{Al}_{2} \mathrm{O}_{3} \cdot 3 \mathrm{H}_{2} \mathrm{O}+2 \mathrm{NaOH} \underset{(\gamma \mathrm{AI}(\mathrm{OH} 3)}{\stackrel{(}{\longrightarrow}} 2 \mathrm{NaAlO}_{2}+4 \mathrm{H}_{2} \mathrm{O} \\
& \text { Boehmite } \mathrm{Al}_{2} \mathrm{O}_{3} \cdot \mathrm{H}_{2} \mathrm{O}+2 \mathrm{NaOH} \underset{(\gamma \mathrm{AIO} . \mathrm{OH})}{\stackrel{205-245^{\circ} \mathrm{C}}{\longrightarrow}} 2 \mathrm{NaAlO}_{2}+2 \mathrm{H}_{2} \mathrm{O} \\
& \text { Diaspore } \mathrm{Al}_{2} \mathrm{O}_{3} . \mathrm{H}_{2} \mathrm{O}+2 \mathrm{NaOH} \frac{\text { High temper }}{\begin{array}{c}
(\alpha \mathrm{AlO} . \mathrm{OH}) \\
\text { High pressure }
\end{array}} 2 \mathrm{NaAlO}_{2}+2 \mathrm{H}_{2} \mathrm{O}
\end{aligned}
$$

Crystalline alumina hydrate is extracted from the digestion liquor by hydrolysis.

$$
2 \mathrm{NaAlO}_{2}+4 \mathrm{H}_{2} \mathrm{O} \longrightarrow \mathrm{Al}(\mathrm{OH})_{3}+2 \mathrm{NaOH}
$$

Gangue solids, usually iron oxides, quartz, and other resistant minerals, are separated from the hot sodium aluminate slurry by physical means such as settling and filtration. The solids (red mud and red sand) are countercurrent washed to recover the caustic solutions, then pumped to specially designed impoundment beds. The mud and sand can be intercepted, neutralized, washed, and stored for reuse [2]. The chemical reactions leading to the alumina as final product are given above.

\subsubsection{Red mud}

According to the composition of the parent bauxite and technology applied for processing, the derived $\mathrm{RM}$ contains mainly of different amounts of $\mathrm{Fe}_{2} \mathrm{O}_{3}, \mathrm{Al}_{2} \mathrm{O}_{3}$, $\mathrm{SiO}_{2}, \mathrm{TiO}_{2}, \mathrm{CaO}$, and $\mathrm{Na}_{2} \mathrm{O}$.

The high alkalinity is considered to be one of the principal reasons for the limited success until today in finding applications for RM. Growing awareness has led to a multitude of studies and semi-industrial trials related to the recycle or valorization 
of RM as a raw material for different industrial applications. An application in building materials, as a component in OPC, filler material, or geopolymers, seems to be a straightforward approach in terms of high quantity reuses [1]. Generally, the use of geopolymer as an alternative binder drew the attention because of its excellent properties, such as high compressive strength, resistance to acidic solutions, and thermal stability, in combination with their lower $\mathrm{CO}_{2}$ footprint [7].

The quantity of alumina produced from bauxite ore depends on the type and the composition of the bauxite ore. Generally authors agree that 1 ton of alumina is produced from 3 ton of bauxite [9]. In average the RM generated per ton of alumina varies between 1 and 1.5 tons, although the amounts from different industrial companies are much broader; it is estimated that over 150 million tons of bauxite residue are produced annually. The quantity of bauxite residue generated at a particular refinery is governed by the processing conditions and bauxite quality [10]. The global inventory of RM stored on land currently is estimated to be over 2.7 billion tons, with an annual growth rate of over 120 million tons.

Over the ACG's 30 years of existence, the quantity of RM produced may very well exceed 20 million metric tons. It should be mentioned that up until the end of the 1980's this mud was simply dumped in the Konkouré river which flows not far from the plant [11].

Figure 2 is a schema allowing the assessment of the accurate amount of alumina and the resulting RM obtainable from crude bauxite.

Bauxite mining and processing have a strong and varied impact on the environment because they entail modifications of the landscape and severe pollution by rejecting wastes into the biosphere (soil, the atmosphere and the water) [13]. Among others RM causes: (i) contamination of water resources with caustic soda and metallic oxide-bearing impurities; (ii) direct contact with fauna and flora;

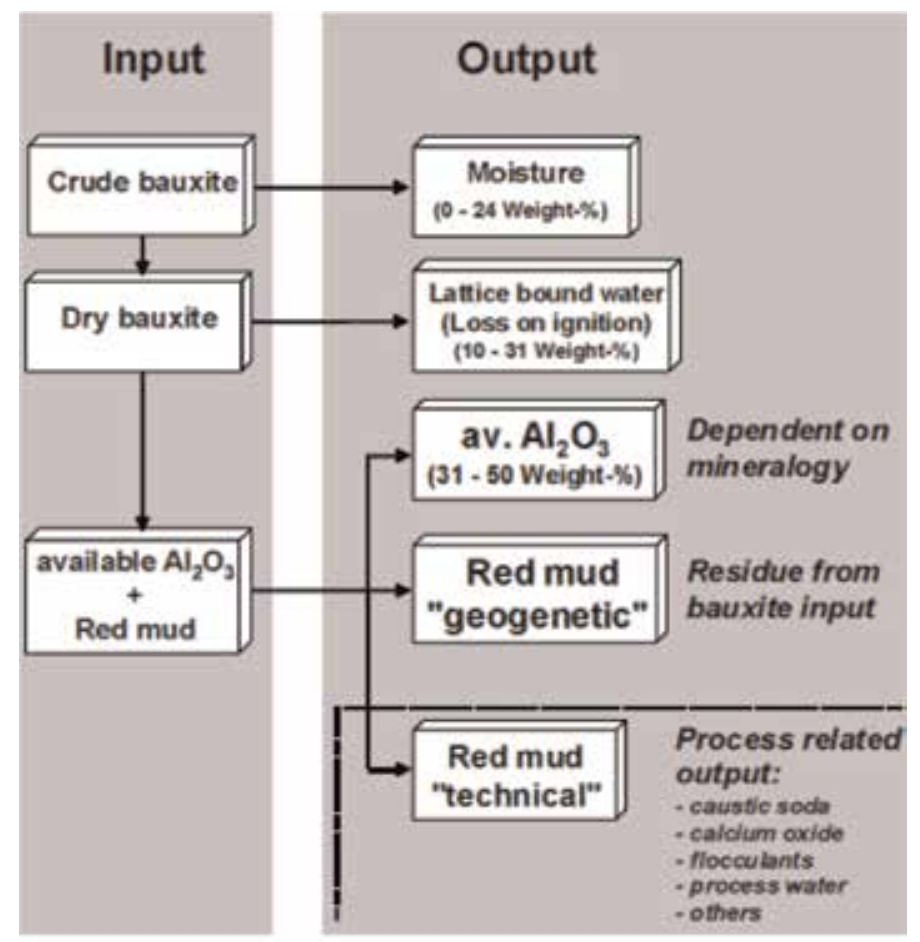

Figure 2.

Calculation scheme for the amount of alumina and red mud that turn out during alumina refinery using chemical and mineralogical data [12]. 
(iii) evaporation that could originate highly alkaline rainfalls; (iv) visual impact on extensive areas [14].

Chemical analysis shows that red mud contains silicium, aluminum, iron, calcium, titanium, sodium as well as an array of minor elements namely $\mathrm{K}, \mathrm{Cr}, \mathrm{V}, \mathrm{Ba}$, $\mathrm{Cu}, \mathrm{Mn}, \mathrm{Pb}, \mathrm{Zn}, \mathrm{P}, \mathrm{F}, \mathrm{S}$, As and etc. [9]. The variation in chemical composition between red mud worldwide is high. The major chemical composition of red mud for selected countries over the world is presented in Table 2. Chemical analysis shows that red mud contains silicon, aluminum, iron, calcium, titanium, sodium as well as an array of minor elements namely $\mathrm{K}, \mathrm{Cr}, \mathrm{V}, \mathrm{Ba}, \mathrm{Cu}, \mathrm{Mn}, \mathrm{Pb}, \mathrm{Zn}, \mathrm{P}, \mathrm{F}, \mathrm{S}$. As and etc. The variation in chemical composition between red mud worldwide is high [9]. The major chemical composition of red mud for selected countries over the world is presented in Table 3.

ACG plant rejects 1 ton of mud per ton of alumina produced and that each ton of mud contains on average 15 kilograms of caustic soda $(\mathrm{NaOH})$ which has not been recovered by washing [11]. Moreover this mud is composed on average of $60 \%$ iron ore $\left(\mathrm{Fe}_{2} \mathrm{O}_{3}\right)$, lime $\left(\mathrm{CaCO}_{3}\right)$ with traces of titanium $\left(\mathrm{TiO}_{2}\right)$. Table 2 shows that $\mathrm{RM}$ from ACG/Fria has the highest $\mathrm{Fe}_{2} \mathrm{O}_{3}$ content and the lowest $\mathrm{Al}_{2} \mathrm{O}_{3}$ one [10].

\subsubsection{Prospects for the valorization of $R M$}

The increasing need of the industry sectors involving aluminum as metal, entailed the improvement of the Bayer process and the subsequent issue of the management of RM. Despite several years of research on the possible valorization of this waste, there is almost no evidence of a large-scale application of this industrial waste to date. Globally research efforts are focused on three fields for the valorization or reuse of RM:

- Civil and chemical engineering applications.

- Mechanical engineering and Metallurgical applications.

- Ecological and biological production purposes.

\begin{tabular}{lccccccc}
\hline \multirow{2}{*}{ Country } & Plant & \multicolumn{7}{c}{ Major composition (\%) } \\
\cline { 3 - 8 } & & $\mathrm{Fe}_{2} \mathrm{O}_{3}$ & $\mathrm{Al}_{2} \mathrm{O}_{3}$ & $\mathrm{TiO}_{2}$ & $\mathrm{SiO}_{2}$ & $\mathrm{NaO}_{2}$ & $\mathrm{CaO}$ \\
\hline Australia & AWAAK & 28.5 & 24.0 & 3.11 & 18.8 & 3.4 & 5.26 \\
\hline Brazil & Alunorte & 45.6 & 15.1 & 4.29 & 15.6 & 7.5 & 1.16 \\
\hline Canada & ALCAN & 31.60 & 20.61 & 6.23 & 8.89 & 10.26 & 1.66 \\
\hline France & Pechiney & 26.62 & 15.0 & 15.76 & 4.98 & 1.02 & 22.21 \\
\hline Germany & AOSG & 44.8 & 16.2 & 12.33 & 5.4 & 4.0 & 5.22 \\
\hline Guinea & ACG/Fria & 53.89 & 14.68 & - & 7.06 & - & 2.1 \\
\hline Guinea & Pt Comfort/Texas/US & 40 & 18 & - & 9.6 & 2.7 & 7.6 \\
\hline Italy & Eurallumina & 35.2 & 20 & 9.2 & 11.6 & 7.5 & 6.7 \\
\hline Spain & Alcoa & 37.5 & 21.2 & 11.45 & 4.4 & 3.6 & 5.51 \\
\hline Turkey & Seydisehir & 36.94 & 20.39 & 4.98 & 15.74 & 10.10 & 2.23 \\
\hline UK & ALCAN & 46.0 & 20.0 & 6.0 & 5.0 & 8.0 & 1.0 \\
\hline USA & RMC & 35.5 & 18.4 & 6.31 & 8.5 & 6.1 & 7.73 \\
\hline
\end{tabular}

Table 3.

Chemical composition of red mud generated in alumina plants in various countries adapted from [13]. 
This chapter addresses specifically the use of RM for the production of geopolymers for construction and other engineering applications.

\subsubsection{Suitability of $R M$ for the production of $G P$}

A polymer is a macromolecule, organic or inorganic, consisting of the repeated sequence of the same pattern, the monomer (from Greek monos: one or only one, and meros: part), connected to each other by covalent bonds. In the following macromolecule $\mathrm{A}-\mathrm{A}-\mathrm{A}-\mathrm{A}-\mathrm{A}-\mathrm{A}-\mathrm{A} \ldots=[-\mathrm{A}-]$. The constituent unit is $\mathrm{A}$; it is formed of a group of atoms that repeats itself. At the molecular level, most macromolecules are in the form of "long and flexible thread". The chemical reactions allowing to pass from a monomer $\mathrm{A}$ to the macromolecule $[-\mathrm{A}-]$ are called polymerization.

Geopolymer is a class of inorganic polymers generally formed by the chemical reaction between silica-rich and alumina-rich solids with a high alkaline solution. It is assumed that they result from the dissolution of alumina and silica into a silicate solution occurring the polycondensation of these monomers into aluminosilicate anions.

The general formula of polymer $\mathrm{A}-\mathrm{A}-\mathrm{A}-\mathrm{A}-\mathrm{A}-\mathrm{A}-\mathrm{A} \ldots=[-\mathrm{A}-]$ corresponds to $\mathrm{M}+\mathrm{n}\left[-\left(\mathrm{SiO}_{2}\right) \mathrm{z}-\mathrm{AlO}_{2}-\right] \mathrm{n}$ in geopolymer chemistry. A monomer $\mathrm{A}$ is equivalent to ( $-\mathrm{Si}-\mathrm{O}-\mathrm{Al}-\mathrm{O}-)$, poly-sialate-siloxo ( $-\mathrm{Si}-\mathrm{O}-\mathrm{Al}-\mathrm{O}-\mathrm{Si}-\mathrm{O}-)$, or poly-sialate-disiloxo (- $\mathrm{Si}-\mathrm{O}-\mathrm{Al}-\mathrm{O}-\mathrm{Si}-\mathrm{O}-\mathrm{Si}-\mathrm{O}-$ ). As shows Table 2, the $\mathrm{RM}$ from the ACG plant in Fria contains about $15 \% \mathrm{Al}_{2} \mathrm{O}_{3}$. In the chapter below the role of $\mathrm{Al}_{2} \mathrm{O}_{3}$ as precursor or monomers provider in geopolymerization will be highlighted. Taking into account the country's bauxite reserves and the subsequent quantity of RM resulting from it processing into alumina, geopolymer production may be a serious option for Guinea for the valorization of RM.

\section{Geopolymerization}

The GP technology has recently attracted increasing attention as a viable solution to reuse and recycle industrial solid wastes and by-products. It provides a sustainable and cost-effective development for many issues where hazardous residues have to be treated and stored under critical environmental conditions [15]. Generally, materials containing mostly amorphous silica $\left(\mathrm{SiO}_{2}\right)$ and alumina $\left(\mathrm{Al}_{2} \mathrm{O}_{3}\right)$ are a possible source for GP production. Furthermore Geopolymers appear to be a potential alternative to the classic hydraulic binders. Some research studies have been carried on to produce alkali-activated materials from RM. Due to Its low reactivity and low $\mathrm{SiO}_{2} / \mathrm{Al}_{2} \mathrm{O}_{3}$ molar ratio $(<2.0)$, it has been combined with other higher grade precursors such as metakaolin and metakaolin to prepare alkaliactivated materials using sodium hydroxide $(\mathrm{NaOH})$ and sodium silicate as alkaline activators solutions. The authors obtained $10.8 \mathrm{MPa}$ compressive strength after 28 days curing [16].

\subsection{Classification of Geopolymers}

Bragg used a method based on the theory of distinct silicate or aluminate anions as the basic unit of constitution. This central unit is a tetrahedral complex consisting of a small cation such as $\mathrm{Si}$ or $\mathrm{Al}$ that lies in tetrahedral coordination with 4 oxygen anions to produce $\mathrm{SiO}_{4}$ or $\mathrm{AlO}_{4}$. The silicon-oxygen bond should never be ionic; it should be polar and covalent [5]. This is since specific silicon and oxygen atoms Cannot move at liberty within the crystalline structure. Covalent bonding is more 
general and holds for silicates, $\mathrm{Al}-\mathrm{Si}$ (such as zeolites), alumino-phosphates and geopolymers. Aluminosilicate based geopolymers such as polysialate consist of $\mathrm{SiO}_{4}$ and $\mathrm{AlO}_{4}$ tetrahedra which are linked alternatively by sharing all the oxygen atoms [5]. Alkali-activated binders have either amorphous or nanocrystalline microstructures. This depends on the amount of alumino-silicate content in the precursor materials and on the mineralogical nature mineralogy of raw materials [17]. Depending on the composition of the starting materials, alkali-activated binders can be divided into two groups as shows Figure 3:

- Alkaline earth binding systems: $\mathrm{Me}_{2} \mathrm{O}-\mathrm{MeO}-\mathrm{Me}_{2} \mathrm{O}_{3}-\mathrm{SiO}_{2}-\mathrm{H}_{2} \mathrm{O}$, the typical example of this group is alkali-activated blast furnace slag OPC.

- Alkaline binding system: $\mathrm{Me}_{2} \mathrm{O}-\mathrm{Me}_{2} \mathrm{O}_{3}-\mathrm{SiO}_{2}-\mathrm{H}_{2} \mathrm{O}$, the typical example of this group is alkali-activated metakaolin or fly ash OPC [3].

Glukhovsky classified the alkaline activators in six groups, where $\mathrm{M}$ is an alkali ion: alkalis, $\mathrm{MOH}$; weak acid salts, $\mathrm{M}_{2} \mathrm{CO}_{3}, \mathrm{M}_{2} \mathrm{SO}_{3}, \mathrm{M}_{3} \mathrm{PO}_{4}$, and $\mathrm{MF}$; silicates, $\mathrm{M}_{2} \mathrm{O}$. nSiO ${ }_{3}$; aluminates, $\mathrm{M}_{2} \mathrm{O}$. $\mathrm{nAl}_{2} \mathrm{O}_{3}$; aluminosilicates, $\mathrm{M}_{2} \mathrm{O} \cdot \mathrm{Al}_{2} \mathrm{O}_{3}$. (2-6) $\mathrm{SiO}_{2}$ and strong acid salts, $\mathrm{M}_{2} \mathrm{SO}_{4}$ [18]. Further $\mathrm{GP}$ are broadly classified as acid activated and alkali activated geopolymers as shown in Figure 1. Acid activated geopolymers were recently introduced, having properties comparable to alkali activated materials e.g. phosphoric acid activated metakaolin produced $30 \%$ higher cold crushing strength than their alkali activated counterparts [19]. The higher porosity of this group of polymers suggested their possible application in waste water treatment and as an adsorbent [20]. Acid activated geopolymers have not been explored and further research in this field is required. Alkali activated GP are materials of special interest in the past four decades due to their superior properties compared to OPC. Based on the alumino silicate matrix they are classified as sialate, sialate silaxo and sialate di silaxo.

\subsection{Raw materials for geopolymer production}

Starting materials are checked for pozzolanic content i.e. $\mathrm{SiO}_{2}+\mathrm{Al}_{2} \mathrm{O}_{3}$. With the advanced mixing technologies, mix design comprised of pozzolanic and semi pozzolanic waste materials have been reported. The base materials found to be suitable

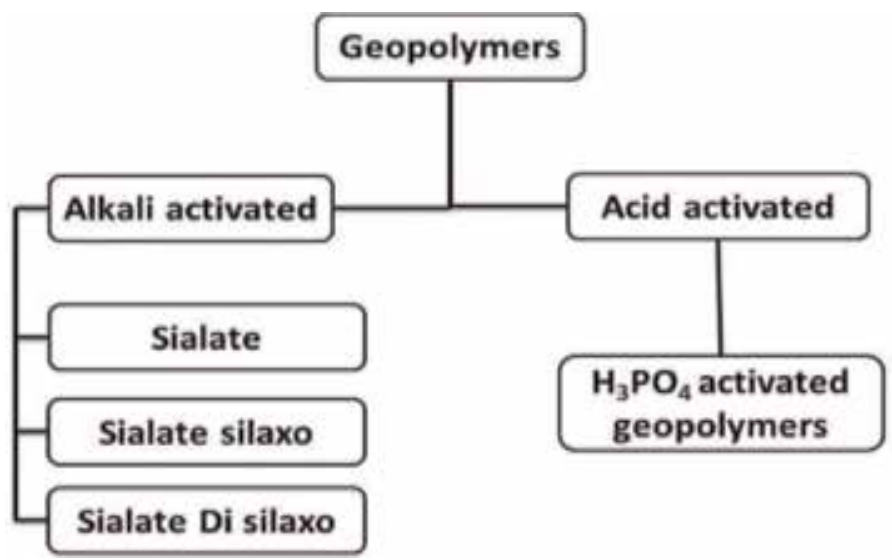

Figure 3.

Classification of Geopolymers [17]. 
comprise natural minerals such as metakaolin, clays, which contains $\mathrm{Si}, \mathrm{Al}$ and oxygen in their chemical composition [16]. By-product from other industries such as fly ash, silica fume, slag, rice-husk ash red mud ( $\int$ I.3.1.), etc. could be utilized alternatively as the source materials. Disposal, price, application and demand of the users are the main factors in the process of the selection of source materials [4].

In order to obtain a GP with desired properties e.g. high strength, low shrinkage, high acid resistance or low cost, a range of ratios need to be controlled: $\mathrm{Si} / \mathrm{Al}$ ratio; $\mathrm{Na} / \mathrm{Si}$ and $\mathrm{K} / \mathrm{Si}$ ratio and water to solid ratio. It is therefore of major importance to characterize the aluminosilicate source and to determine their reactivity, in order to be able to evaluate the amount silicates and aluminates reacting. It should be noted that the particles size distribution or fineness is of importance regarding the reactivity of the aluminosilicate source. The mix can then be optimized by adjusting the type and the amount activators added.

Most of the investigations have used alkali solutions for dissolution of raw materials to form the reactive precursors necessary for geopolymerization. It has been shown that silicate activation increases the dissolution of the starting materials and gives rise to favorable mechanical properties [21].

. Two groups of materials are required to make a geopolymer; one is source materials containing alumina and silica and other is an alkali that activates the polymerization reaction. Basing on their origin materials of the first group are natural or industrial (mainly by-products).

\subsubsection{Natural minerals: Kaolinite, calcined kaolinite (metakaolin) and clays}

- Kaolinite (microsilica): is a clay mineral having the chemical composition $\mathrm{Al}_{2} \mathrm{Si}_{2} \mathrm{O}_{5}(\mathrm{OH})_{4}$ Rocks that are rich in kaolinite are known as kaolin or china clay. Kaolinite is a clay mineral with the chemical composition $\mathrm{Al}_{2} \mathrm{~S}_{2} \mathrm{O}_{5}(\mathrm{OH})_{4}$, which means each particle has one tetrahedral silica layer and one octahedral alumina layer [15]. It is a soft, earthy, usually white mineral, produced by the chemical weathering of aluminum silicate minerals like feldspar. Rocks that are rich in kaolinite are known as china clay, white clay, or kaolin. Kaolin is a fine, white, clay mineral that has been traditionally used in the manufacture of porcelain.

- Metakaolin is a dehydroxylated form of the clay mineral kaolinite in the temperature range of $500-800^{\circ} \mathrm{C}$. It is a highly pozzolanic and reactive material. Kaolinite is a clay mineral with the chemical composition $\mathrm{Al}_{2} \mathrm{Si}_{2} \mathrm{O}_{5}(\mathrm{OH})_{4}$, which means each particle has one tetrahedral silica layer and one octahedral alumina layer. It is a soft, earthy, usually white mineral, produced by the chemical weathering of aluminum silicate minerals like feldspar.

\subsubsection{Industry wastes}

- Fly ash: fly ash is defined as the finely divided residue that results from the combustion of ground or powdered coal and that is transported by flue gasses from the combustion zone to the particle removal system. The characteristics of fly ash are loss on ignition (LOI), fineness and uniformity. LOI is a measurement of unburnt carbon remaining in the ash. Finer gradation generally results in a more reactive ash and contains less carbon. Fly ash is a very fine, powdery material, composed mostly of silica. It consists mostly of silt-sized and clay-sized glassy spheres. These are generally spherical in shape and range in size from 0.5 to $100 \mu \mathrm{m}$ [20]. They consist mostly of $\mathrm{SiO}_{2}$, which 
is present in two forms: amorphous, which is rounded and smooth, and crystalline, which is sharp, pointed and hazardous. Three classes of fly ash are defined by ASTM C 618; Class N fly ash, Class F fly ash, and Class C fly ash [15]. The chief difference between these classes is the amount of calcium, silica, alumina, and iron content in the ash.

- Red mud: RM (see $\int$ I.3.1.) is characterized by strong basicity even with a high water content, because of the presence of huge amount of sodium hydroxide used to extract silicates and alumina. Figure 4(a) shows oven dried RM, Figure 4(b) grounded RM; its color is due to the $\mathrm{Fe}_{2} \mathrm{O}_{3}$ or $\mathrm{Fe}_{3} \mathrm{O}_{4}$, which can make up to $60 \%$ of the mass of the RM.

- Rice-husk ash: Rice husk is the natural sheath that forms on rice grain during its growth. Removed during the refining of rice, the rice husk ash RHA is generated after burning the rice husk in the boiler. At present, the most common method of disposal of RHA is dumping on waste land, thus creating an environmental hazard through pollution and land dereliction problems. The major compounds from rice husk are silica and cellulose which yields carbon when thermally decomposed [22]. Rice husk is unusually high in ash compared to other biomass fuels, close to $20 \%$. The ash is $92-95 \%$ silica, highly porous and light weight, with a very external surface area RHA is an active pozzolan which when combined with line in the presence of water results in a stable and more amorphous hydrate (calcium silicate). Rice husk is unusually high in ash compared to other biomass fuels-close to 20\%. Figure 4(c) shows RHA after burning of RH at ambient temperature. At higher temperatures the RHA color tends to white and its Si content increases.

This is stronger, less permeable and more resistant to chemical attack. Due to its insulating properties, RHA has been used in the manufacture of refractory bricks. Recently RHA has been incorporated in activated aluminosilicates.

- Catalyst residues: Petroleum refineries worldwide process crude oil in fluid catalytic cracking (FCC) units, and 160,000 tons of spent FCC catalyst residue are thus produced every year [23]. The spent catalyst is essentially an agglomeration of zeolite (faujasite) crystals held together by an aluminosilicate matrix including amorphous silica and clays. However, in using this type of residue as a precursor in alkali-activation, it is important to consider the significant heavy metal content of the catalysts, particularly nickel, vanadium and/or lanthanum, as these may impact the performance of the geopolymer materials, and are also potentially leachable under some conditions. Catalysts

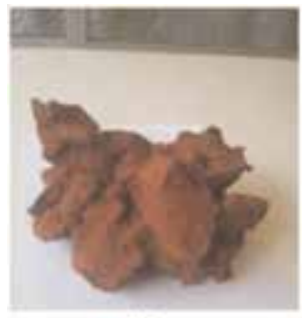

(a)

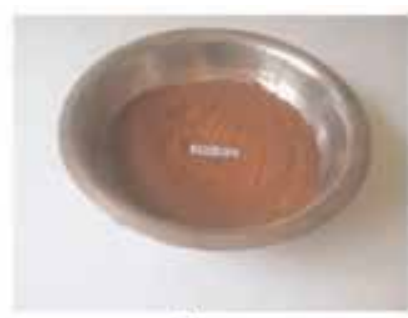

(b)

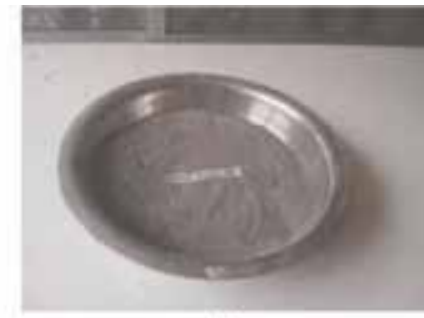

(c)

Figure 4 .

(a) RM oven dried (b) RM ground (c) rice husk ash. 
from different sources and processes also differ in composition and reactivity, meaning that this is rather a diverse class of materials which can provide alkaliactivated products with a range of performance levels [24].

- Ground Granulated Blast furnace Slag (GGBS): Ground-granulated blastfurnace slag is obtained by quenching molten iron slag from a blast furnace in water or steam, to produce a glassy, granular product that is then dried and ground into a fine powder [19]. The main components of blast furnace slag are $\mathrm{CaO}(30-50 \%), \mathrm{SiO}_{2}(28-38 \%), \mathrm{Al}_{2} \mathrm{O}_{3}$ (8-24\%), and $\mathrm{MgO}$ (1-18\%). In general, increasing the $\mathrm{CaO}$ content of the slag results in raised slag basicity and an increase in compressive strength. The $\mathrm{MgO}$ and $\mathrm{Al}_{2} \mathrm{O}_{3}$ content show the same trend up to respectively $10-12 \%$ and $14 \%$, beyond which no further improvement can be obtained [25]. GGBS has now effectively replaced sulfateresisting OPC on the market for sulfate resistance because of its superior performance and greatly reduced cost.

\subsubsection{Particle size and reactivity of raw materials}

Particle size of the raw materials is also important factors in geopolymerization. Finer particle sizes of the RHA improve its reactivity and thereby higher degree of geopolymerization can be achieved. The finer the particle size the stronger the geopolymer [26]. Higher degree of geopolymerization makes the resulting geopolymer more ductile and stronger. As the particle size of the RHA decrease the surface area increase [27]. The increased surface area also results in the formation of more ductile and stronger geopolymers. This suggests that the mechanical properties of geopolymers are depending upon the physical property, the particle size of the raw materials. The strength of geopolymer mortars are affected by the fineness of RHA. The increase in the fineness of RHA increases its reactivity and strength of mortars. RHAs with 1-5\% retained on No. 325 sieve are suitable for making geopolymer mortars.

\subsubsection{Activating alkali solutions}

The efficiency of the alkali activation process of geopolymers is very much dependent on the addition of chemical activators (sodium/potassium hydroxide, soluble silicates, etc.) and also the curing regime (heat treatment) employed on the hardened geopolymer concrete [6]. Strength development of geopolymers fabricated without the addition of chemical activators or subsequent heat treatment is very slow, particularly during the early stages.

The most common alkaline liquid used in geo-polymerization is a combination of sodium hydroxide $(\mathrm{NaOH})$ or potassium hydroxide $(\mathrm{KOH})$ and sodium silicate or potassium silicate [28].

Besides the aluminosilicate as raw material an alkaline activator is required to produce a geopolymer. The alkali component used as an activator is a compound from the elements of the first group in the periodic table. The common activators can be classified as follows:

- Alkali metal hydroxide: $\mathrm{NaOH}, \mathrm{KOH}, \mathrm{LiOH}$.

- Alkali metal silicate (AMS) $\mathrm{Na}_{2} \mathrm{SiO}_{3}, \mathrm{~K}_{2} \mathrm{SiO}_{3}$.

- Alkali metal hydroxide silicate: $\mathrm{Na}_{2} \mathrm{SiO}_{3}+\mathrm{NaOH}$. 
- Metal aluminate $\mathrm{NaAlO}_{2}$.

- Metal carbonate $\mathrm{Na}_{2} \mathrm{CO}_{3}$.

The Alkalinity of the solution is a widely investigated factor and the most significant factor controlling the compressive strength of geopolymer concrete. High alkalinity of the solution accelerates the dissolution of the raw materials, which shortens the setting time. It also enhances the compressive strength of geopolymers. The higher the alkaline concentration is, the higher the compressive strength is obtained.

\subsection{Concept and chemical mechanism of geopolymerization}

Geopolymer is an inorganic polymer with $\mathrm{SiO}_{4}$ and $\mathrm{AlO}_{4}$ tetrahedra being the structural units [29]. Geopolymers composites are also defined as an Al- and Si-rich cementitious, amorphous binder, which is formed by polymerization of an alkali activated solid aluminosilicate precursor [30]. Geosynthesis is based on the ability of the aluminum ion to induce crystallographical and chemical modifications in a silica backbone. Usually polymerization reaction takes place in organic compounds, due to the tetra valancy of the carbon atom. Geopolymerization is an inorganic polymerization. It consists of dissolution and hydrolysis followed by a condensation step in an alkaline silicate plus alumino-silicate system. The chemistry of geopolymerization is similar with the synthesis of zeolites, although the resultant products are different in composition and structure [31]. It consists of chains or a 3D framework of linked $\mathrm{AlO}_{4}{ }^{5-}$ and $\mathrm{SiO}_{4}$ tetrahedra. The more general term inorganic polymer defines a super group with a deviation from the tetrahedral coordination of $\mathrm{Al}$ and $\mathrm{Si}$ and the aluminosilicate chemistry [32]. The dissolution of the mineral results with the formation of $\mathrm{Si}-\mathrm{O}-\mathrm{Al}$ species as monomers. Their reorganization leads to the GP network.

The schema below illustrates the reactions proposed for the polycondensation process [12]. In the reactions (8) and (9) the amount of Al-Si materials used depend on the particle size, the extent of dissolution of Al-Si materials and the concentration of the alkaline solution. The formation of $\left[\mathrm{Mz}\left(\mathrm{AlO}_{2}\right) x\left(\mathrm{SiO}_{2}\right) y \cdot \mathrm{MOH} \cdot \mathrm{H}_{2} \mathrm{O}\right]$ gel is a dominant step in the geopolymerization and essentially relies on the extent of dissolution of aluminosilicate materials (reaction (10)).

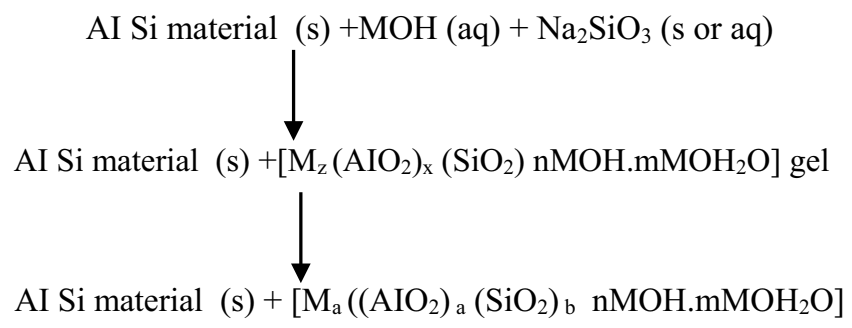

The general empirical formula of geopolymer is as follows:

$$
\mathrm{M}+\mathrm{n}\left[-\left(\mathrm{SiO}_{2}\right) \mathrm{z}-\mathrm{AlO}_{2}-\right] \mathrm{n}
$$

Where $\mathrm{M}^{+}=$an alkali cation $\left(\mathrm{K}^{+}, \mathrm{Na}^{+}\right)$for balancing the negative charge of $\mathrm{Al}^{3+}$ in IV-fold coordination; $\mathrm{n}=$ degree of polymerization; and $\mathrm{z}=\mathrm{Si} / \mathrm{Al}$ ratio. The value of ' $z$ ' represents describe the $\mathrm{Si} / \mathrm{Al}$ ratio, based on which three types can be distinguished: poly(sialate) with 1:1 Si/Al ratio, poly(sialate-siloxo) with 2:1 Si/Al ratio and poly(sialatedisiloxo) with 3:1 Si/Al ratio [7]. Geopolymers possess amorphous to semi-crystalline three dimensional silico-aluminate structures consisting of 
linked $\mathrm{SiO}_{4}$ and $\mathrm{AlO}_{4}$ tetrahedra by sharing the oxygen atoms, which can be designated as poly-sialate $(-\mathrm{Si}-\mathrm{O}-\mathrm{Al}-\mathrm{O}-)(\mathrm{Si} / \mathrm{Al}=1)$, poly-sialate-siloxo $(-\mathrm{Si}-\mathrm{O}-\mathrm{Al}-\mathrm{O}-\mathrm{Si}-\mathrm{O}-)(\mathrm{Si} / \mathrm{Al}=2)$, poly-sialate-disiloxo (- $\mathrm{Si}-\mathrm{O}-\mathrm{Al}-\mathrm{O}-\mathrm{Si}-\mathrm{O}-\mathrm{Si}-\mathrm{O}-)(\mathrm{Si} / \mathrm{Al}=3)$, and sialate links $(\mathrm{Si}: \mathrm{Al}>3)$. The sialate is an abbreviation for silicon-oxo-aluminate. The structures of the above types of poly(sialates) are schematically presented in Figure 6 [23, 29].

Aluminosilicate backbones are formed during geopolymerization process as shows Figure 5. Sialate is an abbreviate form for alkali silicon-oxo-aluminate, the alkali element being ( $\mathrm{Na}, \mathrm{K}, \mathrm{Li}, \mathrm{Ca}$ ) and the term poly(sialate) covers all geopolymers containing at least one $(\mathrm{Na}, \mathrm{K}, \mathrm{Li}, \mathrm{Ca})(\mathrm{Si}-\mathrm{O}-\mathrm{Al})$ and $(\mathrm{Na}, \mathrm{K}, \mathrm{Li}, \mathrm{Ca})-$ sialate unit. Sodalite frameworks and kalsilite frameworks have structural molecules $\mathrm{Na}-(-\mathrm{Si}-\mathrm{O}-\mathrm{Al}-\mathrm{O}-)$ ) and $\mathrm{K}-(-\mathrm{Si}-\mathrm{O}-\mathrm{Al}-\mathrm{O}-)$ respectively [13]. As shows Figure 6, they are chain and ring inorganic polymers that are the result of the polycondensation of the monomer, orthosialate $(\mathrm{OH}) 3-\mathrm{Si}-\mathrm{O}-\mathrm{Al}-(\mathrm{OH})$.

Sanidine frameworks, $\mathrm{K}-(-\mathrm{Si}-\mathrm{O}-\mathrm{Al}-\mathrm{O}-\mathrm{Si}-\mathrm{O}-\mathrm{Si}-\mathrm{O}-)$ may be considered as the condensation result of orthosialate with two ortho-silicic $\mathrm{Si}(\mathrm{OH}) 3$ [13]. The sialate unit may be at the beginning, in the middle or at the end of the sequence. There are six isomorphs: 2 linear, 2 branched and 2 cycles. Leucite frameworks with structural molecule $\mathrm{K}-(-\mathrm{Si}-\mathrm{O}-\mathrm{Al}-\mathrm{O}-\mathrm{Si}-\mathrm{O}-)$ may be considered as the condensation result of orthosialate with ortho-silicic acid $\mathrm{Si}(\mathrm{OH})$. There are three isomorphs, a linear (- $\mathrm{Si}-\mathrm{O}-\mathrm{SiO}-\mathrm{Al}-\mathrm{O}-$ ), mono-siloxo-sialate and 3 cycles. Anorthite frameworks containing 2 sialate unit, Ca-

(- $\mathrm{Si}-\mathrm{O}-\mathrm{Al}-\mathrm{O}-\mathrm{Si}-\mathrm{O}-\mathrm{Al}-\mathrm{O}-$ ) are ring polymers that are result of the polycondensation of the monomer [13].

Crystalline alumina hydrate is extracted from the digestion liquor by hydrolysis.

$$
2 \mathrm{NaAlO}_{2}+4 \mathrm{H}_{2} \mathrm{O} \longrightarrow \mathrm{Al}(\mathrm{OH})_{3}+2 \mathrm{NaOH}
$$

The formation reactions of the above geopolymer material are established by the following two reactions [18].
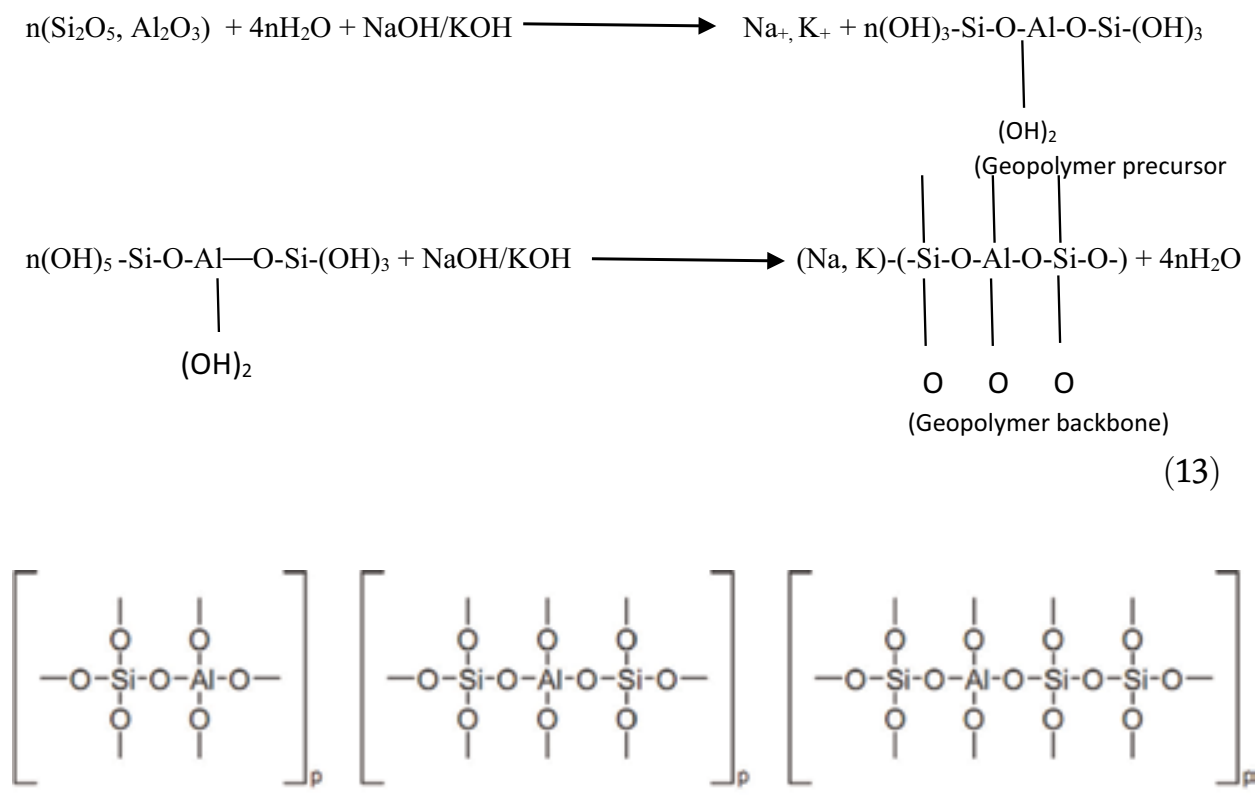

$z=1:$ Poly(sialate) $\quad z=2:$ Poly(sialate-siloxo) z = 3 : Poly(sialate-disiloxo)

Figure 5.

Schema of GP-monomers units [23, 29]. 


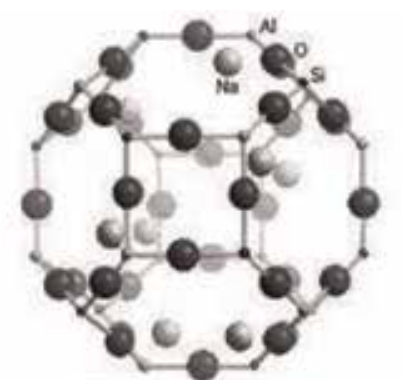

Sodium-Poly(sialate) Sodalite framework Na-PS

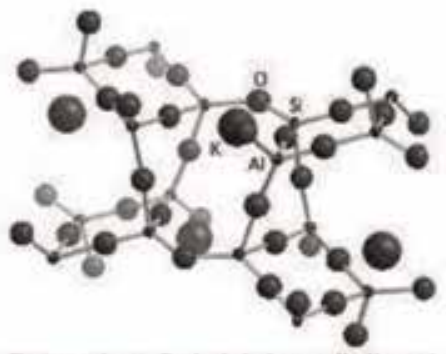

Potassium Poly(sialate-disiloxo) Sanidine framework K.PSDS

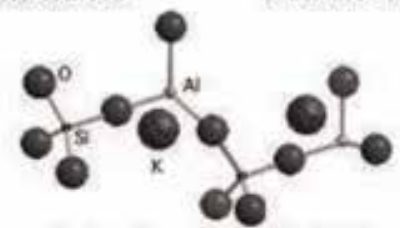

Potassium-Poly(sialate)

Kalsilite framework K-PS
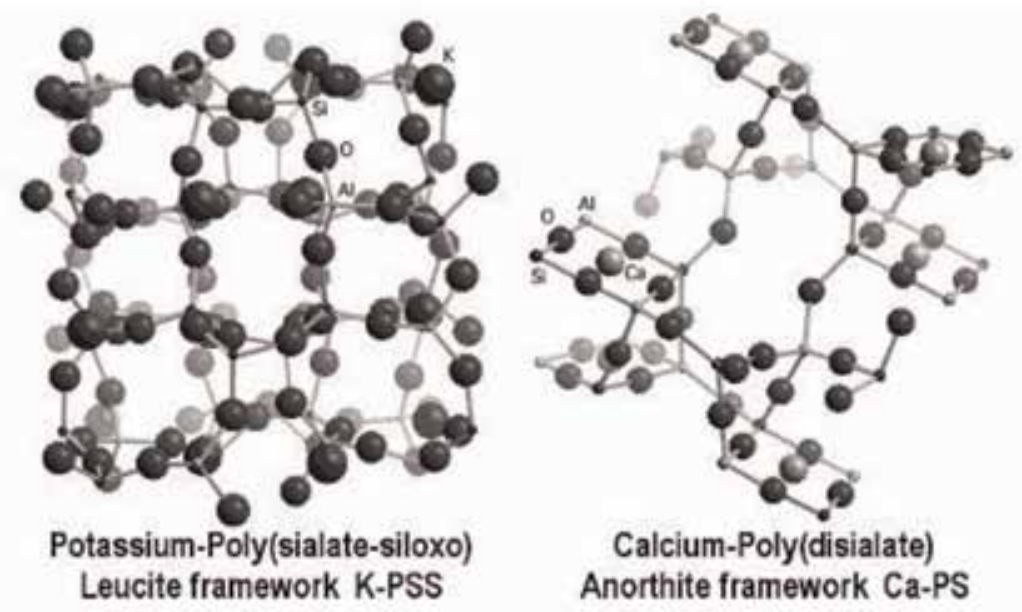

Figure 6.

Polymeric structures from polymerization of monomers [33].

After Duxson, the geopolymer structure consists of cross-linked, $\mathrm{SiO}_{4}$ and $\mathrm{AlO}_{4}$ tetrahedral species where the negative charge on $\mathrm{Al}^{3+}$ in IV-fold coordination is balanced with the positive charges of the alkali ions $\left(\mathrm{Na}+, \mathrm{K}_{+}\right)$. The geopolymerization reaction can be expressed as shown below:

$$
\begin{aligned}
& 2 \mathrm{SiO}_{2} \cdot \mathrm{Al}_{2} \mathrm{O}_{3}+3 \mathrm{OH}^{-}+3 \mathrm{H}_{2} \mathrm{O} \longrightarrow 2\left[\mathrm{Al}(\mathrm{OH})_{4} \Gamma^{-}+\left[\mathrm{SiO}_{2}(\mathrm{OH})_{2}\right]^{2-}\right.
\end{aligned}
$$

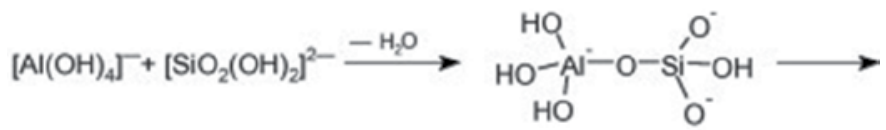

$$
\begin{aligned}
& \stackrel{\text { polycondensafon }}{\longrightarrow}\left[\begin{array}{ccc}
1 & \mid & \mid \\
-\mathrm{Si}-\mathrm{O}-\mathrm{Al}-\mathrm{O}-\mathrm{Si}-\mathrm{O}- & \\
\hline & 9 & 9
\end{array}\right]_{\mathrm{n}}
\end{aligned}
$$


Geopolymers are mainly represented in the models proposed by Davidovits and Barboza the as shown in Figures 7 and 8 [34, 35]. The two models have in common a space, three-dimensional disposition. The Davidovits structural model of GP is designed on the basis of a poly-sialate-siloxo type. It takes on a monolithic type of GP comparable to organic polymers. The water molecules surrounding the $\mathrm{Na}$ ion in the Barbosa model suggests the presence of pores in the structure of the GP.

\subsection{Characterization of geopolymers}

With regard to the characterization of GPs, the use of common materials science techniques presents challenges because of the complex multiphase nature of precursors being structurally disordered: glassy (FA) or thermally disrupted layer $(\mathrm{MK})$. The most widely used tools for microstructural analysis of GP-materials are scanning electron microscopy (SEM), X-ray diffraction (XRD), EDX.

\subsubsection{Microstructure of $R M$ and $R H A$}

The SEM diagram of the RM is shown in Figure 9 RM has relatively porous microstructure with the presence of dispersed particles. The figure presents unequal formed aggregates with smaller particles. The aggregates represent probably $\mathrm{Fe}_{2} \mathrm{O}_{3}$ particles and needle-shaped particles of $\mathrm{Ca}_{5} \mathrm{O}_{4}$.

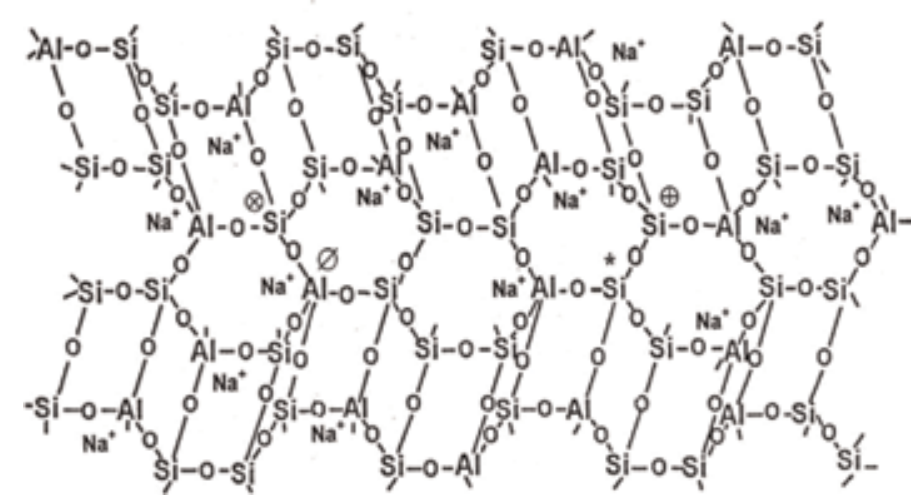

Figure 7.

Davidovits model [34].

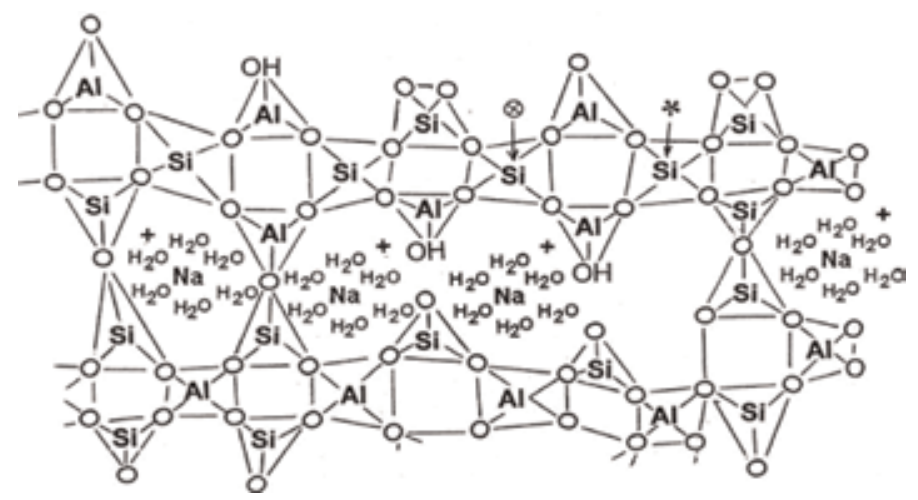

Figure 8.

Barbosa model [35]. 


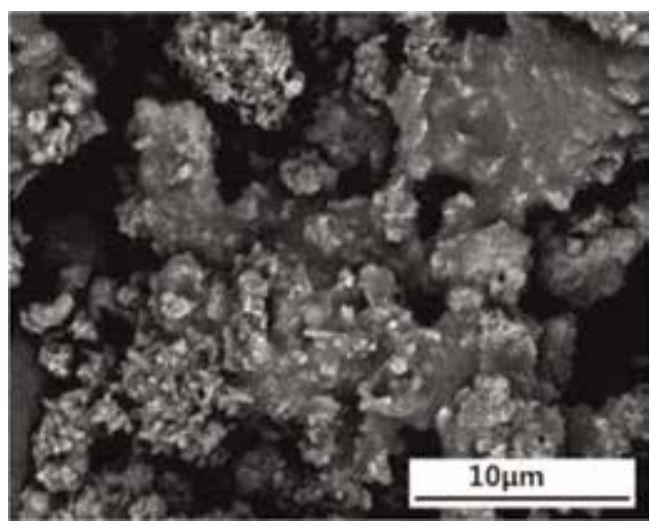

Figure 9.

The SEM micrograph of RM from ACG Plant.

Figure 10 presents the morphological properties of the RHA detected by SEM. It shows a porous and multifaceted particle shape and size. The foremost constituents of rice husk comprise hydrated silica, cellulose and hemi cellulose component and lignin component of approximately. The porous and honeycomb morphology seen can be credited to the burning out of the organic component in the rice husk during combustion.

The XRD diffractogram of RM (Figure 11) shows the presence of hematite $\mathrm{Fe}_{2} \mathrm{O}_{3}$, gibbsite $\mathrm{Al}(\mathrm{OH})_{3}, \mathrm{Al}_{2} \mathrm{O}_{3} \cdot \mathrm{H}_{2} \mathrm{O}$, lapidocrocte $\mathrm{FeO}(\mathrm{OH})$ and calcite $\mathrm{CaCO}_{3}$. $\mathrm{RM}$ displays some undisclosed peaks and a few sharp peaks that are mainly from hematite and calcite, but no observable broad humps [36]. This suggests that the amorphous phases are not present at large quantity. By comparison with its chemical composition, alumina mainly presents as amorphous phases. Thus, red mud provides mainly $\mathrm{Al}$ (in the form of amorphous $\mathrm{Al}_{2} \mathrm{O}_{3}$ or dissolved $\mathrm{NaAlO}_{2}$ ) and $\mathrm{NaOH}$ but little Si to geopolymerization.

\subsubsection{Microstructure of RM-based GP}

There are three parent materials contributing in the synthesis of RHA/RM geopolymers: RM, RHA, and $\mathrm{NaOH}$ solution. However, only amorphous phases in raw materials contribute in geopolymerization reaction [36]. Among the three raw materials, the red mud provides $\mathrm{NaOH}, \mathrm{A}_{2} \mathrm{O}_{3}$, and $\mathrm{NaAlO}_{2}$; rice husk ash provides amorphous $\mathrm{SiO}_{2}$; sodium hydroxide solution provides $\mathrm{NaOH}$.

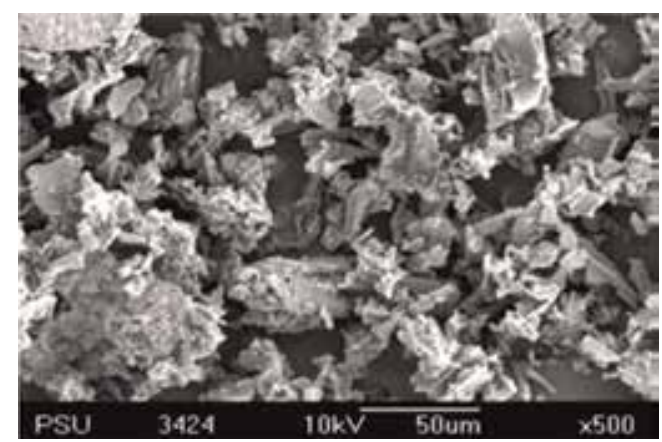

Figure 10.

SEM micrograph of RHA. 


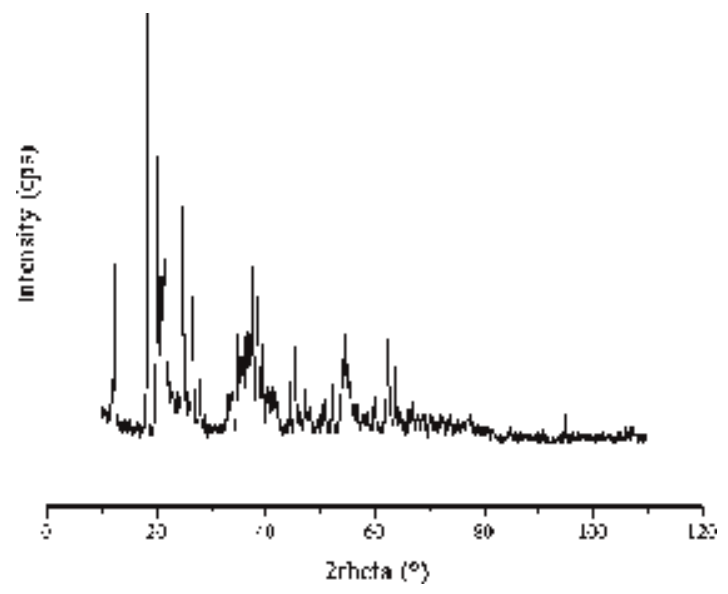

Figure 11.

XRD pattern of red mud.

The SEM [36] of the investigated samples shows that the microstructure of RHA and RM geopolymer comprises non-dissolved particles of RM, which are bonded in an extent gel phase and the formation of gel silicate as shows Figure 12. The reaction with the alkaline solution to form a particulate gel network took place at the border of particles then involving the entire surface.

The XRD diagram (Figure 13) shows that the product is not clean geopolymer matrix, but a composite consisting of the geopolymer structure and crystalline phases from parent materials. It show a broad reflection related to the high amorphous content. However, the center of this reflection is shifted to $2 \theta=29^{\circ}$ due to changes in composition and structure when RHA is activated by $\mathrm{NaOH}$ and $\mathrm{NaSiO}_{2}$ solutions. This is in conformity with the microstructure RM and MK-based GP of red mud and metakaolin based-geopolymers comprising undissolved particles of red mud, which are bonded in an extent gel phase [37]. It indicates a Fe content higher than $65 \%$ assigned to the existence of undissolved red mud. While, microanalysis of the area presented in Figure 13 indicated the formation of gel silicate phase ( $\mathrm{Si}>40 \%$ and $\mathrm{Fe}<7 \%$ ). Therefore, red mud may participate within the geopolymeric structures as active and not as reactive material.

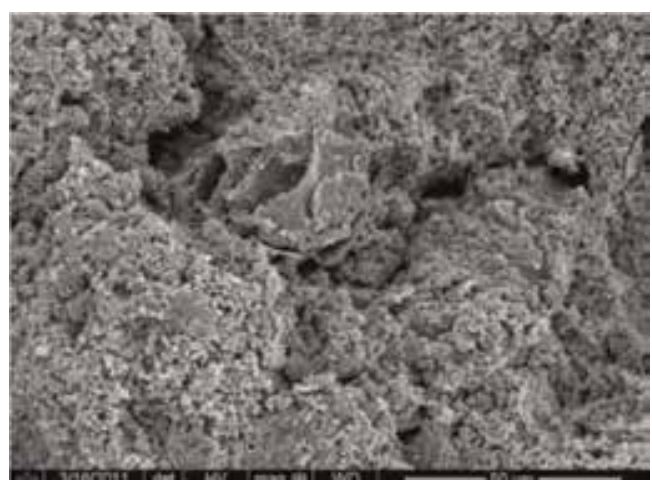

Figure 12.

SEM of RM-RHA based GP [36]. 


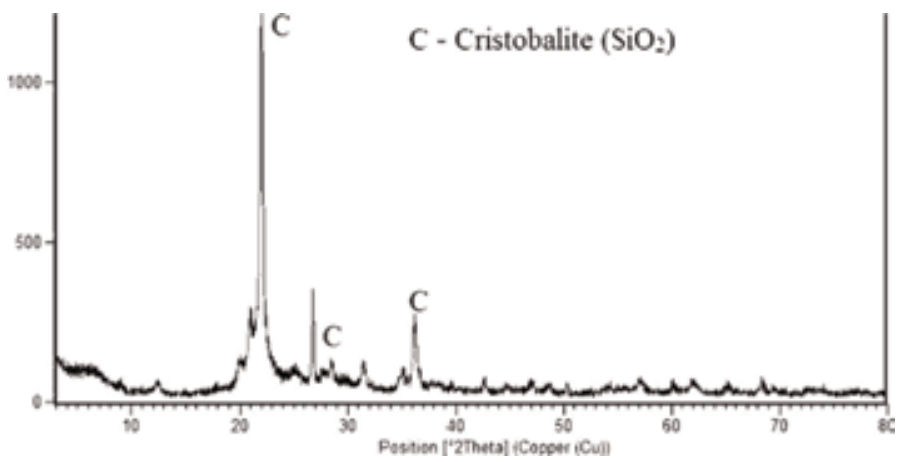

Figure 13.

XRD pattern of RM-RHA based GP [36].

\subsection{Mechanical properties}

Generally, a strong alkaline medium is necessary to increase the surface hydrolysis of the aluminosilicate [6]. Particles present in the raw material while the concentration of the chemical activator has a pronounced effect on the mechanical properties of the geopolymers; on the compressive strength in particular. Compressive strength is an indication of the compactness and strength of a construction material. Most of the inorganic polymer work reported is consisted upon an extensive discussion of compressive strength and its relation with time, temperature, chemical composition, source material and activating alkaline solutions. Besides compressive strength, flexural strength was also reported in the recent papers. It was observed that aluminosilicate based GP produced higher compressive strength compared to other activating systems. Most of the GPs attained maximum compressive strength within 7 days and only partial increase has been recorded in certain cases. Few papers also reported the descending trend in compressive strength with increasing time. This trend was explained on the formation of crystalline zeolites at extended curing time.

\subsubsection{Durability}

Geopolymers durability is the most important issue in determining the success of these new materials. The fact that samples that have been exposed to service conditions for in excess of 30 years show little degradation means that geopolymers do therefore appear to stand the test of time [12]. Since those samples were of the $(\mathrm{Si}+\mathrm{Ca})$ type conclusion cannot be extended to geopolymers defined as alkali aluminosilicate gel, with aluminum and silicon linked in a tetrahedral gel framework. One of the key unsolved questions in the development and application of alkali activation technology is the issue of durability. Whether geopolymer concretes are durable remains the major obstacle to recognition in standards for structural concrete [33].

Efflorescence is originated by the fact that alkaline and/or soluble silicates that are added during processing cannot be totally consumed during geopolymerization [38]. It is the presence of water that weakens the bond of sodium in the aluminosilicate polymers. In the crystalline zeolites the leaching of sodium is negligible, contrary to what happens in the geopolymers. $\mathrm{Na}$ and/or $\mathrm{K}$ ions in geopolymers are 
bounded only weakly in the nanostructure of the geopolymer gel and are therefore almost completely leachable.

\section{Application of geopolymer composites}

Several studies have been carried on to produce alkali-activated materials from RM. Due to its low reactivity and low $\mathrm{SiO}_{2} / \mathrm{Al}_{2} \mathrm{O}_{3}$ molar ratio $(<2.0)$, it has been combined with other higher grade precursors such as metakaolin and fly ash to prepare alkali-activated materials using sodium hydroxide $(\mathrm{NaOH})$ and sodium silicate as alkaline activators solutions. The authors obtained $10.8 \mathrm{MPa}$ compressive strength after 28 days curing. The main application fields of GP are presented in Table 4. The potential use of red mud for synthesis of inorganic polymeric composites was studied to use it in the construction sector as artificial structural elements such as massive bricks [9]. RM was reacted with FA, sodium silicate via geopolymerization reaction to get red mud geopolymers which are a viable OPC material that can be used in roadway constructions. Giannopoulou et al. studied the geopolymerization of the red mud and the slag generated in the ferronickel production, in order to develop inorganic polymeric composites with advanced mechanical and physical properties. The inorganic polymeric materials produced by the geopolymerization of the red mud developed compressive strength up to $21 \mathrm{MPa}$ and presented water absorption lower than 3\%.

They stated that red mud may be viewed as alternatives in the industrial sectors of construction and building materials [39]. The compressive strength of the RMRHA geopolymers seems to be enough competitive, which is also comparable to that of all types of OPC with strengths of 9-20.7 MPa. Thus GP can be used as a OPCitious binder to replace OPC in certain civil engineering applications, such as roadway construction, building materials. Moreover, GP-binder has the ability to immobilize toxic chemicals. Potential use of RM in GP synthesis is summarized in Table 4. It should be expected that the application of the RM-based geopolymers can bring both environmental and economic advantages [15]. Geopolymerization of the RM and byproducts can save not only the expenses for waste disposal, but also the costs for manufacturing OPC. Then recycling of abundant wastes can minimize

\begin{tabular}{ll}
\hline Si/Al Ratio & Application \\
\hline 1 & Bricks \\
\cline { 2 - 2 } & Ceramics \\
\hline 2 & Fire protection \\
\hline 3 & Low $\mathrm{CO}_{2}$ cement and concrete \\
\cline { 2 - 2 } & Radioactive and toxic waste encapsulation \\
\hline$>3$ & Fire protection fiber glass composite \\
\cline { 2 - 2 } & Foundry equipment \\
\hline Heat resistant composite 200-1000 ${ }^{\circ} \mathrm{C}$ \\
\hline $20-35$ & Tooling for aeronautics titanium process \\
\hline & Sealants for industry 200-600 ${ }^{\circ} \mathrm{C}$ \\
\hline
\end{tabular}

Table 4.

Applications of Geopolymeric materials based on the silica to alumina atomic ratio [9]. 
their potential damage to the environment. Lastly the elimination of OPC usage can reduce the $\mathrm{CO}_{2}$ emission caused by firing carbonates.

Silicate-based geopolymer binders have been utilized in applications such as pathways, pavers, mine backfill, railway sleepers, sewerage pipes, and earth retaining [40]. For red mud-based geopolymers to penetrate similar markets, in situ and ambient temperature curing are required. This has been achieved in laboratory trials while targeting a compressive strength above $20 \mathrm{MPa}$ [37].

\subsection{Environment considerations on Geopolymers applications}

Geopolymer production tackles two main issues of the present time. On one hand, with the increasing amount of waste generation from different processes, there has been a growing interest in the use of waste in producing sustainable building materials to achieve potential benefits. Cleaner production is a pressing issue of our time. Residues or byproducts resulting from different industrial processes requires proper management to ensure a sounder environment [14]. The use of recycled materials in new sustainable materials production is very attractive due to the low-cost related to the waste materials in addition to saving required space for landfill purposes and the development as well as improvement in the materials properties.

On the other, the global warming is one of the most pronounced terms in the present time. Thus reducing the greenhouse gas emissions, which is the main reason behind global warming, is the need of the present time and the future. Efforts are underway to develop environmentally sustainable construction materials, which make minimum utility of fast dwindling natural resources and help to reduce greenhouse gas emissions [41-43]. It is an established fact that the greenhouse gas emissions are reduced by $80 \%$ in GP concrete vis-a-vis the conventional OPC manufacturing, as it does not involve carbonate burns. In this connection, GP are showing great potential and several researchers have critically examined the various aspects of their viability as binder system. For manufacturing each tone of the OPC as the primary component of concrete about 1.5 tons of raw materials is needed. Furthermore; in this process about one tone of carbon dioxide will be released into the atmosphere. Geopolymers generate just $0.184 \mathrm{t}$ of $\mathrm{CO}_{2}$ per ton of binder. Although the $\mathrm{CO}_{2}$ emissions generated during the production of $\mathrm{Na}_{2} \mathrm{O}$ are very high, still the production of alkali-activated binders is associated to a level of carbon dioxide emissions lower than the emissions generated in the production of OPC.

\section{Conclusion}

In the light of the above it appears clearly that extensive research has been carried out into the field of geopolymers for better understanding the chemical mechanism conducting to their formation and to develop the ability to design geopolymers with specific applications. In particular the variance of source material makes difficult a standard mix design. Nowadays the most investigations agree that source material, mixing ratio, alkali activator, curation time are key factors in the geopolymerization process. With regard to the immense bauxite resources of Guinea, the development of a subsequent alumina industry is expected and implies two questions: (i) a highly qualified manpower is required to manage the very complex issue of the alumina production and the management of the resulting waste; (ii) a worldwide integrated approach will be required to Takle the management of industrial wastes an environmental challenge and a technological opportunity to develop promising engineering application. The valorization of the red mud is at the same ns. 


\section{Author details}

Sékou Traoré ${ }^{1 *}$, A. Diarra ${ }^{2}$, O. Kourouma ${ }^{1}$ and D.L. Traoré ${ }^{3}$

1 Department of Chemical Engineering, University of Conakry, UGANC, Guinea

2 Department of Mechanical Engineering, University of Conakry, UGANC, Guinea

3 Department of Civil Engineering, University of Conakry, UGANC, Guinea

${ }^{*}$ Address all correspondence to: sktraore@gmail.com

\section{IntechOpen}

(C) 2019 The Author(s). Licensee IntechOpen. This chapter is distributed under the terms of the Creative Commons Attribution License (http://creativecommons.org/licenses/ by/3.0), which permits unrestricted use, distribution, and reproduction in any medium, provided the original work is properly cited. (cc) BY 


\section{References}

[1] Hertel T, Blanpain B, Pontikes Y. A proposal for a $100 \%$ use of bauxite residue towards inorganic polymer mortar. Journal of Sustainable

Metallurgy. 2016

[2] Jamieson E, van Riessen A, McLellan B, Penna B, Kealley C, Nikraz H. Introducing Bayer Liquor-Derived Geopolymers. Elsevier BV; 2017

[3] Shi C, Fernández-Jiménez A. Stabilization/solidification of hazardous and radioactive wastes with alkaliactivated OPCs. Journal of Hazardous Materials. 2006;137:1656-1663

[4] Bray EUS. Mineral commodity summaries geological survey. Bauxite and Alumina. 2016:32-33

[5] Valeton I. Development of Soil Science I. Bauxites: Elsevier Publishing; 1972

[6] Part WK, Ramli M, Cheah CB. An Overview on the Influence of Various Factors on the Properties of Geopolymer Concret e Derived from Industrial Byproduct s. Elsevier BV; 2017

[7] Traoré DL, Traoré S, Diakité S. Bauxite industry in Guinea and value opportunities of the resulting red mud as residue for chemical and civil engineering purposes. Journal of Civil Engineering Research;4(1):14-24. DOI: 10.5923/j.jce.20140401.03

[8] International Monetary Fund January (IMF). Country Report No. 08/20; Guinea: Selected Issues and Statistical Appendix; 2008

[9] Avraamides J, van Riessen A, Jamieson E. Transforming mining residues into viable by-products. Energy Generation. 2010:1-3

[10] Wagh Arun S. A Study of Jamaican Bauxite Waste, Report 154 (Vol. I-III)
International Development and Research Centre; Ottawa, Canada: University of the West Indies. Jamaica: Kingston; 1986. p. 171

[11] Mamedov V. Catalogue des gisements et indices de minéralisation bauxitique en République de Guinée; 2003

[12] Pacheco-Torgal F, Abdollahnejad Z, Miraldo S, Kheradmand M. AlkaliActivated Cement-Based Binders (AACBs) as Durable and Cost Competitive Low- $\mathrm{CO}_{2}$ Binder Materials. Elsevier BV; 2017

[13] Rangan BV. Studies on fly ash-based geopolymer concrete. Malaysian Construction Research Journal. 2008; 3(2):1-20

[14] Mohammadhosseini H, Yatim JM, Sam ARM, Abdul Awal ASM. Durability performance of green concrete composites containing waste carpet fibers and palm oil fuel ash. Journal of Cleaner Production. 2016

[15] Van Deventer JSJ, Provis JL, Duxson P, Lukey GC. Reaction mechanisms in the geopolymeric conversion of inorganic waste to useful products. Journal of Hazardous Materials. 2007; 139(3):506-513

[16] Ye N, Yang J, Liang S, Hu Y, Hu J, Xiao B, et al. Synthesis and strength optimization of one-part geopolymer based on red mud. Construction and Building Materials. 2016;111:317-325

[17] Detphan S, Chindaprasirt P. Preparation of fly ash and rice husk ash geopolymer. International Journal of Minerals, Metallurgy, and Materials. 2009;16(6):720-726

[18] Glukhovsky V. Slag Alkaline Fine Aggregate Concretes. Kiev: USSR, Vysscha Shkola Publisher; 1981 
[19] Perera DS, Hanna JV, Davis J, Blackford MG, Latella BA, Sasaki Y, et al. Relative strengths of phosphoric acid-reacted and alkali-reacted metakaolin materials. Journal of Materials Science. 2008;43:6562-6566

[20] Le-ping L, Xue-min C, Shu-heng Q, Jun-li Y, Lin Z. Preparation of phosphoric acidbased porous geopolymers. Applied Clay Science. 2010;50:600-603

[21] Irfan Khan M, et al. World Sustainability Forum 2014. Conference Proceedings Paper; 2014

[22] He J et al. Synthesis and characterization of red mud and rice husk ash-based geopolymer composites. Cement and Concrete Composites. 2013; 37:108-118

[23] Davidovits J. Environmentally driven geopolymer OPC applications. In: Proceedings of 2002 Geopolymer Conference; Melbourne, Australia. 2002

[24] Rees C, Lukey GC, Van Deventer JSJ. The role of solid silicates on the formation of geopolymers derived from coal ash. In: International Symposium of Research Student on Material Science and Engineering; Chennai, India. 2004. pp. 1-13

[25] Gangadhara RN, Chandra KS. Characterization and comprehensive utilization of red mud-An overview. International Journal for Scientific Research \& Development. 2014;2(01). ISSN (online): 2321-0613

[26] Nazari A, Bagheri A, Riahi S. Properties of geopolymer with seeded fly ash and rice husk bark ash. Materials Science and Engineering A. 2011;528: 7395-7401

[27] Limaye SD. Iranian Journal of Earth Sciences. 2010;2:1-9

[28] Trochez J, Mejía de Gutiérrez R, Rivera Bernal JSA. Synthesis of geopolymer from FCC: Effect of $\mathrm{SiO}_{2} /$ $\mathrm{Al}_{2} \mathrm{O}_{3}$ and $\mathrm{Na}_{2} \mathrm{O} / \mathrm{SiO}_{2}$ molar ratios. Material Construction. 2015;65:e046. DOI: $10.3989 / \mathrm{mc} .2015 .00814$

[29] Davidovits J. Geopolymers: Inorganic polymeric new materials.

Journal of Thermal Analysis. 1991;37: 1633-1656

[30] Davidovits J. Properties of geopolymer OPCs. In: First International Conference on Alkaline OPCs and Concretes. Vol. 1. 1994. pp. 131-149

[31] Davidovits J. Geopolymer Chemistry and Applications. 3rd ed. Saint-Quentin: Institut Geopolymere; 2011

[32] Xu H. Geopolymerisation of aluminosilicate minerals [Ph.D. Dissertation]. Australia: Dept. of Chemical Engineering, University of Melbourne; 2002

[33] Xu H, Van Deventer JS.

Geopolymerisation of multiple minerals. Minerals Engineering. 2002;15(12): 1131-1139

[34] Davidovits J. Geopolymer Chemistry and Applications. 2nd ed. SaintQuentin, France: Institute Geopolymer; 2008

[35] Barbosa VFF, Mackenzie KJD, Thaumaturgo C. International Journal of Inorganic Materials. 2000;2:309

[36] Sékou T, Siné D, Lanciné TD, Bakaridjan C. Synthesis and Characterization of a Red Mud and Rice Husk Based Geopolymer for Engineering Applications, Macromolecular Symposia; 2017

[37] Van Jaarsveld JGS, van Deventer JSJ. Effect of the alkali metal activator on the properties of fly ash-based geopolymers. Industrial and Engineering Chemistry Research. 1999; 38(10):3932-3941 
[38] Zhang G, He J, Gambrell RP. Synthesis, characterization, and mechanical properties of red mud-based Geopolymers. Transportation Research Record: Journal of the Transportation Research Board. 2010;2167:1-9

[39] Giannopoulou I, Dimas D, Maragkos I, Panias D. Utilization of metallurgical solid byproducts for the development of inorganic polymeric construction materials. Global NEST Journal. 2009;11(2):127-136

[40] Traoré S, Diakité S, Traoré DL. Investigation of a red mud and metakaolin-based inorganic polymer material for civil construction applications. International Journal of Materials Engineering. 2014;4(1):25-30. DOI: 10.5923/j.ijme.20140401.03

[41] Snars K, Gilkes RJ. Evaluation of bauxite residues (red muds) of different origins for environmental applications. Applied Clay Science. 2009;46:13-20

[42] van Deventer JSJ, Provis JL, Duxson $\mathrm{P}$, Brice DG. Chemical research and climate change as drivers in the commercial adoption of alkali activated materials. Waste and Biomass Valorization. 2010;1(1):145-155. DOI: 10.1007/s12649-010-9015-9

[43] Xu H, Deventer JSJV. The geopolymerisation of alumino-silicate minerals. International Journal of Mineral Processing. 2000;59:247-266 



\title{
Thermal Evolution of Geopolymer in the Process of High-Temperature Treatment
}

\author{
Jingkun Yuan, Peigang He and Dechang Jia
}

\begin{abstract}
More and more attention had been given to geopolymers (GPs) over the last decades because of an increasing urgency to search for high-performance and/or environment-friendly alternatives to traditional Portland cement. In addition, geopolymer technology could also provide an innovative approach to prepare advanced ceramic products by overcoming problems faced in the conventional preparation technology. With only the need to go through appropriate thermal treatment procedure, geopolymers could be directly in situ transformed into advanced ceramics such as leucite or pollucite with adjustable microstructures, mechanical properties, coefficient of thermal expansion, and melting points. In the process of high-temperature treatment, multiple parameters, such as the composition of geopolymer, treatment temperature, thermal insulation, etc., would affect the phase composition and microstructure of the resulting products. In the present chapter, two kinds of mixed-alkali metal ion-activated geopolymer systems, $\mathrm{Cs}_{(1-x)} \mathrm{Li}_{x} \mathrm{GP}$ (where $x=0,0.1,0.2$, and 0.3) and $\mathrm{Cs}_{(1-x)} \mathrm{Na}_{x} \mathrm{GP}$ (where $x=0,0.1,0.2,0.3$, and 0.4 ), respectively, were designed and prepared. Phase composition, microstructure evolution, and thermal expansion behaviors of the ceramics derived from the geopolymers were characterized and the effects of ion substitution on the thermal evolution of geopolymer were evaluated.
\end{abstract}

Keywords: geopolymer, high-temperature treatment, pollucite, spodumene, amorphous glass phase, phase composition, microstructure, thermal expansion behavior

\section{Introduction}

More and more attention had been given to geopolymers over the last decades because of an increasing urgency to search for high-performance and/or environment-friendly alternatives to traditional Portland cement [1-6]. They were typically synthesized at ambient or elevated temperature by alkali-activated process between alkali-activated solutions and aluminosilicates. And the source of aluminosilicates was very extensive and inexpensive, such as metakaolin, fly ash, blast furnace slag, etc. [7-11]. Most notably, there was almost no emission of greenhouse gases throughout the preparation process, which made geopolymer technology more competitive in terms of environmental and economic advantages.

From their composition, geopolymers were a class of amorphous materials consisting of cross-linked $\left[\mathrm{AlO}_{4}\right]^{-}$and $\left[\mathrm{SiO}_{4}\right]$ tetrahedra units, and the negative charge aluminum in fourfold coordination was balanced by alkali metal 
or alkaline earth metal cation, such as $\mathrm{Na}^{+}, \mathrm{K}^{+}, \mathrm{Mg}^{2+}$, and $\mathrm{Ca}^{2+}[12-15]$. As for geopolymers, alkali metal hydroxides were involved in many processes during the alkali-activated reaction or geopolymerization reaction, including accelerating the dissolution of aluminosilicates, stabilizing the solution species and colloids, reducing the electrostatic repulsion between the anions, and promoting gel formation and rearrangement [16-18]. Therefore, as for alkali metal hydroxide, the $\mathrm{OH}^{-}$group in it mainly accounted for creating the reactive precursors, while the alkali cations would play an important role in catalyzing gel formation, acting as a structure-directing agent. Since the alkali metal was one of the most easily alterable constituents in the framework of geopolymer, it was very valuable to investigate the effects of alkali cation species on the evolution of microstructure and properties of the geopolymer system [19]. Fernández-Jiménez et al. proved that $\mathrm{Na}^{+}$was much more conducive to the coagulation and precipitation process than $\mathrm{K}^{+}$, and the resulting geopolymer gels would consist of a much wider diversity of $\mathrm{Q}^{\mathrm{n}}$ species in the case of $\mathrm{Na}^{+}$[20-22]. Duxson et al. suggested that larger cations were more inclined to bind by the gel in mixed-alkali-activated systems that contained $\mathrm{Na}^{+}$and $\mathrm{K}^{+}$[23]. Ikuo et al. reported that the thermal expansion coefficient (CTE) of the cubic cesium leucite-based compounds decreased with much smaller ions occupying/substituting the crystallographic sites of $\mathrm{Cs}^{+}$, such as $\mathrm{Na}^{+}$or $\mathrm{Li}^{+}$substitutional ions [24-26].

Pollucite $\left(\mathrm{CsAlSi}_{2} \mathrm{O}_{6}\right)$ exhibits a unique thermal expansion curve that has two stages: the average CTE is $\sim 12.5 \times 10^{-6} \mathrm{~K}^{-1}$ from 298 to $473 \mathrm{~K}$ and $\sim 2.2 \times 10^{-6} \mathrm{~K}^{-1}$ from 473 to $1473 \mathrm{~K}[24,27]$. In recent years, many reports have given evidence that the thermal expansion of pollucite decreased with ionic substitution at the $\mathrm{Cs}^{+}$ sites by smaller alkali metal ions, such as $\mathrm{Na}^{+}$and $\mathrm{Li}^{+}$[24-33]. But, the mechanisms about how thermal expansion properties of pollucite are affected have not yet been studied clearly. In general, there were three main methods to prepare pollucite, including the solid-state reaction method, sol-gel method, and ion exchange method from leucite [34]. However, solid-state reaction always required high sintering temperatures and easily suffered from problems of cesium volatilization, agglomeration, furnace contamination, etc. Ion exchange and sol-gel techniques were also uncompetitive due to their high cost and severe preparation conditions. Moreover, it was almost impossible to get fully densified pollucite ceramic products because the volatilization of cesium was inevitable in the high-temperature environment during its preparation process. Therefore, only limited researches have been made on pollucite glass ceramic until now. In contrast, geopolymer technology could be an excellent alternative to prepare pollucite ceramic products through in situ conversion due to its ability to from crystalline ceramic phase after proper thermal treatment [35].

Therefore, as a part of our continuing research, a series of ion-substituted cesium-based geopolymer samples, $\mathrm{Cs}_{(1-x)} \mathrm{Li}_{x} \mathrm{GP}$ (where $x=0,0.1,0.2$, and 0.3 ) and $\mathrm{Cs}_{(1-x)} \mathrm{Na}_{x} \mathrm{GP}$ (where $x=0,0.1,0.2,0.3$, and 0.4 ), were prepared. Phase composition, microstructure evolution, and thermal expansion behavior of ceramics derived from $\mathrm{Cs}_{(1-x)} \mathrm{Li}_{x} \mathrm{GP}$ and $\mathrm{Cs}_{(1-x)} \mathrm{Na}_{x} \mathrm{GP}$ were characterized, with the aim of investigating the effect of ion substitution on the thermal evolution of the geopolymer.

\section{Experiments and characterization}

Simultaneous thermogravimetry (TG) and differential thermal analysis (DTA) (Netzsch STA 409, Germany) were carried out under Ar gas flow $(20 \mathrm{~mL} / \mathrm{min}$ ) with temperature up to $1200^{\circ} \mathrm{C}$ at a heating rate of $5^{\circ} \mathrm{C} / \mathrm{min}$ in alumina crucibles. Sample 
powders were sintered without the occurrence of any reaction between the samples and the crucible.

The phase composition of samples was analyzed using X-ray diffraction (XRD, $40 \mathrm{KV} / 100 \mathrm{~mA}, \mathrm{D} / \mathrm{max}-\gamma \mathrm{B} \mathrm{CuKa}$, Rigaku Corp., Japan) method to obtain the X-ray diffraction spectra at $2 \theta=10^{\circ}-90^{\circ}$ with a scanning speed of $4^{\circ} / \mathrm{min}$. Slow step-scans with a step width of 0.02 and a step time of $3 \mathrm{~s}$ were carried out to determine the shifts of X-ray spectrum.

The microstructure of geopolymers before and after heat treatment was investigated by a scanning electron microscope (SEM, $30 \mathrm{KV}$, Helios Nanolab600i, FEI Co., USA). Energy dispersive spectrometer (EDS) was also adopted to study the elemental arrangement and phase distribution. Transmission electron microscope (TEM, $300 \mathrm{KV}$, Talos, FEI Company) was also employed to analyze its microstructure. For ceramics derived from geopolymer, TEM samples were ion-milled at low temperature, using a Fischione ion mill (Model 2; Export, PA).

\section{Results and discussions}

\subsection{Thermal analysis}

Figure 1 displays the results of thermogravimetry (TG) analysis as to $\mathrm{Cs}_{(1-x)} \mathrm{Li}_{x} \mathrm{GP}$ and $\mathrm{Cs}_{(1-x)} \mathrm{Na}_{x} \mathrm{GP}$ systems, respectively. Both systems showed similar TG curves. There was significant mass loss as the temperature increased until $800^{\circ} \mathrm{C}$. The escape of free water, including water adsorbed on the surface and pore solution, accounted for the mass loss in the interval below $300^{\circ} \mathrm{C}$. The mass loss between 300 and $800^{\circ} \mathrm{C}$ could be mainly attributed to the condensation and polymerization of hydroxyl connected with $\mathrm{Si} / \mathrm{Al}$ atom, which resulted in the formation of oxo-bridge in the framework of geopolymer $[13,36]$. As the temperature rose further, the TG curves remained essentially unchanged, suggesting almost no mass loss in this stage. The total mass loss increased regularly with the increase of $\mathrm{Li}^{+} / \mathrm{Na}^{+}$content. Take $\mathrm{Cs}_{(1-x)} \mathrm{Na}_{x} \mathrm{GPs}$ for example, $\mathrm{Na}^{+}$had a smaller ionic radius than that of $\mathrm{Cs}^{+}$, which means $\mathrm{Na}^{+}$ion had a higher hydration energy than that of $\mathrm{Cs}^{+}$ion [37]. Therefore, the amount of hydration water associated with $\mathrm{Na}^{+}$was much more than that with $\mathrm{Cs}^{+}$ion and, so, it was easy to see why the mass losses increased with increase in $\mathrm{Na}^{+}$ ion substitution amount in the $\mathrm{Cs}_{(1-x)} \mathrm{Na}_{x} \mathrm{GP}$ system.

Figure 2 displays thermal shrinkage curves of these two geopolymer systems. The process of thermal shrinkage could be divided into four stages [14, 38, 39]: (I) Structural resilience $\left(\mathrm{RT} \sim 100^{\circ} \mathrm{C}\right)$ : due to only free water lost in this interval, the
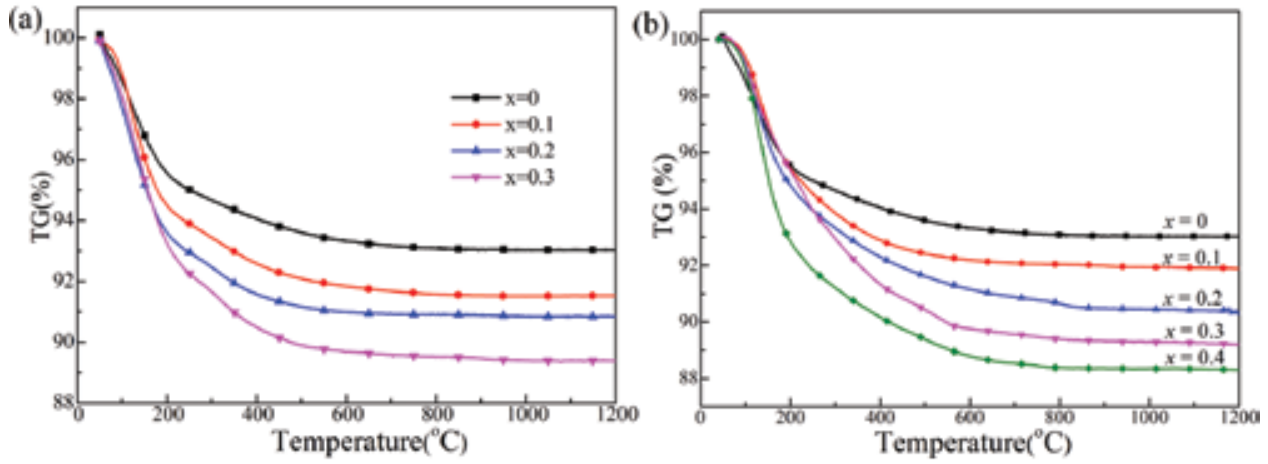

Figure 1.

Thermal gravimetric curves of $C s_{(1-x)} L i_{x} G P s(a)$ and $C s_{(1-x)} N a_{x} G P s(b)$. 
dimensions of the tested samples could be maintained substantially, and the corresponding densification degree of the tested samples did not change significantly synchronously; (II) Dehydration $\left(100-300^{\circ} \mathrm{C}\right)$ : the causes of the shrinkage and deformation in this interval could be attributed to the capillary contraction induced by the escape of water from micro- and nano-pore solutions; (III) Dehydroxylation $\left(300-800^{\circ} \mathrm{C}\right)$ : the condensation and polymerization between $T-\mathrm{OH}$ groups $(T=\mathrm{Al} / \mathrm{Si}$ ) caused the water escape and shrinkage in the interval, with more weight damage and shrinkage at this stage than those in stage (II); (IV) Viscous sintering (above $800^{\circ} \mathrm{C}$ ): the shrinkage in this stage was caused by the generation of molten amorphous glass phase, and the presence of molten amorphous glass phase would facilitate sintering and densification, which also means the maximum shrinkage behavior would occur in this stage $[13,19,40,41]$. When the treatment temperature climbed to $1200^{\circ} \mathrm{C}$, almost no shrinkage was observed, suggesting that the shrinkage process was fully completed.

However, after $\mathrm{Cs}^{+}$ion was substituted, significant differences are observed in Stage IV. For $\mathrm{Cs}_{(1-x)} \mathrm{Li}_{x} \mathrm{GP}$ samples, they all showed two sintering steps in Stage IV. Taking $\mathrm{Cs}_{0.9} \mathrm{Li}_{0.1} \mathrm{GP}$ for example, as depicted in Figure 3, there were two sintering steps: Region i: $850-1050^{\circ} \mathrm{C}$ and Region ii: $1050-1300^{\circ} \mathrm{C}$. On raising $\mathrm{Li}^{+}$ion content from 0 to $30 \mathrm{~mol} \%$, the onset temperature of two steps decreased gradually, from 850 to $730^{\circ} \mathrm{C}$ for Region i and from 1050 to $970^{\circ} \mathrm{C}$ for Region ii, respectively. In general, the melting points of the $\mathrm{MAlSi}_{2} \mathrm{O}_{6}$ decline with decreasing ionic radius of $\mathrm{M}^{+}$ion $(\mathrm{M}=\mathrm{Li}, \mathrm{Na}, \mathrm{K}, \mathrm{Cs})$. Meanwhile, onset sintering temperatures for NaGP, KGP, and $\mathrm{CsGP}$ were $650^{\circ} \mathrm{C}[36], 850^{\circ} \mathrm{C}$ [14], and $1200^{\circ} \mathrm{C}$ [13], respectively, indicating that geopolymer containing $\mathrm{M}+$ ion (MGP) also showed a similar trend with $\mathrm{MAlSi}_{2} \mathrm{O}_{6}$. Therefore, it was reasonable to deduce that LiGP would exhibit the lowest onset sintering temperature, resulting in the lower temperature in Region i of Stage IV. Region ii might be due to melting of Li-based aluminosilicates. It should be pointed out that after doping with $\mathrm{Li}$, all the samples show lower overall thermal shrinkage than pure CsGP, implying that the presence of Li facilitated sintering of $\mathrm{Cs}_{(1-x)} \mathrm{Li}_{x} \mathrm{GPs}$ to dense microstructure. The same trend could also be observed in the $\mathrm{Cs}_{(1-x)} \mathrm{Na}_{x} \mathrm{GP}$ system.

\subsection{Phase composition}

Figure 4 provides XRD patterns of $\mathrm{Cs}_{(1-x)} \mathrm{Li}_{x} \mathrm{GPs}$ and corresponding ceramic products derived from it. For $\mathrm{Cs}_{(1-x)} \mathrm{Li}_{x} \mathrm{GPs}$, all the samples show a typical amorphous character with a broad amorphous hump from $20^{\circ}$ to $30^{\circ} 2 \theta$, and almost no changes in phase composition had been observed based the XRD results of $\mathrm{Cs}_{(1-x)} \mathrm{Li}_{x} \mathrm{GPs}$ with different $\mathrm{Li}^{+}$content. However, a substantial amount of pollucite was observed after
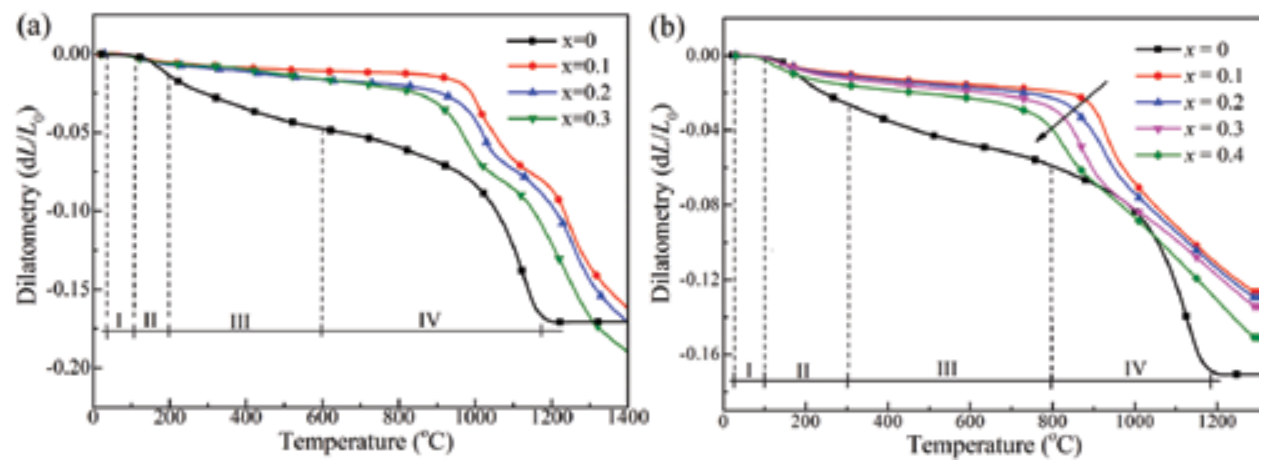

Figure 2.

Thermal shrinkage curves of $C s_{(1-x)} L i_{x} G P s(a)$ and $C s_{(1-x)} N a_{x} G P s(b)$. 


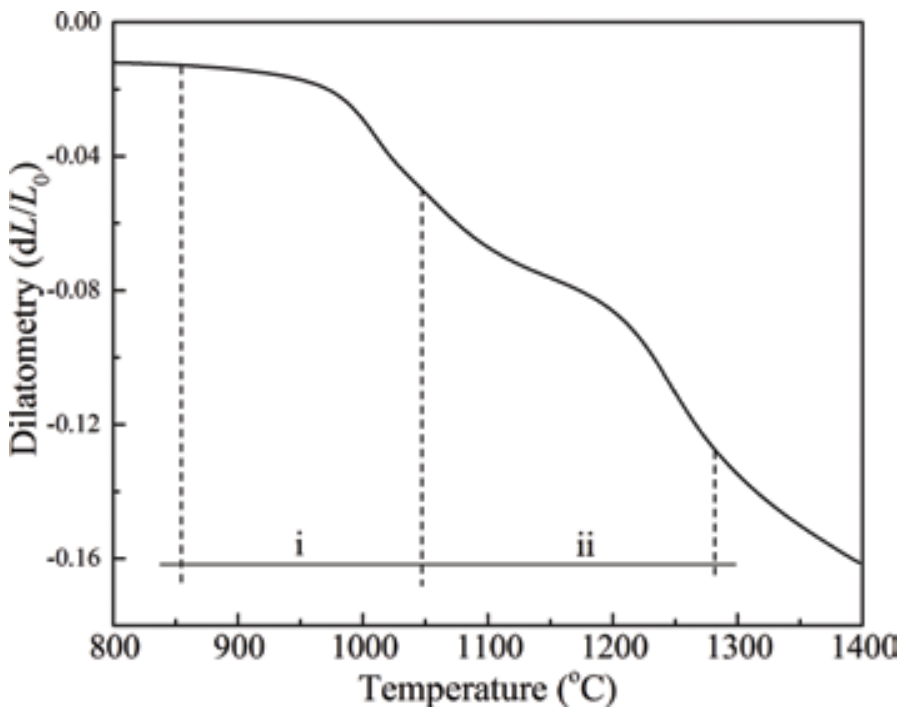

Figure 3.

Partial thermal shrinkage curves of $\mathrm{Cs}_{0.9} L i_{0.1} G P$.
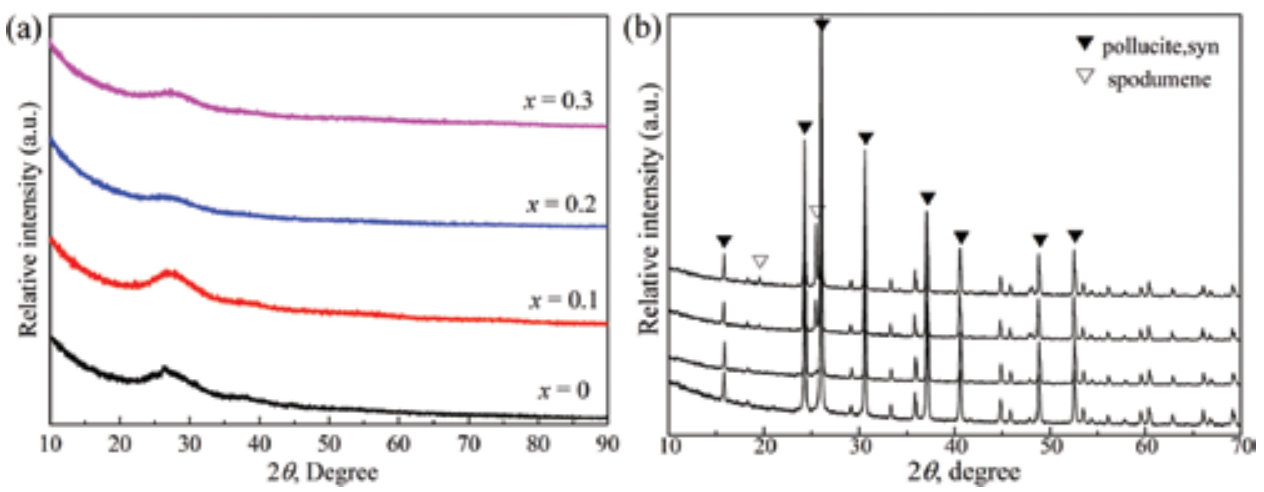

Figure 4 .

$X R D$ patterns of $C s_{(1-x)} L i_{x} G P s(a)$ and ceramics derived from it $(b)$.

pure CsGP was treated at $1300^{\circ} \mathrm{C}$ for $2 \mathrm{~h}$. In addition, a small amount of spodumene was also observed after $\mathrm{Cs}^{+}$ion was partially substituted by $\mathrm{Li}^{+}$ion, and the content of spodumene was proportional to the $\mathrm{Li}^{+}$ion substitution in $\mathrm{Cs}_{(1-x)} \mathrm{Li}_{x} \mathrm{GPs}$ system. The results of quantitative analysis indicated that the content of spodumene was 8.8 and $14.2 \mathrm{wt} . \%$ corresponding to $x=0.2$ and 0.3 in $\mathrm{Cs}_{(1-x)} \mathrm{Li}_{x} \mathrm{GPs}$ system, respectively. However, the spodumene content was too small to calculate using XRD data when $\mathrm{Li}^{+}$ion content was $10 \mathrm{~mol} \%$.

Unlike $\mathrm{Cs}_{(1-x)} \mathrm{Li}_{x} \mathrm{GPs}(x>0)$, the phase composition of $\mathrm{Cs}_{(1-x)} \mathrm{Na}_{x} \mathrm{GPs}(x>0)$ was not completely amorphous after the introduction of $\mathrm{Na}^{+}$ion, and the crystallinity of $\mathrm{Cs}_{(1-x)} \mathrm{Na}_{x} \mathrm{GPs}$ gradually increased as more $\mathrm{Cs}^{+}$ion was substituted. The $\mathrm{XRD}$ results indicated the presence of pollucite in the unheated samples partially substituted by $\mathrm{Na}^{+}$ion (Figure 5a), which suggested that the presence of $\mathrm{Na}^{+}$ion would have contributed to the crystallization of pollucite. As for the crystallization of pollucite, a possible reason could be attributed to the formation of a zeolite containing sodium, aluminum, and silicon, such as analcime $\left(\mathrm{NaAlSi}_{2} \mathrm{O}_{6} \cdot \mathrm{H}_{2} \mathrm{O}\right)$. The crystallization temperature of zeolite was very low, about $300^{\circ} \mathrm{C}$, and the crystallization temperature will become lower $\left(\sim 120^{\circ} \mathrm{C}\right)$ for the samples with low Si/Al 
ratio under the hydrothermal condition $[42,43]$. The geopolymer was nanoporous together with numerous capillaries, filled with pore solution. This structure was like a hydrothermal reaction environment. So, it was possible to produce some fine zeolite nucleus if the reaction time was long enough, although the reaction temperature was low. Analcime and pollucite have similar crystal structure and both were tetragonal and belong to I41/acd (space group). Meanwhile, lattice constant of analcime was $a \sim 13.727$ and $c \sim 13.686$, which was close to that of pollucite, $a \sim 13.677$ and $c \sim 13.691 \AA$. Therefore, it was highly possible that the zeolite nucleus could have served as the nucleation site for pollucite, which contributed to pollucite formation. So, crystalline pollucite could be present in $\mathrm{Cs}_{(1-x)} \mathrm{Na}_{x} \mathrm{GPs}$ when $x>0$, which was not the same as the phenomenon of $\mathrm{Cs}_{(1-x)} \mathrm{Li}_{x} \mathrm{GPs}$ system.

For the resulting ceramics derived from $\mathrm{Cs}_{(1-x)} \mathrm{Na}_{x} \mathrm{GPs}(x>0)$, only crystalline phases of pollucite were observed in the corresponding XRD pattern, which were different with the $\mathrm{Cs}_{(1-x)} \mathrm{Li}_{x} \mathrm{GPs}$ system. So, the difference between $\mathrm{Cs}_{(1-x)} \mathrm{Li}_{x} \mathrm{GPs}$ and $\mathrm{Cs}_{(1-x)} \mathrm{Na}_{x} \mathrm{GPs}$ also indicated that $\mathrm{Na}^{+}$may have only existed in the form of amorphous glass phase.

Based on the result of slow step-scans of ceramics derived from $\mathrm{Cs}_{(1-x)} \mathrm{Li}_{x} \mathrm{GPs}$, it was possible to find that with increase in $\mathrm{Li}^{+}$ion substitution, almost no deviation occurred for the characteristic peaks (4 00 ) and (3 2 1) corresponding to pollucite (Figure 6), which proved that the lattice parameters of pollucite did not change as more and more $\mathrm{Li}^{+}$ions were introduced $[33,44]$. This implied that $\mathrm{Li}^{+}$ions did not occupy Cs crystallographic sites of the pollucite framework and phase separation occurred during heating. Diphasic compositions of product ceramics derived from $\mathrm{Cs}_{(1-x)} \mathrm{Li}_{x} \mathrm{GPs}$ also conform to the aforementioned two-step sintering behavior observed in thermal shrinkage results.

In contrast, for the heated samples derived from $\mathrm{Cs}_{(1-x)} \mathrm{Na}_{x} \mathrm{GPs}$, the peaks $\left(\begin{array}{lll}4 & 0 & 0\end{array}\right)$ corresponding to pollucite shifted to the high-angle region with increase in sodium substitution (Figure 7), which suggested that the lattice parameters of pollucite decreased with increases in sodium content $[33,44]$. The decline of pollucite's lattice parameters proved that $\mathrm{Na}^{+}$partially occupied/substituted the crystallographic sites of $\mathrm{Cs}^{+}$in the pollucite crystal structure during high-temperature processing. The difference between $\mathrm{Cs}_{(1-x)} \mathrm{Na}_{x} \mathrm{GP}$ and $\mathrm{Cs}_{(1-x)} \mathrm{Li}_{x} \mathrm{GP}$ systems could be attributed to the difference between the size of the ions and the form of the substituted ions. Compared with $\mathrm{Li}^{+}$ion, the size of $\mathrm{Na}^{+}$ion was closer to that of $\mathrm{Cs}^{+}$ion. In the $\mathrm{Cs}_{(1-x)} \mathrm{Li}_{x}$ system, $\mathrm{Li}^{+}$ion was only in the form of spodumene in the heated samples. The different forms of $\mathrm{Na}^{+}$and $\mathrm{Li}^{+}$ions also suggested that the $\mathrm{Na}^{+}$ion had a higher degree of freedom
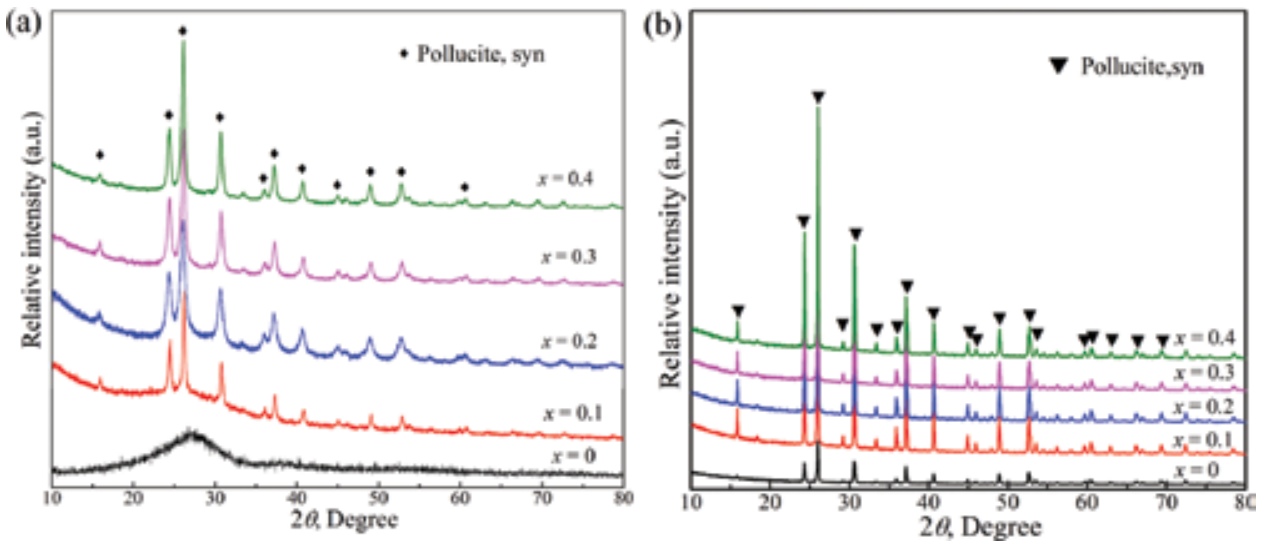

Figure 5.

$X R D$ patterns of $C s_{(1-x)} N a_{x} G P s(a)$ and ceramics derived from it (b). 


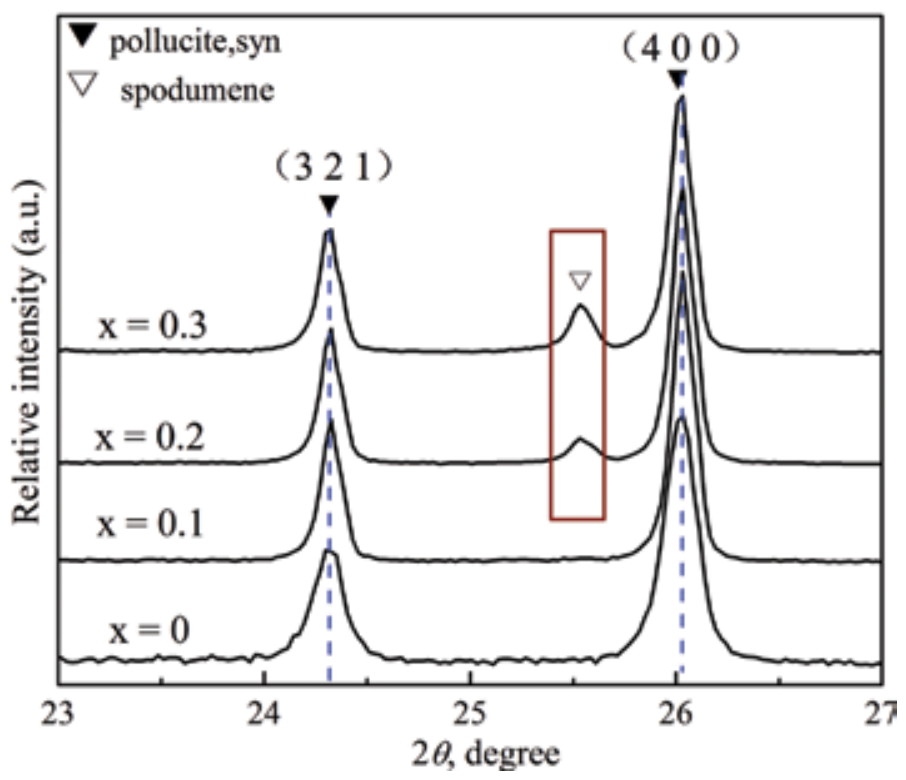

Figure 6.

Slow step-scan XRD patterns of ceramics derived from $\mathrm{Cs}_{(1-x)} L i_{x} G P s$.
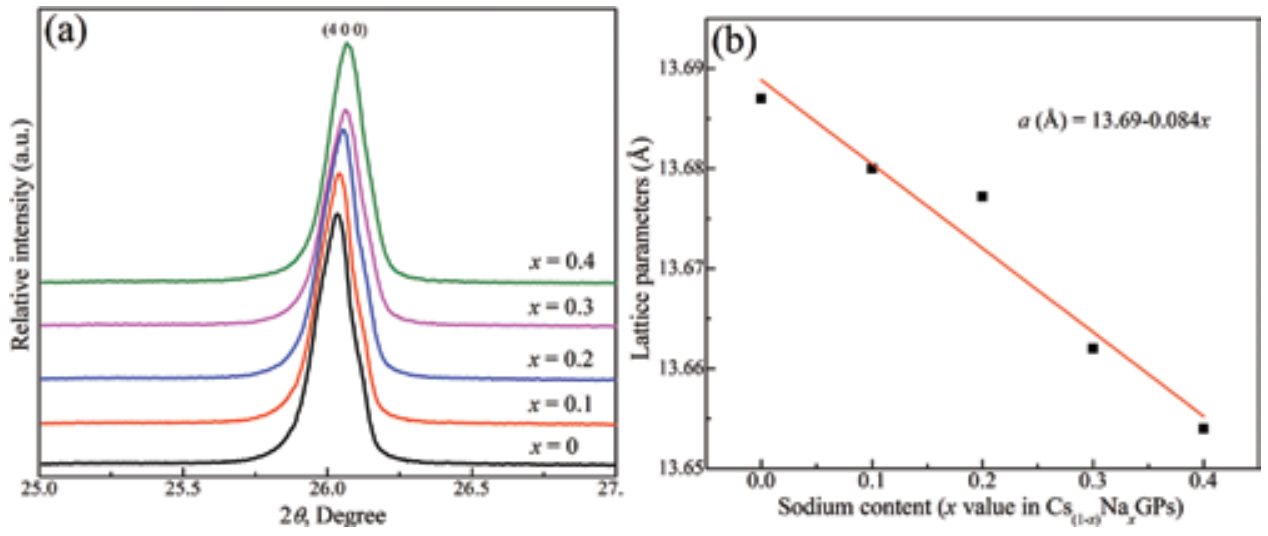

Figure 7 .

(a) The (4 00 ) peak in a $2 \theta$ of 25-27 (b) Lattice parameters of pollucite.

than $\mathrm{Li}^{+}$ion in the mass transfer process. So, it was much easier to occupy/substitute the crystallographic sites of $\mathrm{Cs}^{+}$ion in the pollucite crystal structure with $\mathrm{Na}^{+}$ion.

\subsection{Microstructure evolution}

Figure 8 displays the microstructure of as prepared $\mathrm{Cs}_{(1-x)} \mathrm{Li}_{x} \mathrm{GPs}$. The particles are too small to be observed clearly for pure CsGP. For other $\mathrm{Cs}_{(1-x)} \operatorname{Li}_{x} \mathrm{GPs}(x \geq 0.1)$, the average particle sizes (APSs) are close to $\sim 120, \sim 200$, and $\sim 250 \mathrm{~nm}$ corresponding to $x=0.1,0.2$, and 0.3 , respectively, which could also be attributed to the difference in hydration energy between $\mathrm{Li}^{+}$ion and $\mathrm{Cs}^{+}$ions. By comparison, the hydration energy of $\mathrm{Li}^{+}$was higher than that of $\mathrm{Cs}^{+}$, which means that there were more $\left[\mathrm{AlO}_{4}\right]$ and $\left[\mathrm{SiO}_{4}\right]$ associated with $\mathrm{Li}^{+}$ion than that around $\mathrm{Cs}^{+}$ion in the framework of the geopolymer. Therefore, higher $\mathrm{Li}^{+}$ion contents in the geopolymer always resulted in particles with larger APSs [37]. The same variation trend was also observed in $\mathrm{Cs}_{(1-x)} \mathrm{Na}_{x} \mathrm{GPs}$ system, as shown in Figure 9. 
As for $\mathrm{Cs}_{(1-x)} \mathrm{Li}_{x} \mathrm{GPs}$ system, as shown in Figure 10, these precipitates coarsened substantially and all the geopolymers developed a smooth, glassy texture after heating to $1300^{\circ} \mathrm{C}$. The coarsening was consistent with the considerable shrinkage observed over the sintering temperature range [45]. Closed pore formations were also observed coincident with significant coarsening and surface area reduction. Pollucite crystals could not be directly observed on any of the fracture surfaces of pure CsGP ceramics despite their noticeable presence in the XRD. As for other $\mathrm{Cs}_{(1-x)} \operatorname{Li}_{x} \mathrm{GPs}(x \geq 0.1)$, the corresponding ceramic product derived from it contain large numbers of spherical particles surrounded by a glassy matrix, with the size of coarsening increasing with $\mathrm{Li}^{+}$ion content. The mean diameters of spherical particles were close to $100(x=0.1), \sim 250(x=0.2)$, and $\sim 400 \mathrm{~nm}(x=0.3)$, respectively. The back-scattered electron (BSE) image suggested the presence of diphasic compositions in corresponding ceramic products derived from $\mathrm{Cs}_{(1-x)} \mathrm{Li}_{x} \mathrm{GPs}(x \geq 0.1)$ (Figure 10e). EDS spectra showed that cesium content at point A (Figure 10f) was much higher than that at point B (Figure 10g). Because EDS was a semi-quantitative analytical measure and $\mathrm{Li}^{+}$ion could not be detected by it, so, the results of EDS suggested that spherical particle (point A) and glassy matrix (point B) corresponded to pollucite and spodumene, respectively.

From the fracture morphology after hydrofluoric acid (HF) corrosion, the existence of pollucite grains could be clearly observed in ceramic derived from pure GsGP (Figure 11a). In contrast, a polydisperse distribution of pollucite crystals and pores left after dissolution of molten glass phase during etching after the introduction of $\mathrm{Cs}^{+}$ion, and the coarsening trend of pollucite grains were also obvious (Figure 11).
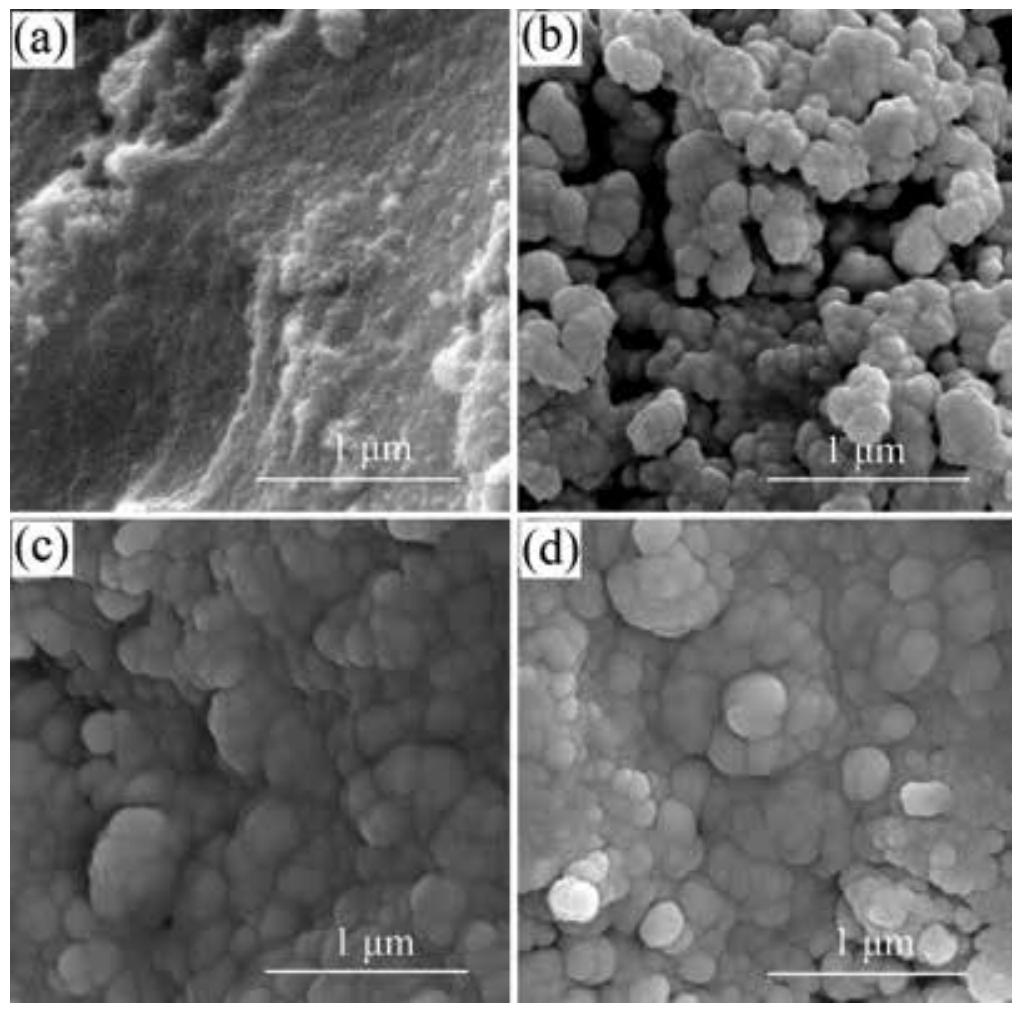

Figure 8.

Microstructure of $\mathrm{Cs}_{(1-x)} L i_{x} G P s,(a) x=0,(b) x=0.1,(c) x=0.2,(d) x=0.3$ (observed from fracture surface). 

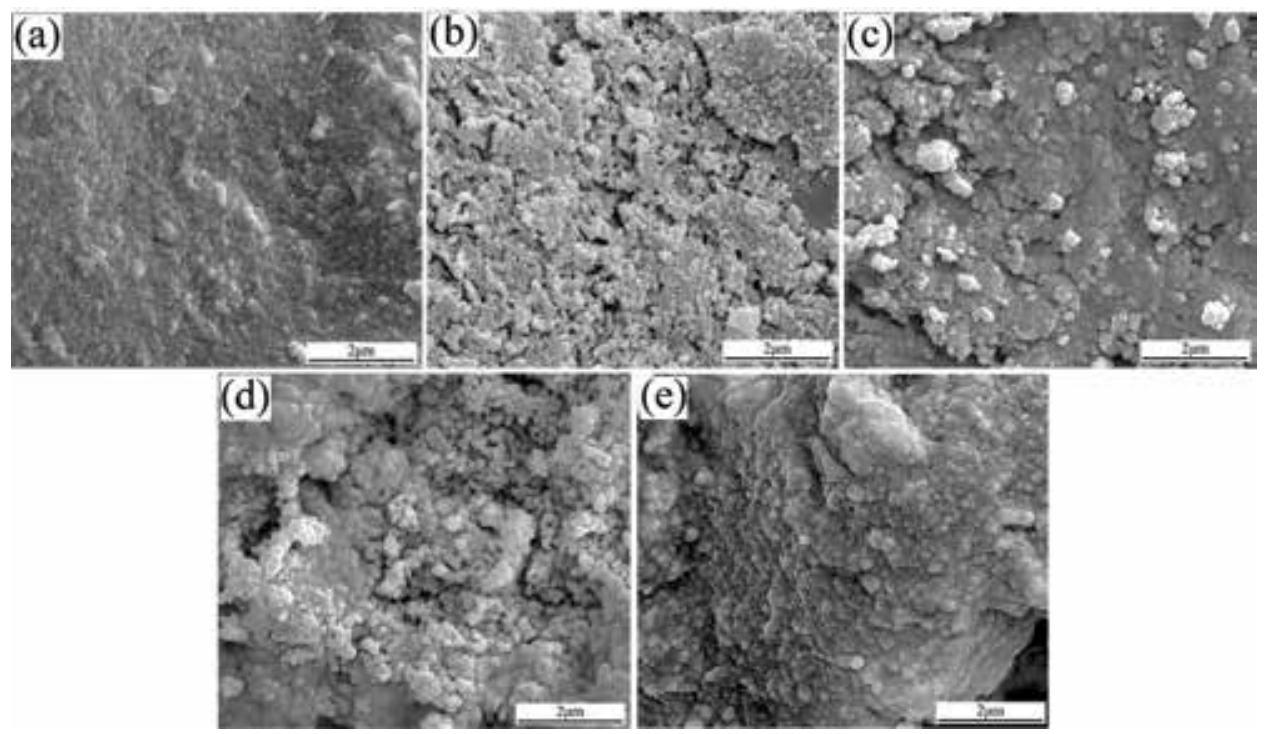

Figure 9.

Microstructure of $C s_{(1-x)} \mathrm{Na}_{x} G P s,(a) x=0,(b) x=0.1,(c) x=0.2,(d) x=0.3,(e) x=0.4$ (observed from fracture surface).

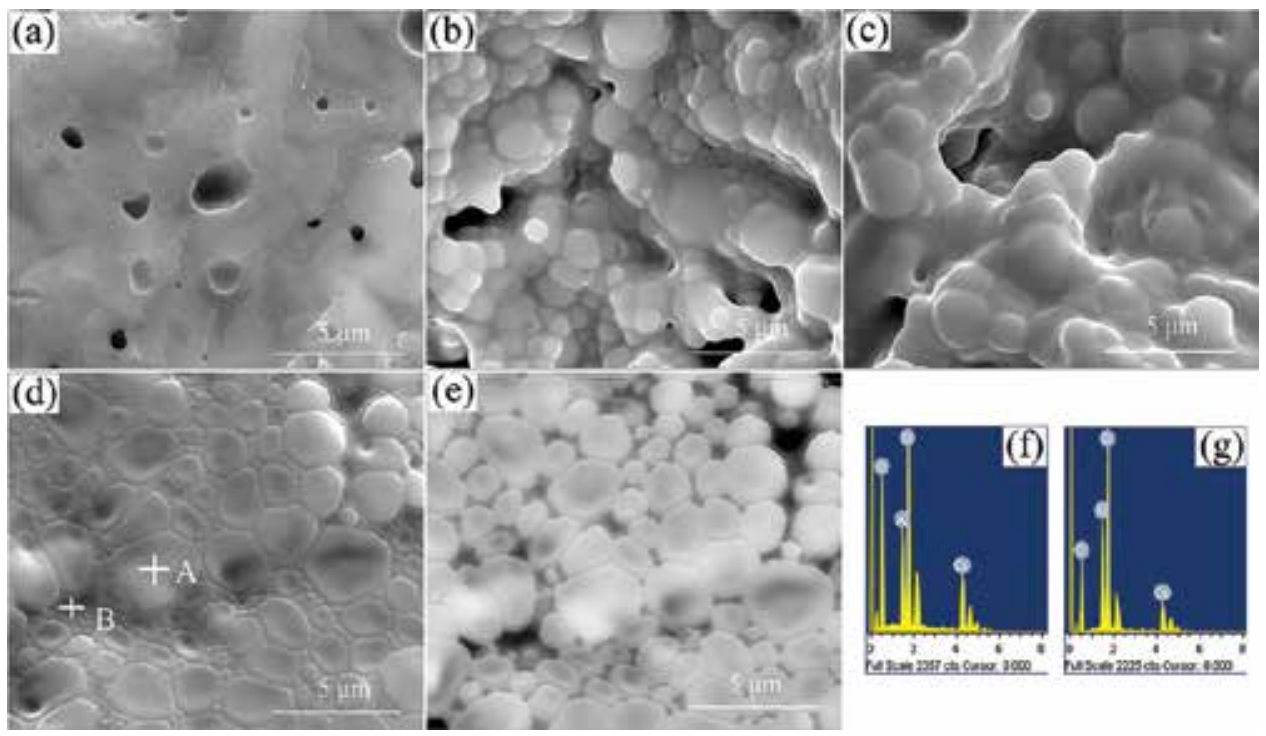

\section{Figure 10.}

Microstructure of ceramics derived from $C s_{(1-x)} L i_{x} G P s,(a) x=0,(b) x=0.1,(c) x=0.2,(d) x=0.3,(e) B S E$ image of $(d),(f)$ EDS spectrum of point $A,(g)$ EDS spectrum of point $B$.

Figure 12 shows TEM analysis of the ceramic derived from $\mathrm{Cs}_{0.7} \mathrm{Li}_{0.3} \mathrm{GP}$. The grain boundaries could be observed clearly, and the selected area electron diffraction (SAED) patterns of area A indicate the existence of spodumene crystallite in the resulting products, which may have arisen from the recrystallization of molten spodumene during cooling. Meanwhile, SAED patterns of area B also proved the corresponding grain should be pollucite, and the spodumene phase, with no fixed shape, mainly distributed among pollucite grains or in the grain junction area.

The microstructure morphologies of ceramic products derived from $\mathrm{Cs}_{(1-x)} \mathrm{Na}_{x} \mathrm{GPs}$ are given in Figure 13. By comparison, the particles coarsened significantly after 


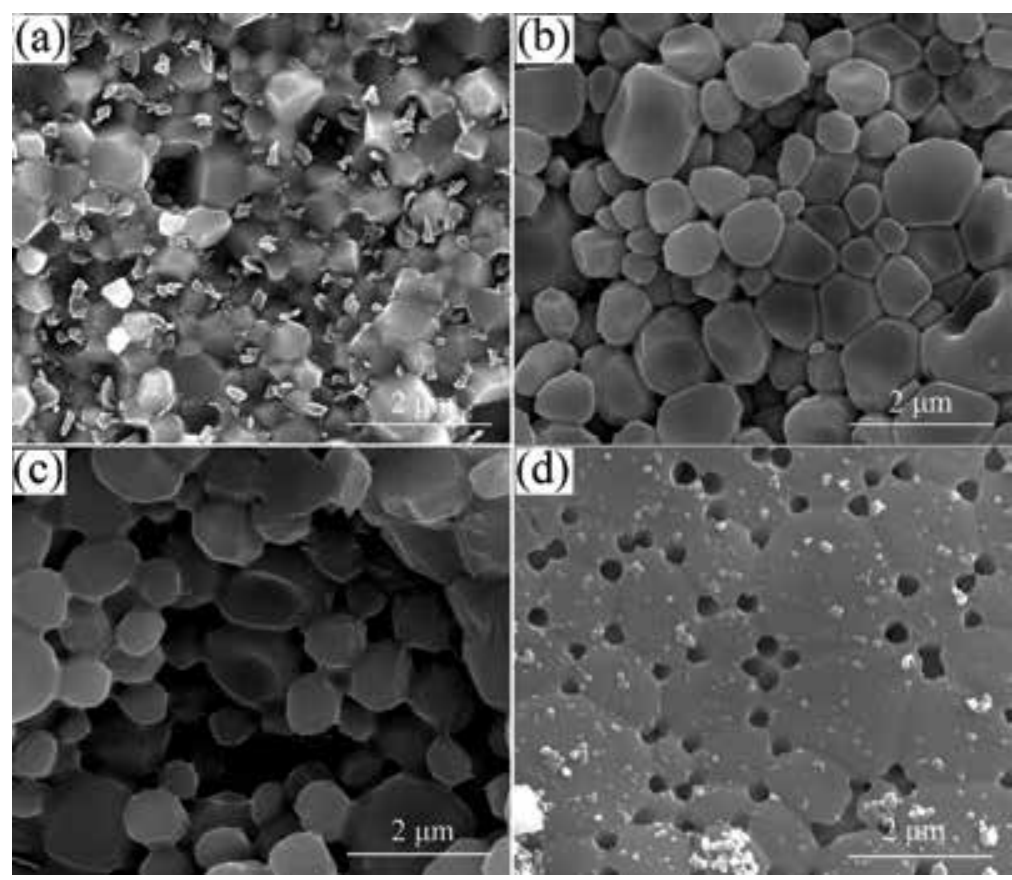

Figure 11.

Microstructure of ceramics derived from $C s_{(1-x)} L i_{x} G P s,(a) x=0,(b) x=0.1,(c) x=0.2,(d) x=0.3$ etched in $4 \mathrm{wt} \% \mathrm{HF}$ at room temperature for $20 \mathrm{~s}$.

being treated at $1300^{\circ} \mathrm{C}$ than that of corresponding unheated $\mathrm{Cs}_{(1-x)} \mathrm{Na}_{x} \mathrm{GP}$ samples. It could be observed that the surface of pollucite grains was covered by smooth and glassy texture. The presence of amorphous glass phase would be conducive to the densification of resulting ceramic products [45].

After etching the samples in $4 \mathrm{wt} \% \mathrm{HF}$ acid for $20 \mathrm{~s}$, pollucite crystals could be clearly observed in ceramics derived from heated $\mathrm{Cs}_{(1-x)} \mathrm{Na}_{x} \mathrm{GPs}$ when $x \leq 0.3$, as shown in Figure 14. It could be clearly observed that the particle size gradually

(a)
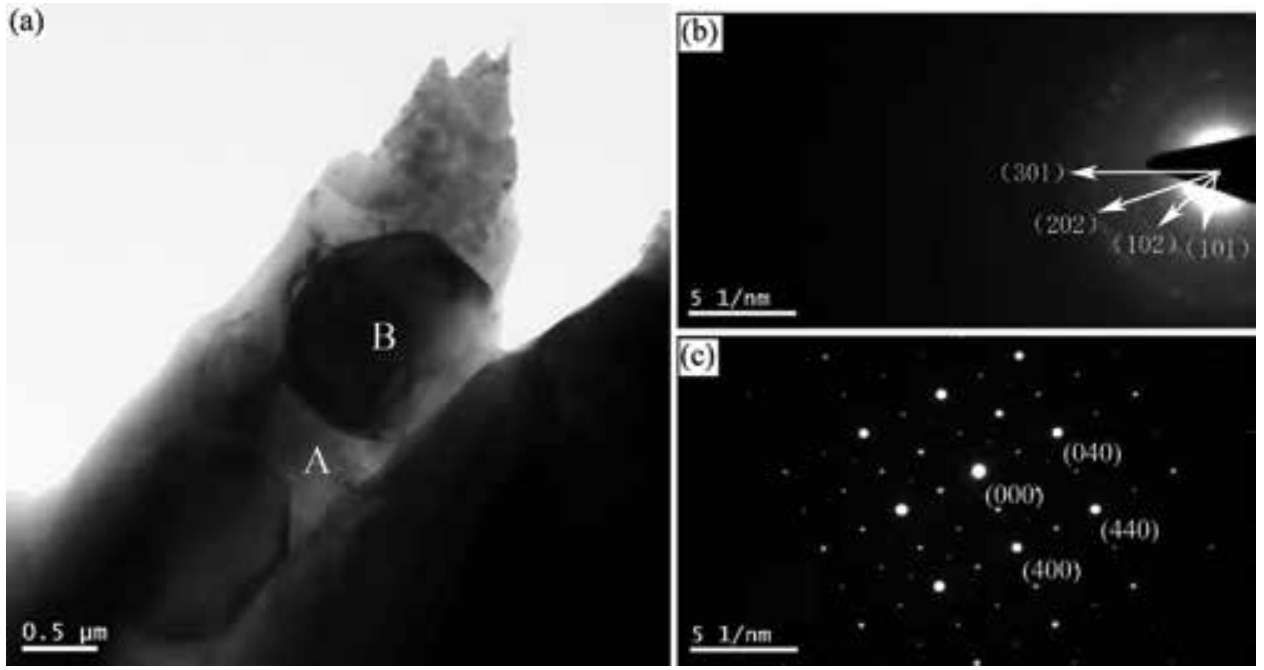

Figure 12.

TEM images of ceramics derived from $C s_{(1-x)} L i_{x} G P s,(a) x=0.3,(b)$ and $(c): S A E D$ patterns of point $A$ and $B$, respectively. 

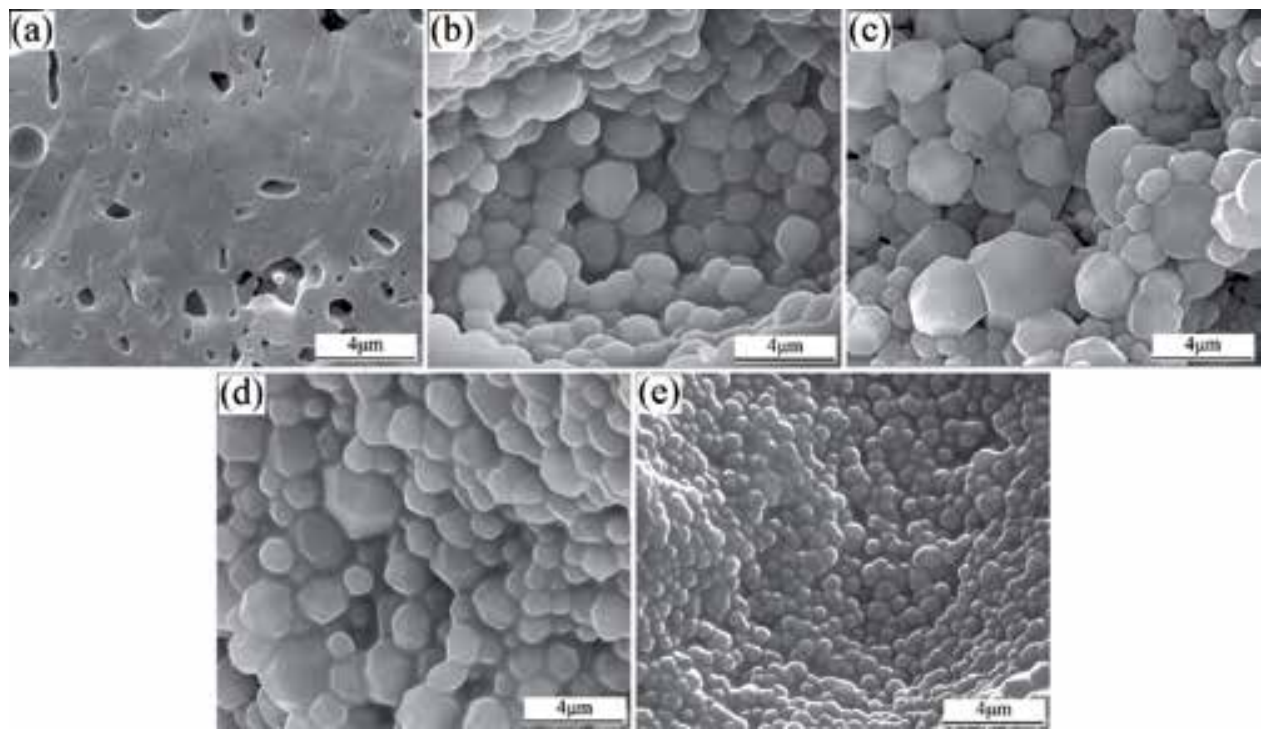

Figure 13.

Microstructure of ceramics derived from $\mathrm{Cs}_{(1-x)} N a_{x} G P s,(a) x=0,(b) x=0.1,(c) x=0.2,(d) x=0.3,(e)$ $x=0.4$.

decreased with increasing $\mathrm{Na}^{+}$ion substitution. Compared with ceramics derived from pure CsGP, many pores could be observed, which should be attributed to the dissolution of the amorphous glass phase in the process of static etching. Due to the content of amorphous glass phase and the $\mathrm{Na}^{+}$ion substitution showed a proportional relationship. So, the residual amorphous glass phase will be more in the sample contained a higher $\mathrm{Na}^{+}$ion substitution. Take $\mathrm{Cs}_{0.6} \mathrm{Na}_{0.4} \mathrm{GPs}$ for example, the vast majority of pollucite grains could not be observed clearly on the corroded surface of corresponding ceramic products due to the higher content of amorphous glass phase.
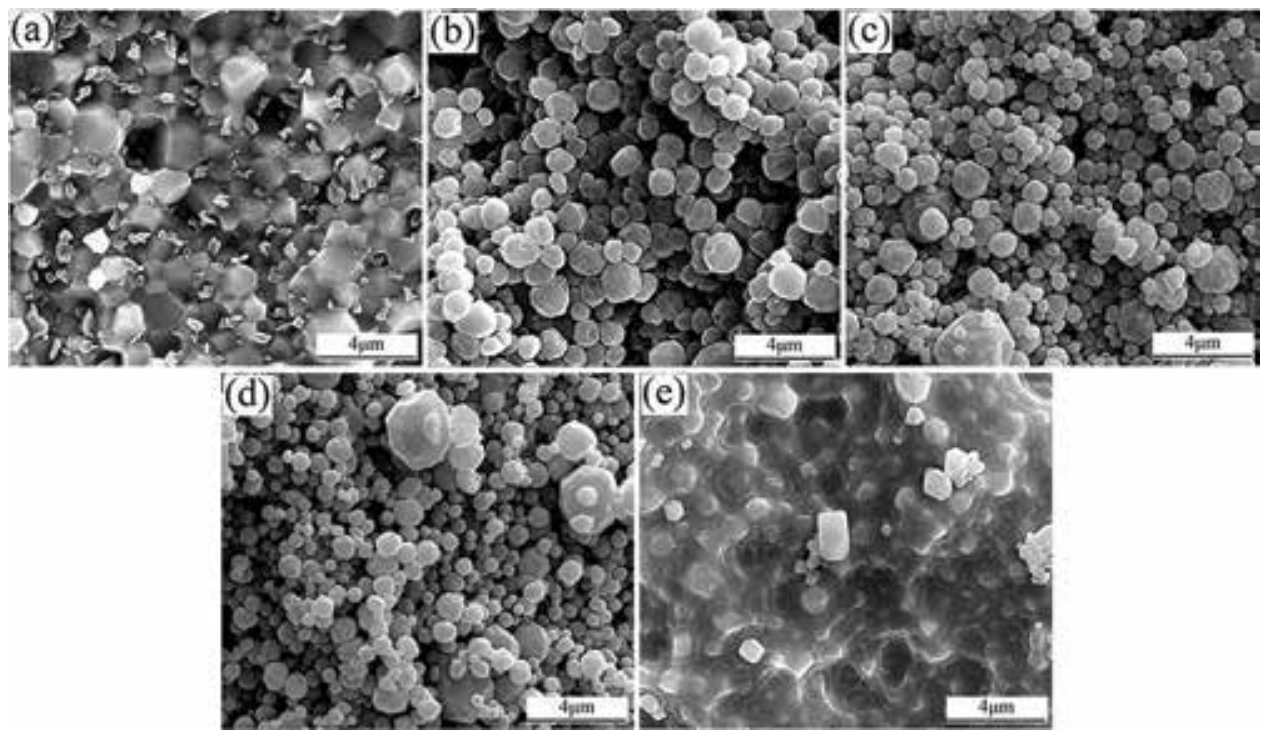

Figure 14.

Microstructure of ceramics derived from $\mathrm{Cs}_{(1-x)} N a_{x} G P s,(a) x=0,(b) x=0.1,(c) x=0.2,(d) x=0.3,(e)$ $x=0.4$ etched in $4 \mathrm{wt} \% \mathrm{HF}$ at room temperature for $20 \mathrm{~s}$. 
Figure 15 shows the TEM analysis of the ceramic evolved from treated $\mathrm{Cs}_{0.6} \mathrm{Na}_{0.4} \mathrm{GP}$. Similar to $\mathrm{Cs}_{(1-x)} \mathrm{Li}_{x} \mathrm{GPs}$ system, the presence of crystal grains could be clearly observed in this diphase composition system. The SAED patterns of area A (Figure 15b) suggested the crystal grain to be pollucite. The results of the map-scan suggested that $\mathrm{Cs}^{+}$ions were distributed only in the interior of crystal grain, which is consistent with the TEM results, as shown in Figure 16. However, $\mathrm{Na}^{+}$showed a completely different distribution. Map-scan results revealed that although the vast majority of $\mathrm{Na}^{+}$distributed among pollucite grains, there was still a small portion present in the interior of pollucite grains, which further demonstrated that $\mathrm{Na}^{+}$ ions partially occupied Cs crystallographic sites of the pollucite framework during high-temperature processing. Combining the SAED patterns of area B (Figure 15c) and the result of the map-scan indicated again that the $\mathrm{Na}^{+}$ion mainly existed in the form of amorphous glass phase and distributed among the pollucite grains.

In heated $\mathrm{Cs}_{(1-x)} \mathrm{Li}_{x} \mathrm{GPs}$ system, the particle size of pollucite coarsened with increases in Li substitution. However, $\mathrm{Cs}_{(1-x)} \mathrm{Na}_{x} \mathrm{GPs}$ system showed a distinctly different variation tendency, in which the particle size of pollucite grains gradually decreased with increasing $\mathrm{Na}^{+}$ion substitution. The phenomenon of grain refinement in heated $\mathrm{Cs}_{(1-x)} \mathrm{Na}_{x} \mathrm{GPs}$ system may have a direct relationship with the presence of zeolite nucleus in corresponding unheated samples. The zeolite nucleus formed in the unheated $\mathrm{Cs}_{(1-x)} \mathrm{Na}_{x} \mathrm{GP}$ samples could serve as the nucleation site of pollucite and accelerate the crystallization process of pollucite. As already mentioned, the number of zeolite nucleus was proportional to $\mathrm{Na}^{+}$ion introduction. Therefore, the growth of pollucite grains was more dispersed as the nucleation sites increased.

\subsection{Sintering mechanism}

A possible sintering mechanism of $\mathrm{Cs}_{(1-x)} \mathrm{Li}_{x} \mathrm{GP}$ system can be suggested in light of the theory of reactive liquid-phase sintering [46]. The composition of
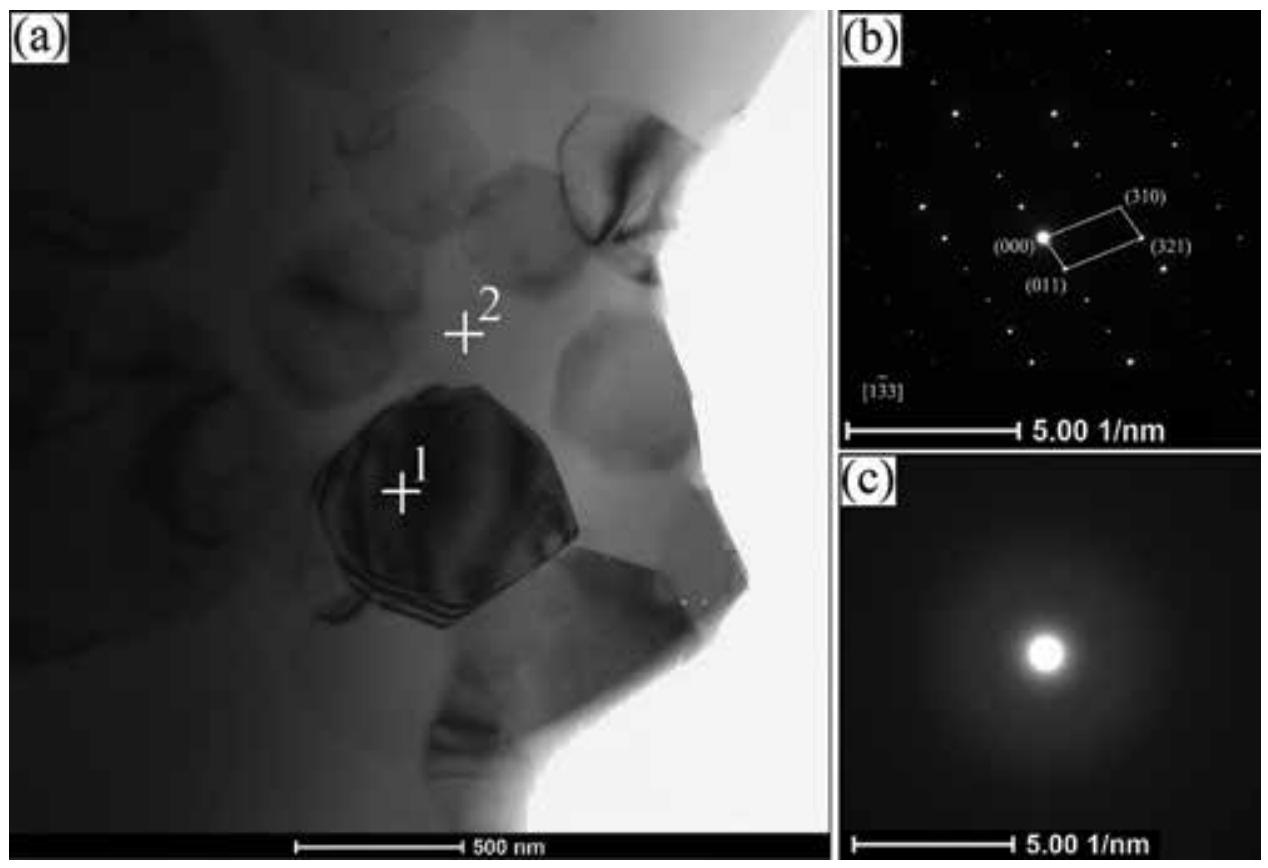

Figure 15.

TEM images of ceramics derived from $C s_{(1-x)} N a_{x} G P s,(a) x=0.4,(b)$ and $(c): S A E D$ patterns of point 1 and 2 , respectively. 


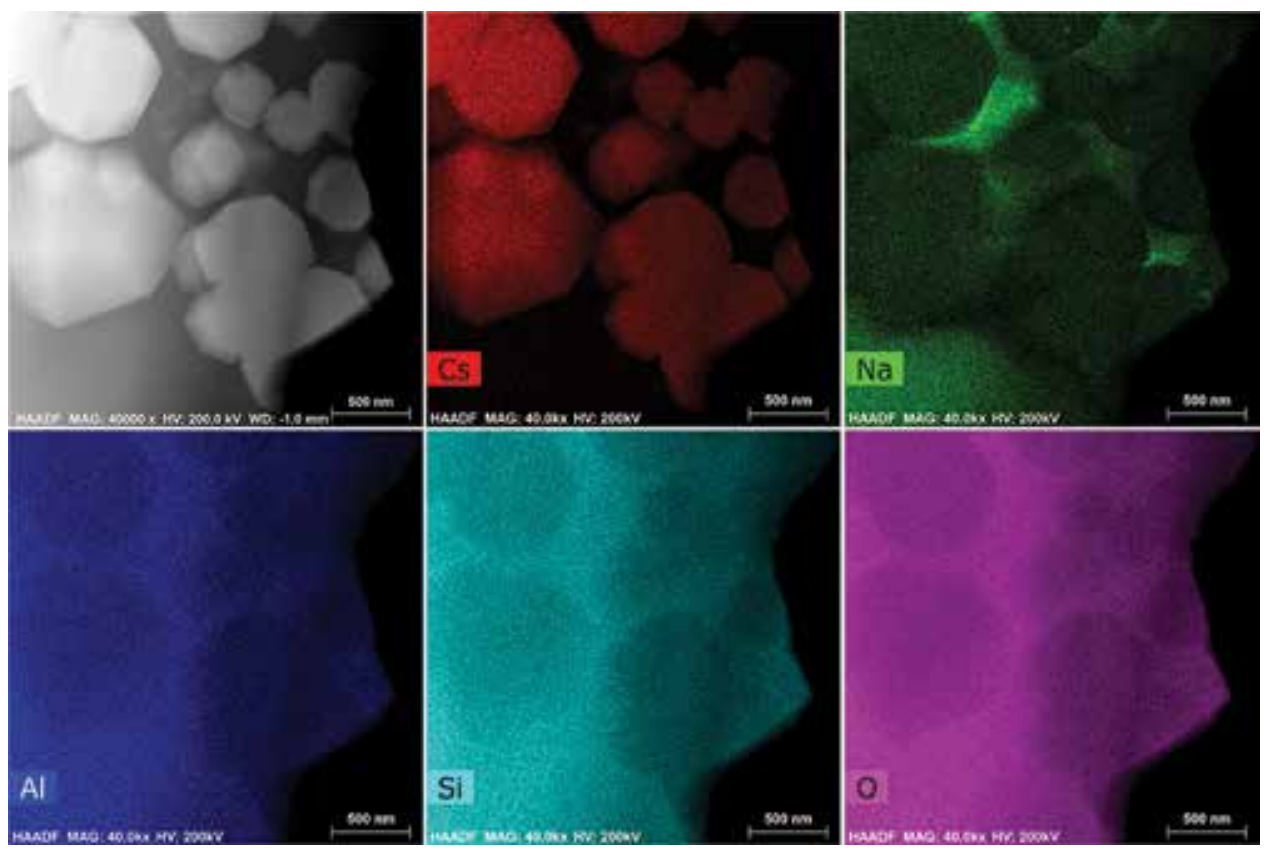

Figure 16.

HAADF-STEM and STEM-EDX images illustrating the element distribution.

$\mathrm{Cs}_{(1-x)} \mathrm{Li}_{x} \mathrm{GP}$ can be expressed as $(1-x) \mathrm{Cs}_{2} \mathrm{O} \cdot x \mathrm{Li}_{2} \mathrm{O} \cdot \mathrm{Al}_{2} \mathrm{O}_{3} \cdot 4 \mathrm{SiO}_{2} \cdot w \mathrm{H}_{2} \mathrm{O}$. In fact, both $\mathrm{Li}^{+}$and $\mathrm{Cs}^{+}$ions were present as silicates, that is, $x_{1} \mathrm{Li}_{2} \mathrm{O} \cdot y_{1} \mathrm{SiO}_{2}$ and $x_{2} \mathrm{Cs}_{2} \mathrm{O} \cdot y_{2} \mathrm{SiO}_{2}$ (the complexity of composition and structure of silicate indicated that $x_{1}, y_{1}, x_{2}$, and $y_{2}$ did not have a certain value). Therefore, it was reasonable to employ $\mathrm{Li}_{2} \mathrm{O}$ and $\mathrm{Cs}_{2} \mathrm{O}$ to express the form of $\mathrm{Li}^{+}$and $\mathrm{Cs}^{+}$ions in this system.

It well known that alkaline metal oxides often participated in the sintering process as a sintering aid in many low-temperature sintering systems $[46,47]$. In addition, as a typical network-modifying agent, the presence of $\mathrm{Li}_{2} \mathrm{O}$ or $\mathrm{Li}^{+}$ ion could promote the densification process of sintering [48-51]. Similarly, the reaction between the alkaline metal oxide dopant and the matrix phase was studied and results showed that the mechanism was exactly the same in many cases. Hence, as for the $\mathrm{Cs}_{(1-x)} \mathrm{Li}_{x} \mathrm{GP}$ system, $\mathrm{Li}^{+}$was an intermediate cation with a stronger electric field intensity in the glass-ceramic system than that of $\mathrm{Cs}^{+}$ion [52]. Thus, with increases in temperature of high-temperature processing, the reaction between $\mathrm{Li}_{2} \mathrm{O}, \mathrm{Al}_{2} \mathrm{O}_{3}$, and $\mathrm{SiO}_{2}$ first occurred at a lower temperature, as in Eq. (1).

$$
\mathrm{Li}_{2} \mathrm{O}(\mathrm{s})+\mathrm{SiO}_{2}(\mathrm{~s})+\mathrm{Al}_{2} \mathrm{O}_{3}(\mathrm{~s}) \rightarrow \mathrm{LiAlSi}_{2} \mathrm{O}_{6}(l)
$$

The presence of liquid spodumene $\left(\mathrm{LiAlSi}_{2} \mathrm{O}_{6}\right)$ and the simultaneous reaction between $\mathrm{Li}_{2} \mathrm{O}$ and the matrix phase decreased the viscosity of the geopolymer system, which doubtlessly accelerated the kinetics of mass-transport processes during the low-temperature sintering. The changes in the sintering processes could reflect from the variation tendency in thermal shrinkage curves with different lithium contents (Figure 3). As the processing temperature rose further, the reaction between $\mathrm{Cs}_{2} \mathrm{O}, \mathrm{Al}_{2} \mathrm{O}_{3}$, and $\mathrm{SiO}_{2}$ would occur at a higher temperature compared with the onset temperature of spodumene, as in Eq. (2).

$$
\mathrm{Cs}_{2} \mathrm{O}(\mathrm{s})+\mathrm{SiO}_{2}(\mathrm{~s})+\mathrm{Al}_{2} \mathrm{O}_{3}(\mathrm{~s}) \rightarrow \mathrm{CsAlSi}_{2} \mathrm{O}_{6}(s)
$$


The presence of liquid spodumene increased the rates of mass transfer and diffusion more easily, conducive to nucleation and crystallization of pollucite $\left(\mathrm{CsAlSi}_{2} \mathrm{O}_{6}\right)$. This was consistent with the decrease in crystallization temperature and the grain coarsening behavior observed above with increasing lithium substitution. Meanwhile, the degree of densification was greatly improved as well. Therefore, the presence of $\mathrm{Li}^{+}$ion contributed to the crystallization and sintering densification via aiding the liquid-phase processes.

The sintering process of the $\mathrm{Cs}_{(1-x)} \mathrm{Na}_{x} \mathrm{GP}$ system was similar to that of the $\mathrm{Cs}_{(1-x)} \mathrm{Li}_{x} \mathrm{GP}$ system. The results above have already proved that $\mathrm{Cs}_{(1-x)} \mathrm{Na}_{x} \mathrm{GP}$ ceramics only contained pollucite and amorphous glass phase. Therefore, the main difference in the sintering process between $\mathrm{Cs}_{(1-x)} \mathrm{Li}_{x} \mathrm{GP}$ and $\mathrm{Cs}_{(1-x)} \mathrm{Na}_{x} \mathrm{GP}$ systems lied in the low-temperature area. The reaction between $\mathrm{Na}_{2} \mathrm{O}, \mathrm{Al}_{2} \mathrm{O}_{3}$, and $\mathrm{SiO}_{2}$ in the $\mathrm{Cs}_{(1-x)} \mathrm{Na}_{x} \mathrm{GP}$ system would occur first at a lower temperature, as in Eq. (3).

$$
\mathrm{Na}_{2} \mathrm{O}(\mathrm{s})+\mathrm{SiO}_{2}(\mathrm{~s})+\mathrm{Al}_{2} \mathrm{O}_{3}(\mathrm{~s}) \rightarrow \text { amorphous glass }(l)
$$

In addition to this lower temperature, the sintering process of the two systems also experienced almost the same process at higher temperature intervals.

\subsection{Thermal expansion behavior}

The results of the dilatometric measurement for $\mathrm{Cs}_{(1-x)} \mathrm{Li}_{x} \mathrm{GP}$ and $\mathrm{Cs}_{(1-x)} \mathrm{Na}_{x} \mathrm{GP}$ ceramics with correction are shown in Figure 17. The thermal expansion of ceramics derived from $\mathrm{Cs}_{(1-x)} \mathrm{Li}_{x} \mathrm{GP}$ and $\mathrm{Cs}_{(1-x)} \mathrm{Na}_{x} \mathrm{GP}$ systems showed an increasing trend with increase in temperature, which could be attributed to the larger atomic spacing at elevated temperatures.

The average thermal expansion coefficient (CTE) was defined as the average value of the relative length change in the temperature range of $\mathrm{T}_{1}<\mathrm{T}<\mathrm{T}_{2}$, as described by the following Eq. (4):

$$
\alpha_{\mathrm{a}}=\left(L_{2}-L_{1}\right) / L_{0}\left(T_{2}-T_{1}\right)=\Delta L / L_{0} \Delta T
$$

where $L_{0}, L_{1}$, and $L_{2}$ are the lengths of the specimen at temperatures of $T_{0}$ $\left(30^{\circ} \mathrm{C}\right), T_{1}$, and $T_{2}$, respectively. From Figure 14, both curves have two very different slopes before and after $\sim 150^{\circ} \mathrm{C}$, indicating that there was a phase transition for pollucite from tetragonal to cubic $[24,25]$. Thus, the average CTE of $\mathrm{Cs}_{(1-x)} \mathrm{Li}_{x} \mathrm{GPs}$ was computed based on data in the interval from 150 to $900^{\circ} \mathrm{C}$.
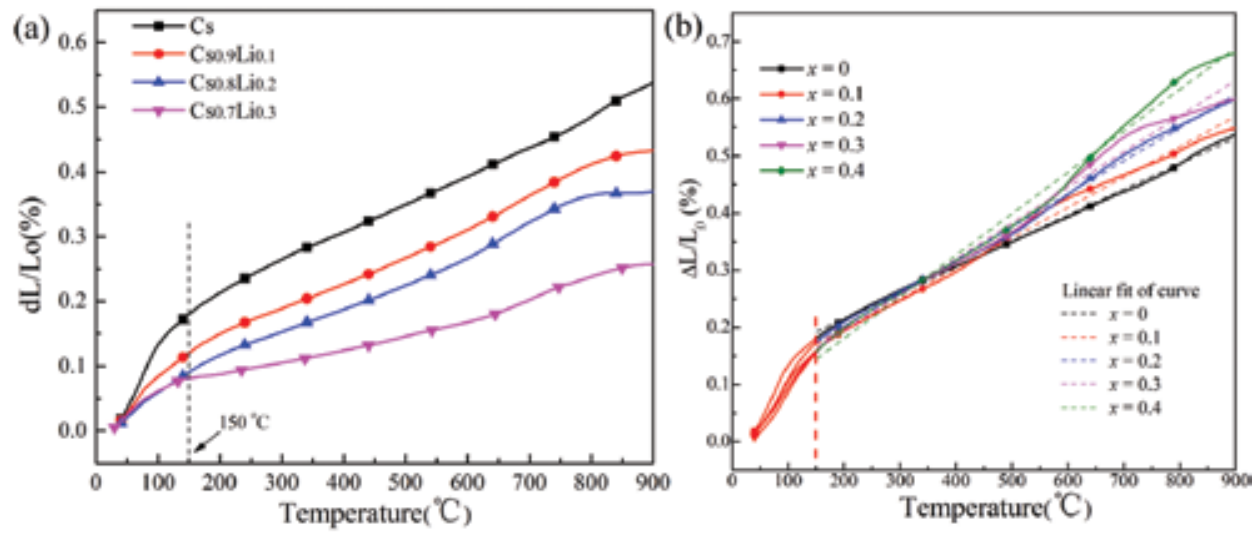

Figure 17.

Linear coefficient of thermal expansion of $C s_{(1-x)} L i_{x} G P(a)$ and $C s_{(1-x)} N a_{x} G P$. 
As for $\mathrm{Cs}_{(1-x)} \mathrm{Li}_{x} \mathrm{GP}$ ceramics, as depicted in Figure 18, it could be observed that the average CTE decreased from $4.80 \times 10^{-6} \mathrm{~K}^{-1}(x=0)$ to $3.61 \times 10^{-6} \mathrm{~K}^{-1}(x=0.3)$. The results obtained from our previous study on the $\mathrm{K}_{(1-x)} \mathrm{Cs}_{x} \mathrm{GP}$ system proved that increase in $\mathrm{Cs}^{+}$ion introduction would decrease the average CTE of the resulting leucite ceramic. The reason could be attributed to the substitution between $\mathrm{Cs}^{+}$ and $\mathrm{K}^{+}$in the leucite framework [33]. However, as for $\mathrm{Cs}_{(1-x)} \mathrm{Li}_{x} \mathrm{GP}$ ceramics, the $\mathrm{XRD}$ results indicated almost no changes in lattice constants of pollucite, which suggested that the integrity of pollucite crystal cell was unchanged after partial substitution by $\mathrm{Li}^{+}$ion. XRD quantitative analysis suggested that the content of spodumene in resulting ceramic products was proportional to the amount of $\mathrm{Li}^{+}$ ion substitution. By comparison, spodumene had a lower CTE $\left(1.0 \times 10^{-6} \mathrm{~K}^{-1}\right)$ than that of pollucite. Therefore, the presence of spodumene could significantly reduce CTE of the whole system, and the higher content of spodumene meant lower CTE. Another reason could be attributed to the role of molten spodumene, possibly as a buffer phase exists between pollucite crystals. Hence, with the increase in $\mathrm{Li}$ substitution or spodumene content, the average CTE of $\mathrm{Cs}_{(1-x)} \mathrm{Li}_{x} \mathrm{GP}$ ceramics decreased evidently.

However, the calculated results showed that the average CTE of $\mathrm{Cs}_{(1-x)} \mathrm{Na}_{x} \mathrm{GP}$ ceramic products showed a completely different variation pattern compared with $\mathrm{Cs}_{(1-x)} \mathrm{Li}_{x} \mathrm{GP}$ ceramic products, increasing from $4.80 \times 10^{-6} \mathrm{~K}^{-1}(x=0)$ to $7.26 \times 10^{-6} \mathrm{~K}^{-1}(x=0.4)$ with the rise of sodium substitution.

For $\mathrm{K}_{(1-x)} \mathrm{Cs}_{x} \mathrm{GPs}$ system involved in our previous studies, the average CTE of the leucite ceramic decreased with increase in the amount of $\mathrm{Cs}^{+}$ion introduced. The reason could be ascribed to $\mathrm{Cs}^{+}$occupying/substituting $\mathrm{K}^{+}$crystallographic sites in the leucite framework, which led to the increase in content of stabilized cubic leucite in resulting ceramic products [33]. However, there was no evidence to suggest any substitution at the lattice level between $\mathrm{Li}^{+}$and $\mathrm{Cs}^{+}$in the $\mathrm{Cs}_{(1-x)} \mathrm{Li}_{x} \mathrm{GP}$ system. Besides, as a diphase system, pollucite and spodumene were present as independent components in the resulting products [38]. Therefore, one could conclude that the decline of average CTE was mainly due to the fact that CTE of spodumene was far lower than that of pollucite.

As for $\mathrm{Cs}_{(1-x)} \mathrm{Na}_{x} \mathrm{GP}$ ceramics, XRD results suggested that the substitution between $\mathrm{Na}^{+}$and $\mathrm{Cs}^{+}$ions caused the decline of lattice constant of pollucite. According to the Ikuo et al. reports, the increase in $\mathrm{Na}^{+}$in the crystal lattice could decrease the thermal expansion of the pollucite, and with the increase in $\mathrm{Na}^{+}$ion substitution, the average CTE of ceramics derived from heated $\mathrm{Cs}_{(1-x)} \mathrm{Na}_{x} \mathrm{GPs}$ decreased [24-26]. However, compared with $\mathrm{Cs}_{(1-x)} \mathrm{Li}_{x} \mathrm{GPs}$ system, the CTE of $\mathrm{Cs}_{(1-x)} \mathrm{Na}_{x} \mathrm{GP}$ ceramics showed an opposite trend with increasing $\mathrm{Na}^{+}$ion
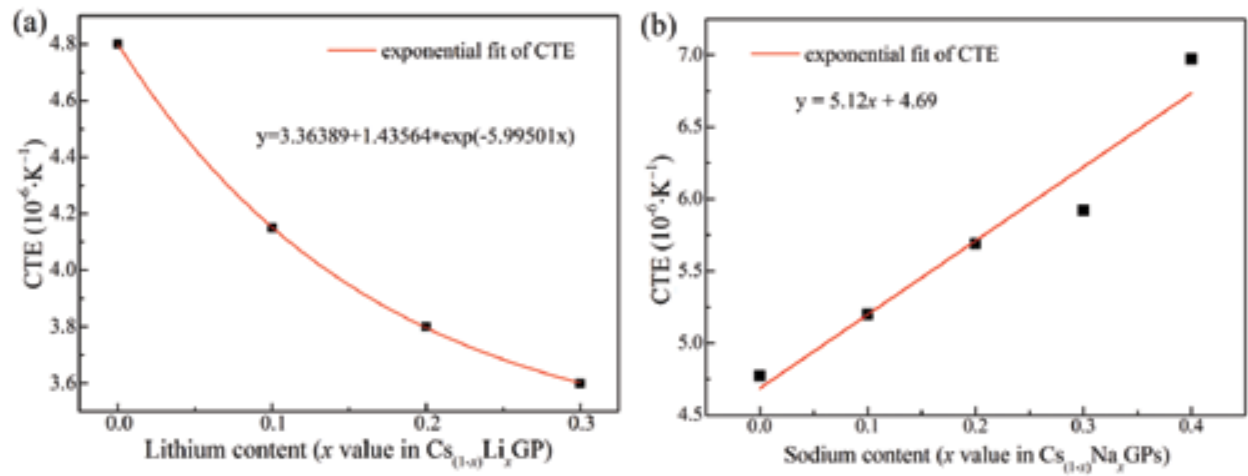

Figure 18.

Thermal expansion properties of $C s_{(1-x)} L i_{x} G P$ ceramics (a) and $C s_{(1-x)} N a_{x} G P$ ceramics $(b)$. 
substitution. The average CTE of $\mathrm{Cs}_{(1-x)} \mathrm{Na}_{x} \mathrm{GP}$ ceramics continued to rise with the increase in content of $\mathrm{Na}^{+}$ion introduction. It is well known that amorphous glass phase containing $\mathrm{Na}^{+}$ion always had a higher CTE $\left(9 \sim 10 \times 10^{-6} \mathrm{~K}^{-1}\right)$ than that of pollucite $\left(\sim 4.80 \times 10^{-6} \mathrm{~K}^{-1}\right)$ [53-56]. By contrast, the effect on CTE caused by the presence of the amorphous glass phase was much stronger than the impact caused by the substitution of $\mathrm{Na}^{+}$for $\mathrm{Cs}^{+}$in lattice level. So, the presence of amorphous glass phase could account for the rise of average CTE. The content of amorphous glass phase was proportional to the amount of $\mathrm{Na}^{+}$ion substitution. Therefore, the average CTE of ceramics derived from $\mathrm{Cs}_{(1-x)} \mathrm{Na}_{x} \mathrm{GPs}$ increased almost linearly with the increasing sodium content.

\section{Conclusions}

In this chapter, the effects of ion substitution on the thermal evolution of cesium-based geopolymers on heating were studied. The following conclusions could be obtained based on the current results.

i. The introduction of $\mathrm{Li}^{+}$or $\mathrm{Na}^{+}$could favor the formation of pollucite in $\mathrm{Cs}_{(1-x)} \mathrm{M}_{x} \mathrm{GPs}(x \geq 0.1)$, respectively. A possible reason could be attributed to the formation of zeolite nucleus, which could serve as the nucleation sites for pollucite. This also provided a novel method for preparing pollucite at low temperature, even at room temperature.

ii. $\mathrm{Cs}_{(1-x)} \mathrm{M}_{x} \mathrm{GPs}$ with different content of ionic replacement showed a similar thermal evolution process. The introduction of $\mathrm{Li}^{+}$or $\mathrm{Na}^{+}$changed the sintering mechanism through decreased onset temperature for viscous sintering stage. With the introduction of more $\mathrm{Li}^{+}$or $\mathrm{Na}^{+}$, the amorphous glass phase in resulting products would be conducive to its densification process. The introduction of $\mathrm{Li}^{+}$ion led to particle coarsening in part because of the rapid formation of a liquid phase on heating and perhaps because the hydration energy of $\mathrm{Li}^{+}$is greater than that of $\mathrm{Cs}^{+}$. However, the particle size of pollucite grain gradually decreased with the increase in $\mathrm{Na}^{+}$contents in $\mathrm{Cs}_{(1-x)} \mathrm{Na}_{x} \mathrm{GP}$ ceramics, which had a close relationship with the role of $\mathrm{Na}^{+}$ ion in the nucleation process of pollucite.

iii. Compared with traditional way, geopolymer technology could be an excellent alternative to fabricate ceramics or ceramic matrix composites in an in-situ convert way. In the $\mathrm{Cs}_{(1-x)} \mathrm{Li}_{x} \mathrm{GP}$ ceramics, the introduction of $\mathrm{Li}^{+}$results in the formation of a multiphase system, including pollucite, spodumene, and amorphous glass phase, and $\mathrm{Li}^{+}$only existed inside the spodumene grains. In contrast, two forms of $\mathrm{Na}^{+}$ions were present in the ceramic products derived from $\mathrm{Cs}_{(1-x)} \mathrm{Na}_{x} \mathrm{GPs}$. Therefore, a small portion was present in the pollucite grains due to $\mathrm{Na}^{+}$occupying/substituting $\mathrm{Cs}^{+}$crystallographic sites of the pollucite framework, while the rest were mostly present in the amorphous glass phase and distributed among the pollucite grains.

iv. The average CTE of ceramics derived from $\mathrm{Cs}_{(1-x)} \mathrm{Li}_{x} \mathrm{GPs}$ and $\mathrm{Cs}_{(1-x)} \mathrm{Na}_{x} \mathrm{GPs}$ showed a completely different variation pattern. The reason could be attributed to the difference between two kinds of substituted ion species, which resulted in different phase composition in the corresponding resulting products. 
Thermal Evolution of Geopolymer in the Process of High-Temperature Treatment DOI: http://dx.doi.org/10.5772/intechopen.81610

\section{Acknowledgements}

The authors acknowledge the support from the National Natural Science Foundation of China (NSFC, Nos. 51372048, 51502052, 51321061 and 51225203). The grant from Fundamental Research Funds for the Central Universities (Grant no. HITNSRIF20165) is also acknowledged.

\section{Author details}

Jingkun Yuan ${ }^{1 *}$, Peigang $\mathrm{He}^{1}$ and Dechang Jia ${ }^{1,2}$

1 Institute for Advanced Ceramics, School of Materials Science and Engineering, Harbin Institute of Technology, Harbin, Heilongjiang, China

2 State Key Laboratory of Advanced Welding and Joining, Harbin Institute of Technology, Harbin, Heilongjiang, China

*Address all correspondence to: yuanjingkun@126.com

\section{IntechOpen}

(C) 2020 The Author(s). Licensee IntechOpen. This chapter is distributed under the terms of the Creative Commons Attribution License (http://creativecommons.org/licenses/ by/3.0), which permits unrestricted use, distribution, and reproduction in any medium, provided the original work is properly cited. (cc) BY 


\section{References}

[1] Hlaváček P et al. Inorganic foams made from alkali-activated fly ash: Mechanical, chemical and physical properties. Journal of the European Ceramic Society. 2015;35(2):703-709

[2] Favier A et al. Mechanical properties and compositional heterogeneities of fresh geopolymer pastes. Cement and Concrete Research. 2013;48:9-16

[3] Zhang Z, Yao X, Zhu H. Potential application of geopolymers as protection coatings for marine concrete I. Basic properties. Applied Clay Science. 2010;49(1-2):1-6

[4] Barbosa VFF, MacKenzie KJD. Thermal behaviour of inorganic geopolymers and composites derived from sodium polysialate. Materials Research Bulletin. 2003;38(2):319-331

[5] Slaty F et al. Durability of alkali activated cement produced from kaolinitic clay. Applied Clay Science. 2015;104(0):229-237

[6] Rickard W, Vickers L, van Riessen A. Performance of fibre reinforced, low density metakaolin geopolymers under simulated fire conditions. Applied Clay Science. 2013;73:71-77

[7] Temuujin J et al. Fly ash based geopolymer thin coatings on metal substrates and its thermal evaluation. Journal of Hazardous Materials. 2010;180(1-3):748-752

[8] Abdollahnejad Z et al. Mix design, properties and cost analysis of fly ashbased geopolymer foam. Construction and Building Materials. 2015;80:18-30

[9] Rahier $\mathrm{H}$ et al. Reaction mechanism, kinetics and high temperature transformations of geopolymers. Journal of Materials Science. 2006;42(9):2982-2996
[10] Messina et al. Alkali activated waste fly ash as sustainable composite: Influence of curing and pozzolanic admixtures on the early-age physicomechanical properties and residual strength after exposure at elevated temperature. Composites Part B-Engineering. 2018;132:161-169

[11] Huseien GF et al. Geopolymer mortars as sustainable repair material: A comprehensive review. Renewable \& Sustainable Energy Reviews. 2017;80:54-74

[12] MacKenzie KJD et al. Formation of aluminosilicate geopolymers from 1:1 layer-lattice minerals pre-treated by various methods: A comparative study. Journal of Materials Science. 2007;42(12):4667-4674

[13] Bell JL, Driemeyer PE, Kriven WM. Formation of ceramics from metakaolin-based geopolymers: Part I-Cs-based geopolymer. Journal of the American Ceramic Society. 2009;92(1):1-8

[14] Bell JL, Driemeyer PE, Kriven WM. Formation of ceramics from metakaolin-based geopolymers. Part II: K-based geopolymer. Journal of the American Ceramic Society. 2009;92(3):607-615

[15] El-Naggar MR, Amin M. Impact of alkali cations on properties of metakaolin and metakaolin/ slag geopolymers: Microstructures in relation to sorption of Cs-134 radionuclide. Journal of Hazardous Materials. 2018;344:913-924

[16] Rees CA et al. In situ ATR-FTIR study of the early stages of fly ash geopolymer gel formation. Langmuir. 2007;23(17):9076-9082

[17] Cundy CS, Cox PA. The hydrothermal synthesis of zeolites: 
Precursors, intermediates and reaction mechanism. Microporous and Mesoporous Materials. 2005;82(1-2):1-78

[18] Brady PV, Walther JV. Controls on silicate dissolution rates in neutral and basic $\mathrm{pH}$ solutions at $25^{\circ} \mathrm{C}$. Geochimica et Cosmochimica Acta. 1989;53(11):2823-2830

[19] Duxson P, Lukey GC, van Deventer JSJ. Thermal evolution of metakaolin geopolymers: Part 1-Physical evolution. Journal of Non-Crystalline Solids. 2006;352(52-54):5541-5555

[20] Fernández-Jiménez A, Palomo A. Composition and microstructure of alkali activated fly ash binder: Effect of the activator. Cement and Concrete Research. 2005;35(10):1984-1992

[21] Fernández-Jiménez A, Palomo A, Criado M. Microstructure development of alkali-activated fly ash cement: A descriptive model. Cement and Concrete Research. 2005;35(6):1204-1209

[22] Fernández-Jiménez A et al. "Metakaolin-slag-clinker blends". The Role of $\mathrm{Na}^{+}$or $\mathrm{K}^{+}$as alkaline activators of theses ternary blends. Journal of the American Ceramic Society. 2013;96(6):1991-1998

[23] Duxson P et al. K-39 NMR of free potassium in geopolymers. Industrial \& Engineering Chemistry Research. 2006;45(26):9208-9210

[24] Ikuo Y, Sachiko T, Hidehiko K. Lowthermal-expansion properties of sodium- and lithium-substituted cubic cesium leucite compounds. Journal of the American Ceramic Society. 2003;86(8):1360-1364

[25] Yanase I, Ichiyoshi K, Kobayashi $\mathrm{H}$. Structural phase transition of Na-substituted Cs-leucite compounds in the range 123-1173 K. Solid State Communications. 2006;139(1):1-4

[26] Kobayashi $\mathrm{H}$ et al. Phase transition and lattice thermal expansion of cs-deficient pollucite, $\mathrm{Cs}_{1-\mathrm{x}} \mathrm{Al}_{1-\mathrm{x}} \mathrm{Si}_{2+\mathrm{x}} \mathrm{O}_{6}$ $(x \leq 0.25)$, compounds. Journal of the American Ceramic Society. 2006;89(10):3157-3161

[27] Yanase I, Konakawa J, Kobayashi $\mathrm{H}$. Influence of cesium nitrate and heating rate on densification and microstructure of Cs-deficient pollucite sintered body. Journal of the American Ceramic Society. 2006;89(1):184-188

[28] Yanase I et al. Fabrication of low thermal expansion porous body of cubic cesium-deficient type pollucite. Journal of the European Ceramic Society. 2005;25(13):3173-3179

[29] Yanase I et al. Tetragonal-to-cubic structural phase transition in pollucite by low-temperature X-ray powder diffraction. Journal of the American Ceramic Society. 1997;80(10):2693-2695

[30] Yanase I, Kobayashi H, Mitamura T. Thermal expansion property of synthetic cubic leucite-type compounds. Journal of the Ceramic Society of Japan. 2000;108(1):26-31

[31] Yanase I, Kobayashi H, Mitamura $\mathrm{T}$. Thermal property and phase transition of the synthesized new cubic leucite-type compounds. Journal of Thermal Analysis and Calorimetry. 1999;57(3):695-705

[32] Yanase I, Ishikawa Y, Kobayashi $\mathrm{H}$. Effect of ball-milling on porous structure of Ca-substituted leucite porous body with low thermal expansion coefficient. Journal of the Ceramic Society of Japan. 2006;114(1336):1115-1120

[33] He P et al. Effect of cesium substitution on the thermal evolution 
and ceramics formation of potassiumbased geopolymer. Ceramics International. 2010;36(8):2395-2400

[34] He P, Jia D. Low-temperature sintered pollucite ceramic from geopolymer precursor using synthetic metakaolin. Journal of Materials

Science. 2012;48(4):1812-1818

[35] Ranjbar N et al. Hot-pressed geopolymer. Cement and Concrete Research. 2017;100:14-22

[36] Duxson P, Lukey GC, van Deventer JSJ. Physical evolution of Na-geopolymer derived from metakaolin up to $1000^{\circ} \mathrm{C}$. Journal of Materials Science. 2007;42(9):3044-3054

[37] Colic M et al. Effect of counterion size on short range repulsive forces at high ionic strengths. Langmuir. 1997;13(12):3129-3135

[38] Yuan J et al. Effects of Li substitution on the microstructure and thermal expansion behavior of pollucite derived from geopolymer. Journal of the American Ceramic Society. 2016;99(11):3784-3791

[39] Zhang M et al. A multiscale investigation of reaction kinetics, phase formation, and mechanical properties of metakaolin geopolymers. Cement \& Concrete Composites. 2017;78:21-32

[40] Duxson P, Lukey GC, van Deventer JSJ. Evolution of gel structure during thermal processing of Na-geopolymer gels. Langmuir. 2006;22(21):8750-8757

[41] Duxson P, Lukey GC, van

Deventer JSJ. The thermal evolution of metakaolin geopolymers: Part 2-Phase stability and structural development. Journal of Non-Crystalline Solids. 2007;353(22-23):2186-2200

[42] He Y et al. The hydrothermal transformation of solid geopolymers into zeolites. Microporous and

Mesoporous Materials. 2012;161:187-192

[43] Qiu S et al. Strategies for the synthesis of large zeolite single crystals. Microporous and Mesoporous Materials. 1998;21(4):245-251

[44] Chlique $\mathrm{C}$ et al. XRD analysis of the role of cesium in sodium-based geopolymer. Journal of the American Ceramic Society. 2015;98(4):1308-1313

[45] Xie N, Bell JL, Krivenw

WM. Fabrication of structural leucite glass-ceramics from potassium-based geopolymer precursors. Journal of the American Ceramic Society. 2010;93(9):2644-2649

[46] Valant $M$ et al. A mechanism for low-temperature sintering. Journal of the European Ceramic Society. 2006;26(13):2777-2783

[47] Huang YR et al. Lithium aluminosilicate glass-ceramic containing $\mathrm{Na}_{2} \mathrm{O}$ for low-temperature anodic bonding in microelectronic mechanical systems. Journal of Non-Crystalline Solids. 2008;354(12-13):1407-1410

[48] Goharian P et al. Lithium ionconducting glass-ceramics in the system $\mathrm{Li}_{2} \mathrm{O}-\mathrm{TiO}_{2}-\mathrm{P}_{2} \mathrm{O}_{5}-\mathrm{Cr}_{2} \mathrm{O}_{3}-\mathrm{SiO}_{2}$. Journal of Non-Crystalline Solids. 2015;409:120-125

[49] He LT, Xia GB, Yang DA. Synthesis and characterization of LTCC composites based on the spodumene/ anorthite crystallizable glass. Journal of Alloys and Compounds. 2013;556:12-19

[50] Ding YJ et al. Influence of alkali metal compound fluxes on $\mathrm{Gd}_{2} \mathrm{O}_{2} \mathrm{~S}$ : $\mathrm{Tb}$ particle and luminescence. Journal of Materials Science: Materials in Electronics. 2015;26(3):1982-1986

[51] Miller MJ, Wang JL. Influence of $\mathrm{Na}$ diffusion on thermochromism of 
Thermal Evolution of Geopolymer in the Process of High-Temperature Treatment DOI: http://dx.doi.org/10.5772/intechopen.81610

vanadium oxide films and suppression through mixed-alkali effect. Materials Science \& Engineering, B: Advanced Functional Solid-State Materials. 2015;200:50-58

[52] Cai DL et al. Inhibiting crystallization mechanism of $\mathrm{h}-\mathrm{BN}$ on alpha-cordierite in BN-MAS composites. Journal of the European Ceramic Society. 2016;36(3):905-909

[53] Thieme C, Ruessel C. High thermal expansion of crystallized glasses in the system $\mathrm{BaO}-\mathrm{ZnO}-\mathrm{NiO}-\mathrm{SiO}_{2}$. Ceramics International. 2015;41(10):13310-13319

[54] Utracki LA. Compressibility and thermal expansion coefficients of nanocomposites with amorphous and crystalline polymer matrix. European Polymer Journal. 2009;45(7):1891-1903

[55] Durandurdu M. Vibrational properties of amorphous germanium under pressure and its thermal expansion and Gruneisen parameters. Journal of Non-Crystalline Solids. 2010;356(20-22):977-981

[56] Som T, Karmakar B. Structure and properties of low-phonon antimony glasses and nano glassceramics in $\mathrm{K}_{2} \mathrm{O}-\mathrm{B}_{2} \mathrm{O}_{3}-\mathrm{Sb}_{2} \mathrm{O}_{3}$ system. Journal of Non-Crystalline Solids. 2010;356(20-22):987-999 



\title{
Review of Sustainable Geosynthetic Development Trend with Environmental Adaptive and Eco-Environmental Performances Point of View
}

\author{
Han-Yong Jeon
}

\begin{abstract}
Most of the geosynthetics contribute to the long-term stability of the soil structure, so products with little change in long-term performance are mainly used. To this end, demand for biodegradable products emphasizing planting and environmental compatibility is increasing. Sustainable geosynthetics can be categorized as "Usual Geosynthetics" and "Green Geosynthetics" on the basis of required performance, and it can be said that it is meaning to expand the use of geosynthetics in the fusion level. In here, "Usual Geosynthetics" refer to functional long-term maintenance and environmental adaptive products, and "Green Geosynthetics" refer to eco-environmental products that are decomposable geosynthetic fibers whose functions are extinguished after a required period of time. In this paper, we introduce sustainable geosynthetics, which are differentiated from raw materials to applicability.
\end{abstract}

Keywords: environmental compatibility, biodegradable, sustainable geosynthetics, usual geosynthetics, green geosynthetics, environmental adaptive, eco-environmental

\section{Introduction}

Terminology of Geosynthetics is that "a planar product manufactured from polymeric material used with soil, rock, earth, or other geotechnical engineering related material as an integral part of a man-made project, structure, or system." Their functions of geosynthetics are shown in Figure 1, and polymeric materials for geosynthetics are shown in Figure 2 [1-3].

Actually, polymeric materials for geosynthetics have their unique properties, and various additives are mixed to have the suitable and various functions of geosynthetics, and the manufacturing process is also different for each product. Figures 2 and 3 show abbreviations and abbreviated definitions and examples of typical geosynthetic products, respectively. 


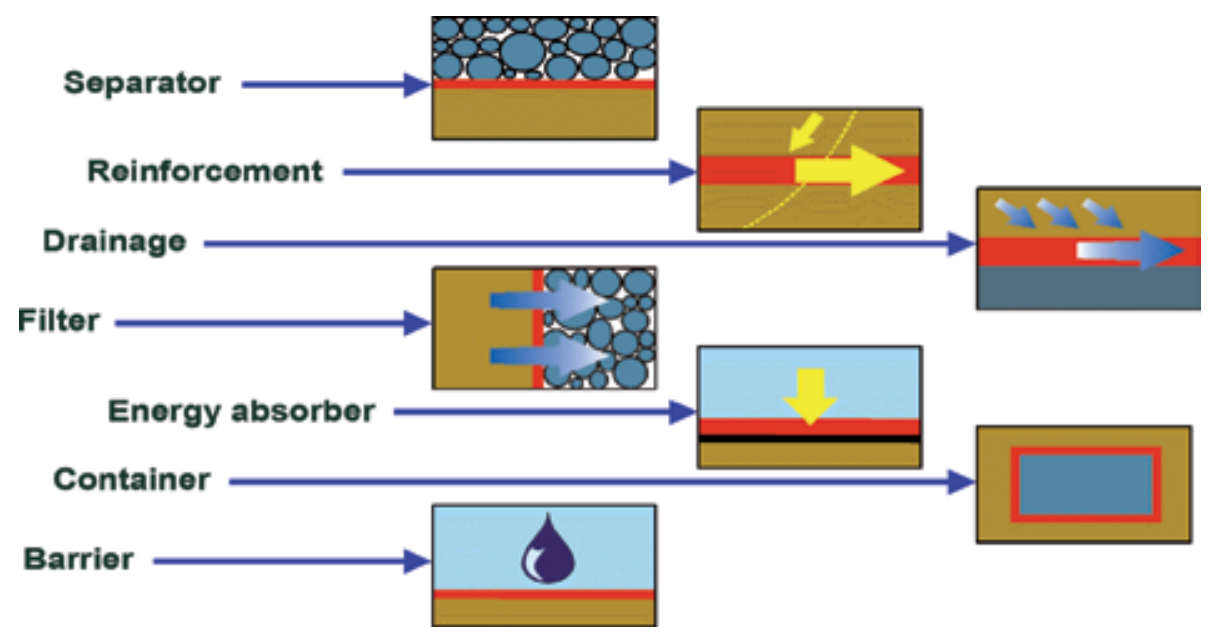

Figure 1.

Functions of geosynthetics in soil structure.

\section{Separation}

separating dissimilar materials so that both can function as originally intended

Reinforcement

providing tensile strength to soils or other materials

\section{Filtration}

allowing cross-plane flow, yet retaining upstream particles

\section{Drainage}

providing in-plane flow, yet retaining upstream particles

\section{Containment (or Barrier)}

preventing liquids, gases, or solids from becoming fugitive

Figure 2.

Functions of geosynthetics for application.

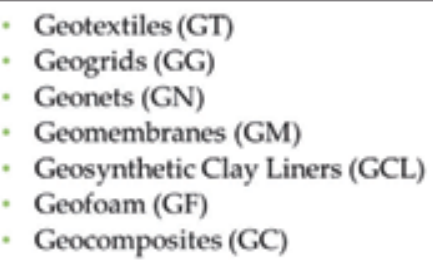

Geosynthetics - polymeric construction materials used in the ground Geotextiles - permeable fabrics capable of multiple functions Geogrids - interconnected sets of ribs used in reinforcement Geonets - integrally joined sets of ribs used for drainage Geomembranes - impermeable polymer liners used as a containment Geosynthetic Clay Liners - bentonite layer between GTs on a GM used as a barrier in containment applications Geocomposites - GSs laminated together or GSs used with soil

Figure 3.

Abbreviations and abbreviated definitions of geosynthetics. 
Review of Sustainable Geosynthetic Development Trend with Environmental Adaptive... DOI: http://dx.doi.org/10.5772/intechopen.90336

\section{Sustainable geosynthetics}

Most of the geosynthetics contribute to the long-term stability of the soil structure, so that products with small changes in long-term performance are mainly used, while demand for biodegradable products emphasizing planting and environmental compatibility is also increasing (Figures 3 and 4 ).

Therefore, sustainable geosynthetics mentioned in this chapter are classified as "Usual Geosynthetics" and "Green Geosynthetics" based on required performance as shown in Figure $5[6,7]$.

First, environmental adaptive geosynthetics, which we have previously described as "Usual Geosynthetics," have not changed much over the past 20 years but have created a paradigm of composite products using extreme strength fibers with the keyword of diversification. The environmentally adaptable geosynthetics can be introduced as "Usual Geosynthetics," which are used to reinforce the ground structure, and the initial strength retention rate should be within the given range during the service life.

In other words, usual geosynthetics are a product that requires a high resistance to instantaneous loads from the outside and also requires a hybrid function that converges to the reinforcement, protection, and blocking functions that are the basic functions of geotextiles. Since natural fibers have the advantage of being eco-friendly
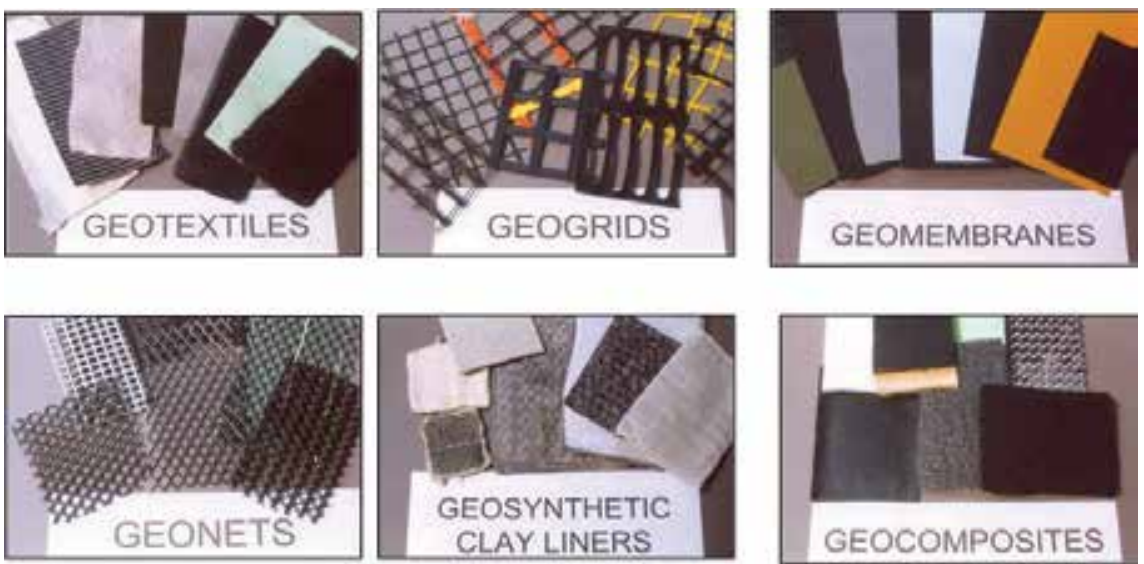

Figure 4.

Examples of typical geosynthetic products.

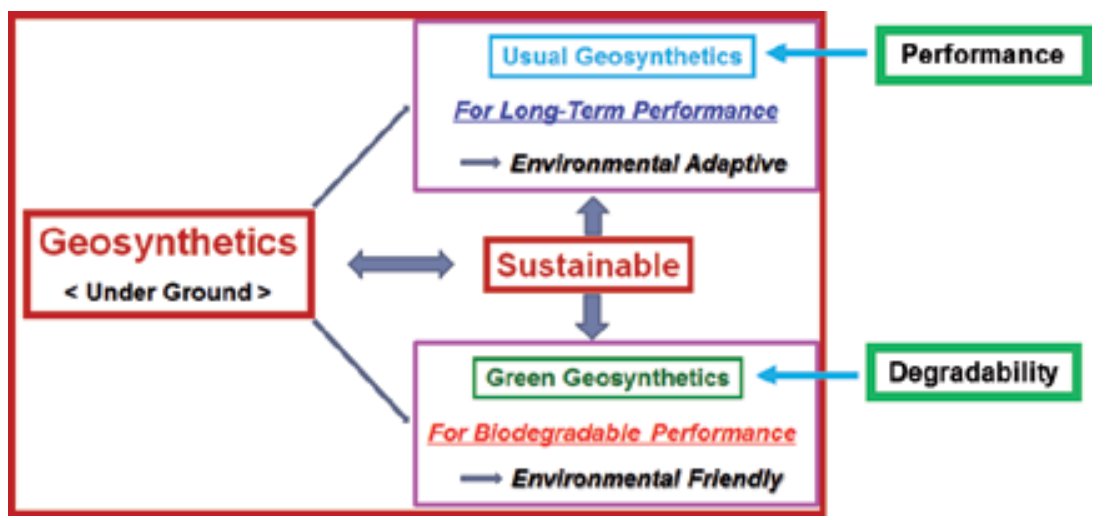

Figure 5.

Schematic diagram of "Sustainable Geosynthetics". 
materials, the utility of geotextile as a raw material has begun to be reemerged in recent years such as various types of cotton, jute, coir, and straw. However, since it is not used much and cannot be mass-produced compared to synthetic fibers, it has difficulties in creating demand. Some of them use natural geotextiles as slope stabilization, erosion prevention, and drainage, but here is no big change [4].

On the other hand, polyolefin (polyolefin) and polyester (polyolefin) are the most widely used synthetic polymer materials. Polyurethane, glass, and carbon polymers are very limited. Since the polymer materials used in the manufacture of geosynthetic products are often used in large quantities by low cost. In general, manufacturing high-performance geosynthetics increases the manufacturing cost, which is economically expensive. In other words, if the performance is the same, a product with a lower manufacturing cost is economically advantageous. Considering this, geosynthetics using recycled polymer materials may be considered, but disadvantages of performance decrease compared to geosynthetics using virgin polymers rather than recycling becomes a problem. Considering the environmental aspects, it is preferable to use recycled polymer materials, but the additional cost of recycling is not recommended in terms of economic performance.

High-performance hybrid polymer materials are being used as convergence geosynthetic products are required to protect, repair, and repair the ground structure from natural disasters such as earthquakes, tsunamis, and typhoons. These convergence geosynthetic products play a pivotal role in improving the stability of geotechnical structures and expanding their applications. Carbon fibers, aramid fibers, and liquid crystal polymer fibers are being used as new materials. In addition, test methods and construction techniques related to these new materials are being developed to expand the performance of these convergence geosynthetic products.

Second, "Green Geosynthetics" refer to products that have sustainable degradable geosynthetic fiber and environmental pollution prevention and restoration functions that do not mean long-term implementation of initial performance in terms of environmental friendliness.

For the slope stabilization/protection field requiring eco-environmental properties, mesh type geocell using biodegradable resin is applied to slope vegetation, river maintenance, eco-slope composition, garden-based layer, landfill slope, and waterproof protection. This reflects the demand for eco-environmental geosynthetics and means that there is a growing need to expand biodegradable geosynthetics to civil/environmental fields. In addition, polypropylene staple fiber products have been developed in the geosynthetics and web structures to emphasize the slope reinforcement function.

In the case of fiber, "biodegradability" means decomposition by microorganisms or bacteria in the soil, which is a geotechnical structure, and the initial performance gradually decreases during the service period [5].

In order to recover the contaminated environment and to manufacture "Green Geosynthetics," a biodegradable resin should be used as a raw material, and it is differentiated from geo-fiber, which cannot be decomposed after construction. Also, when used as a filter, manufacturing of geotextiles in the form of nanofibers helps improve filtration efficiency.

\section{Hybrid geosynthetics}

\subsection{For water permeable and reinforced functions}

In the case of using the geosynthetics alone, it is true that the application field is extremely limited due to the limitation of its function. For this reason, hybrid 
geotextiles suitable for specific functions and environments have been developed, and their usage is also increasing faster than in any field of civil engineering synthetic materials. In other words, a product that combines geogrid and geotext styles, which are widely used in landfills, reinforced earth retaining walls, roads, and soft ground reinforcement, has been developed.

This means geogrid's reinforcement function and geotextile's permeability function, and geogrid and geotextile are bonded through thermal and ultrasonic welding. In this product, the tensile strength and puncture resistance are increased, the effective hole size and the vertical permeability are reduced, but the tear strength is not greatly influenced by the change in weight. In addition, it is expected that when the actual construction is performed from the tensile strain and the creep strain of the geogrid, not only the reinforcing function but also the partial geotextile protection effect can be obtained.

\subsection{For protection and water barrier}

The geomembrane has a smooth sheet shape, so it has low frictional force with the soil and much surface damage is caused by sharp objects such as gravel, concrete slabs, and tree roots in the construction process.

In addition, when the geomembrane used as the cargo material in the landfill is slid at the interface with the soil or other geosynthetics, or when the surface is damaged, it causes problems in the stability of the landfill system during or after the landfill is completed and may be affected by the leachate generated when the waste is decomposed.

Therefore, tensile, tear, rupture, and puncture strength are increased when the geomembrane and geotextile composite are manufactured, and the internal friction angle with respect to the contact soil is increased to improve the shear characteristics. And the stability of the geomembrane leachate is improved by the protection effect of the geotextile.

This phenomenon is due to the fact that the difference in strength between two directions due to stretching, which is generally seen in the geomembrane, is complemented by the thermal fusion bonding, and the resistance to the tensile force is increased due to the reinforcing effect of the geotextile and the geomembrane bonding part.

\subsection{For separation, filtration, and reinforcement}

Geotextile surface smoothness can be improved to improve separation function and reinforcement function of reinforcing geotextile, and AOS (Apparent Opening Size) of geotextiles by differential design can improve filtration function (Figure 6).

These products have the overall performance (chemical stability, high tensile properties, permeability, etc.) as geomembrane protection material in the landfill construction where frequent damage of the aeration sheet is caused by the aggregate applied to the leachate drainage layer and the working vehicle on the top can be used as a composite product.

\subsection{For auxiliary water barrier function}

As shown in Figure 6, hybrid products such as GCL, which are used as auxiliary water barrier materials, have been developed, such as improvement of swelling property, prevention of loss, and improvement of freezing and thawing properties. In addition, bentonite modification and the like are progressing with the aim of improving the swelling property in salt water, and the interest in the product for preventing environmental pollution is also increasing. 

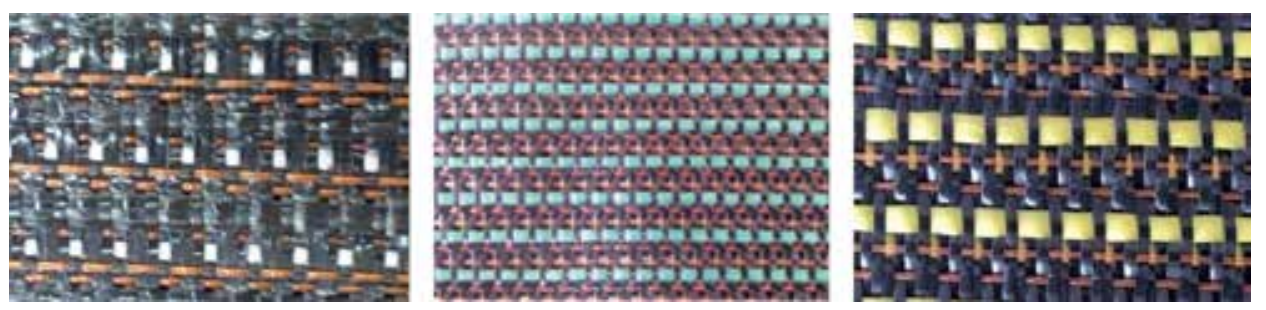

Figure 6.

Geotextiles for [separation/filtration/reinforcement] functions improvement.

As a part of development of hybrid geosynthetic clay liners, GCL applies (1) multi-layered swelling enhanced bentonite, (2) bentonite surface strengthening performance, and (3) bentonite for blocking and removing harmful components. Bentonite reforming and hybrid GCL development give the differentiated performance to the GCL products such as this way.

\subsection{For multi-axial geocomposite}

Geocomposite manufacturing technology and products were developed for the purpose of reinforcement function by developing not biaxial but multi-axial curved knitting materials, which can enhance the ground reinforcement function by applying multi-axial curved knitting technology.

In addition, a smart monitoring high performance multi-axial geocomposite is being developed in order to monitor the damage of the geocomposite due to stress concentration by appropriately embedding the optical fiber sensor in the multiaxial geocomposite as shown in Figure 7.

\subsection{For reflective crack protection}

The life of the pavement is affected by rutting caused by the load of the vehicle and the driving load of the vehicle. In particular, due to differential settlement by rutting, the reflective crack is generated, and the road fracture proceeds due to the propagation of the reflective crack. Reflective crack is also the main cause of differential settlement due to plastic deformation, and it also has a great influence on road stability, causing social problems due to increased casualties due to vehicle accidents.

Therefore, in order to improve the durability and stability of the pavement by reflective cracks and to improve the driving performance of the vehicle, it is necessary to use geosynthetics that can suppress the reflective cracks.
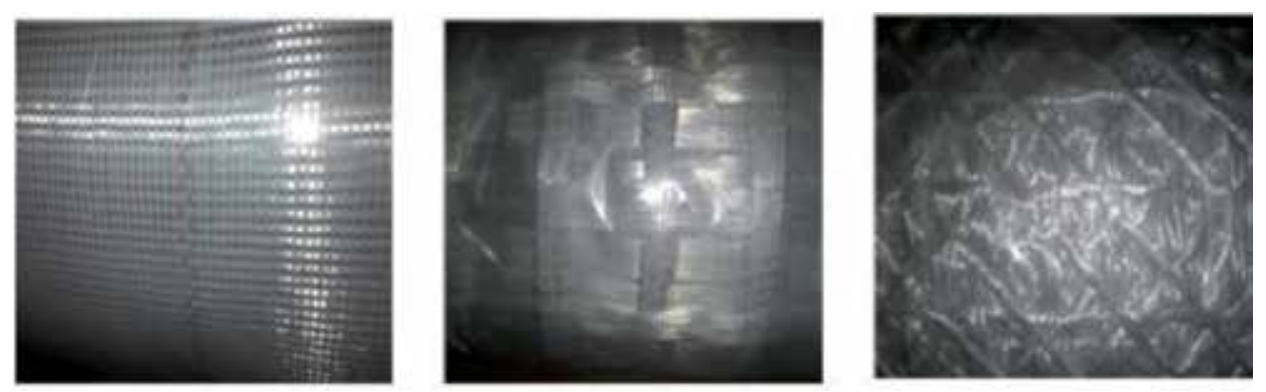

Figure 7 .

Multi-axial geocomposites by optical sensor application technology. 

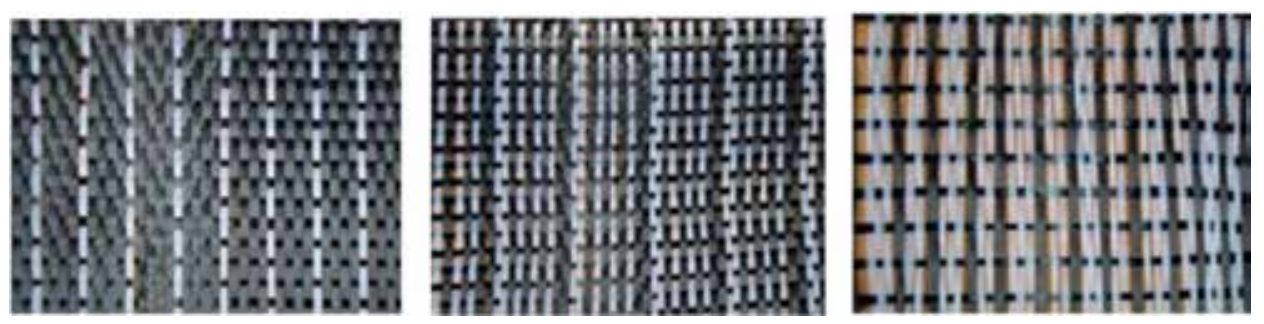

Figure 8.

Anti-reflective crack geosynthetics for road construction.

Taking this into consideration, reinforcement of asphalt and concrete roads using geosynthetics has a great effect on suppressing reflective crack and differential settlement and has the advantage of blocking water penetration by reflective crack.

From the above view, it is necessary to develop geosynthetics that can improve the stability of roads by improving the resistance to fatigue loading of road structures by rutting and differential settlement (Figure 8).

\section{Nanomaterial application to geosynthetics}

Figure 9 shows various aspects of nanofiber manufacturing technology and production where it is seen that mass production of nanofibers is possible by modified electro spinning. Electro spinning is the general method used to manufacture nanofibers, which is similar to the meltblown method, but the current problem is to increase mass production.

Regular size ( $\sim$ denier) fibers are used as 2500-6000 denier to implement the function of geosynthetic products (e.g., separation/reinforcement/drainage/filtration/protection, etc.). However, if micros and nanofibers are used to make geosynthetic products for separation and filtration, more fibers can be integrated in a given space, and separation and filtration will be improved than with regular size fibers. Figure 10 shows the fiber manufacturing method with fiber length, and micro and nanofibers, which are smaller in fiber thickness, are selected for fibrillation process that is different from the general spinning process. Nanofibers, in particular, have not been significantly out of the range of electrospinning.

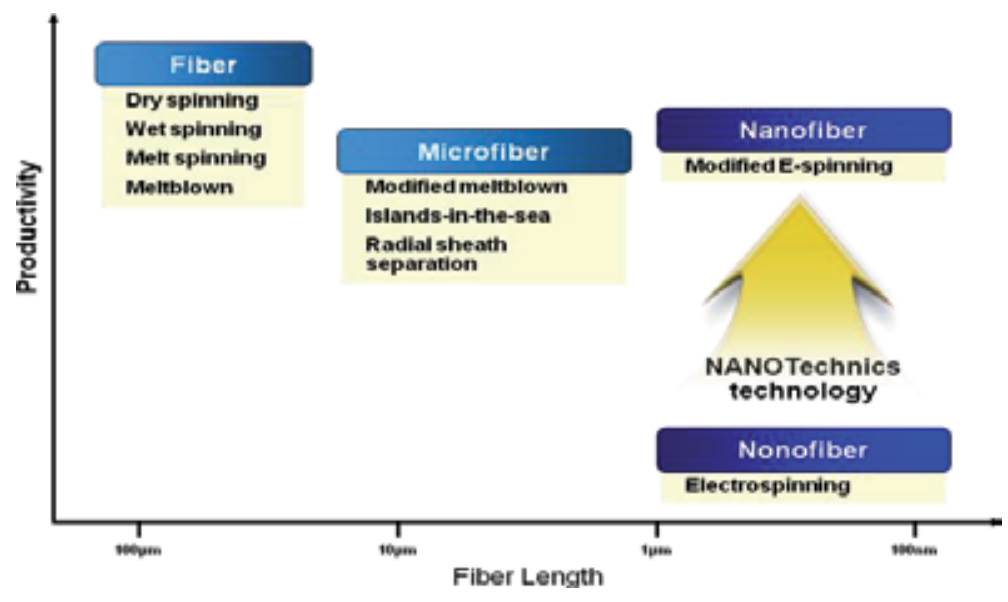

Figure 9.

Fiber manufacturing technology and productivity. 


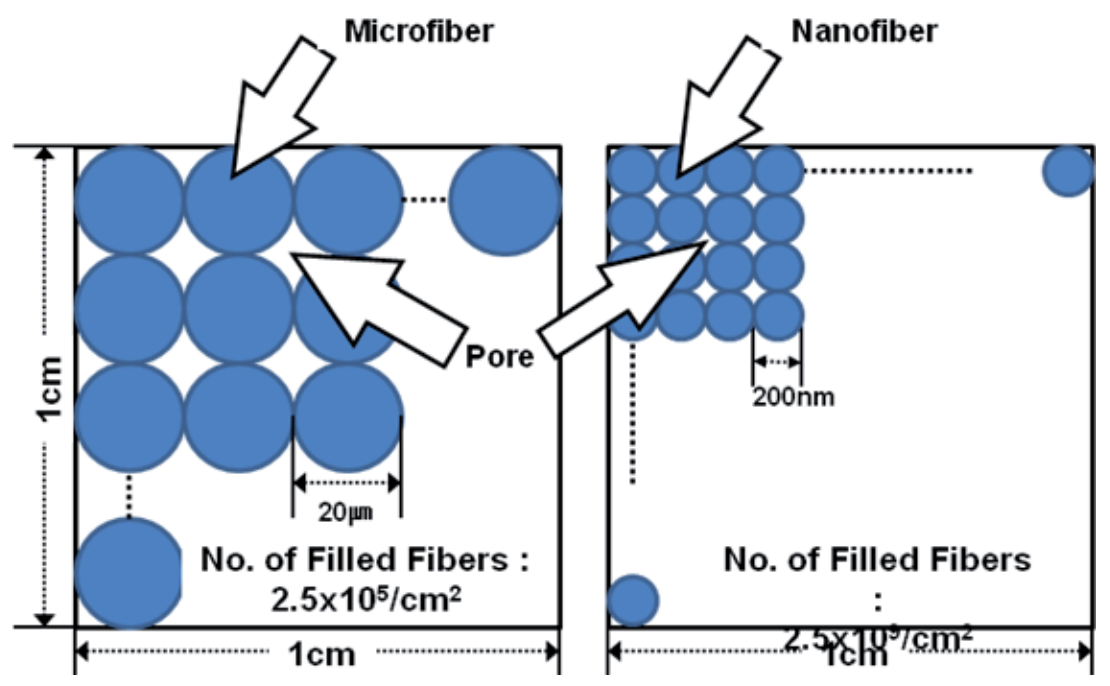

Figure 10.

Fiber filling between microfiber and nanofiber per unit area for geosynthetics.

One of the methods for improving the filtration function is to increase the pore size per unit area. Conversely, increasing the number of filled fibers per unit area in order to improve the adsorption performance reduces the pore size due to the increase in specific surface area. Therefore, the fine particles cannot pass through the pores made of nanofibers, thereby improving the filtration efficiency. It can be seen that liquid and gas filters using micro and nanofibers can be used to adsorb fine particles and heavy metal ions in water and air media (Figure 11).

Figure 12 is a schematic diagram showing the relationship between adsorption and desorption of fine particles in the direction of pressure. Higher particle densities or adsorption rates are required to optimize these filter performances, and micro and nanofibers can be used to maximize the capture and removal efficiency of particles. Figure 13 shows the fiber density per unit area by fiber length and thickness and the filtration area per fiber weight with the filter manufacturing process. HMT and expanded PTFE (polytetrafluoroethylene) fibers have a relatively higher fiber density per unit area than spunbonded, flashspun, and meltblown

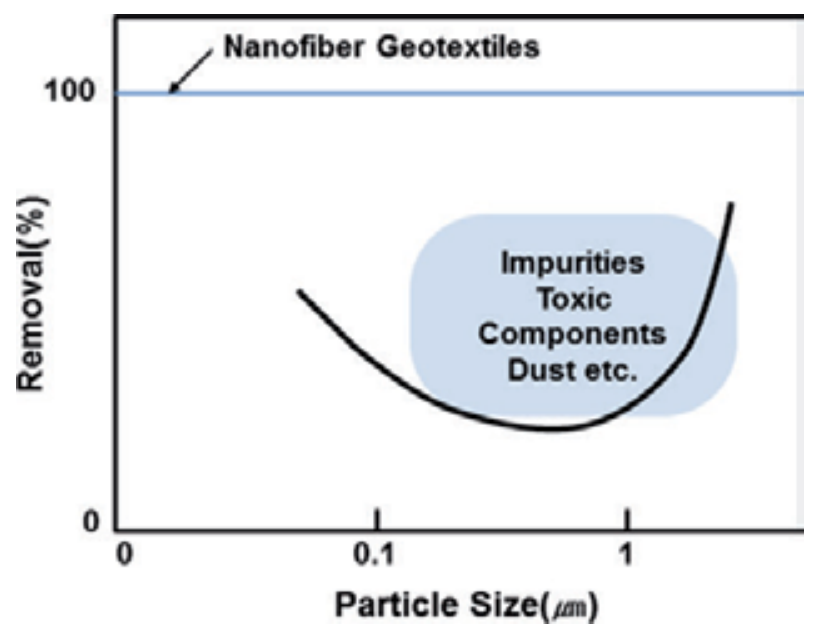

Figure 11.

Effect of using a nanofiber geotextile filter. 

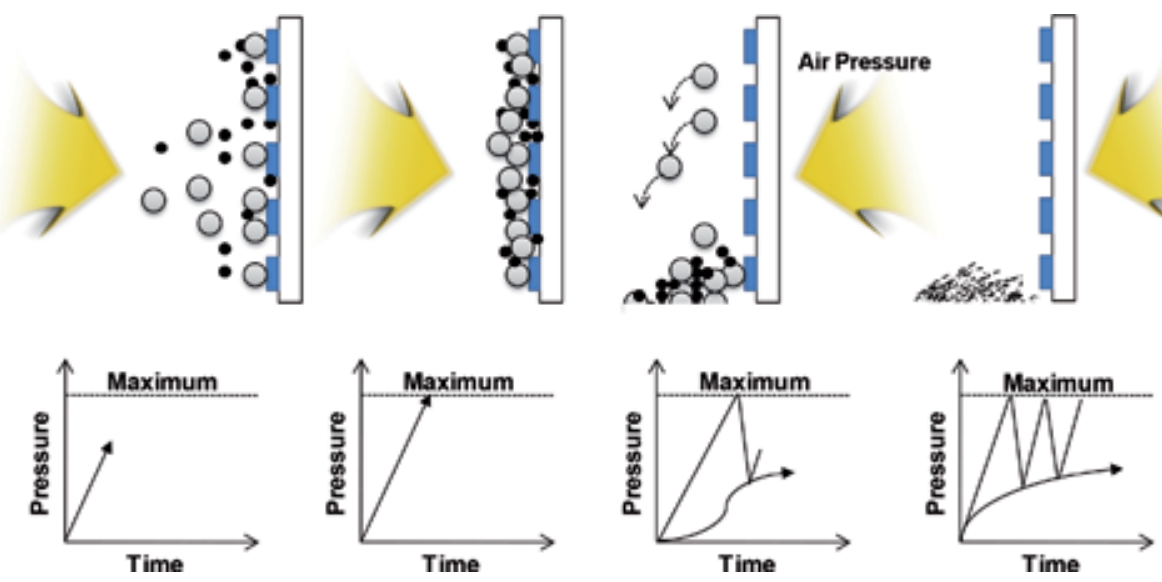

Figure 12.

Maintenance of filtration efficiency for nanofiber filters.

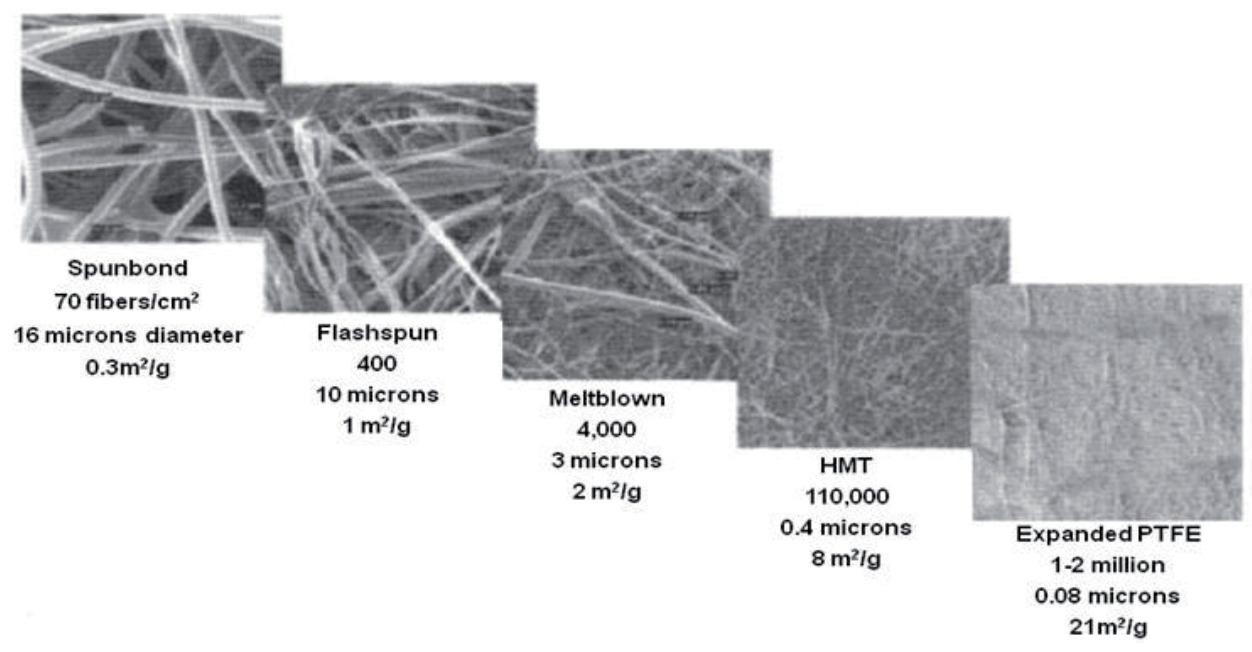

Figure 13.

Comparison of fiber diameter and surface area using nanofiber and other fibers.

fibers. Therefore, it can be seen that the filter performance by the optimization of the specific surface area is excellent. Figure 14 shows the particle distribution area that can be removed using micro and nanofiber filters.

From the above, when applying geosynthetic products made of micro and nanofibers to the environmental field, considering the theoretical basis and validity, considering the limitation and economic disadvantage of fiber manufacturing process, development of differentiated technology and application should be preceded.

In order to remove the heavy metals and toxic substances contained in contaminated soil, a nonwoven geotextile is used, which is a mixture of nanofiber clay with polyester fiber (Figure 15).

The specifications of nonwoven geotextiles with 2-3\% yellow clay particles and the composition of yellow clay particles are shown in Tables 1 and 2, respectively.

Clogging in nonwoven geotextiles means apparent opening size (AOS), which represents the size of the voids between the fibers that make up the nonwoven fabric, and this value depends on the distribution and continuity of the fibers that make up the nonwoven geotextiles. In general, the AOS value could be controlled in 


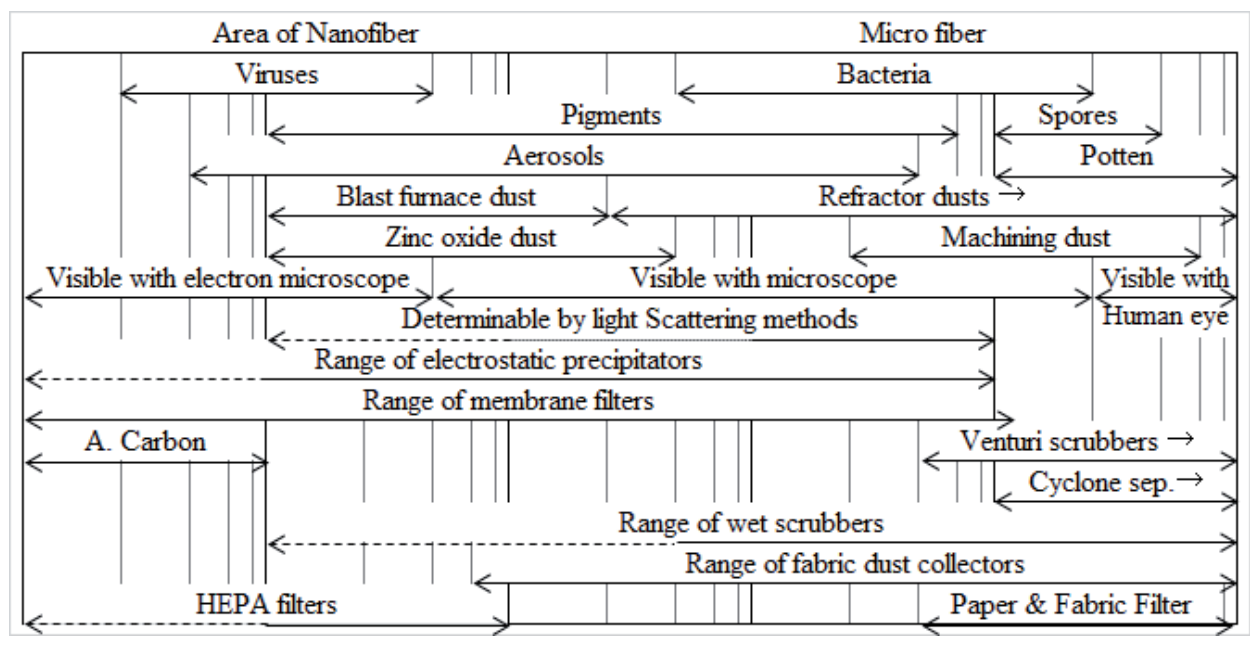

Figure 14.

Relationship between separation fields and membranes using nanotechnology.

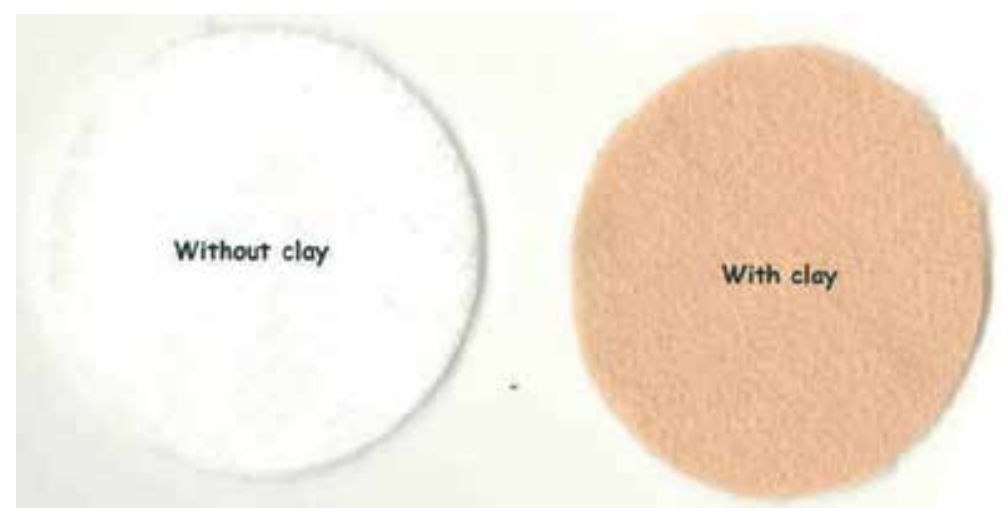

Figure 15.

Clay added geotextile to improve adsorption efficiency.

\begin{tabular}{lcccc}
\hline $\begin{array}{l}\text { Composition } \\
\text { Nonwoven geotextiles }\end{array}$ & $\begin{array}{l}\text { Weight } \\
\left(\mathbf{g} / \mathbf{m}^{2}\right)\end{array}$ & $\begin{array}{c}\text { Yellow clay } \\
\text { content (\%) }\end{array}$ & Raw fiber \\
\hline With yellow clay added & FGT-1 & 272 & $2 \sim 3 \%$ & Polyester Fibers (6 denier \\
geotextiles & FGT-2 & 463 & & Filament) \\
& FGT-3 & 784 & & \\
& FGT-4 & 1514 & & \\
Without yellow clay & GT-1 & 284 & None & \\
geotextiles & GT-2 & 480 & & \\
& GT-3 & 756 & & \\
& GT-4 & 1546 & & \\
\hline
\end{tabular}

Table 1.

Specifications two types of polyester geotextiles.

\begin{tabular}{lccccccccc}
\hline Component & Yellow Clay & $\mathrm{SiO}_{2}$ & $\mathrm{Al}_{2} \mathrm{O}_{3}$ & $\mathrm{Fe}_{2} \mathrm{O}_{3}$ & $\mathrm{TiO}_{2}$ & $\mathrm{CaO}$ & $\mathrm{MgO}$ & $\mathrm{Na}_{2} \mathrm{O}$ & $\mathrm{K}_{2} \mathrm{O}$ \\
\hline Amount & 97.54 & 1.80 & 0.07 & 0.11 & 0.13 & 0.01 & 0.01 & 0.02 & 0.01 \\
\hline
\end{tabular}

Table 2.

Components of yellow clay particles. 
the nonwoven geotextiles manufacturing process and the smaller the AOS value, the lower the permeability.

Figure 16 shows the AOS values before and after burial of nonwoven geotextiles used in landfills. Nonwoven geotextiles (FGT) added with yellow clay particles showed smaller AOS values than nonwoven geotextiles without yellow clay particles. This is thought to be due to the fact that the pores of the FGT of with yellow clay particles are smaller than the GT of without yellow clay particles.

As same as shown in Figure 16, analytical result of AOS value, heavy metals, or harmful components contained in the leachate solution may be more easily removed by adsorption using FGT than GT (Figure 17).

Figure 17 shows the permittivities between FGT and GT before/after burial in the waste landfill site. As same as shown in Figure 16, FGTs showed smaller permittivity than GT due to the clogging effects by smaller AOS values.

Figure 18 shows the adsorption efficiency of the heavy metal component of the nonwoven geotextile of with yellow clay particles, this value is by ICP analysis expressed as a percentage. This is also due to the AOS value of with/without yellow clay as same as shown in Figure 16.

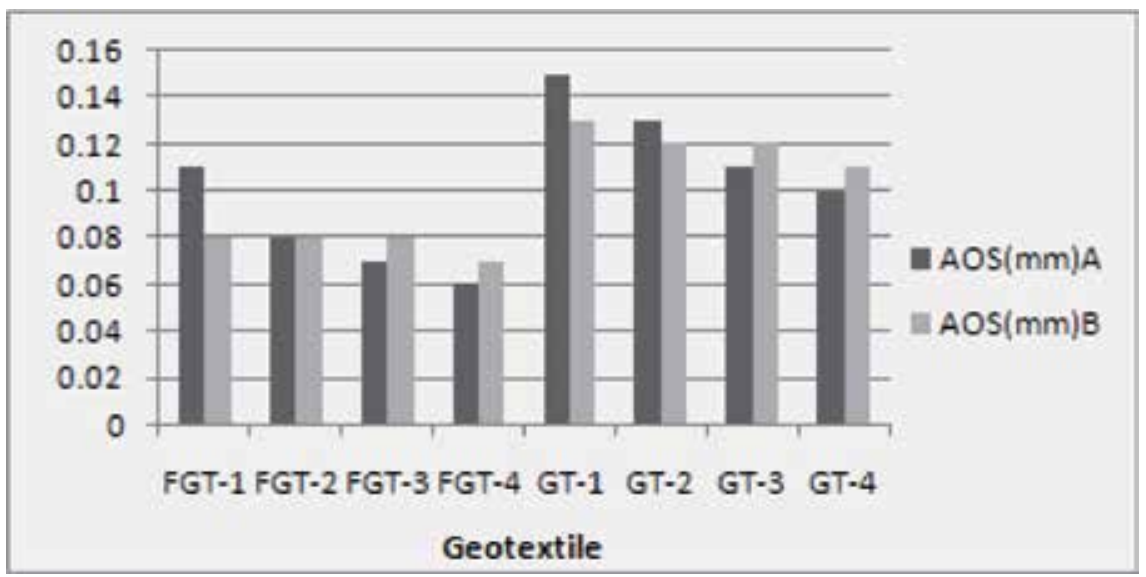

Figure 16.

AOS of with/without yellow clay nonwoven geotextiles before/after immersion. (Where A, B mean before and after immersion, respectively).

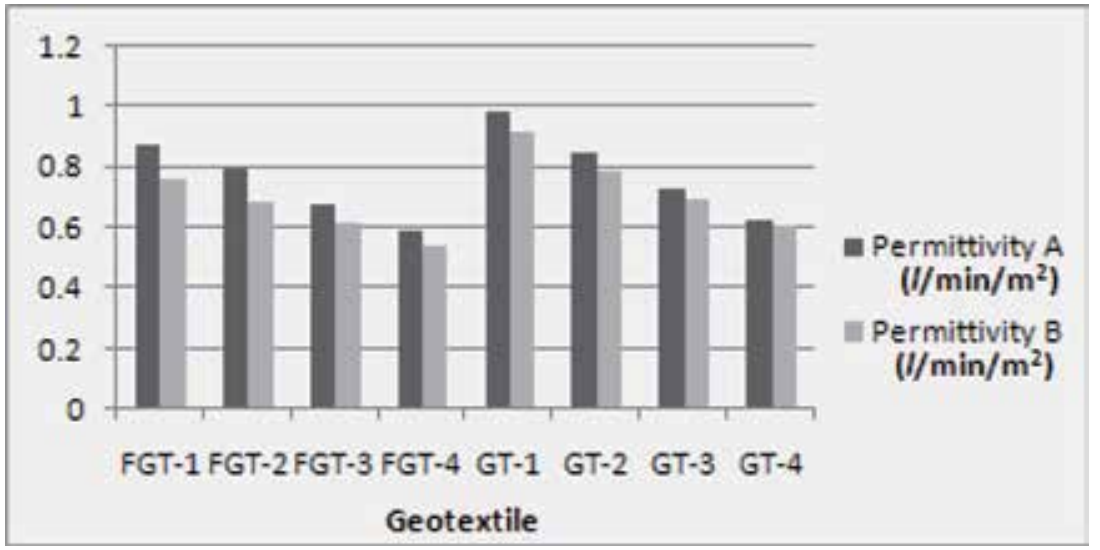

Figure 17.

Permittivity of with/without yellow clay nonwoven geotextiles beforelafter immersion. (Where A, B mean before and after immersion, respectively. 


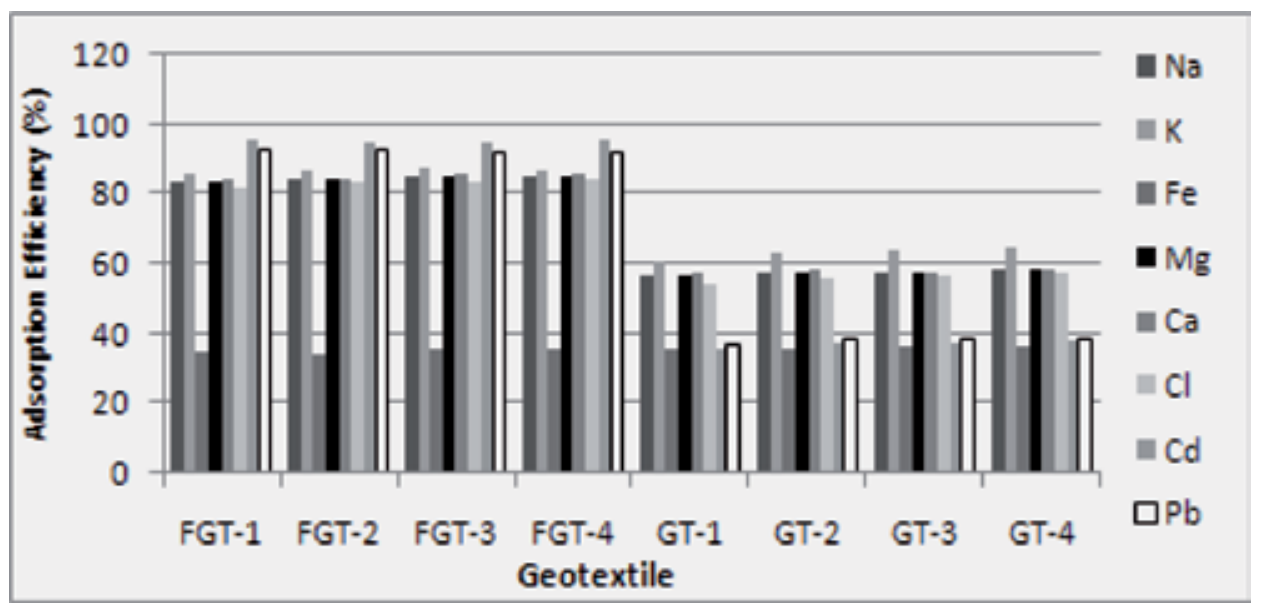

Figure 18.

Adsorption efficiency of with/without yellow clay nonwoven geotextiles.

In the future, if micro and nanofibers are used to manufacture nonwoven geotextiles, the development of technology to control the AOS distribution is expected to create new demands in soil removal, prevention, and restoration.

\section{Author details}

Han-Yong Jeon

Department of Chemical Engineering, Inha University, Incheon, South Korea

*Address all correspondence to: hyjeon@inha.ac.kr

\section{IntechOpen}

(C) 2019 The Author(s). Licensee IntechOpen. This chapter is distributed under the terms of the Creative Commons Attribution License (http://creativecommons.org/licenses/ by/3.0), which permits unrestricted use, distribution, and reproduction in any medium, provided the original work is properly cited. (cc) BY 
Review of Sustainable Geosynthetic Development Trend with Environmental Adaptive... DOI: http://dx.doi.org/10.5772/intechopen.90336

\section{References}

[1] Koerner RM. Designing with Geosynthetics. 5th ed. NJ, PA, USA:

Prentice-Hall Inc; 2005

[2] Geosynthetic Institute. In:

Proceedings of the GRI-21 Conference;

Philadelphia, PA, USA; 2010

[3] IFAI. Geotechnical Fabrics Report Specifier's Guide 2010. Roseville, MN, USA; 2018

[4] Leu W, Luane Tasa PE. Applications of geotextiles, geogrids, and geocells. In: Northern Minnesota, Geosynthetics Conference 2001; Portland, Oregon; 2001. pp. 809-821

[5] Gugumus F. Polymer degradation and stability. 1996;52:131-159

[6] Jeon HY. Polymer Composites, Chapter 14. 1st ed. Singapore: WILEYVCH; 2012

[7] Jeon HY. Evaluation of clay added nonwovens as filter in waste landfill. In: Molecular Crystals and Liquid Crystals. Vol. 484. 2008. pp. 185-194 



\title{
Analysis of the Creep and the Influence on the Modulus Improvement Factor (MIF) in Polyolefin Geocells Using the Stepped Isothermal Method
}

\author{
Juan Carlos Ruge, Julian Gonzalo Gomez \\ and Carlos Andres Moreno
}

\begin{abstract}
The article shows the analysis of the behavior at long-term deformation of geocells for a set time period, due to its importance on the modulus improvement factor (MIF), which is considered in the design stage of a reinforced pavement structure with geocells. When inquiring into the research about the structural behavior that exists in the geocells, as well as the distribution of stresses that this generates, in order to determine how important the existence of a deformation in the geocell is. We proceeded with the sampling and execution of the test "modified stepped isothermal method (SIM) for geocells." The test was carried out under the comparison of the materials and thicknesses of the sample, with the purpose to analyze the influence on the behavior of a pavement structure. The stresses generated at the level of the granular subbase layer of a pavement are taken into account as load effects.
\end{abstract}

Keywords: creep, geocells, modulus improvement factor, stepped isothermal method

\section{Introduction}

One of the most common problems in road geotechnics projects is encountering subgrade soils of low carrying capacity. Multiple solutions are proposed to improve the unfavorable conditions of this type of soil; however, a large part of them can be harmful to the environment. In this sense, alternatives based on design with geosynthetics are important and allow for adequate reinforcement of the unsuitable soft subgrade as a supporting layer of the pavement structure.

However, with the implementation of geosynthetics, problems associated with the stresses experienced by the material were observed, such as UV degradation and long-term plastic deformation. These effects occur in almost all geosynthetics, even in geocells, which will be analyzed in detail in this article.

The first need to reinforce highly compressible soils arose during wartime at the beginning of the twentieth century, when the transport of heavy machinery was required. For this reason, the US Army Corps of Engineers was the first to use and 
develop the cellular confinement system in the late 1970s, as a means to help build roads, runways, platforms, and others; all these solutions were made on very soft soils and under humid conditions.

The main large-scale use of this system of cellular confinement was during the Gulf War, in "Operation Desert Storm", where it transported heavy military material with speed and efficiency. For the purpose of mobilizing large troops, according to the company Geoceldas SA, the defense department of the United States "acquired 6.4 million square feet (600,000 square meters) of cellular geosynthetics for use in various military applications [1]."

In terms of its implementation in design tasks, pavement structure with geocells uses a coefficient of increase for the modules of the materials (MIF), which depends on several factors. Among these is resistance to long-term deformation of the material that makes up the panel of geocells. This generates a mechanism of confinement, which creates an apparent cohesion of the material incorporated therein. If the geocells yield, it is susceptible to losing its properties and begins to deform causing a settlement in the pavement structure, in addition to providing a deconfinement in the geocell filling material $[2,3]$.

Therefore, some consequences of deformation in the geocell are the reduction of the apparent cohesion in the filling material due to the loss of confinement, according to which there is a high decrease in the MIF coefficient taken into account during the design of the structure.

For these reasons, it is important to know the properties of the materials that are involved in the pavement structures and the veracity of the calculations that are made in the analyses. Therefore, when calculating the MIF, it is important to know the long-term deformation of material to give support and certainty in the analyses. Consequently, a modified test based on the SIM for geocells was developed. A test program was carried out using different samples of geocells, exposing results for each one of them.

The definition of the MIF factor refers to the material modulus with reinforcement vs. the material without reinforcement. This value is obtained at the moment of designing a structure with geocell, applying five characteristics of the materialgeocell set, among which is the long-term deformation of geosynthetic. The MIF value depends on the analysis of the creep in the geocells, because if the material becomes deconfined, the increase of the modulus considered in the design will be reduced. For this reason, a safety factor is applied to the MIF, due to the creep in the geocells.

The samples were analyzed under load effects, which contemplate those generated at the level of the granular subbase layer of pavement, thus showing the feasibility of use in this layer and the possible behavior of these over its usable life.

\section{Methodology}

This research was based on the stepped isothermal method (SIM) which is standardized by ASTM D6992 [4, 5]. It was modified to prove the long-term deformation of the geocells and to learn the incidence that this property has when calculating the MIF, which is described as the relationship that exists between the module of a granular material confined with geocells and the same granular material without confinement, determined from Eq. (1) [6]. Basically, the adjustment on the test was based in terms of the width and length of the specimens, which depends on the type of geocell that is being analyzed.

$$
M I F=\frac{E_{\text {reinforced }}}{E_{\text {no-reinforced }}}
$$


Analysis of the Creep and the Influence on the Modulus Improvement Factor (MIF) in Polyolefin... DOI: $h$ ttp://dx.doi.org/10.5772/intechopen.88518

The SIM test determines the long-term deformation of polymers by time-temperature superposition, whose effect was modified for use in polyolefin geocells. This method, known as the "time-temperature superposition principle (PSTT)," establishes that material having a viscoelastic property $(\mathrm{V})$ measured in a time interval coincides with the same measurement in greater times at a lower temperature. Because this method is clearly empirical, it is defined as a principle, because not even theoretical concepts have been developed to sustain it [7].

With the aforementioned considerations, an increase in temperature according to Billmeyer [8], accelerates molecular and segmental movement, leading the system to equilibrium more quickly or "apparent equilibrium," accelerating all viscoelastic processes.

To that extent, the modification proposal is based on systematically dividing the trial into five steps, in which the temperature will be increased with a specific duration for each step. In addition to applying a constant load throughout the trial of $4.4 \mathrm{kN} / \mathrm{m}$, the temperatures reached for each step are $21 \pm 1,44,51$, and $65^{\circ} \mathrm{C}$, respectively.

The first part of the test refers to the simulation of the load exerted on the geocell at the time of compaction of the filling material. It is possible to find a mean of time-temperature superposition according to [9], a temperature of $51^{\circ} \mathrm{C}$ and 1 hour of testing, equivalent to 100,000 hours of use (4166 days or 11 years).

The load of $4.4 \mathrm{kN} / \mathrm{m}$, to which the material is subjected throughout the test, replicates the force supported by the geocell in the granular subbase of a pavement structure. This necessitates implementation of a series of charges which will be imposed through weights that will transmit this force to the geocells.

\begin{tabular}{|c|c|c|c|}
\hline Properties of the material & Testing method & Unit & Values MARV \\
\hline Polymer density & ASTM D-1505 & $\mathrm{g} / \mathrm{cm}^{3}$ & $0.935-0.965$ \\
\hline Black smoke content & ASTM D-1603 & $\begin{array}{c}\% \\
\text { weight }\end{array}$ & $1.5 \% \min$ \\
\hline $\begin{array}{l}\text { Nominal thickness of the cell wall before } \\
\text { texturing }\end{array}$ & ASTM D-5199 & $\mathrm{mm}$ & $1.1 \pm 10 \%$ \\
\hline $\begin{array}{l}\text { Nominal thickness of the cell wall after } \\
\text { texturing }\end{array}$ & ASTM D-5199 & $\mathrm{mm}$ & $1.52 \pm 10 \%$ \\
\hline Physical properties & Testing method & Unit & Typical values \\
\hline Nominal size of the expanded cell & Measured & $\mathrm{mm}$ & $320 \times 287$ \\
\hline Nominal area of the expanded cell & Measured & $\mathrm{cm}^{2}$ & 460 \\
\hline Nominal size of the expanded panel & Measured & $\mathrm{m}$ & $2,56 \times 8,35$ \\
\hline Nominal size of the expanded panel & Measured & $\mathrm{m}^{2}$ & 21,04 \\
\hline Height of the cell & Measured & $\begin{array}{l}\mathrm{mm} \\
\text { (in) }\end{array}$ & $\begin{array}{l}75(3) 100(4) 150(6) \\
200(8)\end{array}$ \\
\hline Resistance of the joints by ultrasound & USAGE GL-86-19 & $\mathrm{N}$ & 1065142021302840 \\
\hline Ultimate resistance to joints tension & $\begin{array}{l}\text { ISO } 13426-1 \\
\text { method B }\end{array}$ & $\mathrm{kN} / \mathrm{m}$ & 15 \\
\hline $\begin{array}{l}\text { Ultimate resistance to tension wide strip } \\
\text { method }\end{array}$ & ISO 10319 & $\mathrm{kN} / \mathrm{m}$ & 25 \\
\hline$\%$ of perforations per unit area & Measured & $\%$ & $12 \pm 2$ \\
\hline
\end{tabular}

Table 1.

Properties of geocell type 1, Provider 1. 


\begin{tabular}{|c|c|c|c|}
\hline Physical properties & Norm & Unit & Typical values \\
\hline Density of the material & ASTM D-1505 & $\mathrm{g} / \mathrm{cm}^{3}$ & $0.950 \pm 0.015$ \\
\hline Thickness of the sheet (textured) & ASTM D-5199 & $\mathrm{mm}$ & $\min .1 .52 \pm 0.15$ \\
\hline Black carbon content & ASTM D-1603 & $\%$ & $2.0 \pm 0.5$ \\
\hline $\begin{array}{l}\text { Resistance to environmental cracking } \\
\text { (ESCR) }\end{array}$ & ASTM D-1693 & hours & $>3000$ \\
\hline Resistance of the joints to the takeoff & ASTM D-4437 & $\mathrm{N} / \mathrm{cm}$ & $>150$ \\
\hline Height of the unit & & $\mathrm{mm}$ & 150 \\
\hline \multirow[t]{4}{*}{ Minimum values of resistance } & $\begin{array}{l}\text { ISO 13426-1 method A: } \\
\text { shear test }\end{array}$ & $\begin{array}{l}\mathrm{kN} / \\
\text { joint }\end{array}$ & 2.7 \\
\hline & & $\mathrm{kN} / \mathrm{m}$ & 8.1 \\
\hline & $\begin{array}{l}\text { ISO 13426-1 method B: } \\
\text { takeoff test }\end{array}$ & $\begin{array}{l}\mathrm{kN} / \\
\text { joint }\end{array}$ & 2.25 \\
\hline & & $\mathrm{kN} / \mathrm{m}$ & 6.75 \\
\hline Number of cells & & $\# / \mathrm{m}$ & 21.7 \\
\hline Diagonal length & & $\mathrm{cm}$ & 30.4 \\
\hline Cell area & & $\mathrm{cm}^{2}$ & 461 \\
\hline Distance between joints & & $\mathrm{mm}$ & 445 \\
\hline Width of the expanded unit & & $\mathrm{m}$ & 2.43 \\
\hline Expanded unit length & & $\mathrm{m}$ & 5.5 \\
\hline Coverage & & $\mathrm{m}^{2}$ & 13.3 \\
\hline Weight of the unit & & $\mathrm{kg}$ & 20.8 \\
\hline
\end{tabular}

Table 2.

Properties of geocell type 2, Provider 2

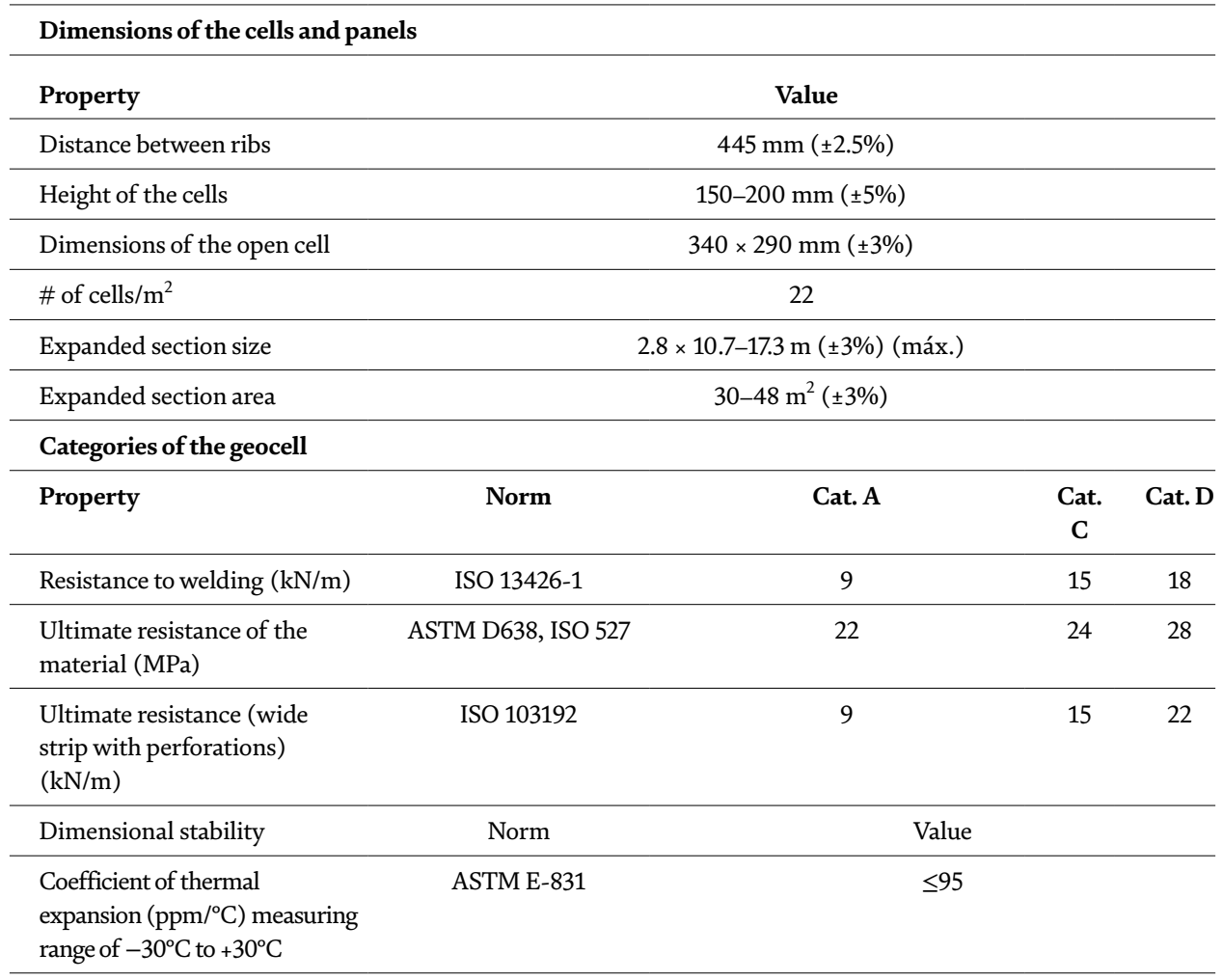


Analysis of the Creep and the Influence on the Modulus Improvement Factor (MIF) in Polyolefin... DOI: http://dx.doi.org/10.5772/intechopen.88518

\begin{tabular}{|c|c|c|}
\hline \multicolumn{3}{|c|}{ Dimensions of the cells and panels } \\
\hline Property & & Value \\
\hline $\begin{array}{l}\text { Time of induction to } \\
\text { oxidation (OIT at } 200^{\circ} \mathrm{C} \text { ) } \\
\text { (mpn.) (virgin material } \\
\text { before any modification) }\end{array}$ & ASTM D-3895 & $\geq 125$ \\
\hline $\begin{array}{l}\text { Resistance to ultraviolet } \\
\text { degradation (HPOIT at } \\
200^{\circ} \mathrm{C} \text { ) (min.) }\end{array}$ & ASTM D-5885 & $\geq 1250$ \\
\hline $\begin{array}{l}\text { Durability of the cell to long- } \\
\text { term cyclical loads (pass) }\end{array}$ & $\begin{array}{l}\text { Accelerated radial } \\
\text { pressure test (TRI) }\end{array}$ & $\begin{array}{l}\text { Cells, joints, and perforations remained intact } \\
\text { without evidence of plastic deformation at the } \\
\text { end of the cyclic loading }\end{array}$ \\
\hline $\begin{array}{l}\text { Efficiency of the internal } \\
\text { friction angle }\end{array}$ & ASTM D-5321 & $\geq 0.84$ \\
\hline $\begin{array}{l}\text { Flexural module for each } \\
\text { temperature }(\mathrm{MPa})\end{array}$ & $\begin{array}{c}\text { ISO } 672 \text { ASTM E2254 } \\
\text { (DAM) }\end{array}$ & \\
\hline$-40^{\circ} \mathrm{C}$ & & $>1150$ \\
\hline$-10^{\circ} \mathrm{C}$ & & $>1050$ \\
\hline$+10^{\circ} \mathrm{C}$ & & $>950$ \\
\hline$+30^{\circ} \mathrm{C}$ & & $>750$ \\
\hline$+45^{\circ} \mathrm{C}$ & & $>650$ \\
\hline$+60^{\circ} \mathrm{C}$ & & $>550$ \\
\hline $\begin{array}{l}\text { Reduction factor } \\
\text { due to permanent } \\
\text { deformation(creep) }\end{array}$ & ASTM D-6992 (SIM) & \\
\hline 5 years & & $<1.2$ \\
\hline 10 years & & $<1.4$ \\
\hline 25 years & & $<1.9$ \\
\hline 50 years & & $<2.9$ \\
\hline
\end{tabular}

Table 3.

Geocell of types 3 and 4 properties, Provider 3.

\subsection{Sampling}

All samples used came from polyolefin geocells available in the Colombian market. The sampling was conducted randomly from a bank of specimens supplied by the manufacturer. For the high-density polyethylene (HDPE) geocells, its polymer contents are not mentioned in this document, since it is known as high-density polyethylene in all the state of the art. While for the Neoloy ${ }^{\circledR}$ Geocell, no typology is obtained since its raw material is patented and there is no information about its polymer composition.

For the first type of HDPE polyolefin geocells from Provider 1, the properties are shown in Table 1.

For the second type of HDPE polyolefin geocells from Provider 2, the properties are shown in Table 2.

For the third type of polyolefin geocell from Neoloy® of Provider 3, the properties shown in Table 3 are available, for categories A, C, and D. 


\section{Procedure of the test}

The laboratory procedure is divided into three parts.

Part I: To start the test, it is necessary to take the measurements of the samples; for this reason the length, width, and thickness of the geocell must be taken.

Part II: The specimen is adjusted to the metal jaws, generating a total interaction between the geocell and the jaws (Figure 1), while Figure 2 shows how the jaws should be placed on both the upper and lower halves to generate the desired load transfer.

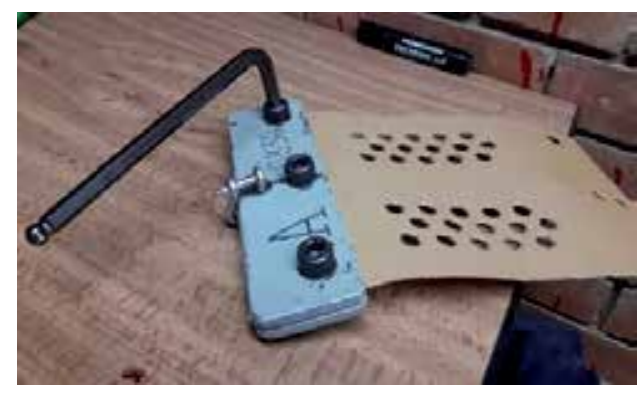

Figure 1.

Adjustment of the sample to the clamp.

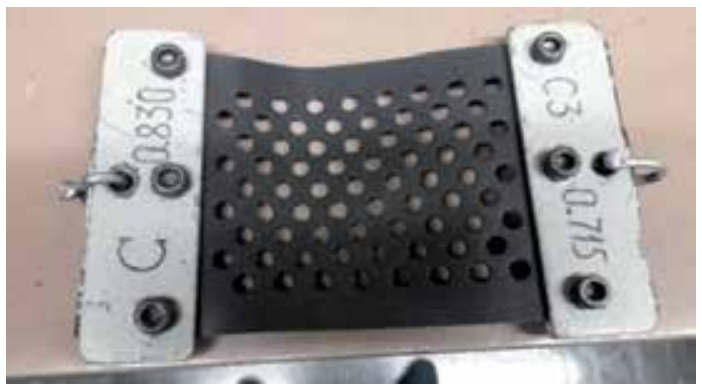

Figure 2.

Placement of the sample to the upper and lower jaws.

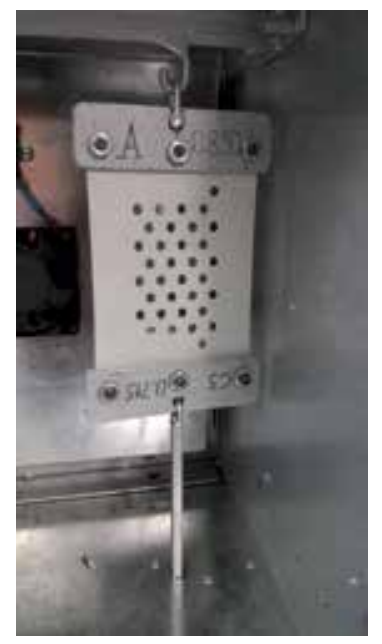

Figure 3.

Installation of the sample in the oven. 

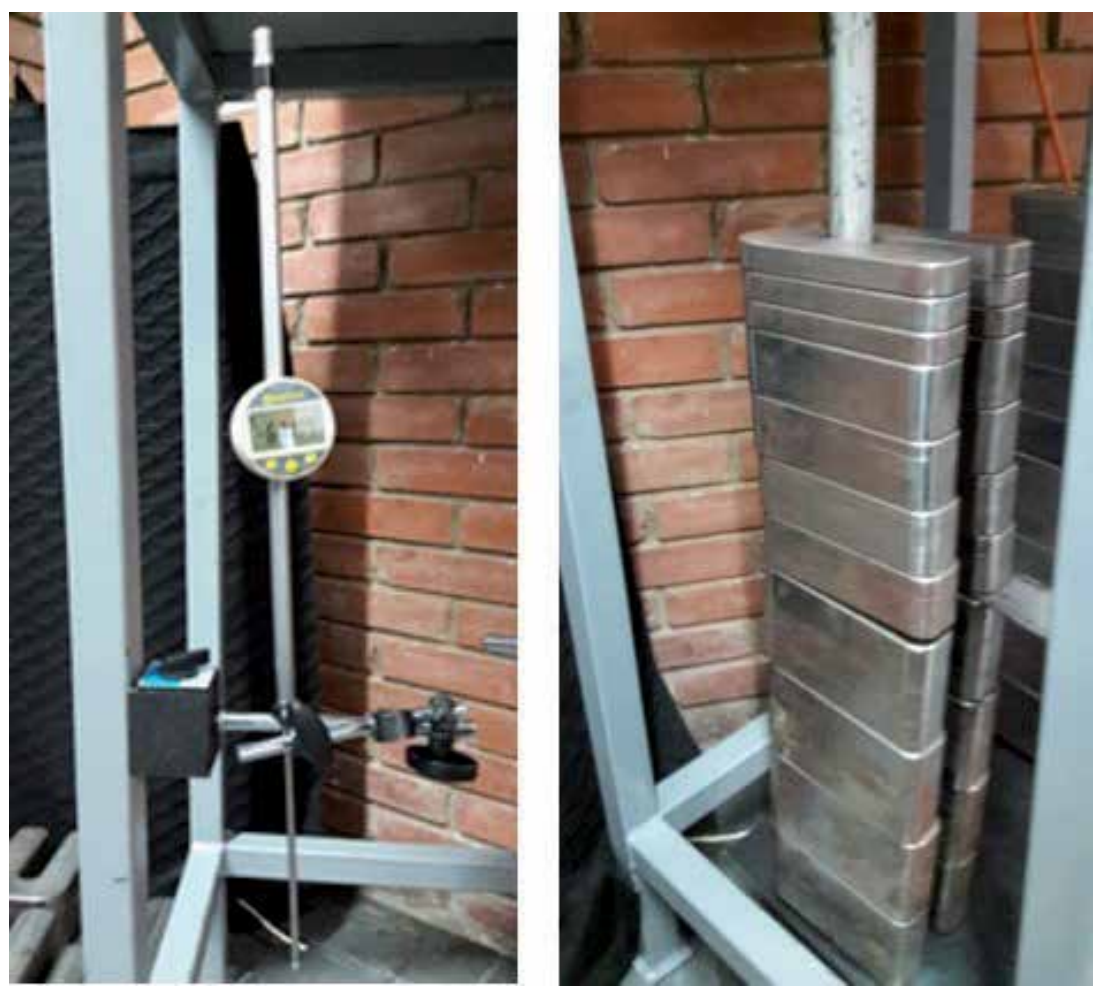

Figure 4.

Deformimeters in the base of the oven (left) and placement of weights in the stems (right).

Part III: In this step, the samples are hoisted in the oven support, complementing the union of the jaw of the lower part of the sample to the stem (Figure 3). After this it is necessary to place the deformimeters in the base that supports the oven (Figure 4, left).

Part IV: The hydraulic jack is placed in the lower part of the rods, generating a support so as not to exert preliminary efforts on the geocells, and then all the necessary weights are placed to reach the force required in the test (Figure 4, right). The oven is subsequently closed.

Part V: The oven is turned on at room temperature $\left(21 \pm 1^{\circ} \mathrm{C}\right)$, then the hydraulic jack is lowered by hanging the stems with the weights, and the first reading of the deformimeter is recorded, after which the steps with the pre-established times begun.

\section{Results}

To obtain the time-temperature superposition data that is necessary in the production of the SIM assay graphs, it was necessary to create an accurate graph, where equivalences (see Table 4) are determined between temperature and time superimposed by every minute that elapsed in temperature; see [10].

An exponential behavior is observed in these correlations, where time depends on temperature (Figure 5). For this reason, an exponential regression shown on the same graph is generated, in order to determine the total time that the geocell was exposed throughout the trial.

The following equation is the result:

$$
T=0.0005 * e^{0,3289 * t^{\circ}}
$$




\begin{tabular}{lc}
\hline Temperature $\left({ }^{\circ} \mathbf{C}\right)$ & Equivalent time (min.) \\
\hline 23 & 1 \\
\hline 30 & 10 \\
\hline 37 & 100 \\
\hline 44 & 1000 \\
\hline 51 & 10,000 \\
\hline 58 & 100,000 \\
\hline 65 & $1,000,000$ \\
\hline
\end{tabular}

Table 4.

Equivalent times.

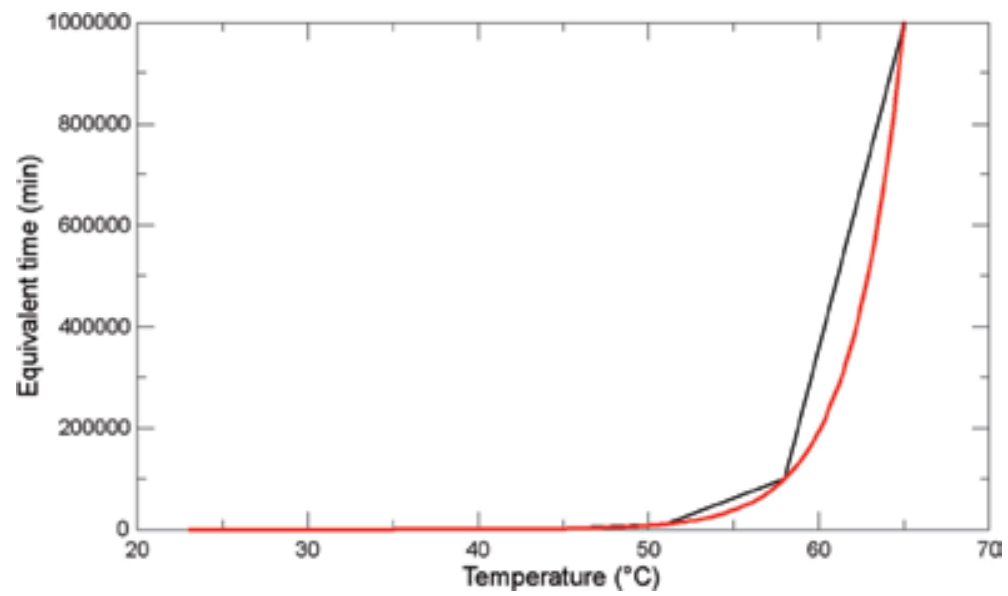

Figure 5.

Time-temperature superposition.

in which.

$T$ : equivalent time in minutes per minute elapsed in temperature $t^{\circ}$.

$t^{\circ}$ : temperature $\left({ }^{\circ} \mathrm{C}\right)$.

The data for the time equivalent to the temperature were obtained based on the above equation, during the course of the different isothermal steps of the test. These equivalent times are shown in Table 5.

After the development of the different graphs made from the tests, it was possible to subtract and make a comparison between the materials that were used in each of the tests, in order to determine which behaved better in the long-term deformation. Figure 6 shows the comparative graph of materials. A red line is again observed, which indicates $3 \%$ of the deformation, which generates a fault in the ground and the possible breakage of the pavement structure.

For the comparative graph of materials, the samples that had been exposed for a while were not considered, given that the other materials did not have this previous exposure and therefore leading to a possible erroneous comparison.

It is important to consider the effect that occurs in the geocells of Neoloy ${ }^{\circledR}$ from exposure to the environment (Figure 7), since these demonstrate the best behavior against long-term deformation [11-15].

Based on the previous results, it is important to make a new comparison in the Neoloy ${ }^{\circledR}$ Geocells, for its ultimate resistance to the wide strip test ISO 103192. 
Analysis of the Creep and the Influence on the Modulus Improvement Factor (MIF) in Polyolefin... DOI: $h$ ttp://dx.doi.org/10.5772/intechopen.88518

\begin{tabular}{lcc}
\hline Step & Time $(\mathbf{m i n})$. & Accumulation of time (years) \\
\hline Ambient & 0 & 0 \\
\hline & 30 & $2.96 \mathrm{E}-05$ \\
\hline & 60 & $5.91 \mathrm{E}-05$ \\
\hline Increase to $44^{\circ} \mathrm{C}$ & 90 & $8.87 \mathrm{E}-05$ \\
\hline $44^{\circ} \mathrm{C}$ & & \\
\hline & 30 & $8.94 \mathrm{E}-03$ \\
\hline Increase to $51^{\circ} \mathrm{C}$ & 167 & 0.33 \\
\hline $51^{\circ} \mathrm{C}$ & & 0.46 \\
\hline & 30 & 3.63 \\
\hline Increase to $58^{\circ} \mathrm{C}$ & 167 & \\
\hline $58^{\circ} \mathrm{C}$ & & 4.94 \\
\hline & 15 & 36.72 \\
\hline Increase to $65^{\circ} \mathrm{C}$ & 167 & \\
\hline $65^{\circ} \mathrm{C}$ & & 78.78 \\
\hline & 60 & 310.89 \\
\hline
\end{tabular}

Table 5.

Equivalent times for the SIM test.

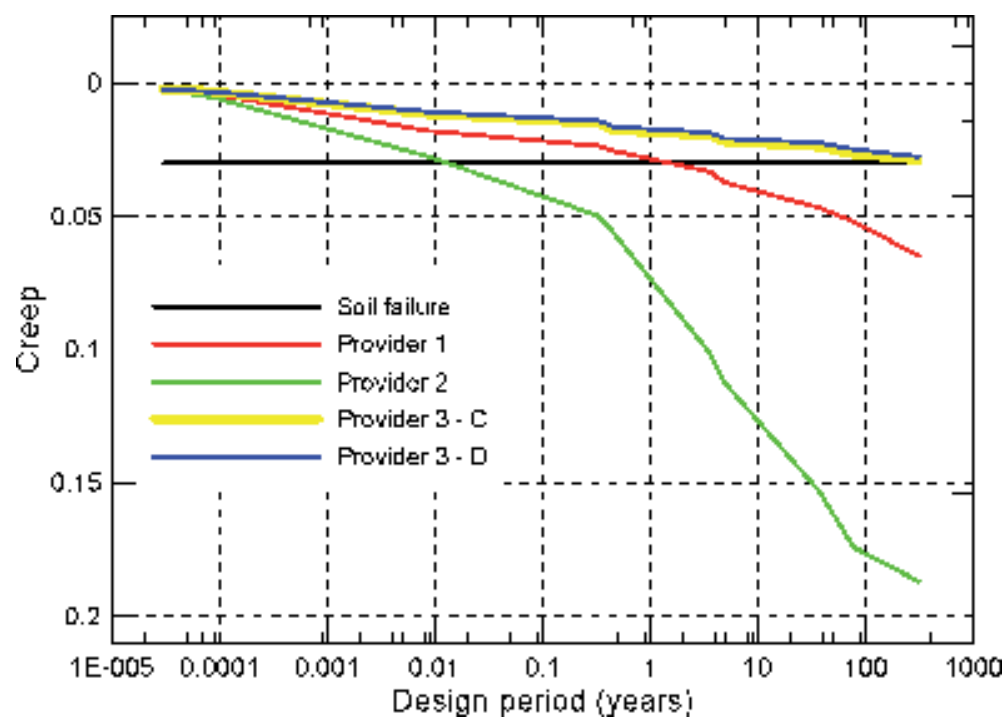

Figure 6.

Comparison of samples tested.

Figure 8 shows the incidence of this property in the behavior to the long-term deformation and the affectation on the MIF.

Continuing with the analysis of the behavior of the polyolefin geocells in long-term deformation, a different behavior was observed among the materials of the HDPE samples, where the thickness determined in part the behavior that was observed throughout the tests. Because of this, the evolution of the specimens in 


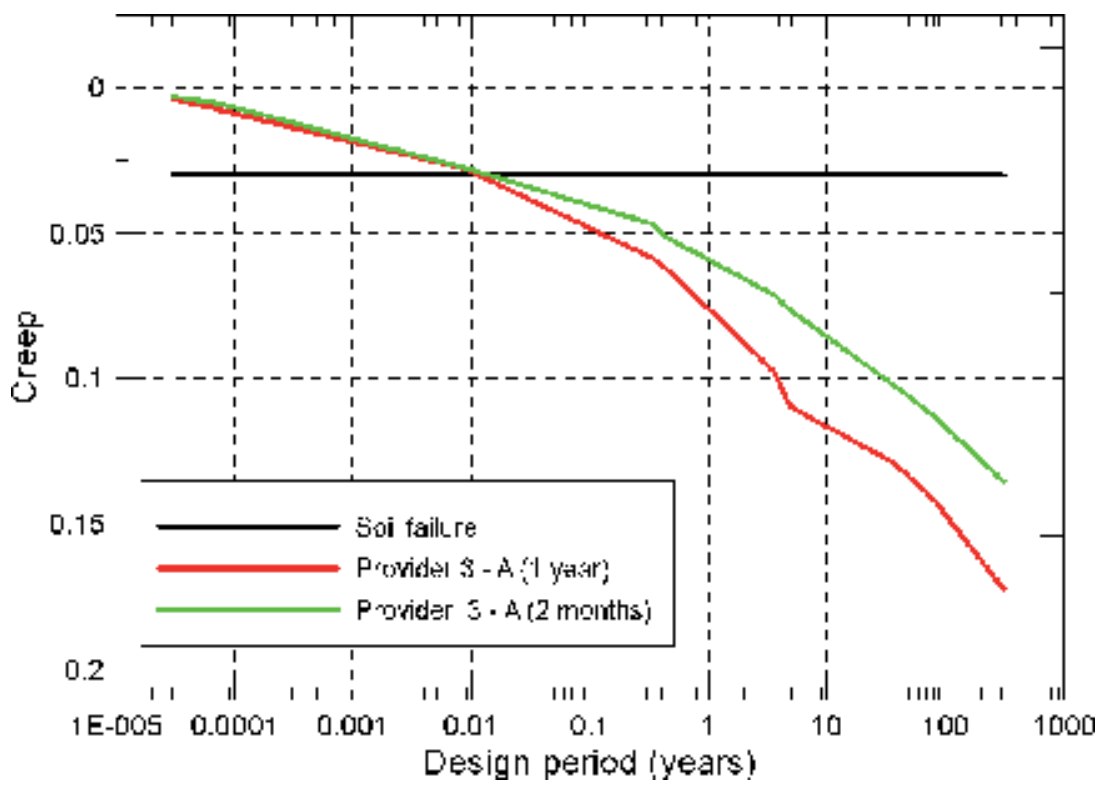

Figure 7.

Behavior according to environmental exposure time (Neoloy $\left.{ }^{\circledR}\right)$.

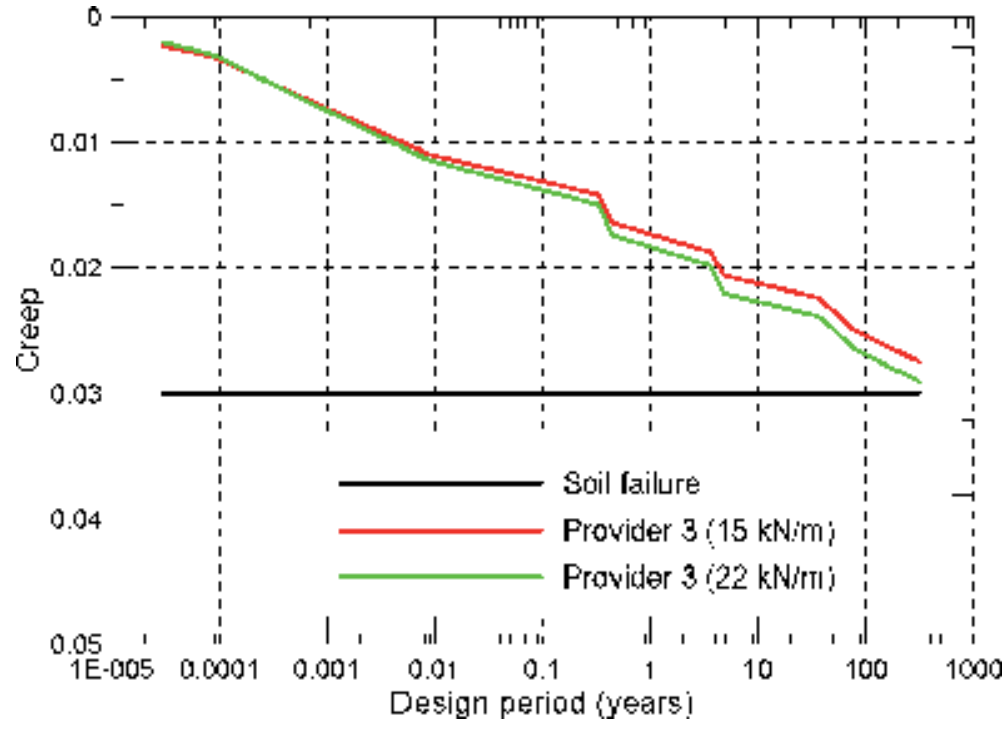

Figure 8.

Behavior of Neoloy ${ }^{\circledR}$ geocells according to resistance of wide strip ISO 103192.

terms of thickness is shown in Figure 9, revealing that the material with greater thickness presents a better response to this type of long-term stress.

As it is possible to extract from the different graphs in categories $\mathrm{C}$ and D composed of Neoloy ${ }^{\circledR}$ from Provider 3, an acceptable behavior was observed against the long-term deformation, this being the material that behaved better during the trials without reaching the $3 \%$ deformation failure in any of the two categories mentioned. Therefore, the geocells would have an MIF factor of high incidence in the module of the material to be confined, as shown in the Mohr circle (see Figure 10).

According to Han [16], the confinement creates an apparent cohesion considering the modification in the normal stresses caused to the granular material. This is 
Analysis of the Creep and the Influence on the Modulus Improvement Factor (MIF) in Polyolefin... DOI: $h$ ttp://dx.doi.org/10.5772/intechopen.88518

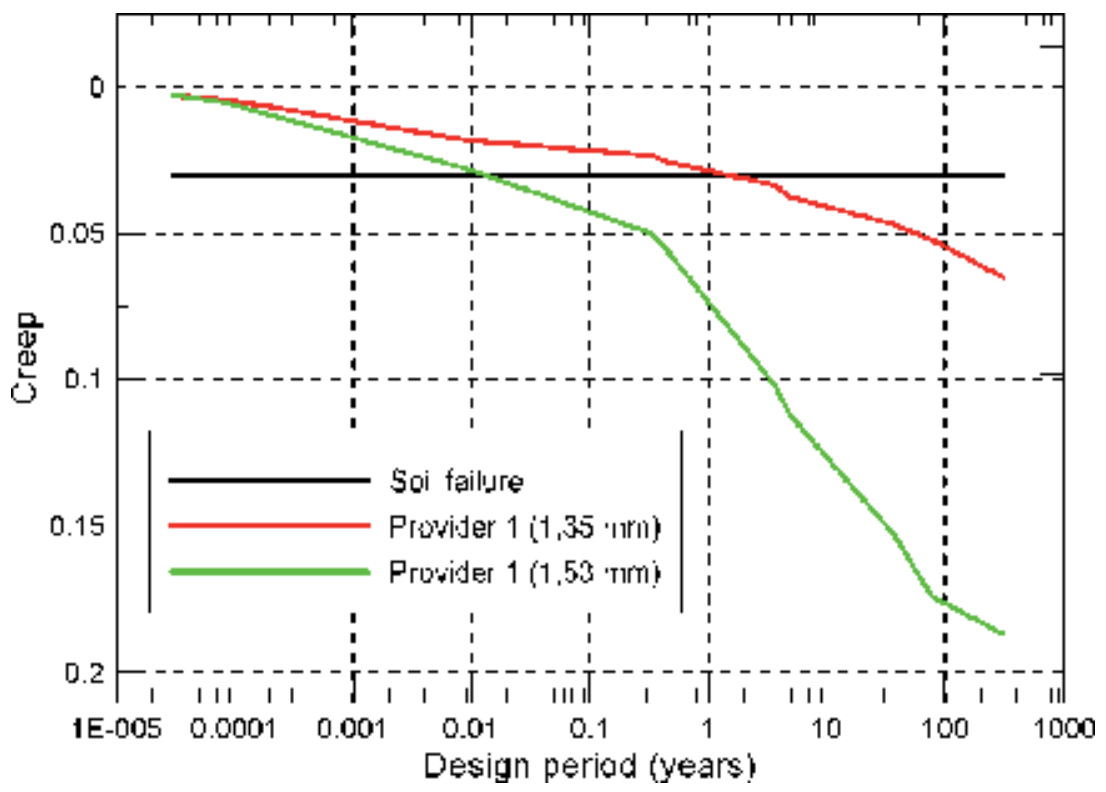

Figure 9.

Behavior HDPE geocells according to thickness.

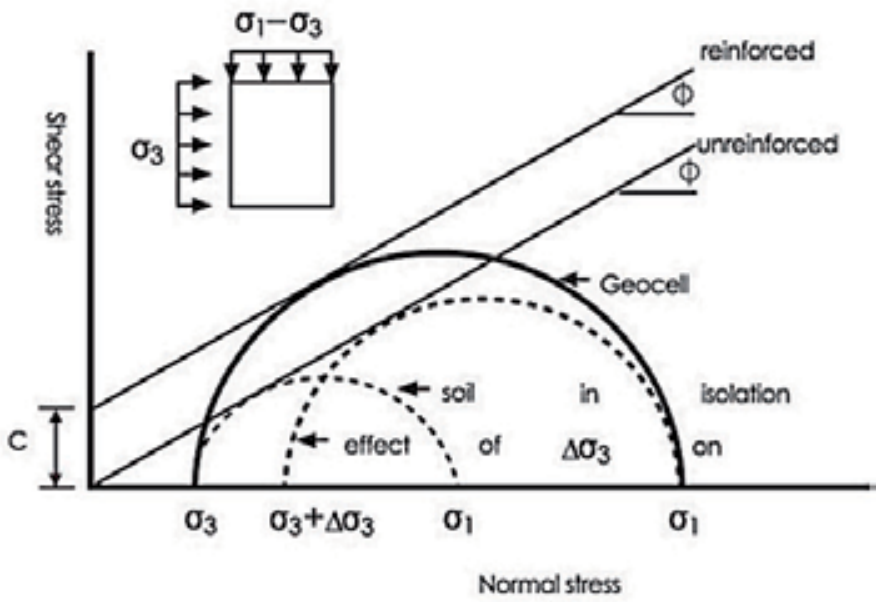

Figure 10.

Mohr circle of granular material with and without reinforcement [7].

only available if the material of the geocell resists the deformations produced by the stresses over the life of the project. Only the Neoloy ${ }^{\circledR}$ Geocells of categories $\mathrm{C}$ and D of Provider 3 manage to comply with the limitation of the MIFs.

When comparing the categories of the Neoloy ${ }^{\circledR}$ material, the great importance of both the thickness of the material and the resistance to the wide strip is observed. The results show better behavior in the geocell that has a greater resistance and greater thickness, displaying a high creep behavior and consequently increasing the MIF, which is significant when designing structures with this geocell methodology.

However, at the end of the tests, a rational time was determined to discharge the geocells. At this time an important behavior was observed in which the samples began to regenerate, decreasing the deformations that were at the end. The effect was established for the geocells that did not fail, showing an "elastic" behavior but 
also maintaining a degree of plastic deformation. Therefore, a linear viscoelastic behavior can be determined, in which there is an initial elastic deformation caused by the stresses generated upon it, followed by a time-dependent delayed deformation, known as material creep. There may be some permanent flow in the material, especially when high loads are applied.

When the unload is permitted to the material, within linear viscoelastic behavior, an inverse process begins, with a certain recovery at the moment, continued by a recovery along the time recovering fluence dependent on the time. The material may or may not reach the original dimensions. If permanent flow occurs in the charging process, there will be a residual deformation even when the load application is no longer allowed [17-19].

\section{Conclusions}

Polyolefin geocells can be considered an excellent reinforcement in the structures of the roads as long as they meet certain specifications, such as resistance to long-term deformation. For the geocells tested, the best performance was obtained by the Neoloy ${ }^{\circledR}$ composite material.

Taking into account the results of the laboratories, the increase factor of MIF modules is directly connected to creep resistance. When confinement is eventually lost due to large deformations in the geocells, the increase will be zero, and the behavior of the granular material belonging to the pavement structure will be the same as if it were not considered reinforced, decreasing its modulus, requiring a greater thickness to comply with the conditions of the structure.

All polymeric material that is exposed to weather, for greater resistance that it possesses, suffers the loss of properties. This could be evidenced when comparing tests with the same material and category, but with different time of exposure to the effects caused by nature (UV rays, air, water, etc.). A lesser deformation was displayed in the sample that had been under condition for a year.

The deformation behavior of HDPE exposed to high temperatures is low compared to Neoloy ${ }^{\circledR}$ material. For this reason, it could be determined that the HDPE geocells, although they have a regular behavior, cannot be located in the base layer of the pavement structures, since these could have temperatures as tested in the "SIM test" or higher, generating a double deformation. One of them would be due to time and the other due to temperature, leading to failure in a very short period of time.

To determine the MIF, it is necessary to know the resistance of the material of the geocell to the long-term deformation, since it is a vital part of achieving high performance, during the entire life of the structure of pavement reinforced with geocells.

The geocells, composed by Neoloy ${ }^{\circledR}$ with a resistance to the wide strip of $15 \mathrm{kN} / \mathrm{m}$, are the most suitable to achieve a subgrade improvement. These geocells have the ability to be used in the granular layers adjacent to the asphalt folder, decreasing thicknesses. The use of these minimum aspects is recommended to guarantee the functionality, serviceability, and long-term operability of structures where geocells are involved. 
Analysis of the Creep and the Influence on the Modulus Improvement Factor (MIF) in Polyolefin... DOI: $h$ ttp://dx.doi.org/10.5772/intechopen.88518

\section{Author details}

Juan Carlos Ruge ${ }^{1 *}$, Julian Gonzalo Gomez ${ }^{1,2}$ and Carlos Andres Moreno

1 Catholic University of Colombia, Bogotá, Colombia

2 Fluent Business Group, Mexichem Colombia S.A.S, Bogota, Colombia

*Address all correspondence to: jcruge@ucatolica.edu.co

\section{IntechOpen}

(C) 2019 The Author(s). Licensee IntechOpen. This chapter is distributed under the terms of the Creative Commons Attribution License (http://creativecommons.org/licenses/ by/3.0), which permits unrestricted use, distribution, and reproduction in any medium, provided the original work is properly cited. (cc) BY 


\section{References}

[1] Geoceldas SA. Historia [Internet]. 2015. Available from: http://www.geoceldas. com/historia [Accessed: 12 April 2017]

[2] PRS Geo-Technologies. PRS stabilizing an unstable world. SIM Test Procedures ASTM D-6992. s.1.: PRS Technical Description; 2016

[3] PRS Geo-Technologies. The effect of creep on geocell design life. s.l.: PRS; 2015

[4] ASTM D6992-16. Standard Test Method for Accelerated Tensile Creep and Creep-Rupture of Geosynthetic Materials Based on Time-Temperature Superposition Using the Stepped Isothermal Method. West Conshohocken, PA: ASTM International; 2016

[5] ASTM International. Standard Terminology for Geosynthetics. Conshohocken: ASTM; 2004

[6] Pavco Mexichem. Manual de diseño con geosintéticos. Bogotá, D.C.: Pavco Mexichem Soluciones Integrales; 2012

[7] Herminda EB. Análisis de la superposición Tiempo-Temperatura: Determinación e interconversión de espectros de relajación y retardo. Buenos Aires: Universidad de Buenos Aires-Facultad de Ciencias Exactas y Naturales; 1991

[8] Billmeyer F Jr. Ciencia de los Polímeros. Barcelona, Reverté; 2004. ISBN: 84-291-7048-0

[9] PRS Geo-Technologies. PRS-Neoweb geocells (tough cells) test specification. PRS Geo-Technologies; 2017

[10] Tsorani G. Geoceldas en la ingeniería. Bogotá: PRS Geo-Technologies; 2017

[11] Kolathayar S, Suja P, Nair V. Performance evaluation of seashell and sand as infill materials in HDPE and coir geocells. Innovative Infrastructure Solutions. 2019;4:17. DOI: 10.1007/ s41062-019-0203-6
[12] George AM, Banerjee A, Puppala AJ, Saladhi M. Performance evaluation of geocell-reinforced reclaimed asphalt pavement (RAP) bases in flexible pavements. International Journal of Pavement Engineering. 2019:1-11. DOI: 10.1080/10298436.2019.1587437

[13] Keshmiri N, Ghareh S, Kazemian S, Hosseinian A. 3D numerical analysis of loading geometry on soil behavior reinforced with geocell element. Journal of Testing and Evaluation. 2019;47(3). DOI: 10.1520/JTE20180194. ISSN: 0090-3973. Special Issue Paper

[14] Venkateswarlu H, Ujjawal KN, Hegde A. Laboratory and numerical investigation of machine foundations reinforced with geogrids and geocells. Geotextiles and Geomembranes. 2018;46(6):882-896

[15] Pokharela SK, Leshchinsky HD, Parsons RL. Experimental evaluation of geocell-reinforced bases under repeated loading. International Journal of Pavement Research and Technology. 2018;11(2):114-127

[16] Han J. Geocell reinforced research. Kansas City: University of Kansas; 2008-2012

[17] Álvarez FB. Comportamiento reológico de los polímeros.

Viscoelasticidad. Universidad de Oviedo-Escuela de Minas de Oviedo; 2013

[18] Jeon H-Y. Review of Long-Term Durable Creep Performance. Creep. IntechOpen; 2017. doi: 10.5772/ intechopen.72330

[19] Yeo SS, Hsuan YG. Predicting the creep behavior of high-density polyethylene geogrid using stepped isothermal method. In: Martin JW, Ryntz RA, Chin J, Dickie RA, editors. Service Life Prediction of Polymeric Materials. Boston, MA: Springer; 2009 


\title{
The Assessment Strategy for Selecting and Evaluating Geoenvironmental Remediation
}

\author{
Meshari Almutairi
}

\begin{abstract}
A large volume of oil-contaminated sand remains in the Kuwaiti deserts, causing threat to the groundwater and ecological system. The main aims of this research are to evaluate the situation of Kuwaiti oil lakes and identify the impact of contaminated soil on ecology and humans in Kuwait. This consists of two phases; the first phase summarises the results from field demonstrations and discusses the prospective of using different techniques for remediation of the oil-contaminated soil in Kuwait, while the second phase aims to compare and select the appropriate soil remediation techniques based on UN requirements. In this chapter, decision mechanism was carried out in compliance with the House of Quality (HOQ) analysis system. The total weighted score for each soil remediation method was determined to obtain the final decision.
\end{abstract}

Keywords: oil lakes, house of quality, soil remediation, Kuwait, TPH

\section{Introduction}

The State of Kuwait sustained significant and widespread environmental damage resulting from the Iraqi invasion in August 1990 and during the 1991 Gulf War. The occupation of Kuwait by the Iraqi army caused substantial damage to Kuwait's environment. Several oil lakes, i.e. oil accumulation in depressions, were formed. During the 1991 Gulf War, estimates of 798 oil wells were set ablaze; out of 914 operational oil wells, 149 were damaged, 45 were gushing oil, and 155 were undamaged [1-3]. Approximately 25 million barrels of ignited crude oil were extinguished using around 12 billion gallons of seawater. The gushing oil was spreading over the desert surface from the oil fire plumes, which covered vast areas stretching from Kuwait to the Kingdom of Saudi Arabia. Within the neighbourhood of the oil wells, various sizes of oil lakes were formed and spread across areas far away from the oil wells. Consequently, combustion products from oil fire and oil spray were able to cause contaminations of soil and groundwater [4]. More than 300 large oil lakes in low-lying areas within Kuwait desert were created from the accumulation of spilled oil. These contamination soil consist of water, salt, $28 \%$ average, in excess of $10 \%$, respectively, where the oil and sand known as "oil lakes" were spreading over the surface of ground. These oil lakes were classified into major and minor; around 45 major oil lakes were located in the Burgan oil field as well as between Ahmadi and Maqwa oil fields; there were another 23 minor oil lakes [5-7]. Saeed [8] reported that the oil lakes contain crude oil and partially combusted oil with soot. At present, most of the oil lakes are dry, with the contamination comprising a black, moderately 


\begin{tabular}{lccc}
\hline Source of contamination & Average depth $\mathbf{( c m )}$ & Extent $\left(\mathbf{k m} \mathbf{~}^{\mathbf{2}}\right)$ & Volume $\left(\times \mathbf{1 0} \mathbf{~}^{\mathbf{3}}\right)$ \\
\hline Dry oil lakes & 25 & 98.38 & 25.5 \\
\hline Wet oil lakes & 64 & 7.19 & 4.6 \\
\hline Oil-contaminated piles & 173 & 8.59 & 14.8 \\
\hline Oil trenches and pipeline spills & 351 & 1.63 & 5.7 \\
\hline Total & & 115.79 & 49.6 \\
\hline
\end{tabular}

Table 1.

Volume of oil trenches and oil lakes in Kuwait (source: [9]).

hard, tar-like dry surface layer. Four categories of oil-contaminated soil layers, namely, soot, tar mat, oil lake, and dry oil lakes, were identified during the field investigation. The fifth category is clean, where no contamination was detected. As illustrated in Table 1, it is fortunate that the Kuwait Oil Company (KOC) has been successful in recovering around 21 million barrels from the oil lakes since the end of the Gulf War with approximately $49 \mathrm{~km}^{2}$ of oil lakes with $16.5 \times 10^{6} \mathrm{~m}^{3}$ in volume left to be recovered [9].

This catastrophe has created one of the greatest environmental impact issues to the coast, air, soil, groundwater, and the vicinity. In addition, it has been noticed that the oil lake depth varies from a few metres to a few centimetres, which constitute more than 60 million barrels of crude oil. Overall, almost 660 million barrels of crude oil were spilled to the surface, and therefore, around 55 million tons of contaminated sand is present in the lakebeds. The persistence of such a phenomenal amount of oil over a large land area is considered as one of the main environmental concerns in the State of Kuwait. There are no similar petroleum catastrophes in history that has ever been as tragic as this incident $[6,7]$. Furthermore, approximately $49 \mathrm{~km}^{2}$ which constitutes $28 \%$ of the total Kuwait land area was covered by oil mist and soot. As time goes by, lighter oil evaporated, oil mist became hard, while smaller and shallower oil lakes became dry thus forming tar mats. Under the extreme weather conditions, these contaminants continue to disintegrate slowly. The thickness of tar mat varies from a few millimetres to approximately $2 \mathrm{~cm}$. The soot changed the soil beneath to black in the long run. It has been found by investigator Kwarteng [7] many of these oil lakes could not be detected from the surface since they were covered with a veneer of sand. Moreover, the author noticed in the different effected area of Kuwaiti desert that, the occasional flash floods and heavy showers were placed when the oil travelled to new sites. There are limited large-scale remediation processes implemented to deal and treat the contaminated areas thus far. The Kuwaiti environment is exposed to these oil contaminated soil and oil lakes since 1991 therefore the contamination is become a weathered oil contamination, which is required special strategy to deal with this disaster. The State of Kuwait is considered as the first country in the world who filed claims from the United Nations Compensation Commission (UNCC) for seeking compensation to rehabilitate and remediate the areas that sustained environmental damage. In 1991 UNCC had decided to sell Iraqi oil for distributing money as recompense "the money to be taken from the Oil-for-Food Programme" for damages suffered from the Iraq invasion. In 2003, the pace of the clean-up is anticipated to significantly increase over years of researches and claims. The UNCC awarded the state of Kuwait about US $\$ 3$ billion in order to rehabilitate the effected area in the Kuwaiti desert during the Gulf War [3]. The KOC, UNCC, and Kuwait National Focal Point (KNFP) are providing the combined effort for the rehabilitation task. Currently, KOC is planned to coordinate bidding for contracts worth hundreds of millions of dinars in the upcoming months which will remain afterward every year. According to experts, the entire process 
is expected to take approximately 29 years. In fact, Kuwait is the first country that claimed for environmental disaster from the Iraq invasion through the United Nations (UN), to rehabilitate Kuwait's environmental damage.

\section{Engineering approaches}

"Soil remediation" is referred to as the efforts which aim to reduce or remove the risks related to the contamination site. This objective can be easily achieved by using various ways; however, the most appropriate remediation method is governed by many factors, such as the conditions of site, financial constraints, and category of contaminants. Nathanail and Bardos [10] proposed that the remediation process can take place by degrading, removing, or transforming contaminants to the acceptable level. In situ and ex situ remediation process for rehabilitation of weathered oil-contaminated soil can be classified based on their treatment process, for instance, biological, chemical, physical, thermal, and electrical [11]. A number of various methods of remediation are presently available. Remediation techniques such as soil vapour extraction, bioremediation, electrochemical remediation and electrokinetic soil remediation, and ex situ soil washing have been developed lately in an effort to remediate soils contaminated with petroleum [12, 13]. In accordance with Ellis et al. [14], appropriate engineering solutions should be taken into account to ensure the remediation zone is contained and migration of leachate beyond the treatment zone is avoided. Should the conclusion require soil remediation, it should be tackled after the evaluation of technologies. The following outlines the soil remediation technology in comparison with the typical treatment approach. This includes remediation technologies that can improve the quality of soil through design and application which are central to soil clean-up process. The remediation is achieved by reducing or removing contaminations such as total petroleum hydrocarbons (TPHs), volatile organic compounds (VOC), semi-volatile compounds (SVOC), and metal contents.

\subsection{Bioremediation}

The biological remediation process is conducted by using microorganisms to degrade the contaminants to safe products and end products. Biological treatments have significant accomplishment by combining with other remediation processes and are easily implemented with contaminated soil [10]. Biological remediation is implemented at a low cost compared to the other alternative techniques [15], even though a wide variation occurs in terms of the environmental consequences, treatment time, and performance of these techniques [16]. As shown in Figure 1, bioremediation in 2008-2009 [17] comprised the most significant portion (21\%) of the innovative activity which was reported by the Federal Contaminated Sites Action Plan (FCSAP) in Canada. Brief explanations of bioremediation process conducted in the remediation of contaminated soil are defined in the following section.

\subsubsection{Land farming}

Land farming is considered as an ex situ remediation process in which the contaminated soil is excavated and then applied into lined beds afterwards; the contaminated soil is tilled mechanically to aerate the waste. The contaminated soil is placed in several layers $0.4 \mathrm{~m}$ thick. A synthetic, concrete, or clay membrane is then used to cover the contaminated soil layer. Oxygen is added, and mixing occurs via ploughing, harrowing, or milling. Nutrients and moisture can be added to support the remediation method [18]. 


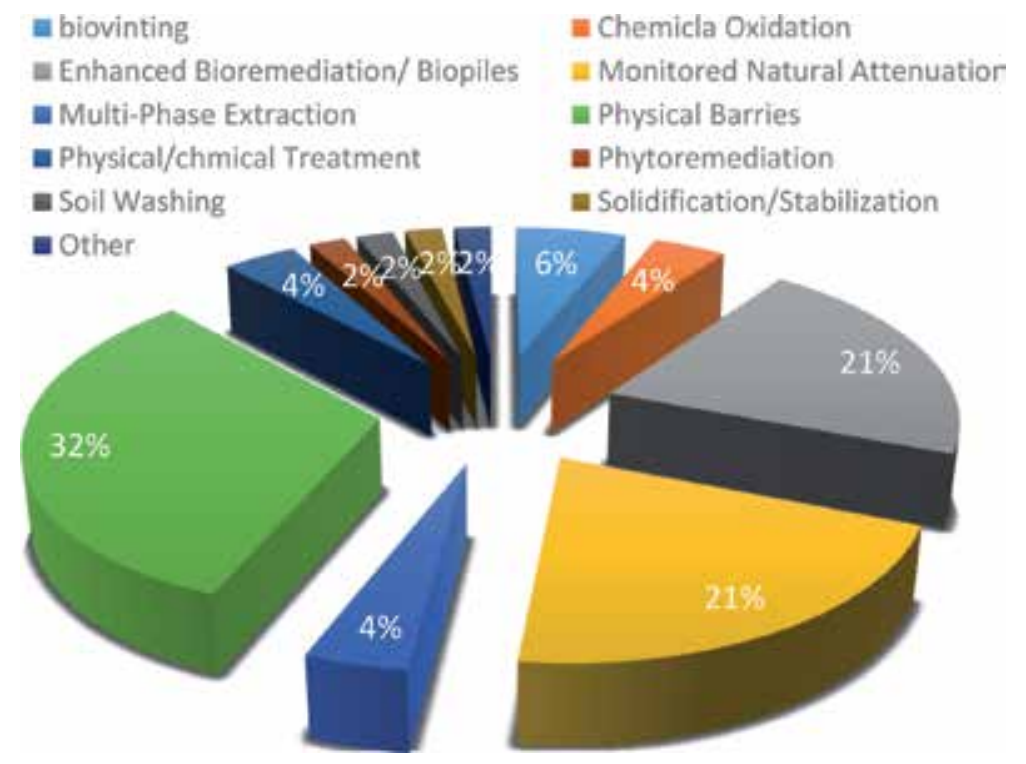

Figure 1.

Distribution of innovative remediation activity (source [17]).

\subsubsection{Vermiremediation}

Vermiremediation is considered a less expensive and more acceptable remediation process for contaminated soil in the world. Generally, earthworms (especially E. fetida) have good resistance against contaminants including heavy metals and organic pollutants within the soil. This approach is carried out using the earthworms to bioaccumulate the contaminants within their bodies; moreover, these earthworms are able to biotransform or biodegrade the contaminants into harmless products with the presence of enzymes. Sinha et al. [19] reported that the earthworms have high resistivity to a number of chemical pollutants present in the soil. They concluded that $5 \mathrm{~kg}$ of earthworms (totalling to 10,000) are able to degrade $1000 \mathrm{~kg}$ of waste, converting the waste into vermicompost within only 30 days. One of the main features of this economic and environmental importance is that polluted land is not only cleansed but also improved in terms of its physical, chemical, and biological quality.

\subsubsection{Bio-piles}

Bio-pile is considered as an ex situ remediation process in which the contaminated soils are excavated and combined with soil amendments and then placed on a treatment area. In order to enhance the remediation process, nutrients and oxygen are pumped into the contaminated soil using air injection system, which is buried under the contaminated soil during the remediation process to provide the required oxygen. This oxygen is supplied through the contaminated soil either by positive pressure or by vacuum to support the biodegradation process [10]. Many factors such as moisture, heat, nutrients, oxygen, and $\mathrm{pH}$ require to be controlled to enhance biodegradation process; the height of the soil piles should be up to 20 feet. This method has been conducted successfully to treat and rehabilitate soils contaminated with non-chlorinated VOCs and fuel-contaminated soil [19]; however, chlorinated VOCs, SVOC, or pesticides might be treated as well, but the effectiveness of the process varies [14]. 


\subsubsection{Bioventing}

Bioventing is considered as an in-situ bioremediation process in which the contaminated soils inject by air pump to enhance and improve the existing soil microbial, where the movement of air is designed to maximise biodegradation while minimising volatilisation [10-19]. Bioventing process is for treating permeable soils because a huge volume of air is required to reduce and degrade VOC. Low air flow rate is required during the process to supply only enough oxygen to maintain the activity of the microorganisms in residual contamination in the soil. The current method provides oxygen using air injection system, which is inserted into the vadose zone. This technology has been implemented successfully to treat and rehabilitate soils contaminated with various levels of TPH or any chemical contaminants that can be aerobically biodegraded [19].

\subsubsection{Windrow}

Windrows are considered as an ex situ remediation process in which the contaminated soils are excavated and combined with compositing materials such as bark, compost, or wood chips and then placed in windrows to increase and improve aeration process and enhance the structure of soil. Windrows are one of the waste management systems that use microbial activity to biodigest organic waste compounds and transform them into safe products. In order to transfer oxygen into contaminated soils, regular turning is conducted, thus enhancing aerobic degradation. Windrows system and waste composting are considered very similar in their methods [10-19]. Many aspects such as moisture, heat, nutrients, oxygen, and $\mathrm{pH}$ need to be maintained in order to improve the biodegradation process.

\subsubsection{Phytoremediation}

Phytoremediation is the term used to describe a process based on biological technology which uses natural plant processes in improving degradation as well as eliminating contaminants in polluted groundwater or soil. In recent years, the emphasis in handling polluted ground has been slowly swung away from the conventional remove, dispose, and cap methods to a more on-site integrated technique. Attempts to develop these integrated approaches have caused a swing in awareness from reviewing the problems to addressing society's needs by devising potential solutions. It is possible to develop potentially sustainable methods such as phytorestoration and remediation which emphasise on restoring the usability as well as the land's social and economical significance. The utilisation of plants in reducing the volume, mobility, or toxicity of contaminants in soil, underground water, or any other polluted media is known as phytoremediation, which is a general term used since 1991 [20]. Several mechanisms are available to make use of plants in the process of phytoremediation for organic compounds, such as phyto-degradation, phytovolatilisation, and rhizodegradation. Many benefits can be offered by employing the phytoremediation method in either minimising risks or saving costs as compared with traditional excavation and landfilling methods, where contaminated materials or other usual methods of implementation are carried out on-site.

\subsection{Thermal desorption}

Thermal desorption aims to increase the volatility of contaminants to a gas phase or allow the contaminants to be melted by heating the contaminated soil. The preparation of this method is by means of rotary kiln plants, fluid bed, or sintering strand, 
which is considered as fast method nevertheless; this method is classified as the most expensive remediation process. It is possible for contaminants such as VOC or SVOC to be vaporised and then rise to the unsaturated zone where they are collected using vacuum system to start another treatment procedure. For geological materials with moderate to high permeability, it is recommended to apply steam. The time it takes depends on three major factors: type and amounts of chemicals present, size and depth of the polluted area, type of soil and situations present [21].

\subsubsection{Ex situ thermal processes}

Ex situ thermal treatments convert pollutants from the soil to a gas phase. The pollutants are released by vaporisation and then burned at high temperatures. Ex situ thermal remediation depends on three factors: type and amounts of chemicals present, size and depth of the polluted area, and type of soil and conditions present [18]. In order to start the treatment process, the soil condition is required to be broken into small grains and sieved in preparation for thermal treatment. A low temperature range of $350-550^{\circ} \mathrm{C}$ is selected to heat the contaminated soil. Burning of the gases takes place at the top of the surface, but the VOC or SVOC are not destroyed. The gases at approximately $1200^{\circ} \mathrm{C}$ can be then combusted in an after-burner chamber; however, dioxins are destroyed $[18,19]$. Moreover, ex situ thermal remediation processes are ideal for removing hydrocarbon compounds.

\subsubsection{In situ thermal processes}

The process involves injecting a steam-air mixture at $60-100^{\circ} \mathrm{C}$ into the contaminated soil to avoid the shifting of pollutants to the groundwater; the steam-air mixture should stay in that temperature range. After the injection, VOC and SVOC get converted from the soil to the gas phase. The gases are then removed from the subsurface using a soil vapour extraction (SVE) system and then remediated at the surface. Furthermore, in situ thermal remediation is used for homogeneous soils with high permeability and low organic content. In situ thermal processes are only appropriate for destroying pollutants, which can be stripped in the lower temperature range (e.g. BTEX) [10-18].

\subsection{Physical and chemical remediation}

Physical remediation method aims to rehabilitate and remediate contaminants by separating contaminants from soil. This method is focused on the physical differences between the contaminants and soil (e.g. volatility, behaviour in electric field) or among their physical properties (e.g. particle size, density, etc.) and soil properties [10-18]. There are several physical and chemical remediation techniques available for soil remediation which are described in the following section.

\subsubsection{Solidification/stabilisation}

Solidification/ Stabilisation (S/S) process is considered as an in-situ fixation or immobilization, which aims to alter the condition of contamination compounds to innocuous, and/or immobilize condition by using stabilizing agents into an area of contaminated soil. This process make the status of the contamination soil to be in lowpermeability mass (solidification), or chemical reactions between the contaminants and stabilising agent which able to decrease their mobility (stabilisation) or physically bound. It is vital to have good knowledge of the hydrological regime, and it can be used to moderate- to high-permeability soils as well as different types of contaminants. 


\subsubsection{Electro-remediation}

Electro-remediation is an in situ remediation system which requires the use of low-intensity direct electrical current across pairs of electrode which is placed into the ground of the contaminated site. This ion migration are depending on their charge therefore, contaminates shifted towards respective electrodes. The remediation process can be supported using surfactant to accelerate the separation of contaminants at the electrodes. This technology is primarily a separation and removal procedure for extracting contaminants from various soils such as saturated or unsaturated soil, sludge, and sediment; additionally, this method is limited for sites where the soil is wet or saturated with water [22].

\subsubsection{Soil venting and air sparging}

Soil venting and air sparging or SVE are used in treatment approaches by injecting gas (usually air or oxygen) into the saturated zone to volatile contaminants and stimulating biodegradation by augmenting subsurface oxygen concentrations [10-23]. The remediation system of SVE can be applied successfully for VOCs in relatively moderate- to high-permeability geologic soil. Among others, soil vapour is useful to extract compounds with high vapour pressure for low molecular weight (LMW) compounds. Nevertheless, this method is not suitable for organic compounds with low volatility, for example, polycyclic aromatic hydrocarbons (PAH), and unable to expel super heavy oil pollutants which contain high concentrations of resins and bituminous materials [24]. After airflow is switched off, contamination may transfer from these less accessible spots of contamination to recontaminate the soil atmosphere. Under high pressure of injection, it is easy to fracture the soil material which leads to pathways of air transfer to decrease the side effect of the treatment. In addition sparging must be activated with venting to detain the emissions of VOCs in air leaving the saturated zone. Treated soil, either from SVE in conjunction with air sparging or SVE alone, is usually collected for subsequent treatment, probably catalytic oxidation [25]. SVE has been conducted successfully to treat and rehabilitate soils contaminated with VOC, SVOC, or any chemical contaminants that can be aerobically biodegraded [19]; various factors need to be controlled during the remediation process such as moisture, heat, nutrients, oxygen, and $\mathrm{pH}$ to enhance the bioremediation process.

\subsubsection{Soil washing}

Soil washing aims to use liquids such as water, occasionally combined with detergent or surfactant with mechanical processes, to separate the contaminants from soils. Frequently, the higher contaminated part of the soil is the fine fractions of soil. Moreover, if the fine fraction content is more than 30-40\%, it may not be cost-effective to conduct the separation as a further remediation stage [26].

\subsubsection{Geosynthetic applications}

As geoenvironmental applications are considered as a potential for rehabilitating contaminated soil, geosynthetic materials become vital in the industrial field, particularly geomembranes. The main role of a geomembrane is to reduce the migration of contaminants whether existing as liquid or vapour, either existing as a composite or a single liner barrier system, via base liners and into the surrounding environment [27]. Previous researches deduced that geomembranes could be used as protective layers nearby diesel tanks, in temporary containment barriers, landfill 
and treatment walls, or in mining applications [28-30]. Geomembranes have been employed and evaluated for the first time in the soil remediation area, as a layer for biopile method in the composite liner barrier system used for treating hydrocarboncontaminated soil [31]. Geomembranes have been used for a variety of applications during remediation of heavily contaminated sand with polychlorinated biphenyls (PCBs), hydrocarbons, and metal $[32,33]$. They proposed to construct geomembranes in the landfill site as the base barrier system to filter and treat the contaminants from the spring thaw. This technique is required when contaminated soil or landfill needs to be isolated from the surrounding groundwater or ecological system to prevent the release of hazardous gases or liquids. Furthermore, Various advantage can be obtained by using geomembrane such as protecting people from contacting with hazards or reduce the impact of discharge water through the contaminated land which allow to decrease in leachate of these hazardous to the groundwater.

\section{Methods}

\subsection{Site investigation}

Field investigation was formulated to recognise, manage, and remediate the oilcontaminated sand. As the first step, the concentration and type of contamination present ought to be determined in the Greater Al-Burqan oil field. The data from the investigation will be utilised to plan future rehabilitation works. As such, the aim of this survey can be summarised as:

- Classify the types of damage.

- Assess the level of contamination in the affected soil.

- Provide information to assist in future land use planning and to determine remediation options using House of Quality (HOQ) analysis system.

The selected approached was based upon the concepts of soil survey. The main parameters measured were the depth of contamination (by site measurement), TPH level (using gravimetric method), colour of the soil (using Munsell colour chart), and the texture of the soil. The site investigation categorises the oil-contaminated soil into four layers, namely, liquid oil, tar mat, oily soil, soot and clean soil with no contamination. For remediation the bulk of the contaminated soil to be dealt with has oily soil characteristics; also in some areas the oily soil placed under the liquid oil requires to be treated. In addition, all of these areas may contain unexploded ordnance (UXO). Any method for remediation of the tar mat and soot would need to take into account that they occur over an extensive area and form a thin layer on the soil surface.

\subsection{Preliminary survey}

It is evident from the field data in Figure 2 that these layers of contaminated oil can be segregated based on their colour and property consistency. Typically, weathered crude oil is black, oily soil is dark brown to black with a moderate to slightly hard consistency, while the colour of tar mat is black with a hard stability. The depth of these oil lakes is $70 \mathrm{~cm}$ below the surface; therefore, the crude oil has penetrated the soil to different depths subject to the condition and characteristics of the soil belowground (Figure 2). 


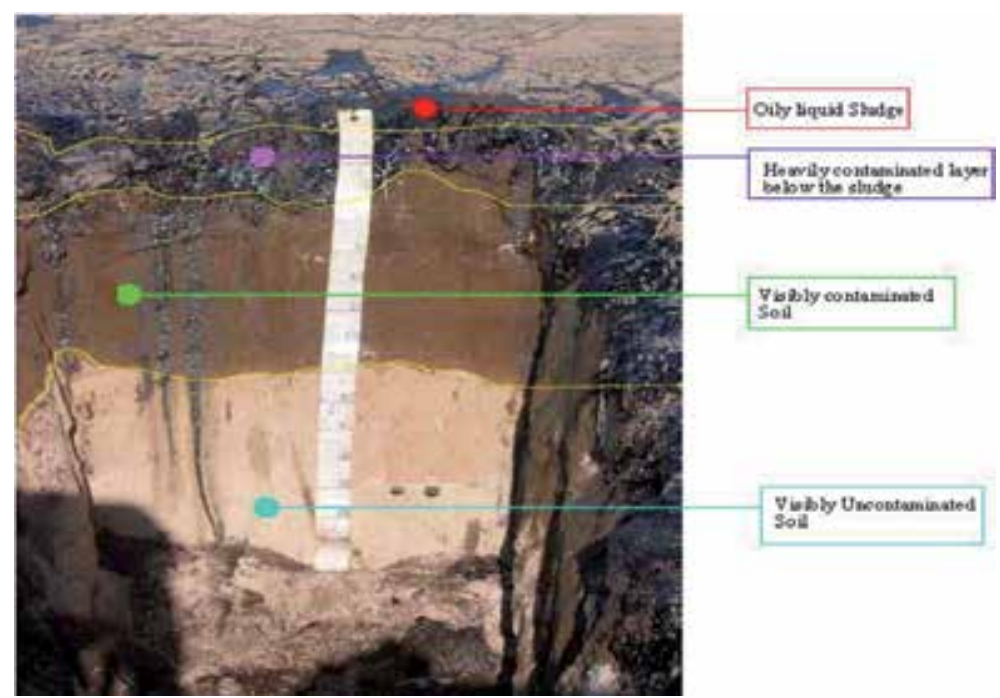

Figure 2.

The layers in the oil lake at the Burgan oil field in the State of Kuwait (13 Jan 2012).

A thick oily sludge deposit has covered the affected areas with a thicker layer beneath, and oil has seeped through aided by gravity and rainfall $[6,7]$. Besides this, the quality of oil has deteriorated caused by prolonged exposure to the extreme weather. The volatile hydrocarbons within the oil structure have been lost, and the oil has endured changes in its chemical and physical properties causing its sale not as lucrative. The nature of layers and the manner they are arranged provide indication of the category of contamination, the three contamination categories in Figure 2. Different sorts of oil-contaminated soils might not be differentiated using only the analytical results. For example, field investigation is vital to classify these contaminations, as they require various remediation methods to remediate or rehabilitate the contaminated site or options of land use; furthermore, varying physical characteristics are noticed during the investigation.

\subsection{Characterisation of oil lakes}

It is vital to evaluate the characteristics of Kuwait's oil-contaminated sands such as organic and inorganic material contents and soil particle size distributions in order to select the appropriate treatment method. All analytical methods were conducted at the University of Portsmouth, UK.

\subsubsection{Soil sampling}

The soil samples were collected from the Burgan oil field in the south of the Kuwaiti desert. The sample was collected from the edge of lake no. 105, in September 2011 (Figure 3). Firstly, the KOC and Ministry of Defence (MOD) checked for unexploded bombs and landmines, and then a hand shovel was used to remove about $3 \mathrm{~cm}$ of oily sludge from the soil surface. Then, after which heavily oil-contaminated soil (concentration of oil 35\%) was collected at a depth of approximately $30 \mathrm{~cm}$ below the surface level of oily sludge. Subsequently, the samples were placed into plastic containers after being excavated from the soil with a shovel. This project has been focused on the contaminated layer below the oil sludge layer, meanwhile the sludge will be taken by the KOC for reuse. 


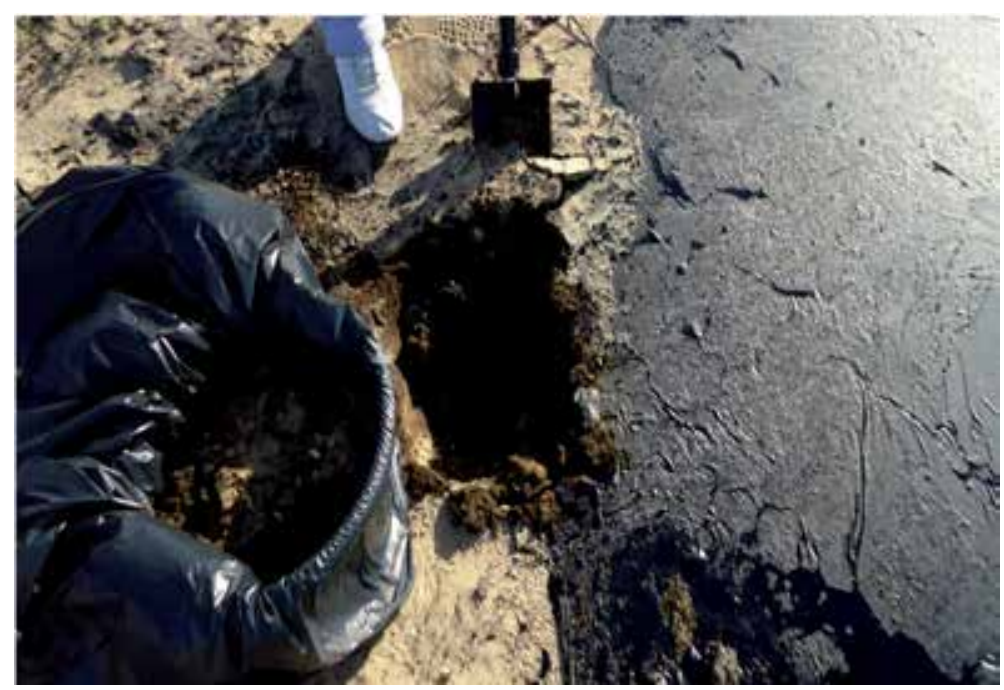

Figure 3.

Sample collection from Burgan Lake No. 105.

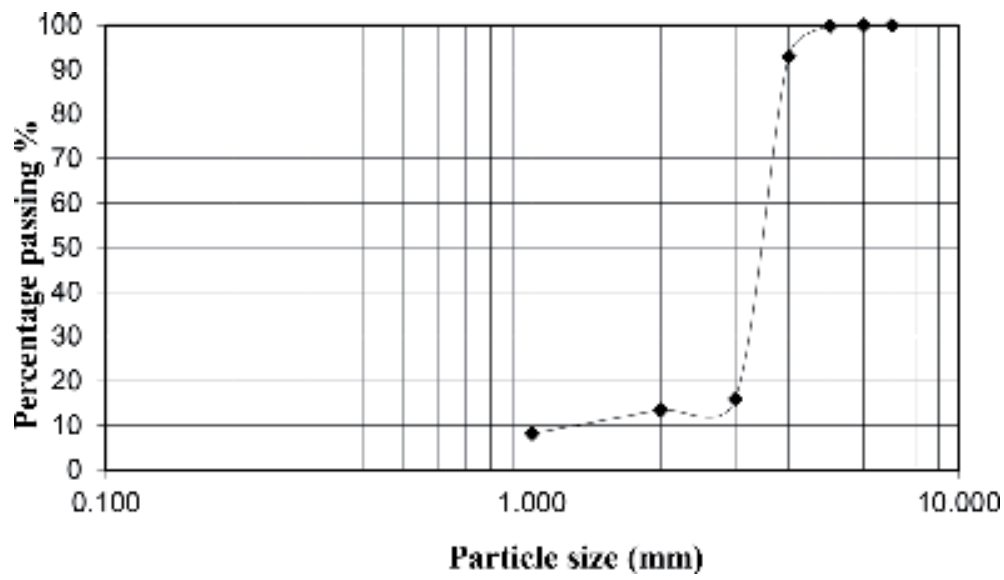

Figure 4 .

Particle size distribution on wet basis.

\subsubsection{Properties of oil lakes}

Soil properties are classified into two categories: chemical properties and physical properties. The soil samples were taken from the Burgan oil field to classify and analyse the physical properties according to the soil layers. The constant head permeability test were used to measure the soil permeability. These samples were considered as moderately permeable soil, with an average permeability rate of $0.064 \mathrm{~mm} / \mathrm{s}$ having been recorded. Due to the presence of oil on the top layer, it prevented water from penetrating. Furthermore, mechanical sieve analysis (Figure 4) was carried out based on British Standards (BS 1377: Part 2:1990) [34] for wet sample to eliminate coarse fraction as well as to ensure homogeneity for the oil-contaminated soil. Chemical properties were investigated by determining TPH and measuring concentration of metal contents in Kuwaiti oil-contaminated sand.

As illustrated in Table 2, the results indicate the presence of some ions such as $\mathrm{Ba}, \mathrm{Cr}, \mathrm{Fe}, \mathrm{Ni}, \mathrm{Pb}, \mathrm{Cd}$, and $\mathrm{Ag}$, as well as high concentration of TPH. The present preliminary study showed that with the high average value of electrical 
The Assessment Strategy for Selecting and Evaluating Geoenvironmental Remediation DOI: http://dx.doi.org/10.5772/intechopen.88166

\begin{tabular}{lcc}
\hline Parameters & Concentration of metals $(\mathbf{m g} / \mathbf{k g})$ & KEPA limit $(\mathbf{m g} / \mathbf{k g})$ \\
\hline Barium $(\mathrm{Ba})$ & 0.78 & 10 \\
\hline Chromium $(\mathrm{Cr})$ & 0.52 & 5 \\
\hline Iron $(\mathrm{Fe})$ & 8.10 & 5 \\
\hline Nickel $(\mathrm{Ni})$ & 0.43 & 10 \\
\hline Lead $(\mathrm{Pb})$ & 0.70 & 5 \\
\hline Cadmium $(\mathrm{Cd})$ & 1.1 & 1 \\
\hline Silver $\mathrm{Ag}$ & 0 & 5 \\
\hline $\mathrm{TPH}$ & 367,234 & 10,000 \\
\hline $\mathrm{pH}$ & 7.8 & $5.5-7.5$ \\
\hline
\end{tabular}

Table 2.

The concentration of metals during the washing of Kuwait oil residual [36].

conductivity (EC) $(2455 \mu \mathrm{S} / \mathrm{cm})$, the existence of ions could be caused by using seawater to extinguish fires from oil well. Moreover, $\mathrm{pH}$ for the contaminated sample was found slight higher than the permissible level as shown in Table 2. For the purpose of selecting the most appropriate treatment method, the chemical and physical properties of the lake as well as unexploded ordnance, weathered soil, and local conditions are taken into consideration.

\section{Determination of remediation options}

In carrying out decision-making process, a number of techniques could be utilised, for example, pairwise comparison chart, decision matrix, force field analysis, cost-benefit analysis, and HOQ. HOQ is used in this study among various available methods. This decision-making tool is considered as a simple decision mechanism with potential of implementation at various stages of advertising and product manufacturing. Function deployment instrument is required to develop the specifications into the product and organise customer requirements as well as enhance procedure of work. This decision-making tool needs to assign weight to each specification also; upon outlining personnel responsible for decision-making ought to outline weighted symbols among the progressions that constitute the interlink between the proposed processes and specifications and non-weighted symbols between the processes themselves. Towards the end, the sum of the product of the specified weight by the equivalent symbol weight is determined by calculating the accumulated score for each process. Moreover, HOQ provides assistance to engineers in focusing on specified needs and deciding on the best sequence in the case that the process goes ahead. Because of this, HOQ was employed for this project to incorporate the requirements of UNCC and KNFP and choose the best technique of remediation method for which the remediation process will proceed.

\subsection{Establishing house of quality}

Within this research, relationships were established between pre-set objectives outlined by UNCC and KNFP and various methods of remediation chosen by the team. In contrast to the numerical evaluation matrix, HOQ utilises symbols to demonstrate the relationship between objectives and alternatives in addition to the connection between alternatives themselves. In an effort to compare the proposed 
methods of remediation, all the needs were incorporated and translated into engineering characteristics. This is beneficial in assessing the available remedial methods with the pre-set engineering characteristics and comparing them with one another. The detailed description of the UN requirements is described hereunder:

a. Remediating various contaminated soil.

b. Operate with severe weather conditions (extreme temperature).

c. Simple to operate and assemble.

d.Produces least effect on groundwater, air, soil, employees, and neighbouring environment.

e. Short time duration.

f. In compliance with the requirements of Environmental Protection Agency (EPA).

g. Previous success percentage in Kuwait or comparable conditions.

h.The panel is of the opinion that remediation of oil-contaminated material by means of high-temperature thermal desorption is unjustifiable, given the conditions of this claim.

In an effort to weigh these criteria, Ejbarah et al. [35] carried out a series of discussions with consultants, environmental engineers, and scientists, and undertaking literature review, UN requirements were aimed to develop the weighted objective tree. Based upon the outcomes, weights are assigned to each objective creating the weighted objective, as listed in Table 3. The outcome of the study is utilised to distinguish, appraise various solutions, and determine the importance

\begin{tabular}{lc}
\hline Engineering characterisation & Assigned weight \\
\hline 1. Reduction in major contaminants & 0.36 \\
\hline 2. Can be used in Kuwait's climatic conditions & 0.18 \\
\hline 3. Does not cause health problems to the worker & 0.12 \\
\hline 4. Simple to operate and assembly & 0.07 \\
\hline 5. Generates least residuals & 0.03 \\
\hline 6. Creates least equipment contaminants & 0.03 \\
\hline 7. The least pollution to air & 0.027 \\
\hline 8. Only small area needed & 0.02 \\
\hline 9. The least pollution to groundwater & 0.018 \\
\hline 10. Does not cause noise pollution & 0.015 \\
\hline 11. Requires shorter duration & 0.01 \\
\hline 12. In compliance with the requirements of EPA & 0.06 \\
\hline 13. Previous experience in Kuwait or similar surroundings & 0.06 \\
\hline Total score & 1 \\
\hline
\end{tabular}

Table 3.

Weights of engineering characteristics (source: [34]). 


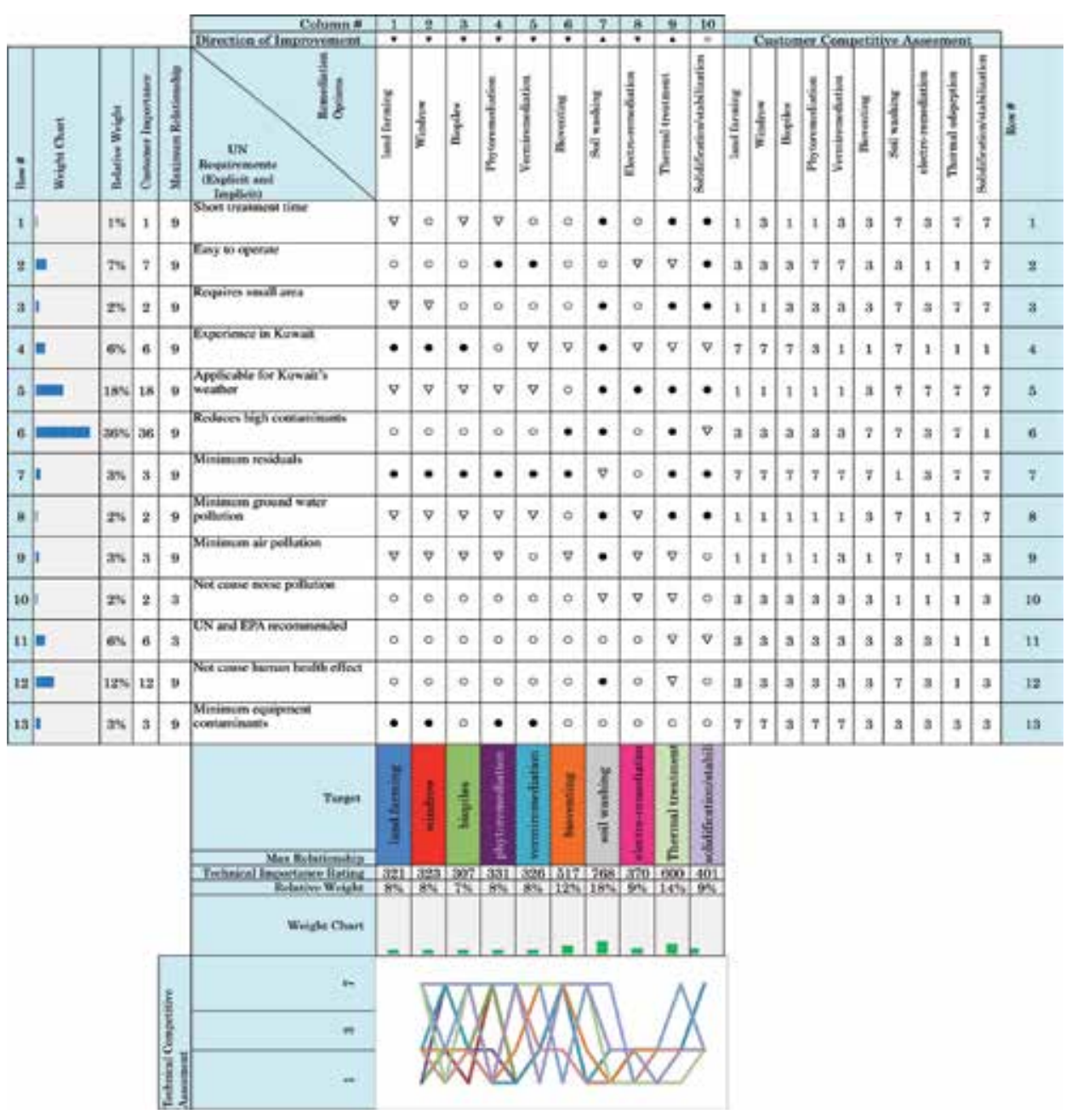

Table 4.

Interrelationship matrix among several soil remediation methods.

between the objectives listed. These engineering techniques are effective in removing potential risks posed by contaminants, require comparatively shorter duration to operate, and can frequently be used extensively.

\subsection{Investigating alternative methods}

The "soil remediation" terminology relates to the efforts which seek to eradicate or reduce the risks connected to contaminated soil. Several soil remediation methods have been considered in an attempt to remove the impact of crude oil pollution on the environment. There are large variances in the biological, chemical, and physical characteristics of the contaminants, as well as a number of soil remediation methods are available in the market; selection of suitable and economical technology for the remediation of specific contaminants may not be an easy. In this study using a HOQ analysis system, only 10 remediation technologies have been considered: land farming, windrow, phytoremediation, vermiremediation, bioventing, soil washing, biopiles, electro-remediation, solidification/stabilisation, and thermal. These approaches have been selected in accordance with previous successful investigations into the remediation of hydrocarbon-contaminated soil. For each of 
these techniques, the chosen methodology and theories are discussed in a comparative evaluation based on the specialised research conducted.

\subsection{Define the relationship symbol and weights}

The relationship between the characteristics and each remediation method was clarified in Table 4; the main target of this section is to find the appropriate remediation method among other alternative methods. The symbols used with their corresponding values are defined and listed below:

\section{Strong positive with a weight of 7}

2. Positive $\bigcirc$ with a weight of 3

\section{Moderate $\nabla$ with a weight of 1}

The interrelationship symbols were set to identify the potential of implementing the selected remediation process in sandy soil. The symbols are used and listed below:

\section{More suitable $\mathbf{A}$ without problems}

2. Suitable $\diamond$ with a few concerns

\section{Less suitable $\nabla$ to work}

\section{Results and discussion}

\subsection{Evaluating alternatives}

A range of remediation alternatives are briefly presented in Table 4, and it explains why it is the treatment alternative of choice for Kuwait's oil-contaminated sand. This chapter explains the decision-making process behind using soil washing and other remediation techniques. In order to choose the most appropriate method, an exhaustive list of each remediation option was reviewed. As shown in Section 2, each treatment was briefly described after thorough research in order to develop an interrelationship between these methods. As a result, the matrix was formulated and evaluated to show the interrelationship, although the requirements were assessed and ascertained against the alternatives and the weights. Therefore, weighted alternatives have been formulated. The process can be started by altering the set symbols to their corresponding values. The characteristic weight is multiplied by each value. This procedure was repeatedly employed for all the characteristics, and the total sum was kept at the last phase.

As seen in Table 4, the relative weight for biopiles is 7\%; there is a similar weight score recorded among land farming, windrow, phytoremediation, bioventing, and vermiremediation; the outcome showed that the score of relative weight was about $8 \%$. Similarly, the result also demonstrated that the scores of relative weight for thermal adsorption and soil washing were 14 and 18\%, respectively, and that the score for both electro-remediation and solidification/ stabilisation was $9 \%$.

Correspondingly, Table 4 also showed that there were no real concerns for all the methods employed except for one: soil washing. From the results, soil washing 
appears to be the best method in view of their total score, while thermal cannot be employed based on UN requirements. This method was the most appropriate and hence employed in selecting an optimised treatment method to match the conditions under study. Each of the remedial methods was assessed against the set requirements, and their capability to treat sandy soil was investigated. The results obtained in this study showed that the soil washing was the best method to meet the objectives of the project. This method can be employed on its own or performed in series. The selection of the method for remediation is also essential for subsequent soil or site use. Later restrictions of land use may be as a result of groundwater pollution from the application of nitrates and due to the nitrogen release from the endogenous decomposition of microorganism [36]. Using (ex situ) techniques for soil washing, the coarser material which has been cleaned is without any clay or organic materials, which can be used for construction use such as subgrade fill or backfill. The major change in the soil materials takes place during the thermal treatment. Usually, high-temperature procedures damage the organic compounds and clay minerals; hydroxides are being transformed into oxides, and main minerals are changed to fines. For thermally treated soils which are transformed to slurry, their values of $\mathrm{pH}$ are quite high $(\mathrm{pH} 11)$; therefore the products are not ideal for future use; however, the UN requirement does not allow to use it for remediation of Kuwait's oil lakes. In addition, compared with other thermal and bioremediation technologies, soil washing method has some major benefits. Some of the benefits are their cost-effectiveness, scalability, and exceptional ability to remove oil from contaminated soil in short time. Limited successes have been reported with different remediation process. Thus it encourages researchers to develop and enhance the selected techniques of soil washing, so as to make it cost-effective, environmentally friendly, and effectiveness. The standard removal efficiency of TPH shall be tested and observed over a period of time. This involves developing methods for extraction of TPH from soil samples.

A large number of remediation methods have been designed in an attempt to reduce the effects of petroleum pollution on the environment. Due to the large differences in the physical, chemical, and biological characteristics of the contaminants, as well as the large number of soil remediation methods available, selection of an appropriate and economical technology for the remediation of particular contaminants can be difficult. In this study using a multi-criterion analysis system, only nine remediation technologies have been considered: land farming, windrow, phytoremediation, vermiremediation, bioventing, soil washing, biopiles, electro-remediation, and solidification/stabilisation. Various criteria were evaluated and assessed to select appropriate methods such, soil constraints, implement in surface soil, if any further treatment is required when the remediation process is completed, which compounds can be removed, time for clean-up and cost. Among others, the ability of wastewater treatment was investigated. The evaluation study shows that bioventing, electro-remediation, and the solidification/stabilisation approaches are not applicable for use in sandy soil, once the bioventing required low permeable soil, while electro-remediation needs saturated soil with water. Furthermore, solidification/stabilisation is used at the subsurface soil. Solidification/stabilisation, electro-remediation, bioventing, and biopiles are generally considered to be the most expensive treatments. However, land farming and bioventing need around 2 years to complete the remediation process and were not effective for HMW. In this study, soil washing techniques were selected as well. It has less profound side effects, while removal of contaminants can be controlled by enhancing washing factors. The selected techniques require 1 year or less to achieve the remediation target and are the cheapest of the available approaches. 


\section{Conclusion}

The scenario in Kuwait is somehow exceptional as the contamination is primarily caused by crude oil, which has been weathered under open environment for 25 years. The exposure to the environment has caused most of the volatile substance within the crude oil to evaporate into the atmosphere with heavy compounds left as residue. Due to the complex nature of contaminated soil and the undeniable fact that contaminations in different situations present a "cocktail" of various types of pollutants, therefore, different types of remediation dealing with different ranges of contaminants, limited success have been reported in remediation of contaminated soil. The higher levels and wider ranges of TPH have shown interesting patterns at Kuwait's oil lakes. Most importantly, these contaminated sites have not yet been restored, which poses continued potential hazards to the environment and human health. Therefore, it is also important to estimate the characteristic of the contaminated soil; the tests can be performed to simulate the field conditions and provide categorisation for the sample. Without this key information, it is impossible for the planning of land use and options of remediation to be taken into account. Based on the literature, bioremediation is unlikely to be successful given the high concentration of TPH and high concentration of the metal salt in Kuwaiti contaminated soil. Furthermore, thermal system is not allowed to be used in this project (UN conditions), and hence the technique based on decision tool with HOQ, soil washing, was selected to deal with this issue. Selecting a remediation scheme challenges decision-makers to compare and select the appropriate soil remediation techniques by making a tool of engineering decision based on a set of UN requirements.

\section{Acknowledgements}

The author is grateful to the staff of Research \& Technology Group in Kuwait Oil Company (KOC) especially for sampling and metals analysis and many thanks to Naim bin Masood Intermediate School in Jeleeb Al-Shuyoukh (Kuwait) for motivating me to get back on the waggon and continue with my research and invention.

\section{Author details}

\section{Meshari Almutairi}

1 School of Civil Engineering and Surveying, University Portsmouth, United Kingdom

2 Kuwait Oil Company (KOC), Ahmadi, Kuwait

*Address all correspondence to: mesmutairi@kockw.com; meshari.almutairi@myport.ac.uk

IntechOpen

(C) 2019 The Author(s). Licensee IntechOpen. This chapter is distributed under the terms of the Creative Commons Attribution License (http://creativecommons.org/licenses/ by/3.0), which permits unrestricted use, distribution, and reproduction in any medium, provided the original work is properly cited. (cc) BY 


\section{References}

[1] Petroleum Economist. The oil fires story. International Energy Journal. 1992;59:21-28

[2] PAAC. Environment Damage Claims Prioritization Report. Kuwait: Public Authority for the Assessment of Compensation Resulting from Iraqi Aggression (PAAC); 1999

[3] United Nations Compensation Commission (UNCC). Claim of the State of Kuwait. Claim No. 5000454. Report No. S/AC26/2004/17. United Nations Compensation Commission; 2004

[4] Al-Awadhi N, Al-Daher R, Balba M, Chino H, Tsuji H. Bioremediation of oilcontaminated desert soil: The Kuwait experience. Environment International. 1998;24(1/2):163-173

[5] Al-Ajmi D, Misak F, Khalaf M, Al-Sudairawi M, Al-Dousari A. Damage Assessment of the Desert and Coastal Environment of Kuwait by Remote Sensing. Report KISR 4405. Kuwait: Kuwait Institute for Scientific Research; 1994

[6] El-Baz F, Abuelgasim A, Koch M, Pax-Lenney M, Lambin E, Al Dosari A, et al. Detection by satellite images of environmental change due to the Gulf war. In: El-Baz F, Makharita RM, editors. The Gulf War and the Environment. Lausanne: Gordon and Breach Science Publishers; 1994. pp. 1-24

[7] Kwarteng A. Multitemporal remote sensing data analysis of Kuwait's oil lakes. Environment International. 1998;24:121-137

[8] Saeed T, Al-Bloushi A, Al-matrouk K. Kuwait Oil Lakes: Composition of the Oil and Effects of Weathering. Kuwait: Kuwait Institute for Scientific Research; 1997
[9] Al-Naseem A, Al-Duwaisan D.

Characterization of oil contaminated soil, Kuwait oil lakes. In: 2nd International Conference on Environmental Science and Technology (IPCBEE). Vol. 6.

Singapore: IACSIT; 2011

[10] Nathanail CP, Bardos RP.

Reclamation of Contaminated Land. John Wiley \& Sons Ltd; 2004. ISBNS: 0-471-98560-0

[11] Riser-Roberts E. Remediation of Petroleum Contaminated Soil: Biological, Physical, and Chemical Processes. Boca Raton: Lewis Publishers; 1998

[12] Bennett B, Larter S, Carbognani L, Pereira-Almao P. Identification and characterization of reaction proxies for monitoring the progress of thermal processing of heavy oils and tar sands under vis-breaking conditions. Energy and Fuels. 2008;22:440-448

[13] Sui X, Ji D. Impact of ultrasonic power density on elution of super heavy oil and its biomarkers from aging soils using triton X-100 micellar solution. Journal of Hazardous Materials. 2010;176:473-480

[14] Ellis R, Balba MJ, Theile P. Bioremediation of oil contaminated land. Environmental Technology. 1990;11:443-454

[15] Zhao D, Liu C, Liu L, Zhang Y, Liu Q, Wu W. Selection of functional consortium for crude oil-contaminated soil remediation. International Biodeterioration \& Biodegradation. 2011;65:1244-1248

[16] Banerji SK, Zappi ME, Teeter CL, Gunnison D, Cullinane MJ.

Bioremediation of Soils Contaminated with Petroleum Hydrocarbons Using Bioslurry Reactors. Miscellaneous Paper IRRP-95e2, Final Report. U.S. Army Corps of Engineers; 1995 
[17] Federal Contaminated Sites Action Plan (FCSAP). Federal Contaminated Sites Action Plan Annual Report 2007-08; 2009

[18] Van Deuren J, Lloyd T, Chhetry S, Raycharn L, Peck J. Remediation Technologies Screening Matrix and Reference Guide. Vol. 4. Federal Remediation Technologies Roundtable; 2002

[19] Sinha RK, Herat S, Valani D. Earthworms-The environmental engineers: Review of Vermiculture Technologies for Environmental Management \& resource development. International Journal of Environmental Engineering. Special Issue on Vermiculture Technology for Environmental Management and Resource Development. Agricultural sciences. 2010;3(7)

[20] McCutcheon SC, Schnoor JL. Overview of phytotransformation and control of wastes. In: Phytoremediation: Transformation and Control of Contaminants. Hoboken, NJ: John Wiley \& Sons, Inc.; 2003

[21] Koning M, Hupe K, Stegmann R. Thermal processes, scrubbing/ extraction, bioremediation and disposal. Biotechnology. 2000;11b:306-317

[22] Yang JW, Lee YJ, Park JY, Kim SJ, Lee JY. Application of APG and Calfax $16 \mathrm{~L}-35$ on surfactant-enhanced electrokinetic removal of phenanthrene from kaolinite. Engineering Geology. 2005;77:243-251

[23] Bardos R, Morgan P, Swell RPJ. Application of in situ remediation technologies-11. Contextual frame work. Land Contamination \& Reclamation. 2000;8:1-22

[24] Ji GD, Guo F. Impact of ultrasonic power density on hot water elution of severely biodegraded heavy oil from weathered soils. Chemosphere. 2010;79(2):210-215
[25] Evans D, Jefferis SA, Thomas AO, Cui IS. Remedial Process for Contaminated Land. Principle and Practice Publication C549. London: CIRIA; 2001. ISBN 0860175499

[26] Wallace S, Cork J. Remediation of Basford Gasworks Using Soil Washing Contaminated Soil. London: Thomas Telford Ltd; 1998. pp. 65-74

[27] Shackelford CD. The ISSMGE Kerry Rowe lecture: The role of diffusion in environmental geotechnics. Canadian Geotechnical Journal. 2014;51(11):1219-1242

[28] Mumford K, Rayner J, Snape I, Stark S, Stevens G, Gore D. Design, installation and preliminary testing of a permeable reactive barrier for diesel fuel remediation at Casey Station, Antarctica. Cold Regions Science and Technology. 2013;96:96-107

[29] Hosney MS, Rowe RK. Performance of GCL after 10 years service in the Arctic. Journal of Geotechnical and Geoenvironmental Engineering. 2014;140(10):1-12

[30] McWatters RS, Rowe RK, Wilkins D, Spedding T, Jones DD, Terry D, et al. Geosynthetics in Antarctica: Performance of a composite barrier system to contain hydrocarbon-contaminated soil after 3 years in the field. Geotextiles and Geomembranes. 2016;44(5):673-685

[31] McWatters R, Rowe RK. Permeation of volatile organic compounds through EVOH thin film membranes and coextruded LLDPE/ EVOH/LLDPE geomembranes. Journal of Geotechnical and Geoenvironmental Engineering. 2015;141(2):1-15

[32] Poland JS, Riddle MJ, Zeeb BA. Contaminants in the Arctic and the Antarctic: A comparison of sources, impacts, and remediation options. Polar Record. 2003;39(04):369-383 
The Assessment Strategy for Selecting and Evaluating Geoenvironmental Remediation DOI: $h$ ttp://dx.doi.org/10.5772/intechopen.88166

[33] Kalinovich I, Rutter A, Poland JS, Rowe RK, et al. Surface permeable reactive barriers for $\mathrm{PCB}$ remediation in the Canadian Arctic. Journal of Environmental Management. 2012;101:124-133

[34] British Standard. Methods of Test for Soils for Civil Engineering Purposes. Classification Tests. BS 1377-2:1990; 1990

[35] Ejbarah N, Al-Jarallah R, Al-Duwaisan D. House of quality application in soil remediation. Kuwait oil lakes. In: 2nd International Conference on Environmental Science and Technology IPCBEE. Vol. 6.

Singapore: IACSIT Press; 2011

[36] Slenders H, de Wit H, Staijn B, Kok T. Dutch Handbook on Soil Remediation Techniques; an Evaluation of Remediation Techniques. Final Report 1057570; 1997

[37] Kuwait Environmental Public Authority (KEPA). Maximum Limits Allowance for Occupational Exposure to Chemical Substances. Appendix No. $3-1 ; 2014$ 
